Portland State University

PDXScholar

$1-1-1981$

\title{
The perinatal regionalization policy: a study in form and development
}

Linda Umbdenstock

Portland State University

Follow this and additional works at: https://pdxscholar.library.pdx.edu/open_access_etds

\section{Let us know how access to this document benefits you.}

\section{Recommended Citation}

Umbdenstock, Linda, "The perinatal regionalization policy: a study in form and development" (1981). Dissertations and Theses. Paper 433.

https://doi.org/10.15760/etd.433

This Dissertation is brought to you for free and open access. It has been accepted for inclusion in Dissertations and Theses by an authorized administrator of PDXScholar. Please contact us if we can make this document more accessible: pdxscholar@pdx.edu. 


\title{
THE PERINATAL REGIONALIZATION POLICY:
}

A STUDY IN FORM AND DEVELOPMENT

\author{
by \\ Linda Umbdenstock
}

A dissertation submitted in partial fulfillment of the requirements for the degree of

\author{
DOCTOR OF PHILOSOPHY \\ in \\ SYSTEMS SCIENCE
}

Portland State University

Linda Umbdenstock (C) 1981 
TO THE OFFICE OF GRADUATE STUDIES AND RESEARCH:

The members of the Committee approve the dissertation of

Linda Umbdenstock presented May 1, 1981.

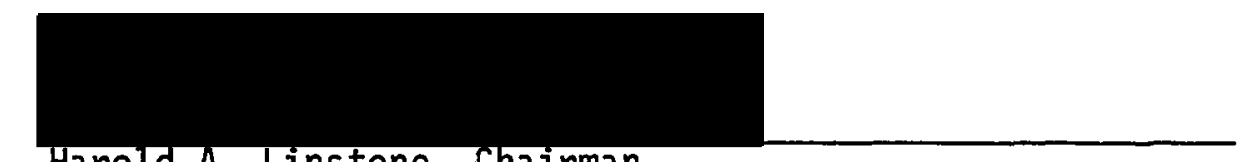

Harold A. Linstone, Chairman

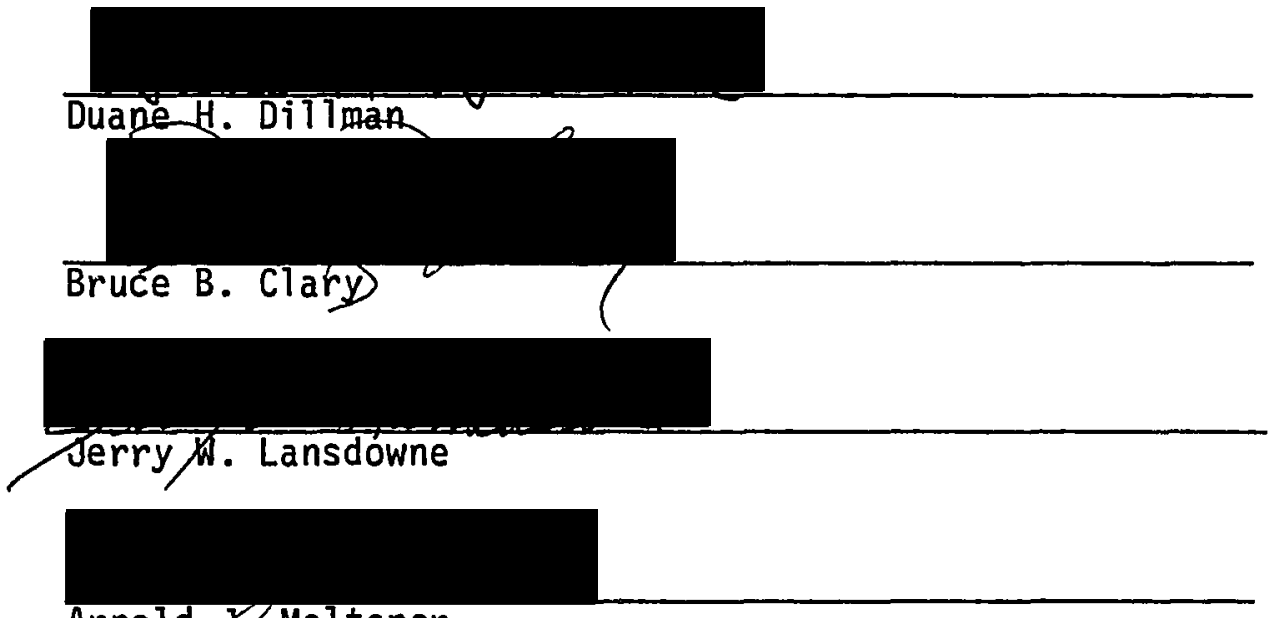

Arnold $\mathscr{X}:$ Meltsner

APPROVED:

Stanley E. Raureh, Deart of Graduate Studies and Research 
AN ABSTRACT OF THE DISSERTATION of Linda M. Umbdenstock for the Doctor of Philosophy in Systems Science presented May 1, 1981.

Title: The Perinatal Regionalization Project: A Study in Form and Development.

APPROVED BY MEMBERS OF THE DISSERTATION COMMITTEE:

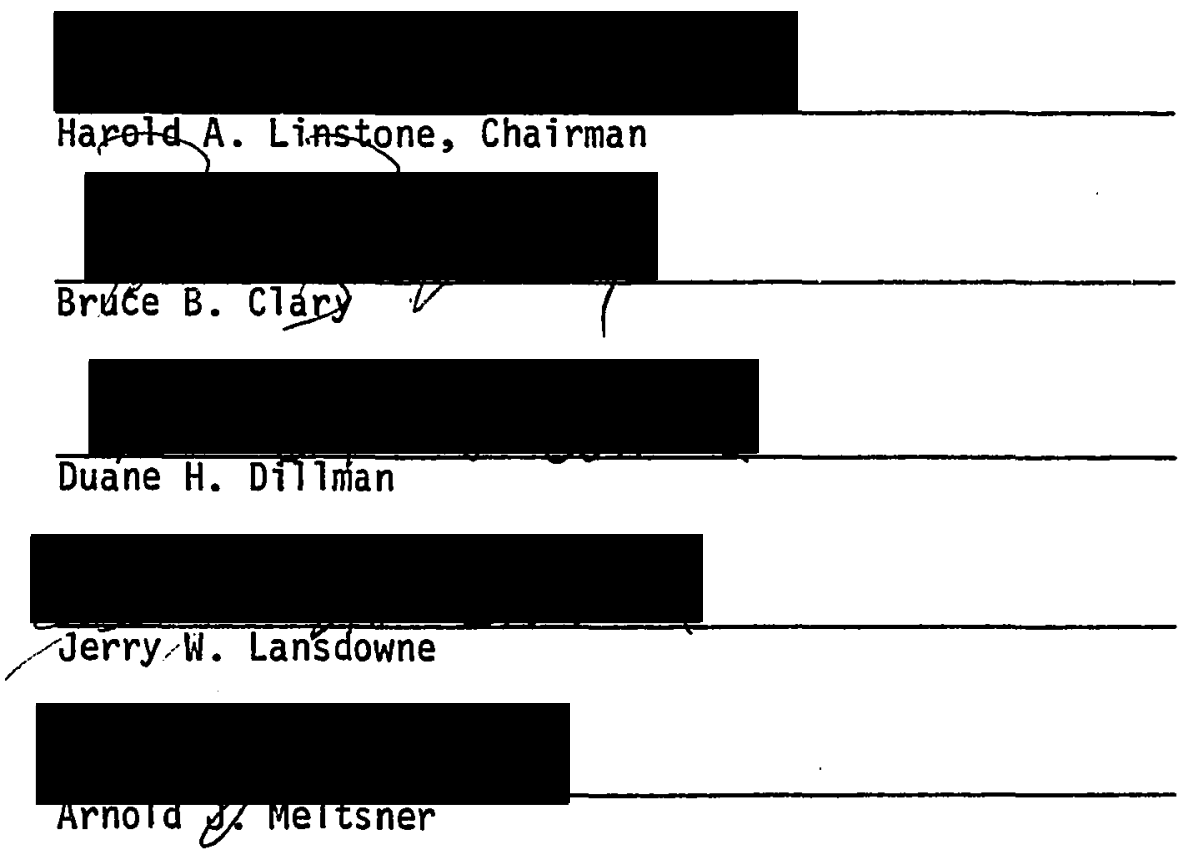

The purpose of this research was to demonstrate one way in which the analytical and creative components of policy can complement one another to provide insight for understanding emergent (developmental) and cooperative systems. As a case study, this research examined a perinatal 
regionalization project--a new health care delivery system--to determine how it might develop from this point in its history, i.e., what form it might take. The key questions were: how do we design a workable and significant system? How much is science; how much art?

Given the emergent social nature of the system, a twofold approach was required. The first approach, analytically organized, used multiple perspectives in gathering information for policy planning and implementation. The second approach, process oriented, used a new form of Delphi as a creative, participatory decision technique to design a policy structure.

Application of multiple perspectives to a prospective issue, combining them with the participatory approach of the decision Delphi and distinguishing methods appropriate for emergent policy systems were departures from previous research.

Data collection involved content analysis, extensive interviewing, and participant observation. Analysis based on three perspectives, technical-rational $(T)$, organizational $(0)$, and personal $(P)$, yielded distinct pictures of the emerging social technology of regionalized perinatal health care delivery. The $T$ perspective emphasized the well-ordered approach to implementation and indicated some areas to reinforce and develop based on measured outcomes. The 0 perspective emphasized the network of interrelated roles, procedures, and reinforcements (sources of satisfaction). It noted junctures for making inroads into the existing sysiem. The $P$ perspective provided the most immediate grasp of the essential and unique world of the participants. It found that images serve as both compelling visions and forces for change characterized by 
this non-trivial uniqueness. Delphi found that systems structures can be generated endogenously.

Analysis of the three perspectives found that each of the three requires a type of research appropriate to it. In fact, the elusive $P$ perspective can be formulated experientially--a self-reflective type of research--and communicated creatively. Both enhance its value. Analysis also found that while the three are distinct, each adds a dimension to understanding that would be lost without it. They can be integrated as mutual contexts of each other. Analysis found that the form of communication is as important as the form of research. Non-traditional means are more appropriate. Analysis found that design considers form as system self-image, system bourdary, and system control. These distinguish the new system from the old. The concept is quite different from implementation as a sequential process in policy. 


\section{ACKNOWLEDGMENTS}

The measure of effort involved in a project such as this dissertation is not so much the number of years or number of pages as the depth and extent of sharing, challenging and support of so many colleagues and friends. I am grateful beyond measure to:

Each of my committee members. I must mention Dr. Linstone as guide and Dr. Dillman as close advisor.

My family, especially my parents.

Fred.

My co-workers on the project, especially Jim Gore and Ken Wong, and the participants in the study.

My women's group, to Frances Makepeace, Sister Ann Mary Bender, Eloisa and Martin Mondrus, and all my friends who understood my need for hibernation.

My teachers and classmates in the system science program, to Drs. Maruyama, Sahal and Kohn, to Michelle Carlson, Mualla McCarty, Yavus Gonenc.

Brook Jacobson for editorial assistance.

Sher Komoto for professional and technical assistance into the wee hours of the morning on a schedule beyond any reasonable demand of friendship. Her moral support went even beyond. 
TABLE OF CONTENTS

PAGE

ACKNOWLEDGMENTS . . . . . . . . . . . . . . . . . . .

IIST OF TABLES • • • • • . • • • • • • • • • • • • •

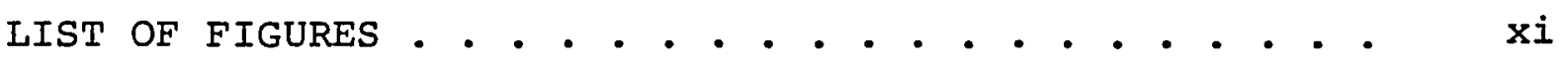

CHAPTER

I INTRODUCTION AND OVERVIEW . . . . . . . . . . 1

The Problem, Issues and Approach . . . . 3

Purpose, Importance, and Iimitations . . . 4

II THE CASE STUDY: BACKGROUND, SETTING AND STUDY

DEMANDS . . . . . . . . . . . . . . 12

Background: Concerns and Proposals in the

Delivery of Perinatal Health Care . • . 12

Setting: The Study Area . . . . . . . 18

Perinatal Health Concerns

The Medical Center

County Regionalization of Health

Services

The Perinatal Regionalization Project

Study Demands: Special Requirements for

Conducting the study . . . . . . . . . 25

III REVIEW OF SELECTED LITERATURE . . . . . . . . 28

Concepts of Development . . . . . . . 29

Types 
Relation to Social Systems

Relation to Planning Theories

Form in Relation to Development . . . . 39

Metamethods as Design Process . . . . . 44

Origins: the Concept and Use of

Fundamental Different Approaches

Traditional Approaches

Brain Research

Evidence from Applied Areas

The Two Approaches in Policy Science/

Analysis

State of the Art

Multiple Perspectives

Delphi

"Right Brain" Approaches: Guidelines

Conclusions . . . . . . . . . . . .

IV METHODOLOGY FOR DATA COLLECTION, ANALYSIS, PR.OCESS FACILITATION, AND COMMUNICATION OF

Perspective I: Technological (or Rational)

Perspective . . . . . . . . . . . .

Objectives

Data Collection

Data Analysis

Perspective II: Organizational Perspective

Objectives

Data Collection

Data Analysis

Perspective III: Individual (Personal)

Perspective . . . . . . . . . . . . .

Objectives

Data Collection

Data Analysis

Decision Delphi

Objectives 
Participants

Procedure for Initiating the Delphi Procedures for Facilitating the Delphi Process

Expected Outcomes and Communications of Results . . . . . . . . . . . . .

$V$ ONE PERSPECTIVE ON REGIONALIZATION:

RATIONAL PLANNING AND IMPLEMENTATION • • • • • 124

The Rationale . . . . . . . . . . 124

The Key Decisions . . . . . . . . . 126

Implementation Strategies . . . . . . 128

Cost/Benefit Indicators . . . . . . . 128

Performance Measures and Impacts . . . . 138

Analysis of Changing Input Factors . . . 141

Population Changes

Decreased Public Sector Funding

Workforce Changes

Regulatory Pressures

Summary • • • . • . . . . . . . •

VI ONE PERSPECTIVE ON REGIONALIZATION:

ORGANIZATIONAL POTENTIAL AND CONSTRAINTS

REGARDING CHANGING RELATIONS . . . . . . . . 154

The Organization as an Entity . . . . . 154

Organizational Dynamics . . . . . . . 160

Organizations as Interlinking Networks . . 164

Turfs

Standard Operating Procedures (SOP)

Messages

External Postures

Boundry Spanners

Summary: Keys to Understanding . . . . . 
VII ONE PERSPECTIVE ON REGIONALIZATION: THE

MILIEU OF PERSONAL IMAGES AND INSIGHTS

IN THREE STORIES . . . . . . . . . . . . . . 203

Story 1, A Portrait: The Doctor is In . . 203

Story 2, A Chorus: Voices of the People . 209

Introduction

The Chorus

Story 3, A Story after Kafka . . . . . . 218

Commentary . . . . . . . . . . . . 221

Story Shaping: Contextual Research

Some Responses

VIII THE DELPHI PROCESS - . . . . . . . . . . .

Round 1: Direction of Regionalization . . 226

Round 2: Implications and Tasks . . . . 231

Round 3: Support and Decision . . . . . 233

After the Delphi . . . . . . . . . 234

IX RECOMMENDATIONS RELATED TO THE
PERINATAL REGIONALIZATION EFFORT . . . . . . 236

From Perspective I . . . . . . . . . 237

The Issues in Developing Perinatal

Regional Systems

Strategies for Continued Development

From Perspective II. . . . . . . . . 240

The Issues in developing a Regional

System

strategies for Continued Development

From Perspective III . . . . . . . . . 244

The Issues in Developing a Regional

System

Strategies for Continued Development 
The Issues in Developing a Regional System

Strategies for Continued Development

Regionalization Potential . . . . . . 248

$\mathrm{X}$ ANALYSIS OF CASE STUDY CONCLUSIONS:

CONTRIBUTIONS TO METAMETHODS AND TO THE

ISSUES SURROUNDING POLICY DESIGN IN

ESSENTIALLY DEVELOPING SYSTEMS • • • • • • •

Conclusions Advancing the state of the

Art in Metamethodology . . . . . . . . .

Multiple Perspectives

The Delphi

Conclusions on Policy Design in

Essentially Developing Systems . . . .

IIST OF REFERENCES • • • • • • • . . • . • • . 275

APPENDICES . . . . . . . . . . . . . . . . . 285

APPENDIX A: SUGGESTIONS FOR APPLYING MULTIPLE PERSPECTIVES BASED ON LEARNINGS FROM THIS STUDY

Getting to the Bottom of it: Investigative Interviewing Strategies . . . . . . .

Selection of Interviewers

Selection of Respondants and Gaining

Access

Conducting an Interview

Checks

Doing Research in Three Perspectives...

Communicating Multiple Perspectives . •

APPENDIX B: THE DELPHI INSTRUMENTS . . . . .

Round II . . . . . . . . . . . . 314

Final Round . . . . . . . . . . . 328 


\section{LIST OF TABLES}

I Perinatal Regional Providers and Participants

II Allison's Three Models . . . . . . . .

III Elmore's Four Models of Implementation . .

IV Steinbrunner's Perspectives . . . . . . .

$\mathrm{V}$ Andersen's Three Perspectives . . . . . . .

VI Linstone Perspective . . . . . . . . . . 76

VII The Methods Used for Analysis and Synthesis • 95

VII People Interviewed . . . . . . . . . . 105

IX Organizational Perspective . . . . . . . 107

$\mathrm{X}$ Distribution of Invited Participants . . . . 111

XI Empirical and Creative, Analytical, and Synthesizing Components Used in the Study . . 122

XII Examples of First Level Outputs . . . . . . 136

XIII Changes in Regional Health Resources . . . 136

XIV Key Project Interventions and Results . . . . 137

XV Regional Deliveries, Birth Rate and County Hospital Proportion, 1972-1978 . . . . 
TABLE

XVI Comparisons of Spanish/surnamed Maternal

and Infant Complications and Outcomes,

for Those with and Without Prenatal

Care, December, 1978 . . . . . . . .

144

XVII Hired Staff vs. Workload, County Hospital, 1975-1980 . . . . . . . . . . .

XVIII Short and Long Term Interventions for

Obstetrical Overload . . . . . . . . .

XIX Organizational Perspective: Keys to

Understanding . . . . . . . . . . . . .

XX Distribution of the Delphi Participants . .

XXI How the 3 Perspectives See Aspects of

Regional Development . . . . . . . . .

XXII Perspectives of Mutual Contexts . . . . . .

261

XXIII Prospective Value of the Methods . . . . . . .

273 
LIST OF FIGURES

FIGURE

PAGE

1. Design of the Study . . . . . . . . . . . 5

2. Layout of Chapters . . . . . . . . . . . 8

3. Three Sources of Concern and Development in the 70 's Contributing to this study . . . . . 10

4. Relationship of 3 sources in this study . . . . 11

5. Ideal Systems: Regionalizwd Perinatal Health

Care Delivery . . . . . . . . . . . 15

6. County/School Staff Overlap (Sample) . . . . 24

7. Analog and Digital Communication . . . . . 50

8. Right Brain Instruction: Before and After Drawings . . . . . . . . . . . . . .

9. A Comparison of the Multiple Perspectives and their sources . . . . . . . . . . 78

10. Content of Perspectives . . . . . . . . . 80

11. Multiple Perspectives: A Singerian Inquiring System • • • • • • • • • • • • • • •

12. Principles of the Perinatal System . . . . . . 127

13. Program Components . . . . . . . . . . . 129 
14. Plan of Action Objectives and Activities (Sample) . . . . . . . . . . 130

15. Time Line of Activities (Sample) . . . . . 131

16. Proposed and Year I Organizational Charts

Comparison . . . . . . . . . . . . 132

17. Major Project Milestones . . . . . . . . . 134

18. Major Changes in Project Approach (Sample) . . 134

19. Birthweight-specific Disability in Infants:

1 Year Follow-up Study ......... 140

20. Actual and Projected Deliveries - County

Hospital, 1973-1980 ........... 145

21. Workload in Labor and Delivery- County General

Hospital, 1975-1979 .......... 146

22. Overview of the County Obstetrics Overload . . 150

23. Overview of the Labor and Delivery Staffing

Problem ............. . 151

24. Sample Medical and Nursing Hierarchies . . . 167

25. Comparison of Implementation and Design . . . 266

26. Catastrophe Theory Model of Development . . . 269

27. Perspective-bound Basis for Miscommunications . 29:7 
CHAPTER I

\section{INTRODUCTION AND OVERVIEW}

For more than ten years the medical profession in America has been concerned and embarrassed over the U. S. standing in the world in birth-related mortality rates. Parts of the country are comparable with underdeveloped countries in this respect and overall the U. S. ranks 17 th in the world. Despite significant advances in medical knowledge and technology, the decline in mortality rates did not keep pace.

It was established that early access to prenatal care is a key factor in successful. hirth outcomes. Yet many pregnant women have little or no access to care of any kind. Furthermore, the newest technologies relating to high risk pregnancy and birth and infant intensive care are generally located in hospitals associated with medical schools and other wellendowed hospitals -- again not generally accessible to all who need it. Nor was there a systematic means of "filtering down" to the practitioner in the field, the advances in medical knowledge and skill.

In the early 1970 's, the National Foundation - March of Dimes brought together professional organizations in the fields relating to perinatal care to address these problems. The result was a proposal for perinatal regionalization which 
recommended systematic delivery of health care providing for access for all pregnant women and their babies to the appropriate type of care. Concurrently, they addressed the rising health care costs and quality of care issues.

In and of itself, perinatal regionalization represents a systems approach to the planning of health services. Potential for an even more effective approach is offered by several recent developments in the system Science field.

During this same time period, some theory-oriented scientists raised the issue of essentially different types of systems. Breaking away from traditional concepts of systems as adaptively stable, these theorists put forth the concept of an emergent system -- one in the process of development. Meanwhile, in the area of systems applications, the mainstream group was using "scientific" concepts of organization and control to solve routine system problems. Some were engineering human systems based on these principles. A few mavericks questioned the application of essentially technological approaches to all human system problems. They reinterpreted the system concept of holism which had come to mean comprehensiveness to encompass the experiential, the creative, and the appreciative as intrinsic principles of human systems. Systematic research in this area led to the development of the metamethodologies of multiple perspectives and decision delphi.

The system theoretic concepts surrounding emergent 
(developmental) systems provide adequate grounding and the state-of-the-art methods of multiple perspectives and decision delphi provide an appropriate approach to the problems raised by perinatal regionalization as a developing system. Hopefully, an exploration of this particular system will further clarify the theoretical issues in the process of application.

\section{THE PROBLEM, ISSUES, AND APPROACH}

This Project is a case study which examines a "new" perinatal regionalization project to determine how it might, policy-wise, develop from this point in its history, i.e., what form it might take as a system. Two points should be kept in mind in this regard: the system where it is is the subject of this paper; the design of its future development is the task. Hence this paper is a policy study of a social system operating in an emergent (rather than a maintenance) mode.

The development of perinatal regionalization systems raises a number of specific theoretical issues relative to system design:

- How do we think about designing the workable, determining and implementing methods and controls which are both manageable and significant within the policy context? How much is science? How much is art (or pragmatics)? 
- How do we conceptualize the process of change as it occurs in an emergent process? Can we assess and use the dynamics of the system under study in a developmental (in contrast to maintenance) mode? What are the implications for stability?

- How do we address the endogenous and coordinative processes implied by the social system context? What are the specific requirements of a social system as contrasted to biological or mechanical systems?

These three issues hold profound implications for the policy analyst -- both in determining how $s /$ he approaches the task and in defining his/her specific role. It is our contention that given the emergent social nature of the system being considered, a twofold approach by the analyst is required.

Thus, this study is conceived in two parts representing two approaches. The first, analytically organized, uses multiple perspectives in gathering information for policy planing and implementation. The second, process oriented, uses a form of Delphi as a creative participatory decision technique to design a policy structure. The diagram in Figure 1 conveys the two basic approaches taken in this study. The justification for this dual approach and supporting evidence is related in Chapters II and III.

\section{PURPOSE, IMPORTANCE, AND IIMITATIONS}

The purpose of this study is to demonstrate one way in 
5.

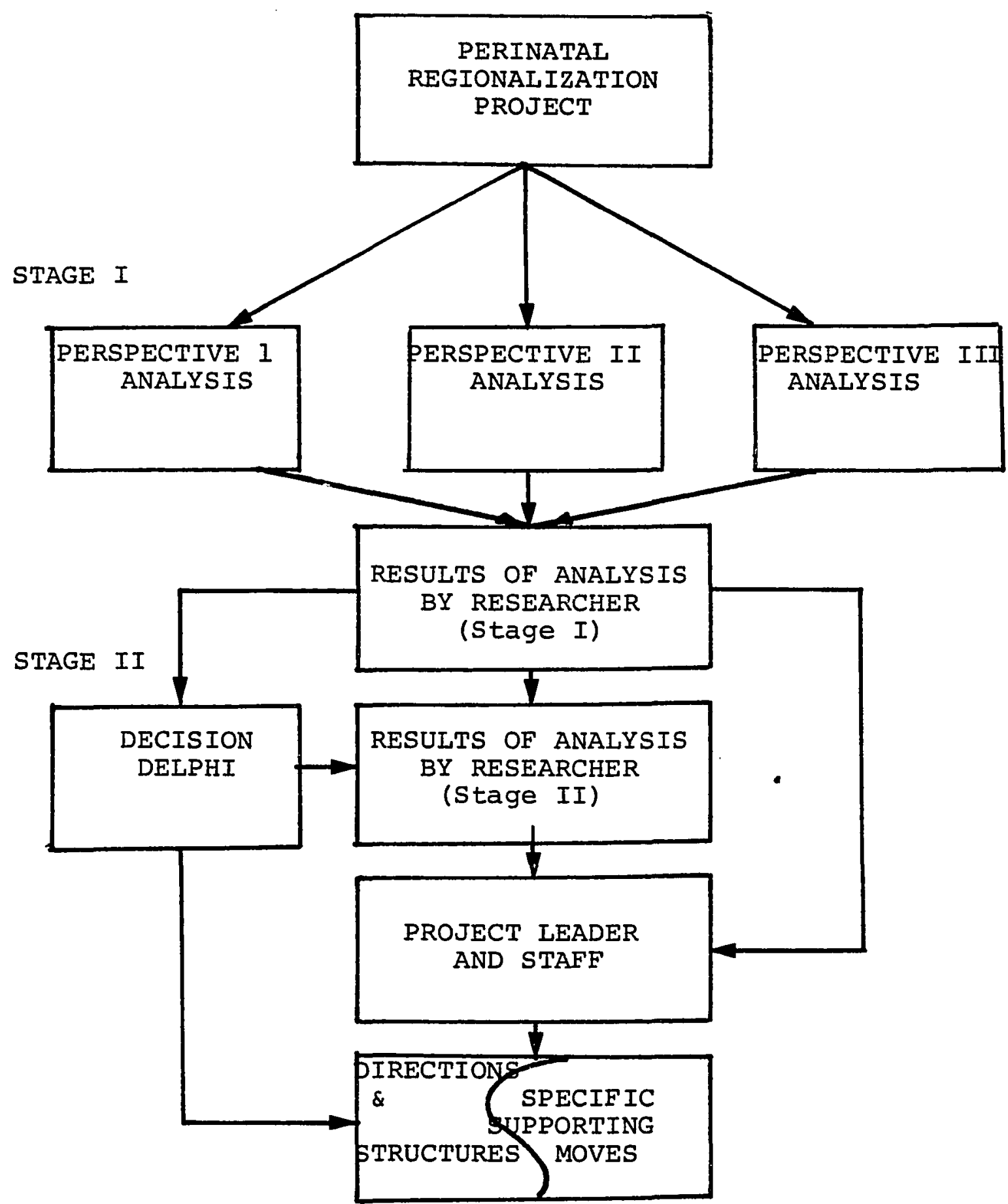

Figure 1. Design of the study. 
which the analytic and creative elements of policy can complement one another and provide insights for understanding the nature of emergent and cooperative systems. Not, then, a traditional experimental testing of hypotheses, this study nevertheless intends to show for systems which are emerger:and cooperative, multiple perspectives will yield substantially better information for design of workable policy than a rational perspective taken alone. For these systems, the participatory strategies of Delphi will contribute in both an analytic sense and in a creative sense, resulting in courses of action which are developmentally evolved from a common understanding of the system.

This st:udy provides several innovations within the policy sciences:

- Along with a concurrent project conducted by the Futures Research Institute on technology assessments, the first known prospective tests of the multiple perspectives are undertaken

- Proposing the addition of a dimension other than analytic to the multiple perspectives enhances their prospective value and makes the perspectives, themselves, more than a rational-deductive exercise -it becomes also politics-in-the-process and creative

- Contribution to the study of implementation in policy is made by demonstrating how it can fit within the design module of the policy schema 
- Application of these specific methods by means of specific techniques to the policy design area of emergent-cooperative systems potentially contributes to policy analysis in the difficult area of regionalization broadly conceived -- especially in the neglected area of development

- Application to an area crossing both the public and private sectors is made by other than legislative means

The extensive study of the research objectives in one perinatal regionalization project provides a significant challenge for policy development. Furthermore, typical policy problems are encountered. Thus, should the result prove successful, they would warrant serious consideration of their applicability to other projects with the hope that the results can be replicated and extended as one case does not demonstrate its universal applicability.

The essentially open-ended nature of the decision process proposed here is, by definition, beyond the authority of the researcher to control. The measure of success is by way of comparison of potential -- not actual -- outcome of the direction of perinatal regionalization.

The relationship of the chapters based on this discussion is given in Figure 2. Chapter 2 discusses the background of the perinatal regionalization concept, one setting in which it was applied -- the one used for the case study, 


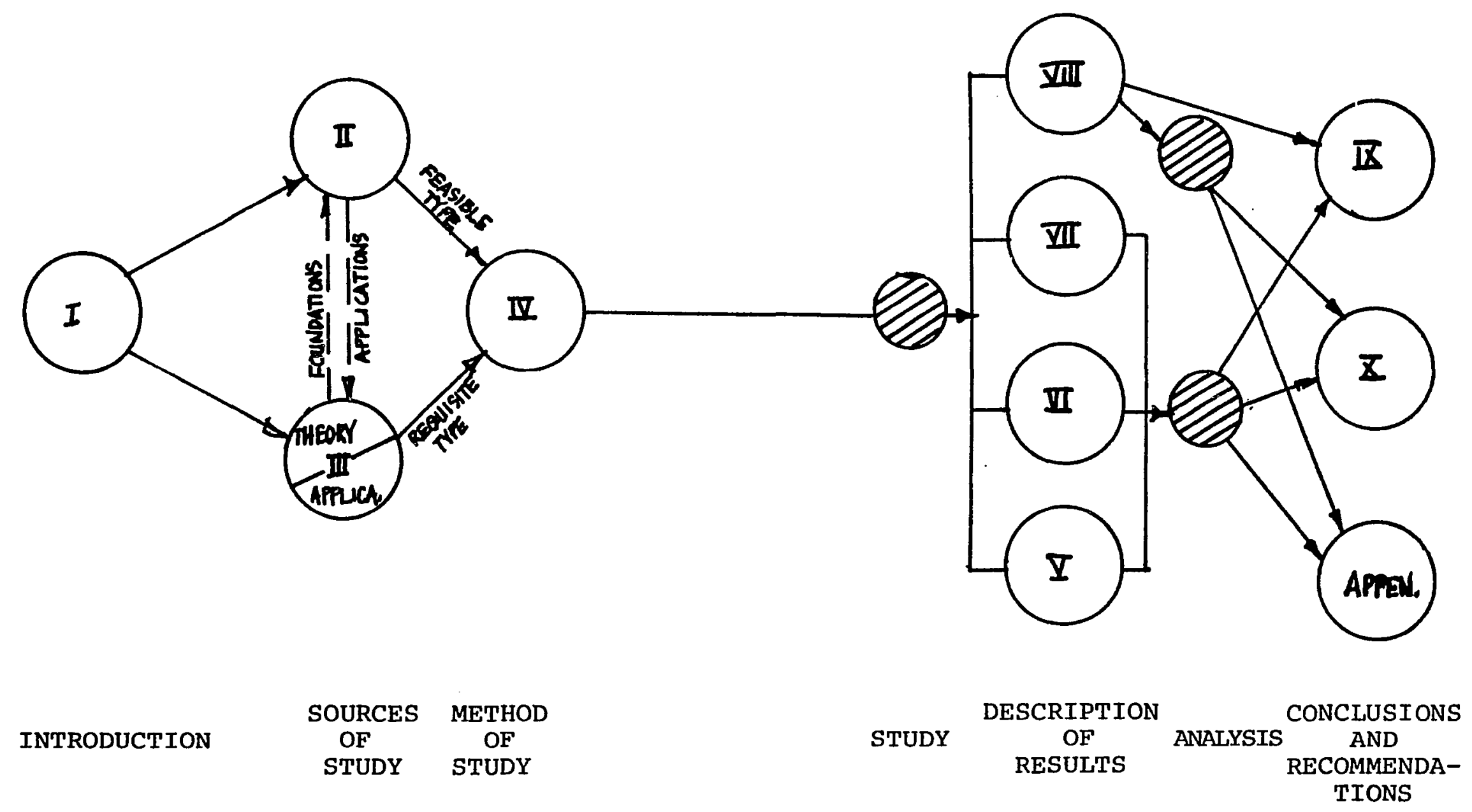

Figure 2. Layout of Chapters. 
and considerations for the approach of the study. In Chapter III, a review of the literature relevant to the trends surrounding the theoretical concepts of development and form and the required approach to application of developmental system, metamethods, is given. Chapter IV outlines the specific methodology used in this case study. Chapters V, VI and VII give the results of the three perspectives used and Chapter VIII presents the results of the Delphi. Chapters IX through $x$ draw abservations relevant to the case studv and the broader system theoretical and application issues. The following figures ( 3 and 4 ) serve to summarize the preceeding discussion on how the study is derived. They also serve as an orientation to the remainder of the document. 
Sources:

REAL WORLD CASE STUDY

Developments: (Perinatal Regionalization Concept)

Perinatal Regionalization Project

Question:

Where do we go from here?

Issue Focus:

Policy \& Implementation

Need:

A way to think about the system and a way to move forward
ACADEMIC INVESTIGATION APPLICATIONS

\section{THEORY}

S.0.A. in Metamethods:

- Multiple Perspectives

- Decision Delphi

Radical System Change

(Morphogenesis, emergence)

Essentially cooperative Social Systems

What kinds of problems can these methods be appropriate to? Role of analysis/
creativity

Extension to prospective use in emergent policy systems
What can be said about a system prospectively \& in application?

Form \& Design

Dual Approach:

- Analytic

- Creative/Synthetic

Figure 3. Three sources of concern and development in the 70 's eontributing to this study . 


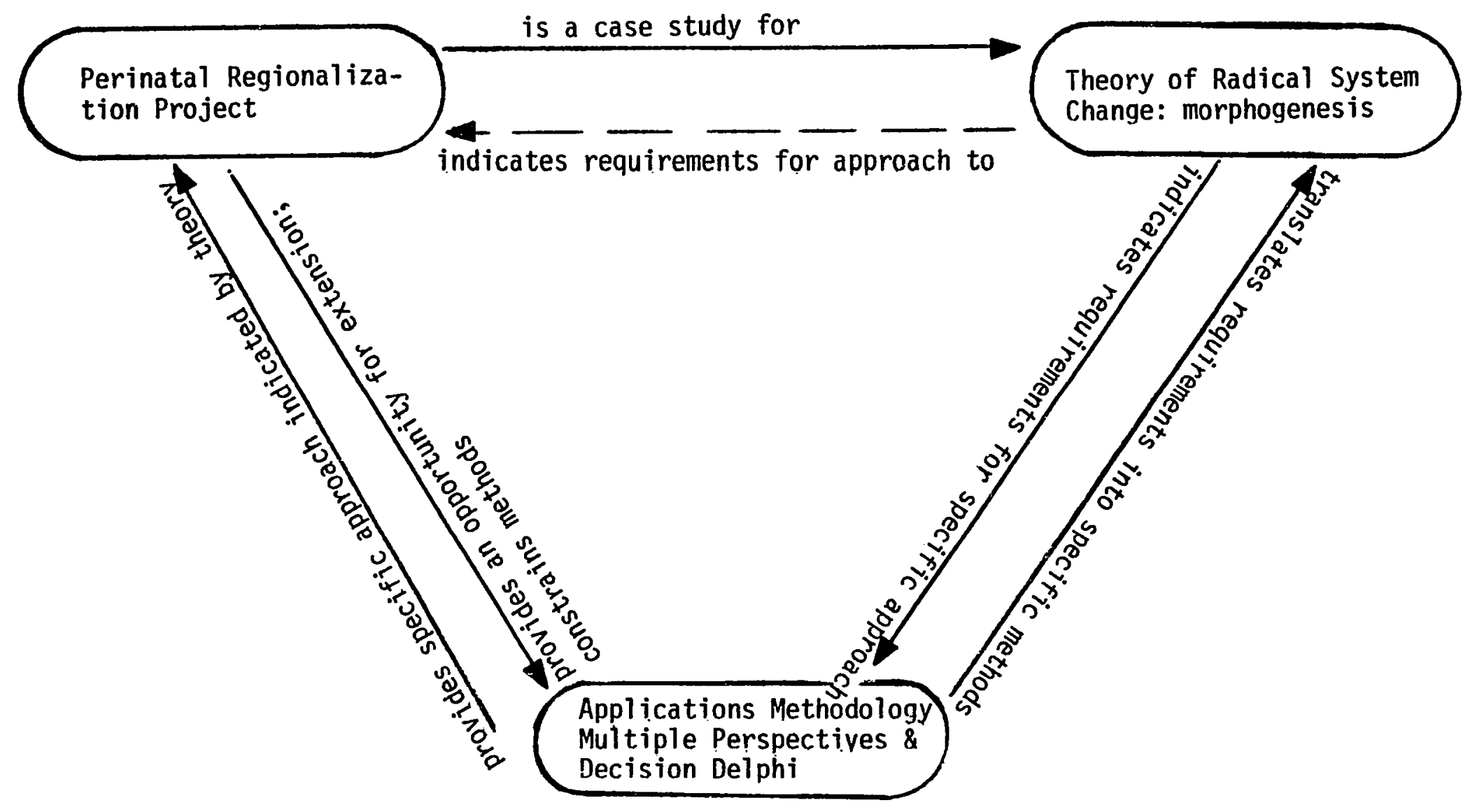

Figure 4. Relationship of 3 sources in this study. 
CHAPTER II

THE CASE STUDY: BACKGROUND, SETTING

AND STUDY DEMANDS

The case study, a perinatal regionalization project, represents a challenge to policy planners and implementers: can regionalization be successful? What local issues and conditions highlight types of problems and their resolution? What study methods are called for?

\section{BACKGROUND: CONCERNS AND PROPOSALS IN THE DELIVERY OF PERINATAL HEALTH CARE}

Health care as an industry accounts for ten percent of America's Gross National Product (1). With advances in medical technology and pharmacology, Americans now spend six times as much as they did in 1960 for health care (2). Still they are not significantly healthier than their counterparts in other industrialized nations, as measured by such key indicators as maternal, fetal, and neonatal mortality. Perinatal or bith related mortality rates in low income areas of the U.S. are comparable to underdeveloped countries. The nation as a whole, ranks 17 th behind such nations as Australia, Canada, and Japan (3).

Among the variety of factors contributing to these statistics lie some troubled findings. Despite the technical 
advances of the past half century ninety per cent of American hospitals are small, (2) often poorly equipped, and insufficiently staffed. The bulk of medical resources -- new buildings and new technologies -- accrue to a few wealthy urban areas. These hospitals more advantageously compete for doctors and other medical personnel, thus they draw further resources away from those high density, high risk populations which represent the greatest need for care. This imbalance is aggravated by rising costs which stem from under-utilized facilities, and serve to make health care, particularly quality care, less accessible to the largest segment of the population.

In an attempt to remedy this situation the concept of regionalization was put forth in the 1970s. Drawing upon similar models of coordination and cooperation in land use planning, transportation and education consortia, selforganizing participants in the field of perinatal medicine looked to this new means of providing optimal care to all pregnant women and their new-borns by utilizing available resources in a new way. The idea of perinatal regionalization was advanced by a multi-disciplinary group of doctors -the Joint Committee on Perinatal Health. It consisted of representatives from the American College of Obstetricians and Gynecologists, American Academy of Family Physicians, American Academy of Pediatrics, American Medical Association, and the National Foundation -- March of Dimes. 
The Committee's 1975 report, "Toward Improving the Outcome of Pregnancy," (4) defines perinatal regionalization as

a system which assures that neededcare of the best quality available can be made accessible to all... (with) attention given to the working of the system in terms of coordination and communication among all components

Since that landmark document, the concept has been explored and further specified. The diagram in Figure 5 represents typical relationships. Various features of a regional system are commonly included in major references on the subject. Hospitals within a region are designated by the level of patient risk they are capable of handling, based on an objective analysis of equipment, staff, and expertise. At least one high level technical facility exists in each region. Methods to communicate and coordinate medical services within the region are developed. Providers within the system assess the risk level of patients for appropriate level of care. Consultative services and diagnostic laboratories are available. A patient referral and transport mechanism and follow-up on high risk patients are in operation. Standardization of medical records facilitates risk assessment and referral. Often the records are computerized for reporting and research. Additionally there are programs of continuing education for all types of providers within the system, interdisciplinary evaluation and methods for monitoring cost/effectiveness of the care provided. (4 through 11) 
--Generalists

--Minimal equipment

-A mix of generalists and specialists

--Some highly specialized equipment (usu. depends on type of specialists)

--Highly specialized

--Highly technological

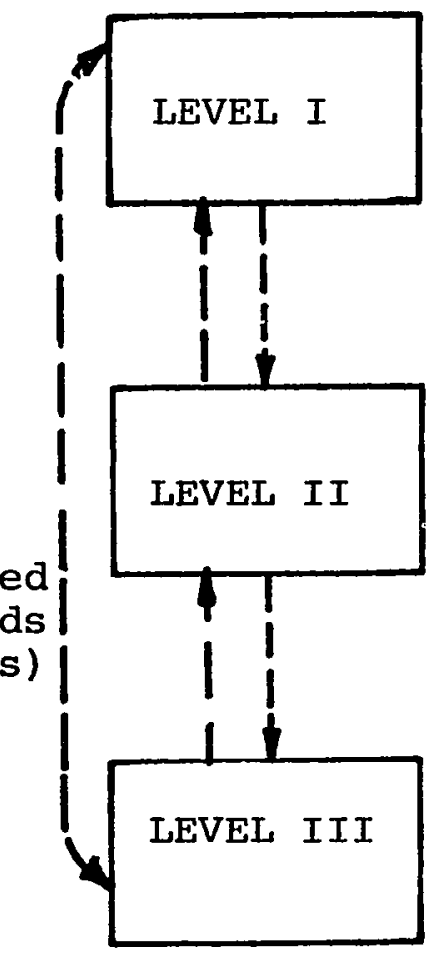

--Normal baby and/or mother

--Normal baby

--Moderately ill baby and/ or mother

--Seriously ill

baby and/or mother

Figure 5. Ideal system: regionalized perinatal health care delivery. 
Recent studies have shown that maternal, fetal, and neonatal mortality rates can be reduced if high-risk mothers and their infants are identified in early pregnancy and if optimal medical techniques are applied. (12 through 15) While regionalization seeks to reorder health resources in a more efficient and equitable way, its acceptance is by no means automatic among health professionals and institutions. For all the new components and advancements in the health care industry, its traditional approach to actual delivery of care is marked by a lack of cooperation, accountability, or equitable distribution of resources. Writing about this problem, Ginzberg (16) points out that basic demographic and epidemiological information is rarely used, or even available to target the needs of a given population. Much less is there any common set of priorities established in the community or means of cooperating between public and private groups to meet those priorities.

In short, the whole notion of a formal "system" including planning, quality control, and accountability in health care delivery contrasts sharply with the current modus operandi of rival hegemonies.

Reluctance surrounding such a comprehensive revision of practice is reflected in the numerous practical problems encountered by perinatal regionalization programs as reported in their stuaies $(17,18,19)$ : 
- fear of regimentation and bureaucratic entanglement negating professional autonomy

- fear of relegation to normal care management and exclusion from high risk (higher status, more interesting) case management

- inability of smaller hospitals to compete and subsequent loss of physicians and patients to more extensively-equipped facilities

- distance to be traveled by physicians

- fear of change in the physician/patient relationship

- lack of admission or referral policies, methods of financing

- lack of admitting privileges (acceptance of physician to admit patients at a given hospital)

- lack of definition and estimation of patients (high versus low risk)

- lack of clear definition and increased expectations and complexity in medical standards and their potential affect on malpractice litigations and revenues

- threat of increased government interference and licensing requirements

- ambiguous role of the general practitioner and the family practice specialist as relates to the provision of perinatal care

- social/religious aspects of referral hospitals (e.g. sterilizations and abortions)

- economic nature of hospitals and the differences between public, private non-profit, and private profit institutions

The system envisioned by regionalization, as can be seen from these problems, represents an innovation, a social technology which implies the coming-into-existence of a new 
entity, a new complex of relationships and a new consciousness, i.8., a different level of awareness and self-identity as a group.

Given this required reorientation and radical redefinition of the entire system, it is important to ask "Can regionalization in application, be successful?" "Can it work?"

In 1975, a private foundation supported the concept and funded a number of perinatal regionalization projects for five years. The projects remained separate and their aproaches to the problem of regionalization evolved as distinct and unique to their local needs. One project concentrated on maternal and infant transport to increase access and efficacy of care. This approach is important to their local needs: an extended rural area with few tertiary centers that have the staff and equipment available for intensive care.

The case examined in this study was another of the funded projects. Its setting, too, is unique as is its pursual of regionalization.

\section{SETTING: THE STUDY AREA}

The study area (referred to hereafter as the Region) represents the highest need area in its county, a large metropolis. The County. Department of Health, the State Department of Health, and the federal Department of Health, Education, and Welfare categorized this Region as a "medicalIy underserved area" and a "health manpower shortage area." 
These two designations are quantifiable measures of an area's need and have implications for the types and quality of health care services available to the population. In fact, the health needs in the Region are a closely linked part of the particular system of poverty, low education level, and high unemployment.

The Region contains about 1 million people: approximately 40\% White, 40\% Black, 15\% Spanish-surnamed, and 5\% Other. There has been, however, a dramatic increase in the Spanish-surnamed population and the 1970 census is believed to have greatly under-represented this particular group. Data from the 1980 census is not yet available. The Region's population is younger than the County's, overall. It represents the lowest median family income of any other area in the County, and the 1980 census is expected to show a decline in the economic conditions of this community.

A shortage of resources clearly exists in all areas of service provision in the Region. This shortage has been persistent and is projected to continue.. It represents a challenge to health and other service providers in the area.

\section{Perinatal Health Concerns}

The Region currently leads the County in fetal, neonatal, and infant death rates. It has the highest teenage and adolescent birth rate as well. These rates are complicated by the socioeconomic conditions referred to above. Most 
significantly, the Region has a higher and faster-rising birth rate than the County as a whole, due to the high birth rate for Blacks and Spanish-surnamed, the large influx of Spanish-surnamed, and the comparatively younger population. In the Region, a County general hospital and nine County clinics comprise the public sector. The private sector has one non-profit hospital, several smaller forprofit community hospitals, several free clinics, many private practices, and a private non-profit medical school acting in conjunction with the County hospital. (See Table

I ). The Perinatal Regionalization grant was obtained by the Medical School because of the key role of the Medical Center (Hospital/School) in the regionalization plan.

The Medical Center

The community orientation of the Medical Center reflects its origins. Built through community pressure and an increased awareness of the area's need, much of the original impetus and awareness stemmed from racial unrest and community activism in the 1960s. The Medical Center is composed of a tertiary level acute general hospital and a medical school, both of which are relatively new.

The obstetrical unit of this hospital is budgeted for 300 deliveries per month, although the average number of deliveries is close to 550. By 1979, the Hospital was among the largest delivery centers in the state. 
TABLE I

PERINATAL REGIONAL PROVIDERS \& PARTICIPANTS

Participants in Perinatal

Providers in Region Regionalization ${ }^{1}$

Medical School

- 1

Level 3 Hospital

1

1

Level 2 Hospital

1

1

Level I Hospital

$6^{2}$

$5 / 1$

Public Clinics

10

10

Free Clinics

3

3

Health Maintenance

Organizations

1

1

Private Providers

Obstetricians

Pediatricians

Family Medicine and

General Practitioners

$19^{3}$
unk
$22^{5}$

$8 / 63^{4}$

3

$3 / 28$

1. Early/current

2. 3 closed now

3. With offices in the geographic region (others have patients in the region).

4. 11 use project medical records, 17 have admitting privileges at one of the participating hospitals ( 9 in active use).

All use Staff In-Service

5. Unknown 
The Medical School provides education and training for medical students who have completed their graduate work and are entering the intern/residence phase of their preparation. The medical school is currently a private, non-profit educational institution established for education (physician and allied health professions), community-based health delivery, and research. The classical medical school dilemma of research versus patient care affects these priorities and the interaction between programs, departments, and planning functions. The Medical Center has a region-based design.

\section{County Regionalization of Health Services}

In the early 1970s the County implemented its own regionalization plan to increase access, continuity, and quality of all health care. It sought to contain costs and to design a framework for coordination and allocation of county health resources. This plan addressed regionalization within the public sector at a management/fiscal level. It referred mainly to the geographic allocation and administration of services. Its importance lies in the establishment of an administrative setting in which perinatal regionalization could occur more rapidly at local levels. The County plan, however, differs greatly from perinatal regionalization efforts in scope, details, and the level at which most interventions take place. Perinatal regionalization also includes the private sector which the county plan excludes. Its 
organization is quite distinct though nevertheless confusing in the overlap of the two systems.

County actions affected the School's perinatal regionalization efforts primarily in the way that administrative appointments were made to operate the County system. For example, the Chairman of the Department of obstetrics and Gynecology in the Medical school holds joint responsibijities as the County Regional Director of ob/Gyn, the Chief of the Department of ob/Gyn at the Hospital, and the Principal Investigator/Project Director of the Perinatal Regionalization Project (See Figure 6 ).

\section{The Perinatal Regionalization Project}

The Region is an area scarce in personnel, funding, and equipment devoted to perinatal care and an area of high fetal, neonatal, and infant mortality. Thus, the Project concentrates on the coordination of existing and development of new resources to increase the quality and availability of care. While the Chairman of the Department of Ob/Gyn at the Medical School had sparked considerable interest in the concept of regionalization and enlisted much cooperation in establishing a regional system, the grant itself was awarded to the Department. The funded Project drew upon the resources of all the divisions and special programs in the Department of ob/Gyn and a great number of other departments in the Medical Center as well as the hospitals,.clinics, and private offices 


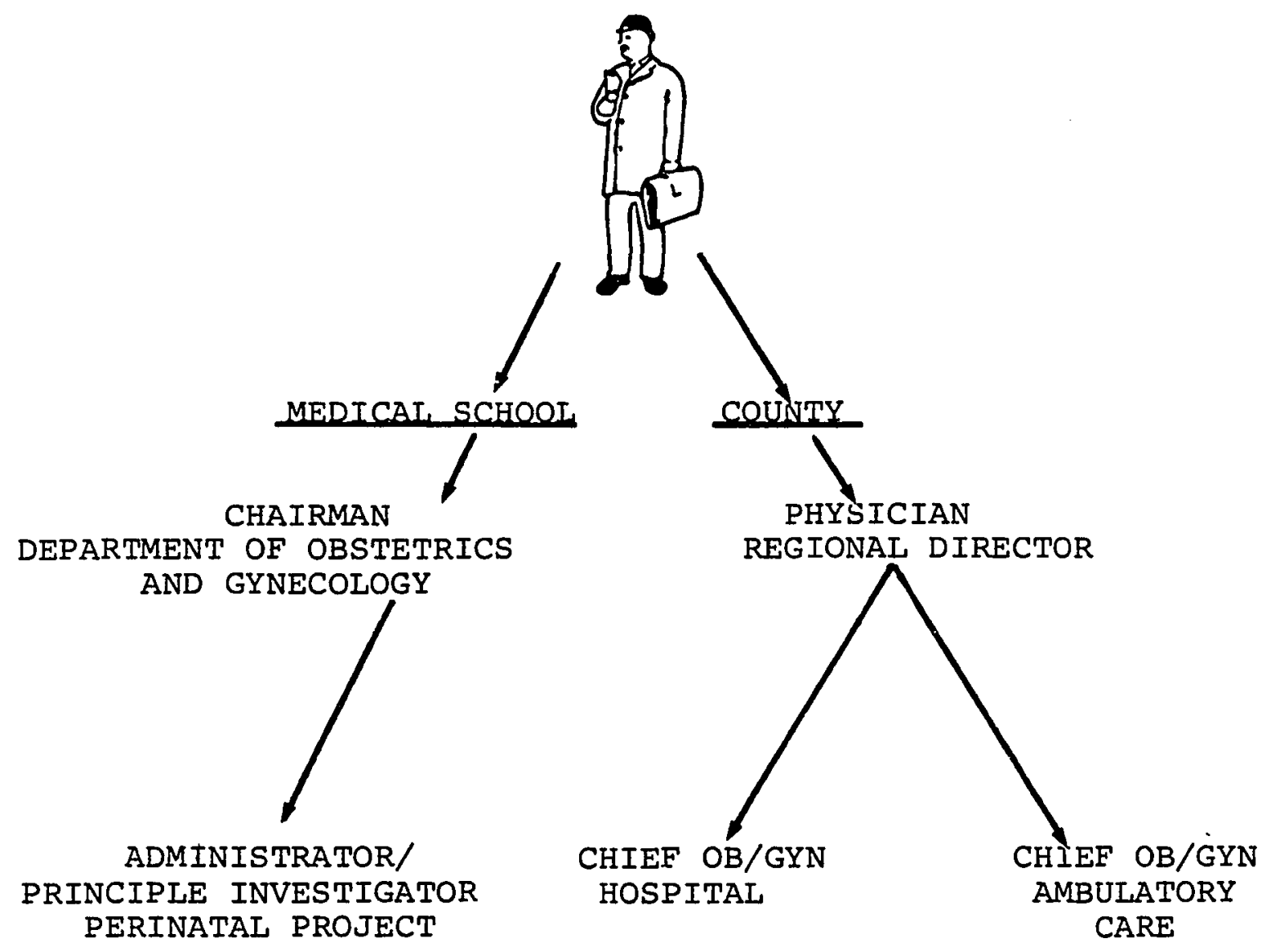

Figure 6. County/School staff overlap (Sample). 
providing care. (See Table I ).

Health professionals involved in perinatal regionalization in the Region include physicians, nurses, administrators, planners, research and data staff, and support and clerical workers.

A variety of medical specialties and sub-specialties participate in perinatal regionalization: obstetrics/gynecology (perinatology, genetics), pediatrics (neonatology, genetics), family practice, and general practice.

This voluntary participation in a system developing coordination among hospitals, clinics, and private physicians is evolving in the Region. While a measure of success is apparent, it is not clear whether these achievements are sufficient to carry perinatal regionalization over the survival threshold. The continuation of regionalizaton beyond grant support depends on the present and future policies and decisions, one of which concerns the level of private sector voluntary involvement. Further development of and commitment to a perinatal system determine whether these efforts are continued. What approaches facilitate this process in this particular Region?

\section{STUDY DEMANDS: SPECIAL REQUIREMENTS FOR CONDUCTING THE CASE STUDY}

Two fundamental characteristics of perinatal regionalization systems require consideration in system design (the 
what of this study) and the methods of study (the how). First, institution of regionalization in mixed private/public sector industry is a radical departure from policy-as-initiation of new systems under a given jurisdiction (change of guard but legitimate option of one in power) or from policyas-refinements in certain system components (better mousetrap but mousetraps are familiar). The current health care "system" is basically a loose social/ecological system of adaptive relationships structured by localization of resources and access patterns. The proposed regionalized system is a formal, planned one consciously reordering those relationships with certain improvements and efficiencies in mind. The requisite change is not simply one of attitude (acceptance vs. resistance to change), behavior (qaining competence in new skills), or management (adaptation or organization of a new activity or program). Rather an entire reordering of roles and relationships of professions and institutions is called for. This radical restructuring according to a different set of norms and relationships can be called a state of emergence. The concomitant difference in approach to this type of system in contrast to a maintenance type will be examined in the next chapter.

Second, unless regional health care delivery is mandated by Federal, State, County, or City authorities, regionalization systems remain essentially cooperative. The independence of participating institutions remains intact. 
Cohesiveness is built on something other than legislation or professional ethics and is unenforceable in the usual way. Planning and policy then require a different conceptualization. These, too, will be examined in the next chapter. In addition to holding implications for the design of such systems, the concepts of essential emergence and cooperation affect how the system-in-progress is studied. It is inappropriate and potentially destructive of developing relationships to expect to gain access to the kind of confidential, institution-specific data required by typical cost-benefit, institutional, and psychometric studies. Further, highly specific parameters would need to be developed for an experimental design. The parameters known ahead of time, are not likely to be the most significant ones on which to expend research effort. Every attempt was made in this study to respect all participants' rights to privacy while providing information significant to the understanding of policy design processes like regionalization. 
CHAPTER III

REVIEW OF SELECTED LITERATURE

The main topics selected for this review relate several theoretical and applied areas of advancement in System Science in the past decade. From theory the concept of development opens the way for considering the characteristics of and approaches to emergent systems. This is relevant to human/ social systems for policy/planning. The concept of form relates the enigmatic shape a new system assumes based on its selfconception and self-regulation. From applications the need is established for a metamethods approach to policy/planning --that of design through careful selection and active use of particular methods appropriate to emergent systems. The progress in applied areas and their sources in both traditional distinctions and contemporary research and application are reviewed. The particular methods of Decision Delphi and Multiple Perspectives flow from these considerations.

This chapter is divided into three main parts and a simmary section:

1. Developmental concepts distinguished by type and the relationship of these types to social systems and planning models.

2. The relationship of development to forms of 
structure, function, environmental context, behavior and control; description of the dynamics of that relationship

3. The metamethods of development as a means to approach the "problem solving" process; the sources and use of the dual modes of information processing (analytic and creative) and the current state of the art.

4. Summary of the approach taken based on issues and needs, theoretical and practical.

\section{CONCEPTS OF DEVELOPMENT}

Most systems studies conceptualize a system as a static entity. Even when one speaks of system dynamics, this usually refers to a basically static system functioning in its environment, or to the internal operations and flow processes of the system as it maintains itself.

Another theoretical approach is the concept of system development. As applied to social systems, the form which emerges from developmental design process is a creation specific to the needs of the participants, but also useful to those involved in similar endeavors. Such an approach may not only point up the inadequacies of the various static theories but yield exciting possibilities for the future. The notion of "development" has been in vogue for quite a while -- ever since the time dimension rose to consciousness 
as an addition to statics. As discussion ensued in various fields, be it Anthropology, Political Science, Psychology, or Economics, it became obvious that some fundamentally different concepts infused the notion. "Developing" nations are now discussed in place of "under-developed" ones. The concept often refers to modernization -- a linear stage process with basically the same end point, a capital-dominated economy based on scientific knowledge and urbanized societal values (20). In this respect "modernized" or "developed" becomes another word for "Westernized".

Whether we compare static models of growth measured by population, capital or resource exchange; or models with goals such as learning curve theories, stage or transfer theories or dialectics, all of these follow a more or less predetermined course (20).

\section{Types}

A useful categorization of developmental types is offered by Wilden (2.I, p. 354f.)

1. Homeostasis is adaptation for the sake of structure maintenance. This is a steady state process in which the system seeks to maintain a constancy of structure despite environmental changes. Maintenance processes, be they organizational, ecological, industrial, social, or psychological, have long been the focus of study. They are non- 
developmental.

2. Homeorhesis is pre-programmed growth through maturation or learning. It is development according to a pattern existing within system norms. Structures are elaborated, but not essentially changed. The endpoint and pathway to it are krown.

3. Homeogenesis is planned revolution. It is "replacement of one structure by a homologous structure" without fundamental change of norms or change in levels of organization.

4. Morphogenesis is a restructuring or renormalization with respect to new goals; that is, the "elaboration of new structures through systemic activities," such as an evolutionary leap, or a technological revolution. Although such changes may be adaptive and may involve learning, they in fact entail a discontinuous change and emerge at a new level of organization.

Most cybernetic theories fall within the limits of the iirst three types. Even the second as applied to social systems was a radical departure from the mechanistic conceptions of homeostasis which in itself first advanced the interplay of system-environment dynamics. The concept of system with environment versus system in environment only becomes apparent within a perceptual mode which is contextual rather than categorical. "There is no telelogical 'law of emergence' in 
evolution." (21, p.356) Clearly the process of emergence is a radical alteration at a metalevel and quite beyond the routine stability of cybernetic models as normally understood.

In this new mode stability takes on new meaning: the system, destabilized beyond its normal controls, either selfdestructs or radically restructures on a different level. This is sometimes called ultrastability.

The chief characteristics of morphogenetic systems include discontinuities, new levels of organization, change of norms, and changes in basic goals. Wilden (21) lists the following properties of the emergent metasystem:

--Increased adaptive range (viability) or increased semiotic freedor

--Increased variety or a new order of organization (complexity)

--structural innovation

--The generation of modified subsystems (after the event)

--More sophisticated selectivity

--Changes in the order of adaptivity or learning

--Increased memory

--Increased possibilities of simulation

--Increased goal-changing possibilities

--Increased sensitivity to noise

--Increased level of noise between the new system and its environment (p. 375) 
Prior to Wilden's typographics, Maruyama (23) contributed some revolutionary thought to the concept of development. In his classic call for a second cybernetics, he introduced the concept of mutual in contrast to sequential causation, which lies at the heart of non-linear change. InitialIy Maruyama's concept was taken to imply an alterating interaction, or action/reaction exchange. He, however, has defined mutuality as having reference to a simultaneity of action and effect occuring or registering in relation to one another. (24) Going beyond this he was the first to recognize a fundamental difference in type of process involved. In addition to the previously noted deviation counteracting processes, he pointed to deviation amplifying processes. $(23,25)$ Maruyama's "deviation amplification" process heralds that of "morphogenetic change." (23) He was the first to use it as a systems concept. He sees morphogenetic change as a different kind of change. He speaks of "the kick-off point" - some conjunction of events or ideas which signals a new process of development.

A new level or type of development is also implied in Bateson's (26) description of learning types. Each level or order of learning is a commentary on or frame for the one preceding. Thus, Type I learning is change, Type II is a change in the learning process (through added sets of alternatives), and Type III is a change in the system of sets. All of this occurs at the individual level. Type IV learning is 
evolution, which occurs beyond the individual at a social level.

Relation to Social systems

Dunn (20) takes the concepts of levels and evolution and moves beyond the individual and organization to system evolution. Development is contrasted to growth (as in wilden's homeorhetic model) which Dunn sees as an increase in scale. His concept of development contrasts with traditional models of change which are characterized by their linear deterministic properties and definite end states. Dunn's developmental model represents an increased level of complexity in which new behavior, new structure, new rules, and new options arise from pre-existing ones through a process of transformation. ( $p$ 86) Dunn's "transformation" is comparable to "emergence" in wilden.

It is important to recognize the critical distinction each of these authors make. They are not comparing different kinds of growth existing side by side on the same level but contrasting different orders of growth or different types of logic.

Dunn, Bateson, Maruyama, and Wilden have each in some way touched upon the idea of a developmental leap which arrives at a new level and in doing so comments on what went before.

Maruyama (27) characterizes this as a epistemological 
difference in the type of change; Bateson (26), as a difference in logical typing; Wilden (2l), as metalevel; and Dunn (20), as levels of complexity (or order of organization). Dunn (20) goes a step further. Development in social systems is characteristically different from that of biological systems. The cognitive dimension added to open-ended probalistic pathways yields a motivation for modifying the present and the ability to do so.

In this way, Dunn $(20$, p. $82 \mathrm{f}$.$) sets forth clearly the$ quality of sccial systems which makes them unique. Social learning is inventive and directly communicated; thus it is generated and tested by both logical and normative criteria. It is not solely reactive as in a homeostatic mechanism, nor is it only mutually adjustive as in an ecological system. It is anticipatory, directive, and deliberate and has as its distinctive charateristic a decision-making and goalsetting capability that sets it apart as the cognitive function particular to human beings. It is precisely this human quality which predisposes social systems to social evolution. Creativity, a change in the rules, in the boundaries, or in the form is not only an optimum game strategy. It is of the essence.

At this point Maruyama (28), always cautious about hierarchical descriptions, would admonish us to look at this process from another perspective, or in fact, from several perspectives rather than the single perspective of 
management. For Maruyama, management should not be thought of as control over others or over nature, but as a mutual dynamic; that is, the parties to the interaction are not simply adjusting to one another but are mutually stimulated to a new level of relationship. This process may involve multiple paths or perspectives in reaching the new level of organization. The process increases differentiation (29).

Even as the concept of morphogenesis awaits definitive description, its importance to social systems has just begun to be appreciated.

Relation to Planning Theories

The relationship between morphogenetic development and planning has yet to be clearly articulated. Jantsch (30) embodies the spirit of design to a larger extent than other writers on the topic in that he links the "creative" and "political" with the rational. Recognizing what Vickers (31) called the "appreciated" world, he sees planning as a creative and normative activity, and as such, an internal evolutionary force. He sees "system design" as the current frontier in planning.

While Jantsch (30) has much to say about design process in evolution, he offers no solid theory of application. His insights are those of a Westerner whose head is in Eastern mysticism while he tries to anchor his feet in the jargon of systems. Yet he is blazing a trail in an important and 
formidable new area. He models a relationship between levels of perception as applied to systems and to change. Each successive level of development incorporates the perceptive capacity of the preceeding ones.

His model straddles the more traditional hierarchichal and sequential system- approaches to planning, and is no less categorical. Even though his categories cross two dimensions, their interaction remains within the cybernetic process of negative feedback.

Dunn (20) repudiates traditional planning models and emphasizes creativity as capable of effecting dramatic social revisions. Its sole constraints are the possible and the valuable. Societal learning deals with social change not as an optimum game strategy, but as a fundamental change in the rules which is recognized as both necessary and desirable. Dunn's concept of "adaptive generalization" requires both learning and a capacity for learning. His emphasis on invention and action laudably moves away from the mutually reactive or adjustive model drawn from ecological systems, but yields a managerial proposal in that it sets up control over forces. In this respect it is hierarchical.

Dror (32) goes farther in this direction. He acknowledges the creative and appreciative aspects of planning but in his Design for Policy Science he mentions these as adjuncts to the main business of "systematic knowledge and structural rationality." (p.53ff.) 
Maruyama (33) distinguishes among three types of planners: hierarchists, individualist, and mutualists in terms of their gross characteristics such as "planning by experts," a "to each his own" attitude, and "grass roots" generated approaches.

Lindblom's (34) strategy of disjointed incrementalism falls between the latter two. He denies the possibility of attaining the rationalist ideal, and cites the hidden but serious dangers resulting from failed attempts at it. Basically he is saying that comprehensiveness is not possible, (and he makes an excellent case here); whatever small "gains" can be achieved politically are the best we can hope for. The problem however, is not comprehensiveness, but higher order basic understanding as a guide for the very survival he desires. That level of understanding along with the level of political forms of decision-making is the missing ingredient. The form of the problem to be addressed and the form of resolution are both theoretically approachable and intrinsically bound to human creative value-based (cultural perception included) understanding. As Dunn (20, p.297 points out, the strategy advocated by Iindblom has merit for the normal problem solving process but not for emergent far-reaching change.

The mutuality suggested by Maruyama (28) implies a process approach. Other writers specify the process as one of learning as an approach to planning. 
The concepts of societal guidance and social learning arise through understanding the unique nature of social systems. Friedman (35) and Michaels (36) contribute to a growing body of literature on this topic. They both bring to theoretical exposition concrete examples from government and industry. Friedman concentrates on the role of the planner in a mutual learning transaction with clients. Michaels seeks to demonstrate why social learning, not engineering, is the only way to plan in turbulent times. He concerns himself with the preconditions of planning, i.e., with changes and resistance in individual attitudes and organizational structure. He is pessimistic in focusing exclusively on learning to change and neglecting the complex dynamics of anticipation and despair that press upon the human condition and drive toward transcending what is.

Kohn (37) critiques social learning theories as unsubstantive. He proposes a holistic approach to planning which recognizes a qualitative goal of long-range stability and is based on demonstrated systems principles relating to structure, development of roles, functions, and resources. Each phase of the process relates to some envisioned outcome. In this respect planning and policy become issues of design.

FORM IN RELATION TO DEVELOPMENT

Form is essentially an active relationship. Bateson (26, p.287) describes it as "the correspondence between the 
message and its referrent. In art, form is the interplay of vision, skills (mastery), and materials such that one's mastery transforms materials under the guidance of a creative idea.

Form is perceptual. Thompson $(38, \mathrm{p} .326)$ saw it as morphology or shape, the holism of which is "like music or the work of a craftsman, the attunement of art and nature."

Thompson was probably the first to note form in terms of the structure of change and its geometry. This geometry is dramatized in the types of models of change recently delineated by Thom (39). Already applications of his simple catastrophe models are evident in work by people such as Holling (22). Particularly interesting in light of our theme is a description of ultrastability using the structural models of change of Thom and applying them to such areas as ecology, urban economics, and neurotic behavior. The description of the "catastrophe" as a sudden leap to another level of organization after a series of incremental steps appropriately represents the phenomena.

Although they did not use the term "leap." Wilden and Dunn describe this "leap" process as emergence $(21,20)$. Regulation or control in these systems takes on new meaning -not as typical environmental constraints or exogenously imposed controls, but as their design. The form adopted by an emergent system is a re-creation of its self-image, the remaking of its own boundaries. 
Various dictionary definitions of form reflect this use of the term from various fields. It stands in contrast to substance, and refers to a particular modality, good order, essential nature. From the arts, it conveys the connotation of "organization...relationship...so as to produce a basic image." (40) The shape a thing takes, its form, relates simultaneously to its conception and development, to its essential organization, to its purpose and to the definition of the work itself. The boundary of an emergent social system is its principles and its uniqueness. The optimal regulator for this type of system, as Sahal (41) demonstrates, is the image of the system itself -- not of its environment. Kohn (42) relates the recognition of the appropriate type of regulation to conditions of policy successs.

As various authors $(42,43)$ have noted, social systems are basically multi-stable, that is they have many ways to achieve the same goals and enforce the same behaviors. Kohn (42) demonstrates in numerous examples how a piecemeal policy approach aimed at one element consequently cannot work. Furthermore, specifically in a type of policy system faced with radical survival choices, individual policy-makers cannot induce policy decisions unacceptable to the rest. The system itself provides regulation in this fundamental sense.

Another way of looking at form is to define it as regulatory norms or goals. Vickers (31), Michaels (36), Dunn (20), and Jantsch (30) all comment on social system 
regulation in this way. Others, Boulding (44), Polak (45), Jantsch (30), refer to the "image" which serves as guide to development.

Even though regulation is a boundary condition of a selforganizing system, the environmental context as it bears on this type of system cannot be overlooked. The first and still very important contribution in this area is Emery and Trist's (46) delineation of four types of environments and their causai relations. They enlarge the scope of "systems" in an organizational context from one of individual organizations to one of inter-organizational awareness with its concomitant interdependencies. The concept of turbulent field is a precursor to recognition of the need for radical redefinition. The individually centered self-image of an organization in a context of "persistently strong action and deepening interdependencies" gives way to a perception of Iinked organizations needing a strategy of cooperation and development of new values which act as a power field (p. 28).

Terreberry (47) expands on this work by formalizing the inter organization analysis field. She, in Iine with other theorists, distinguished between organizational change as externally induced and organizational adaptation as a function of the ability to learn. Information, search, and memory constitute key requirements for this process.

It is apparent that the form of structure, or regulation and environmental context, is unique with respect to 
essentially developing systems. One needs to go further. The types of form are different as the types of development. They can be conceived as different paradigms within the sociology of knowledge (Kuhn,48) or in culturally-based approaches to all human activity (Maruyama,24) as the difference between digital and analogic communication (Wilden, 2l) between science and art (Bruner, 49) or between left brain and right brain processes (Edwards, 50; Sperry, 51; Levy, 52; and others). This is at the crux of policy design for the development of emergent systems with unpredetermined, unmarked control mechanisms. It is analogous to the difference between cooperation and law. A fundamentally different approach is necessary which does not negate the role of traditional analytic approaches. The two approaches as metamethods will be discussed in the next section.

To summarize so far, we have proposed that:

1. The metalevel of change must be recognized in certain cases.

2. That these are cases of fundamental change emergence).

3. That these emergent social systems require a design for change that is essentially creative. They combine skill and raw materials (what is) with creative vision. 
METAMETHODS AS DESIGN PROCESS

Metamethods can be described as the methods of the method, or in other words the approach taken to problemsolving (or development) in its broadest sense. Usually aspects of study/analysis, planning, implementation, and conclusions are included as part of the process. These same activities take on another whole meaning when viewed from a different approach. In contrast to a sequence of study-plando, the seeing is in the doing and vice versa.

An analogy can be drawn from the sensation-perception field of psychology. Sensation is physiological; it refers to the messages carried by afferent nerves stimulated by the environment. Perception is a higher order dynamic cognitive process involving not only interpretation of sensory messages but an active "exploring, seeking out, and responding in continual interaction between organism and environment" (emphasis added, 53, p. 6). The distinction is taken even further by the commonly cited unique characteristics of the information processing modalities of left and right brain hemispheres or of science and art. Not only does dominance or preference affect the choice of modality, the problem situation to be investigated itself calls for certain emphases and mixes of the modalities. Metamethods, then, is the process wherein one designs (provides an organization), encompassing and integrating the 
divergent modes appropriate to both the actual situation, the type of system, research skill and resources at hand -all congruent with the particular direction desired.

The origins of radically distinct approaches have both a long history and recent legitimation. The field of policy science/analysis has also reflected the differences, even as it raises questions centering on implementation and radically new (emergent) systems. Several new methods in the systems applications area assist in developing some more appropriate designs of actual human/social systems. In addition, clues are provided engaging in a design process by the characteristic approaches of the so-called right brain method.

Origins: The Concept and Use of Fundamentally Different Approaches

Traditional Approaches: The use of fundamentally different approaches to the perennial problems to which people address themselves is commonly recognized -- whether they stem from the methods and philosophies of East and West, science and art, analog and digital information processing. The question is the legitimacy, and therefore usefulness, of the approaches in devising explanations of phenomena and thus reliable plans of action and in creating satisfactory and workable systems. 
The literatures and philosophies of East and West have long been viewed as a basis for different approaches to problem solving. The reductionism growing out of the classical Greek tradition serves as the foundation for objective, rational Western science. The East is perceived as a fount of mystical insight stemming from the I Ching (Book of Changes), various Taoist and Buddhist sources, the Sufi and Vedantu literatures. The holistic approach of the East has seemed to many to be part of a fabric with the occult, with primitive uninformed beliefs and practices, with altered states of consciousness (often associated with drugs) or religious activism (often associated with esoteric cults, costumes, and practices) -- all seemingly, and occa unally professedly, anti-rational.

On the other hand, cofounder of the American Indian Movement, Russell Means (54) sees rationality as "a curse since. it can cause humans to forget the natural order of things. A wolf never forgets his or her place in the natural order. Europeans do... Material gain is an indicator of false status among traditional people, while it is 'proof that the system works' to Europeans (p. 30 and 26). Gain, efficiency, control, abstraction versus being are seen as the basis of the European mentality whether capitalist or Marxist.

Various attempts to k=idge the gap for "modern" types 
include books about science, the Tao of Physics (55), a zen type samurai approach to strategy in the Book of Five Rings (56) used by Japanese businessmen in planning sales campaigns, and popular works like Zen and the Art of Motorcycle Maintenance (57). The Tao of Physics points not only to the great field opened by subatomic physics beyond our normal perceptual capacities, but in so doing hints at the different philosophical base required to perceive, let alone understand, the seemingly counter-experiential. This is verified by the statements of physicists themselves.

One is led to a new notion of unbroken wholeness which the classical idea of analyzability of the world into separately and independently existing parts... We have reversed the usual classical notion that the independent "elementary parts" of the world are the fundamental reality, and that the various systems are merely particular contingent forms and arrangements of these parts. Rather, we say that inseparable quantum interconnectedness of the whole universe is the fundamental reality, and that relatively independently behaving parts are merely particular and contingent forms within this whole. David Bohn and B. Hiley. (58, pp. 93-109)

The great extension of our experience in recent years has brought to light the insufficiency of our simple mechanical conceptions and, as a consequence, has shaken the foundation on which the customary interpretation of observation was based. Neils Bohr. (59, p. 2)

Bohr had the highest form of "musicality" in the sphere of science. That word "musicality" is not a familiar word. It is a feeling for what is beautiful, for what is right, a smell for the right way you look at things. Its like working a picture puzzle when somebody puts a piece in a place 
where you and I would say it doesn't belong. Einstein as reported by Wilhelm (60, p. 43).

In more formal discourse, Kuhn (48) studied and popularized the distinction between normal process in science and paradigmatic shifts in which fundamentally different frameworks of interpretation replace each other periodically. Churchman (61) examined the different scientific/applied approaches arising from the philosophies of key Western thinkers -- Liebnitz, Locke, Kant, Hegel, Singer -- all analytical. The differences are more fundamental, however. When Scheele (62) added the existentialist Merleau-Ponty to this list by demonstrating the use of the negotiated construction of reality, he showed that reality is not merely a given to be analyzed. Thus, he follows the tradition of Schutz (63), Berger and Luckman (64), the phenomenological camp in sociology.

Another area of traditional distinction is that between science and art. Science is reductionistic, art is holistic; science generalizes intellectually, art specifies experientially. Bruner (49) in his on knowing: Essays for the Left Hand discusses art as a form of knowing different from that of science. Science is essentially analytic, art creative (though science too must start with some insight such as the dreamed or imagined shape of the Benzene ring, the DNA double spiral, the curved space of relativity, the twistors of Penrose's subatomic theory). 
Bruner notes that the experience of art has no verification, only a "shock of recognition." Because art is essentially holistic, its form is that communicates. Similar1y, myth is an aesthetic device which can help in the collaboration of eternal reality (powerful forces) and the day to day human condition through resonnance. Poetry uses language not only to state meaning but to convey it through the literal power of the word in its sound, rhythm, and structure.

Yet another traditional more recent is the one arising from communication theory with its information processing approach. One of the most clearly delineated distinctions comes from the work of Wilden (21) using psychologicalcultural foundations as well as system theory. The differences are seen in terms of analog-digital processing in Figure 7.

While we often choose to focus on a given item, we usually see in context. Contextual seeing involves a gestalt, an image (forceful, immediate, detailed, and real), an aesthetic. The "laws" of this mode of seeing are aesthetic principles not laws of deductive logic (24). Communication, seen as a contextual as well as a literal process, makes sense to us and conveys the message in the total interpretation of total form. Complex levels of negation are possible in not only inflection and body language, but in the framing of the entire situation (Bateson, 26; 
1. Intraorganismic Communication

On/oft firing of neuron, logical net-

Sequence, rhythm, frequency, spatial
patterning

Total system

Decision, recall

Part of system

2. Interorganismic Communication

Distinctions cstablished by receiver Distinctions cesteblighed by sender

Contcxt of all communication

Concerns relations, connections, Mepresents limits

wholes, systems

$\begin{array}{ll}\text { Sequence and simultancity } & \text { Combination } \\ \text { Contiguity } & \text { Combrinstion }\end{array}$

$\begin{array}{ll}\text { Cuntiguity } & \text { Comlinatiou } \\ \text { Sinsilarity } & \text { Substitution }\end{array}$

\section{Logical Distinctions}

Concrete

Territory

'Mefusal ó '́css'

Dillerence and similarity

No logical typing

Cannot communicate about itsclf

Scmantic-Pragmatic

Mleaning

Scquence and simultaneity

Continuous

liull

Whole, relations

Maps continuums precisely

Presence and absence

Similarity and contiguity

Abstract
Map
Alsence, zero
'Fither/or'
Opposition and identity
Logicil typing
Communication about communica-
tion
Syntactic
Signification
Spacc and time coordinates
Discontinuous
Fill of hules
Elements, cntities
Can only map boundarics preciscly
Prescnce or abscnce
Code and messagc, substitution and
combination

- Not including languagc.

\begin{tabular}{|c|c|}
\hline Analog Aspect & Digital Aspect \\
\hline $\begin{array}{l}\text { 'Prc-categorical" } \\
\text { Can rcpresent successions simultane- } \\
\text { ously }\end{array}$ & $\begin{array}{l}\text { 'Catcgorical' } \\
\text { Indicatcs simultaneitics successively }\end{array}$ \\
\hline Obscrver in the system & $\begin{array}{l}\text { Observer assumed to be outside the } \\
\text { system }\end{array}$ \\
\hline $\begin{array}{l}\text { 'Subjective' (contextual) } \\
\text { linuwledge of 'relations' }\end{array}$ & $\begin{array}{l}\text { 'Objective' } \\
\text { Knowledge of 'facts' }\end{array}$ \\
\hline $\begin{array}{l}\text { Relativisitic } \\
\text { Retlons }\end{array}$ & Absolutist \\
\hline Ecosystems & Entitics \\
\hline Open system & Closure \\
\hline $\begin{array}{l}\text { Firce llow of meaning } \\
\text { 'Untamed thought' (la pensée sauvage) }\end{array}$ & $\begin{array}{l}\text { Binding of signification } \\
\text { 'Scientific' thought; rationalism, em- }\end{array}$ \\
\hline Conunitre & Savoir \\
\hline
\end{tabular}

4. Iluman Commmmicalion

\begin{tabular}{|c|c|}
\hline \multicolumn{2}{|r|}{ D } \\
\hline Senses & Denotative langunge \\
\hline 'Limulion' & 'Re:ison' \\
\hline livoc:ation of relition & Transinission of alsstractions \\
\hline Presculting & Nituing \\
\hline Ilich rulational scmantics (ambiguous) & $\begin{array}{l}\text { Powerful syntax (unambiguous); weak } \\
\text { scmantics }\end{array}$ \\
\hline Pusition, context, situation & Text, message \\
\hline Mlemiory & Rememoration \\
\hline Understandings & Agrecments, codicils \\
\hline l'ain is pain, pain is a sign & 'Puin' is a signifier \\
\hline 'Nitural' body moyements & Conventionalized body movemeats \\
\hline Suchtrorstcllung (thing-presentation) & W'orleorstellung (word-presentation) \\
\hline lmages, jcons & Signiliers \\
\hline 'Natural' symbols & Artificial or conventional syinbols \\
\hline Similurity and contiguity & Metaphor and netonymy \\
\hline Difference, similurity & Opposition, ideutity \\
\hline Intcractive & Individual \\
\hline
\end{tabular}

5. Langunge

Refusal, repudiation, rcjection, dis- Negation

$\begin{array}{ll}\text { avowal } & \text { Word, means } \\ \text { Rcferent, goal } & \text { Concepts } \\ \text { Nclationship } & \text { Information }\end{array}$

Concepts

Connotation (meaning) $\quad$ Derotation (significntion)

Figure 7. Analog and digital communication

Source: Anthony Wilden, Systems and Structure, 21. 
Wilden, 21; Maruyama, 27). What emerges from all of the traditional distinctions is that one part is seen as language based and definitive. The other as experientially-based and perceptual. The former reflects a distrust of the intuitive as based on insufficient data.

\section{Brain Research: Research on commissurotomized} brain patients (those with brains surgically split to control profound seizures) in the. late 1960's proved to be an exciting development quickly popularized. It not only legitimated the traditional distinctions but grounded them in "hard" scientific data. Moreover it indicated that the "other" mode of processing had its own natural advantages which were neurophysiological rather than merely mystically rooted. Both processing modes were recognized as forms of reasoning though different in approach and differentally useful. The leading researchers in the field were making inferences widely quoted:

The main theme to emerge... is that there appear to be two modes of thinking, verbal and nonverbal, represented rather separately in left and right hemispheres, respectively, and that our educational system, as well as science in general, tends to neglect the nonverbal form of intellect. What it comes down to is that modern society discriminates against the right hemisphere. (Roger W. Sperry, 51)

The data indicate that the mute, minor hemisphere is specialized for Gestalt perception, being primarily a synthesist in dealing with information input. The speaking, major hemisphere, in contrast, seems to operate in a more logical, analytic, 
computer-like fashion. Its language is inadequate for the rapid complex syntheses achieved by the minor hemisphere. (Jerre Levy and R. W. Sperry, 52)

As usual, growing popularism is accompanied by scientific skeptisism. But the late 1970's, Gazzaniga (who himself had written The Bisected Brain (65) a few years earlier) now wrote an incisive critique of the theory of hemispheric specialization in 1978 (66). Researchers in the area agree, as they proceed ever more deeply into the research process, that questions emerge concerning possible methodological artifacts from various types of research. Work on brain damaged patients, including those with hemispherectomies and commissuratomies raises issues of to. what extent and in what way functional compensation might have occurred so that normal brain functioning is not what is being observed. Anaesthetization of alternate hemispheres is a process done primarily for medical rather than pure research purposes and its subjects thus also have suspected brain damage. Normal subjects, on the other hand, exhibit many compounding effects.

Gazzaniga (66) distinquishes between what he calls the facts of cerebral lateralization and the theory of hemisphere specialization. He points out that the research substantiating specialization has all been of a "manipulospatial" type in which the perceptual and response mechanisms have been confounded. Offering evidence from his own 
research as well, he concludes there is no perceptual asymetry residing in the right hemisphere, and no genetically specified cognitive styles residing in the hemispheres separately. Lateralization differences arise not from a genetically pre-wired neuro-substrate but for most people from the localization of language mechanisms in the left hemisphere through evolutionary processes and subsequent displacement of other functions to the right. However, it is evident in brain damaged people that there is a degree of plasticity permitting some lateralized function to be replaced by the other hemisphere. Normal functioning requires the integration of information across hemispheres. The critique, however, is not the end of the discussion on left-right brain hemispheric distinctions. Many authors (for example 67-70) in the information processing camp also identify various artifacts and refine the theory with more sophistication than those reflected in the first publications. However, they seem to find no inconsistency with the information processing theory. In fact, the approach seems to provide for a higher level organization of data (functional) in contrast to a simple neurophysiological substratum (structural) which does not provide for the complexity of findings. Kinsbourne (67) relates the functional distance of cerebral control centers to the efficiency of hemispheric performance. Nebes (68) discusses the tautology of temporal 
primacy of perception and dominance of hemisphere. Harcum (69) distinguishes between functional and structural dominance and notes how the former may mask the latter. Asymetry is seen by him as more indicative of information processing than of innate hemispheric superiority -- a distinction not made by Gazzinga (66). Nebes (68) argues that the nature of the task -- both sensory and response (involving counterbalanced controls) specifies hemispheric involvement. This is a refinement of the information processing approach. Thus a response hierarchy specifies that while motor responses are generally cross lateral, any verbal transformation (i.e. writing) is left-dominated.

Another fascinating challenge to Gazzaniga comes from the yet untranslated work of Tsunoda reported by Sibutani (70). Hemispheric differences, including language, appear not to be genetic in origin but environmental. Further the differences appear to depend on cultural language development shaping hemispheric differences rather than genetically or evolution-determined language capacity of the left hemisphere shaping the development of language. Moreover these differences are not simply those of language per se but of oral language (shown by differences consistently found in deaf mutes). Japanese and certain other groups with vowel dominated languages process consonants and vowels, natural and mechanical sounds in the left hemisphere, while 
Westerners normally process consonants and most language functions in the left but vowels, natural, and mechanical sounds in the right hemisphere. Emotions may also be channeled differently.

Perceptual abilities are seen by Geschwind (71) to reside in both hemispheres; aspects of language are in both, facial recognition in both. Nevertheless the distinct types of information processing, while requiring closer examination even in its more sophisticated form, provide an approach to understanding a massive amount of data on the left and right hemispheric differences. In addition to the data on the topic, the psychological patterns directing researchers are intriguing and lend support to the "other side" in its critique of the objectivity of the dominant approach. While left-right differences have come to the fore, (left specializations over a century ago, right mostly in the last two decades), the supermacy of the left brain approach has been maintained. Sagan (72) for example, will extol the creative right while insisting on its ultimate verification and validation by the left through its scientific approach.

Studies of cross-cuing and interference of one hemisphere to the other, however, may indicate at least a justification for the opposite point of view. When the right side responds to a task unknown by the left and the left is asked why the response is made, it often fabricates or 
guesses $(52,66)$. It needs a reason for behavior and acts in much the way attribution theory does in predicting on the macro level -- reason does not always direct behavior but reality is interpreted and rationalized after the fact based on responses to it. On the other hand, the right hemisphere does not have language to explain its insights and must resort to other methods. It can, for example, instead of naming a number seen, allow the left to enumerate, stopping it at the proper digit. It can register resistance to wrong data through information $i i$ alone has. It can draw from a memory storehouse to assess the fit of an item. The question is thus raised, is what we call intuition the nonverbal knowledge of the right promoting acceptance or rejection of the data of the left? Does the uncanny sense of a successful business executive who disagrees with computer modelled goals, hierarchies, cost-benefit projections, etc. reflect a wider though unnamed base of information being drawn upon -- legitimately, not irrationally?

\section{Evidence from Applied Areas: While the question}

CF the neurophysiological basis of different approaches is an active one, as yet inconclusive, evidence continues to grow from another source -- the applied areas. Whether or not the basis for hemispheric differences is known, the effect of differential processing modes can be demonstrated -- challenging science to catch 
up in analyzing the mechanism and naming the inputs of the phenomenon. The applied areas of child development, learning to draw, anthropology as change agent, evaluation as an illumination process, medical diagnostics and holistic health, various psychotherapy methods point in this direction.

Leary of new crusades of pseudointellectualism and pop-psych themselves, Fadely and Hasler (73) found in their extensive experience with children in clinical and school settings a different type of child. This child called the alpha or natural child is not different because of developmental or functional, emotional or intellectual abnormalities. But neither does s/he fit into the conventional language-oriented culture because $s /$ he functions from a non-verbal cognitive process. They attribute the difference to unequal hemispheric capacities. The child can be taught all skills and behaviors but must be taught differently. Standard tests showed average verbal skills but not a preference for verbalization. Performance is chosen. Cognitive organization not capacity was reflected. Drawing on the Right side of the Brain (50) is a method of teaching "a course in enhancing creativity and artistic confidence as its subtitle indicates, not simply a "how to draw" book. It helps develop the pre-conditions, the relations of drawer and drawn from which the drawing follows -- with dramatic improvement in a short time. It works. 
No matter the age, occupation, skill level, anxiety about drawing ability, her students become skilled and confident drawers. See selected before and after drawings from the book, Figure 8. As Edwards (50) states,

The magical mystery of drawing ability seems to be, in part at least, an ability to make a shift in brain state to a different mode of seeing/perceiving. When you see in the special. way in which experienced artists see\% then you can araw. (p. 3I)

Edwards relates how students feel the shift in processing modality. Professor and artist Martin Mondrus recognized the phenomenon she described and demonstrated as being in a state of artistic endeavor.

Another area which demonstrates successful results of an "insight" modality is in the area of applied anthropology . Foster (74) gives many examples in which an anthropologist gathers pertinent data but must "intuit," so to speak, the inner connections of a different culture so that the information can be used to introduce programs or policies which are helpful instead of destructive. Consider the differences in approach to the following cases given by Foster.

In the early stages of contact with Western culture many of the native peoples of New Guinea have experienced recurring mass hysteria movements known by the generic phrase "Cargo cult."

In 1922 F. E. Williams was appointed Government Anthropoligist in Papua, an Australian Mandated Territory. His first major study was of the Vailala Madness, a Cargo Cult religious movement which for ten years had disturbed the administration of Papua. Williams concluded that the movement 

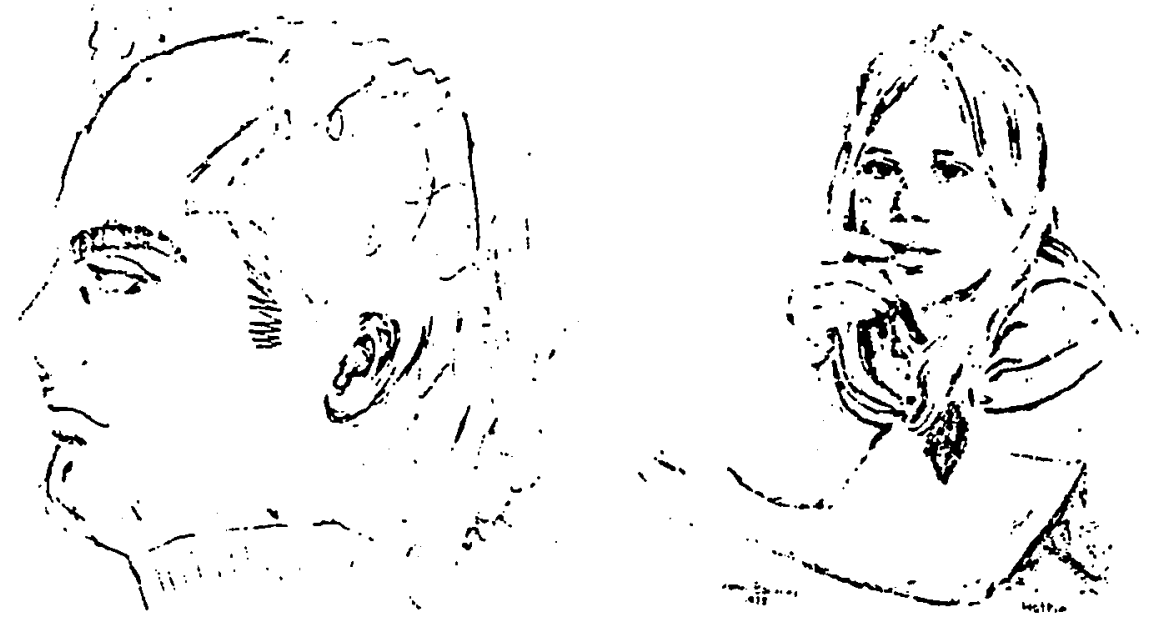

John Buxmer January 3, 1978
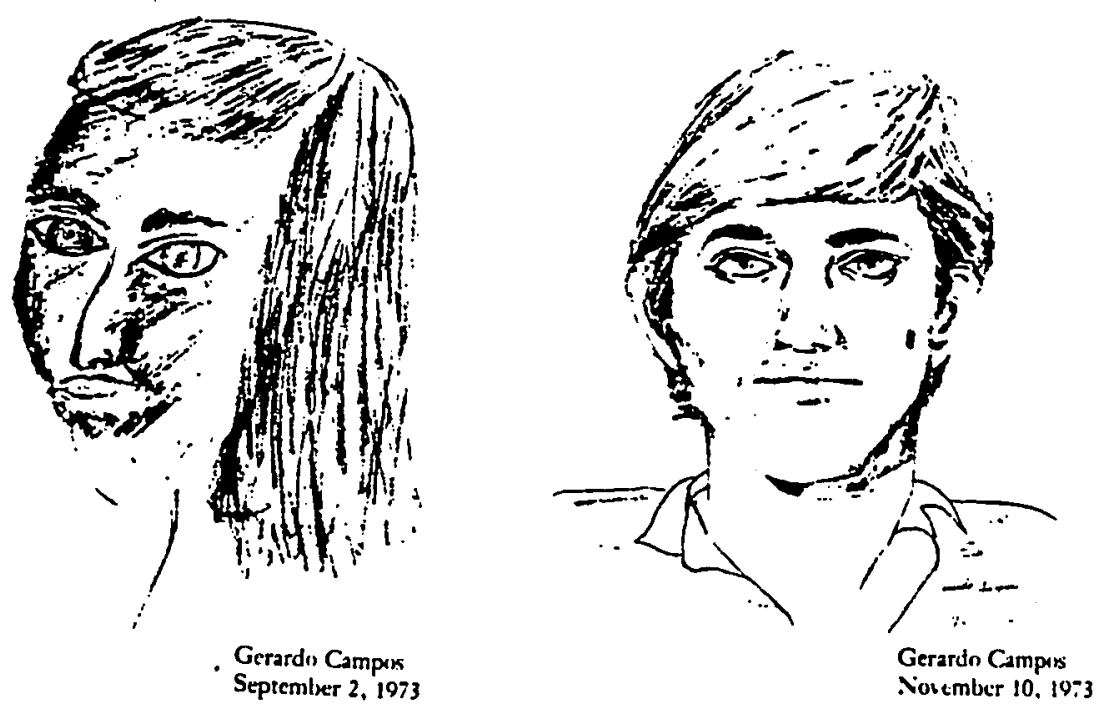

Figure 8. Right brain instruction: before and after.

Source: Betty Edwards, Drawing on the Right side of the Brain, Los Angeles: J. P. Tarcher, 1979. 
continued because Christianity had not proven to be a sufficient substitute for the native forms it replaced, that it constituted no serious threat to the political stability of the territory, and that the government should not intervene, but allow it to run its course. The Lieutenant Governor of Papua, in spite of personal beliefs to the contrary, accepted Williams' analysis and recommendations, and no action was taken.

Williams' appraisal proved correct. When he revisited the area ten years later he found that the movement had largely, although not entirely, disintegrated. The destruction of native property had ceased, native rituals were being reintroduced, mass hysteria had disappeared, and the natives were peaceful. By contrast, in other places where government had intervened to suppress Cargo Cult movements, violence and bloodshed had resulted. (74, pp. 18f.)

The information was not derived by a count of majority opinion on some issue, nor by experimental design, but by careful study resulting in insight into process and connections.

A further example from anthropology contrasts different cultural modalities which:Parmedes and Hepburn (75) have labeled left and right brain processes.

Thomas Gladwin, an anthropologist contrasted the ways that a European and a native Trukese sailor navigated small boats between tiny islands in the vast Pacific Ocean.

Before setting sail, the European begins with a plan that can be written in terms of directions, degrees of longitude and latitude, estimated time of arrival at separate points on the journey. Once the plan is conceived and completed the sailor had only to carry out each step consecutively, one after another, to be assured of arriving on time at the planned destination. The sailor uses all available tools, such as a compass, a sextant, a map, etc., and if asked, can describe exactly 
how he got where he was going.

The European navigator uses the left-hemisphere mode.

In contrast, the native Trukese sailor starts his voyage by imaging the position of his destination relative to the position of other islands. As he sails along, he constantly adjusts his direction, according to his awareness of his position thus far. His decisions are improvised continually by checking relative positions of landmarks, sun, wind direction, etc. He navigates with reference to where he started, where he is going, and the space between his destination and the point where he is at the moment. If asked how he navigates so well without instruments or a written plan, he cannot possibly put it into words. This is not because the Trukese are unaccustomed to describing things in words, but rather because the process is too complex and fluid to be put into words.

The Trukese navigator uses the right-hemisphere mode. The second mode is not simply a matter of "primitive" versus technologically advanced cultures. Mark Twain (76) wrote of his similar process of learning to navigate in his Life on the Mississippi.

In the applied area of evaluation, Parlett and Hamilton (77) and Patton (78) have successfully employed methods of "illumination" as well as experimental design. The purpose of the former is to illuminate problems, issues, and significant program features in contrast to measuring outcome. Thus categories are not pre-set but derive from observations, interviews, document analysis, etc. Knowledge from the unique not just the generalized is sought. The system adopted is not an abstraction but a particular 
interpretation in this particular setting, "a unique pattern of circumstances, pressures, customs, opinions, and work styles which suffuse the practice" (76, p. 5). Evaluation, then, by their metaphor captures the performance in contrast to merely reading the script and noting the applause meter. A number of such illuminative evaluations including one at Massachusetts Institute of Technology have shown not only that certain programs were successful or not but why, how and with what deeper significance.

Holistic health efforts emphasize not only preventative maintenance practices but strong emotional-attitudinal integration. One cancer patient support center near stanford University amazed doctors there with pain relief methods using visualizationand guided imagery. These contribute to self-health attitudes used in conjunction with chemo and radiation therapy with dramatic results, for example, a disappearing brain tumor (79).

Another holistic health application is in diagnostics. Several years ago the author heard a neurosurgeon who advocated the use of developed intuition in efficient diagnosis of cases. Questions about a patient's musical tastes or relationship with a grandfather, were not necessarily irrelevent. A nontraditional, "intuitive" course of questioning revealed information yeilding a $96 \%$ accuracy rate (verified by surgery and tests. Disagreement with a panel of peers usually resulted in verification of his accuracy by autopsy). 
He advocated the development of the skill of following hunches derived from a total view of the person -- not just a particular symptomatology.

"Freeing" from one's usual mode of processing, is the basis of relaxation exercises and hypnosis as used in treatment of phobias, biofeedback control of pain and other altered states of consciouness which are now commonly recognized. The shift in type of processing is both internally perceptable and externally monitorable.

The applied areas using processing modes attributed to the "right brain" are productive. They demonstrate along with brain research and the traditional Iinear/holistic split in approaches that the metarational emphasis is on the integrated design process in contrast to left mode planning methodology. Design and form are perceptual -- they use an active space and arrangement held together by active energy. What does this mean for policy science-analysis/ left-right controversy in the policy field?

The Two Approaches in Policy Science/Analysis

Policy can be considered the design of the workable in human systems. It is meant to set direction and to bring about change. The question of how to do that, however, has resulted in a great debate in policy analysis between the "rationalists" and the "realists" -- two different approaches. 
In attempting to improve the quality of policies and the policy-making process in general, the realists examined past policies -- a mode descriptive in nature and relying on the historian's approach more than anything else. The result is a chronology of affairs considered significant to the policy and a laying out of interpreted consequences. In contrast, the rationalists, given impetus in the system analysis revolution, sought theoretically-based and empirically-tested ways of improving policy. They adapted the systems approach in policy formulation, complex simulation models, application of econometric models, evaluationresearch methodology, operations research, and so forth. But, the credibility and applicability of these methods to the human arena have been questioned from their introduction. The realists, in turn, are accused of having a no more than haphazard chance of making an impact on the course of human affairs through policy.

Lindblom (34) is satisfied with an incrementalist approach based on mutual adjustment -- "science of muddling through" -- but is dismissed as a disjointed incrementalist for this avoidance of responsibility for long-range consequences. Wildavsky $(80)$, in his turn, wants to "rescue policy analysis from PPBS." Tribe (81) questions whether the policy sciences are really analysis at all or just ideology and Hoos $(82)$ has minced no words in her negative appraisal of systems analysis in approach to policy. 
The lines are drawn between those techniques derived from a quasai-scientific or rational approach, and those stemming from an appreciation of the vagueries of the human condition, especially as these are manifest in sophisticated political interactions. The former is reductionistic, the latter elusively holistic.

The dilemma has spurred a number of attempts at integration -- for example Baum's (83) existentialist approach. Wiseman (84) proposes one "systematic yet retaining political realism". Dror (32) maintains the primacy of the rational approach and plan -- a routine function that goes back to maintenance systems -- while admitting the importance of related variables such as:

-..political feasibility analysis, examination of social power implications of alternative policies, and analysis of coalition needs and political consensus implications... the early involvement of politicians, community leaders, etc., in the analytical activities; and the limits of analysis as a perceptive set for cognizing human reality and aspirations (pp.55f.)

The root question is how does one get results; how does change occur? Pressman and Wildavsky's (85) review of the implementation literature in 1973 found only superficial discussion of this problem.

Usually, implementation is viewed as what one does after policy is set. Hence it is a problem either of administrative follow-through i.e., you hire someone to carry through the plan (in which case it becomes a routine function 
that refers back to maintainence systems) or it is a problem, often sticky, of motivating people to do something. In this respect, "the separation of policy design from implementation is fatal" ( 85, p.xvii) Nevertheless, the authors are looking at little more than the personal and organizational realities constituting "feasibility" and "desirability."

What the controversy highlights is the inadequacy of either the rational (analytic) or the synthetic (creative, holistic) approach used alone particularly to address fundamental change (development, emergence). Implementation when seen as a key factor in the success or failure of a policy becomes intrinsic to policy design is conceived as an issue of policy form. Both analytic (rational) and synthetic (creative) approaches play crucial roles in developing systems.

Not only is information for system planning necessary but so is a means to foster the self-organizing processes of a system in development. The two approaches discussed so far gives away to the three inquiry styles described by Jantsch $(30)$. He describes the rational method of inquiry as looking at the river objectively from the shore. In what he terms the mythical method, the inquirer is in the river and is steering by means of cues. The evolutionary approach considers the inquirer and stream (course of human history) as one. 
The rational method is thus supplemented by a two fold process of creativity. The difference is in the method of system inquiry. The inquirer in the firsttwo styles is the usual researcher using two distinct types of research -often called the quantitative and qualitative methods. These distinguish the researcher's type of involvement in the process of analyzing and planning for the system. In the third style, the inquirer is the self-organizing assembly of potential participants. The emergent system itself is a self-reflective mode. The role of a researcher is only to facilitate the group in its process, not study and offer conclusions to them. This latter approach is appropriate to the study of a developing system because the inquirer is the system in emergence. It is necessary because we as a human group incorporate the rational with the intuitive in any evolutionary leap, not in any additive or combinatory way but in a way that is holistic.

Thus, specific methods are needed to accomodate the inquiry styles at once empirical (analytic prescriptive as well as contextual descriptive) and self-organizing (process oriented). The role of the analyst is perilously predominant in the empirical, while in the latter $s /$ he serves as facilitator. The former uses the analyst as commentator, interpreter, and developer of courses of action; the latter, as arranger of information and group experience in its own search for "feel" or "fit" of a set of considerations. These 
are aesthetic concerns and are essential to the design of the system because they are intrinsic to the human perspective. In a real setting with real people at a point of major transition, they are not only appropriate, but are required as part of a credible process.

While the evolutionary inquiry style may err from systematic distortions such as myopia or cultural chauvenism, the two empirical styles are prone to err through neglect of a critical dimension or use of an inappropriate framework. Including distinct political and creative points of view in the process is one way to improve their results. Only recently have some concrete suggestions been put forth in this area. There are examined in the next section.

The State of the Art

Two quite different approaches are coming to the fore as metarational means of integrating the dualistic elements of policy science/analysis -- one uses diverse perspectives to analyze a given policy area and propose courses of action These are referred to as multiple perspectives. The other approach uses participatory methods to develop a course of action through the group's progressively deepening understanding of the situation in all its ramifications. These are the various process approaches. Multiple Perspectives permit formal presentations of different points of view -- not only the point of view of rational 
systems, but of organizations and individuals. These perspectives provide different pictures of a policy area because of their underlying organizing concepts. In essence, though, they are all analytic and instrumental. Endogenous process approaches, on the other hand, are always to some extent participatory. Their origins stem from small group processes such as brain-storming, T-groups, and the vast array of processes now used in everything from therapy to business. Inter-organizationally, process techniques are based on political models -- bargaining -negotiating -- usually through formally designated representatives. The prime way of enlisting the views and support of a wide range of individuals and independent organization remains the form of public meetings and hearings -- which still acts as a "vote" counting, loose survey method for some decision group, usually public officials. Facilitators of the group process have employed simulation and gaming methods. Nevertheless, the emphasis remains on increasing understanding or changing attitudes as a prelude to decision-making. A new method for simultaneously increasing communication, understanding, development of options, and a course of action among a diverse and independent group is a new variation of the Delphi -- the Decision Delphi (86). It truly belongs to participatory methods, characterized by the inseparability of perception and action (insightful, experential, learning), self-reflexiveness, appreciative mode and synthesis or 
creative result -- all in contrast to the analytic-instrumental approaches. The development of multiple perspectives and Decision Delphi are recent and represent some state of the art achievements in the dual approaches.

Multiple Perspectives: A number of analysts have called for the need to recognize and use multiple perspectives. Allison (87), one of the first, bases his multiple models on the bodies of information gathered by various disciplines; Churchman (61), and after him Mitroff and Turoff (88), base theirs on the appraoches to truth found in different philosophies. All of these writers seek to com- . pensate for the incompleteness found in a single point of view by supplementing them with others.

Applying his derived models to a policy analysis case, Allison (87) demonstrated the incompleteness of understanding based on any one model alone. One gains a feeling of "getting inside" the "real way it happened" through the addition of the organizational process and bureaucraticpolitical perspectives. (See Table II for description.) Marmor (89) and Mead (90) found these models helpful in the analysis of public social policy implementation. Mean (90) in addition to explanatory factors (historical and anecdotal) sought to apply organization and political theory. Moreover, he proposed to define for future studies, quantitative indicators of the analytic 
TABLE II

Allisoa's Three blodels

\begin{tabular}{|c|c|c|c|}
\hline & Rational Acior & Orzonizstional Process & Bureaueratic Politics \\
\hline Basie Unit of Analy is & Action as elioice of total system & $\begin{array}{l}\text { Aetion as organizationsl ou:pu: in } \\
\text { frmework of present capabitaties } \\
\text { and constraints }\end{array}$ & $\begin{array}{l}\text { Aetion as political :csultant (barzining. } \\
\text { compromise) }\end{array}$ \\
\hline Ortanizing concepts & 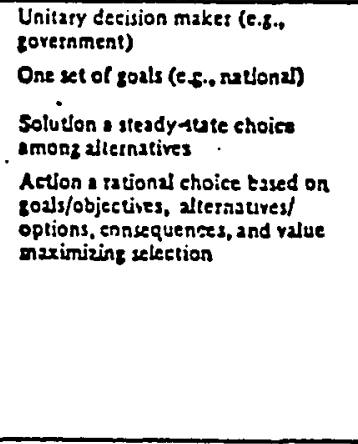 & 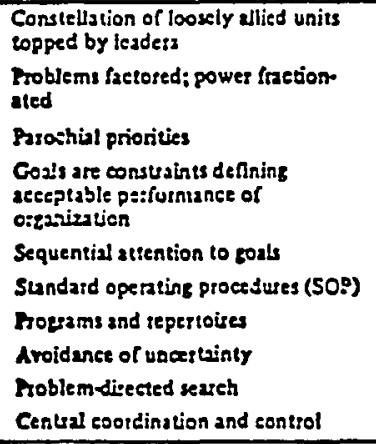 & 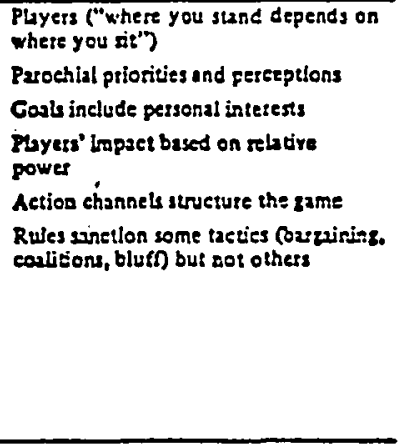 \\
\hline $\begin{array}{l}\text { - Mrizani Inference } \\
\text { patrera }\end{array}$ & $\begin{array}{l}\text { Actions we maxnisiag means to } \\
\text { actiere ends }\end{array}$ & $\begin{array}{l}\text { Acelons predseiced } \\
\text { on SOP' }\end{array}$ & $\begin{array}{l}\text { Action resultant of bergetrias } 22 \mathrm{me} \\
\text { among individuals }\end{array}$ \\
\hline Ceneral propositions & 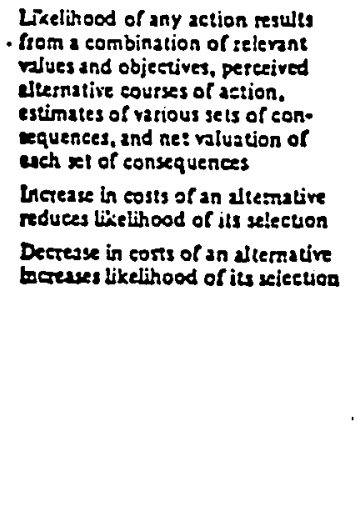 & 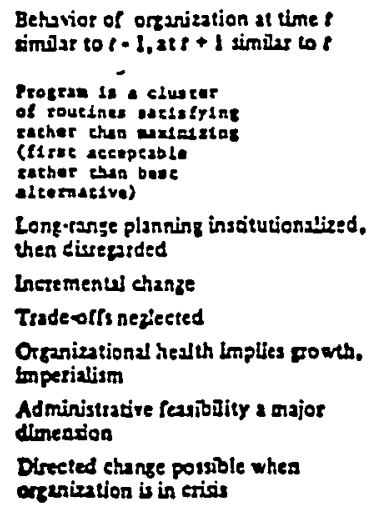 & 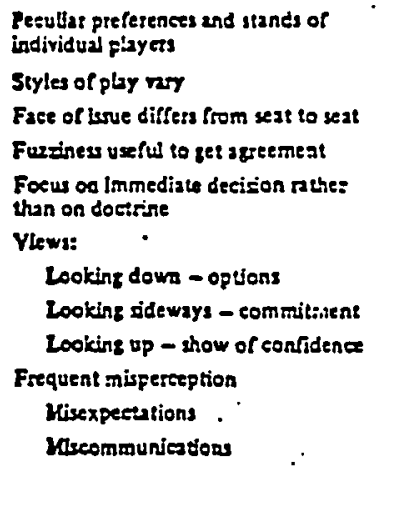 \\
\hline
\end{tabular}

Soatee: C. T. Allison, Essence of Decirion, Little, Brown \& Co., Boston, 1971. 
constructs.

Allison himself has questioned whether there vere more models. Subsequent analysts feel there are. Developing the notion of models, they extended, combined, or proposed different perspectives. Elmore (9l) calls his the systems management, bureaucratic process, organizational development, conflict and bargaining models (See Table III for description). Steinbrunner (92) names his, the analytic, cybernetic, and cognitive paradigms (see Table IV for description); Anderson (93), the rational, organizational, and cognitive perspectives (see Table $\mathrm{V}$ for description); and Iinstone (94) the technical (T), organizational (O), and individual (P) perspectives (see Table VI for description). For further analysis and comparison see Linstone (94). What emerges from employing various perspectives is the different cast the problem takes when viewed from the analytical constructs found in the various perspectives. They demonstrate the need for at least multi-disciplinary approaches for the differing degrees of detail and scale swept into the analysis, and for the differing time frames offered by each. Anderson proposed that the choice of perspectives simply match the requirements for a given analysis. There seems to be some consensus in the use of three in terms of the managability of three along with the power and balance gained by using more than one. The strands of influence, however, and the development of the various 
TABLE III

ELMORE'S FOUR MODELS OF IMPLEMENTATION

\begin{tabular}{|c|c|c|c|c|}
\hline & $\begin{array}{l}\text { Model I } \\
\text { System Mananement }\end{array}$ & $\begin{array}{l}\text { Model II } \\
\text { Bureaucratic Process }\end{array}$ & $\begin{array}{l}\text { Model III } \\
\text { Organizational } \\
\text { Developmental }\end{array}$ & $\begin{array}{l}\text { Model IV } \\
\text { Conflict \& Bargain- }\end{array}$ \\
\hline $\begin{array}{l}\text { Organizational } \\
\text { Descriptor }\end{array}$ & $\begin{array}{l}\text { Rational value maxi- } \\
\text { mizers: goal di- } \\
\text { rected behavior }\end{array}$ & Discretion \& routine & $\begin{array}{l}\text { Satifies Basic psy- } \\
\text { chological \& social } \\
\text { needs of individual }\end{array}$ & Arenas of conflict \\
\hline Power \& Control & Hierarchical control & $\begin{array}{l}\text { Fragmented \& dispersed, } \\
\text { specialized }\end{array}$ & $\begin{array}{ll}\text { Maximize individual } & T \\
\text { control, participa- } & \\
\text { tion, commitment; } & \text { t } \\
\text { distributes respon- } & c \\
\text { sibilities } & \\
& \end{array}$ & $\begin{array}{l}\text { Temporary ability } \\
\text { of person or unit } \\
\text { to mobilize suffi- } \\
\text { cient resources to } \\
\text { manipulate others' } \\
\text { behavior (non-for- } \\
\text { mal power base) }\end{array}$ \\
\hline Decision-Making & $\begin{array}{l}\text { Optimal Allocation of } \\
\text { responsiblity }\end{array}$ & $\begin{array}{l}\text { Controlling discretion } \\
\& \text { changing routine }\end{array}$ & Consensus & Bargaining \\
\hline Implementation & $\begin{array}{l}\text { Consists of defining } \\
\text { a detailed set of ob- } \\
\text { jectives to reflect } \\
\text { policy, assigning re- } \\
\text { sponsibilities \& stan- }\end{array}$ & $\begin{array}{l}\text { Consists of identifying } \\
\text { discretion, need for } \\
\text { change of routines, de- } \\
\text { vise alternates, induce } \\
\text { replacement }\end{array}$ & $\begin{array}{l}\text { Consensus \& accommo- } \\
\text { dation between policy- } \\
\text { makers \& implementors }\end{array}$ & $\begin{array}{l}\text { Series of bar- } \\
\text { - gained decisions } \\
\text { resulting in pre- } \\
\text { servation of bar- } \\
\text { gaining process }\end{array}$ \\
\hline
\end{tabular}


TABLE IV

STEINBRUNNER'S PERSPECTIVES

\section{Analytic Paradigm}

Analytic evaluation of al ternative outcomes

Models used for causal learning

Decision based on optimal choice

Decision maker makes assessment of relative values

New Information added as in Bayesian statistics

Collective decision making assumes equivalence with theoretical individual

\section{Cybernetic Paradigm}

Uncertainty reduction by routintzation

Servomechanism or feedback control

Learning through automatic error-control

Problem fractionalization

Decistonmaking by recipe rather than blueprint

\section{Survival or perpetuation}

deciston criterion not optimization or satisficting)

\section{Cognitive Paradigm}

Much information processing is done without conscious direction

Inferential memory, consistency, reality, simplicity, and stability as basis for mental Information processing

Structure of cognitive operations has regularities bearing on decision process

\section{Strong bellefs exist despite uncertainty}

Strong rellance on negative logic

Thought patterns: grooved thinking, uncormitted thinking, and theoretical thinking

Source: H. Linstone, et. al., "The Use of Alternate Decision Models for Technology

Assessment," NSF Project, Futures Research Institute. Portland, Oregon:

Portland State University, 1980. 
TABLE V

ANDERSEN'S THREE PERSPECTIVES

\section{Rational}

Perspective

- Alternatives specified

- Consequences assessed

- Goals or objectives

- Choice (often by optimization)

- Decisions collective (single actor)

- Problen bounded
Organizational

Perspective

- Multiple actors, parochial interest

- Goals as constraints ("don't go above or below")

- Sequential attention to goals ("grease the squeaky - Store and recall informawhee 1s")

- SOP's

- Decomposable environments

- Problen directed search

- importance of information channeling

- Short run actions and corrections based on feedback

- No Prediction of long term consequences

- Limited flexibility
Cognitive

Perspective

- Limited information proces capability

Tendency to filter out inconsistent images

tion consistent with past experience

- Focus on simplistic hypotheses rather than scan options

- Small peer roup reinforcement

(use of task force)

Reality socially construct ed (Merleau-Ponty)

Role of Mathematical Models (e.g., system cynamics) in Perspective

- high light problen definition

- evaluate consequences of alternative policies

- explicitly present tradeoffs

- forum for collective decisions (replaces diverse mental models)
- focus attention on long term goals

- ignore sequence of goal attention

- provide guidelines for problem directed search

- aid organizing information processing

- ignore short-run feedback

- aid development of interagency policies

- tend to develop infeasible policies
- expand information process ing capabilities (ability to handle many variables and interactions

- aid formetion of images and analogies (structural models (I)

- counteract simple extrapolations

- force causal hypothesis and then clarify trade-of $i$

- impact depends on the relative social positioning of the model and the user

(1) Example: Axelrod's cognitive maps

Source: H. Linstone, et. al.. "The Use of Alternate Decision Models for Technology Assessment," NSF Project, Futures Research Institute. Portland, Oregon: Portland State University, 1980. 


\section{LINSTONE PERSPECTIVES}

\begin{tabular}{|c|c|c|c|}
\hline & TECHNICAL (T) & ORganization (0) & INDIVIDUAL (P) \\
\hline $\begin{array}{l}\text { WeLT- } \\
\text { ANSCHALUNG }\end{array}$ & Sclence-technology & organization & psychology-behavior \\
\hline \multirow{9}{*}{$\begin{array}{l}\text { CHARACTER- } \\
\text { ISTICS }\end{array}$} & Cause-effect & cause-effect \& challenge-response & challenge-response \\
\hline & Objective & objective \& subjective & subjective \\
\hline & Problem solving & problem avoidance/delegation & $\begin{array}{l}\text { leaders and followers } \\
\text { game-in-process for most }\end{array}$ \\
\hline & Analysis & analysis \& synthesis & intultion \\
\hline & Prediction & $\begin{array}{l}\text { recognition of partial unpredict- } \\
\text { ability } \\
\text { action/implementation }\end{array}$ & fear of change and unknown \\
\hline & Optimization & satisficing & creativity and vision by few-"the yogi" \\
\hline & Complete rationality & $\begin{array}{l}\text { Parochial priorities } \\
\text { incremental change }\end{array}$ & $\begin{array}{l}\text { partial rationality } \\
\text { inner world/self } \\
\text { Maslow hierarchy of needs }\end{array}$ \\
\hline & $\begin{array}{l}\text { Use of averages, probabilities } \\
\text { Trade-of } f \text { s }\end{array}$ & $\begin{array}{l}\text { standard operating procedures } \\
\text { factoring/fractionating problems }\end{array}$ & $\begin{array}{l}\text { learning } \\
\text { power/influence/dominance - "the } \\
\text { commissar" }\end{array}$ \\
\hline & Left neocortex & left and right neocortex & left and right neocortex \\
\hline $\begin{array}{l}\text { PrefERRED } \\
\text { InOUIRING } \\
\text { SYSTEM }\end{array}$ & $\begin{array}{l}\text { Lockean-data } \\
\text { Leibnizian-model } \\
\text { Kantian-multimodel }\end{array}$ & $\begin{array}{l}\text { Hegelian-dialectic } \\
\text { Merleau-Ponty-negotiated reality }\end{array}$ & $\begin{array}{l}\text { Intuition-noumena } \\
\text { individual reality }\end{array}$ \\
\hline $\begin{array}{l}\text { TIME } \\
\text { CONCEPT }\end{array}$ & $\begin{array}{l}\text { Technological time } \\
\text { Zero discounting }\end{array}$ & $\begin{array}{l}\text { Social time } \\
\text { Moderate discounting }\end{array}$ & $\begin{array}{l}\text { Biological time } \\
\text { High discounting }\end{array}$ \\
\hline
\end{tabular}

Source: H. Linstone, et. al., "The Use of Alternate Decision Models for Technology Assessment," NSF Project, Futures Research Institute. Portland, Oregon: Portland State University, 1980. 
perspectives suggest an underlying basis to the designation of several as containing and ordering the preceeding ones (Figure 9).

Other considerations as well suggest an underlying basis. All of those espousing multiple perspectives are basically adding types of information by adding types of analysis. Within each perspective, different approaches can be used depending on the school of thought chosen within the applicable field.

The organizational perspective is a good example. What Allison calls organizational process model is really one approach to organization. He laid it out as bureaucratic organization. Elmore ( 91 ) above distinguished four strains of approaches within organizational theory to apply to implementation analysis. Katz and Kahn (95) list several more types which conceivably could serve as the basis of analysis. Linstone raises the question then, as to whether there is a distinction between the content of a perspective (goals and plans versus organizational structure versus personal characteristics, for example) and a pointof-view or modality of study assumed in the process of analysis (organizations looked at as rational structures versus organizations looked at as interpersonal dynamics). This latter presumes that a given analyst uses a point of view consonant with a penchant for a certain type of analysis -- a certain world view. 
Note: Only representative sources are shown.

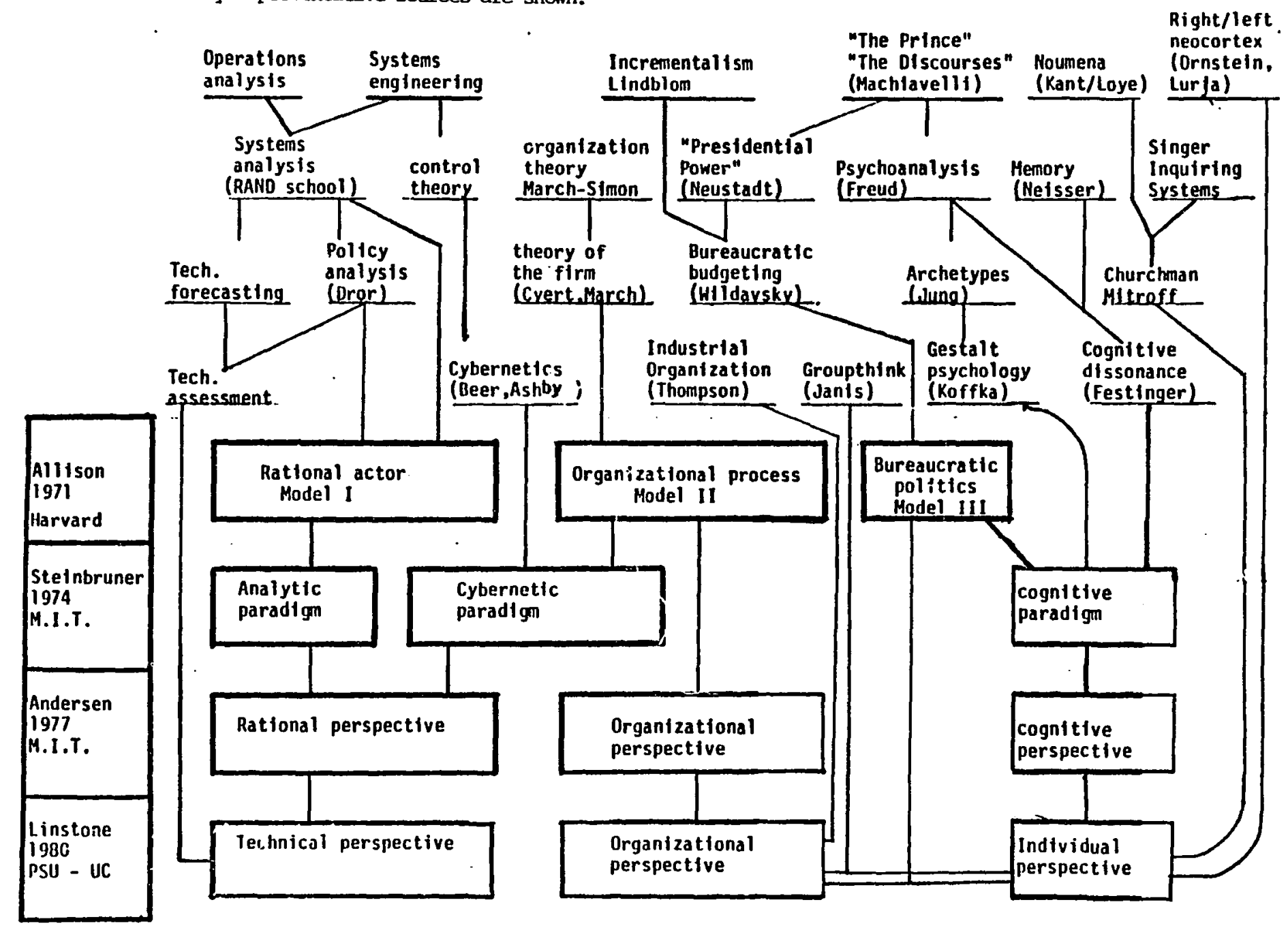

Eiqure 9. A Comparison of the Multuple perspectives and their Sources

Source: H. Linstone, et. al., "The Use of Nlternate Decision Models for Technology Assessment," NSF Project, Futures Research Institute. Portland, Oregon: Portland State University, 1980. 
For Allison, a type of action (choice, output, resultant) comprises the content (unit of analysis) and is organized by theoretical concepts and inference patterns. The focus of investigation for Steinbrunner, Anderson, and Iinstone is decision-making from various organizing perspectives. Iinstone, however, distinguishes between content and perspective. He has moved from description of dynamics to descriptions of points of view. The difference is evident by comparing Figure 10 and Figure 11 . His formulations for the content areas, the setting, the subject matters pertaining to the various schools of thought within applied disciplines, the relationship of the perspectives, all are clearer than those formulations of the other authors. His multiple perspectives are constructed with a three prong, internally consistent, total approach to a problem area such as policy and technology assessment, to provide significant information. This approach organizes both the research topic and the task including the method of data gathering, analysis, and report. Multiple perspectives, then, provide even more than research triangulation for the purposes of overcoming bias. Whereas the use of theory triangulation, multiple methods, multiple investigators, multiple sources of data, methodological mixing (a strategy of mixing data design and analysis resulting in holistic-inductive and hypothetical deductive strategies) are compensatory for research inadequacies (96), multiple perspectives shape the very 


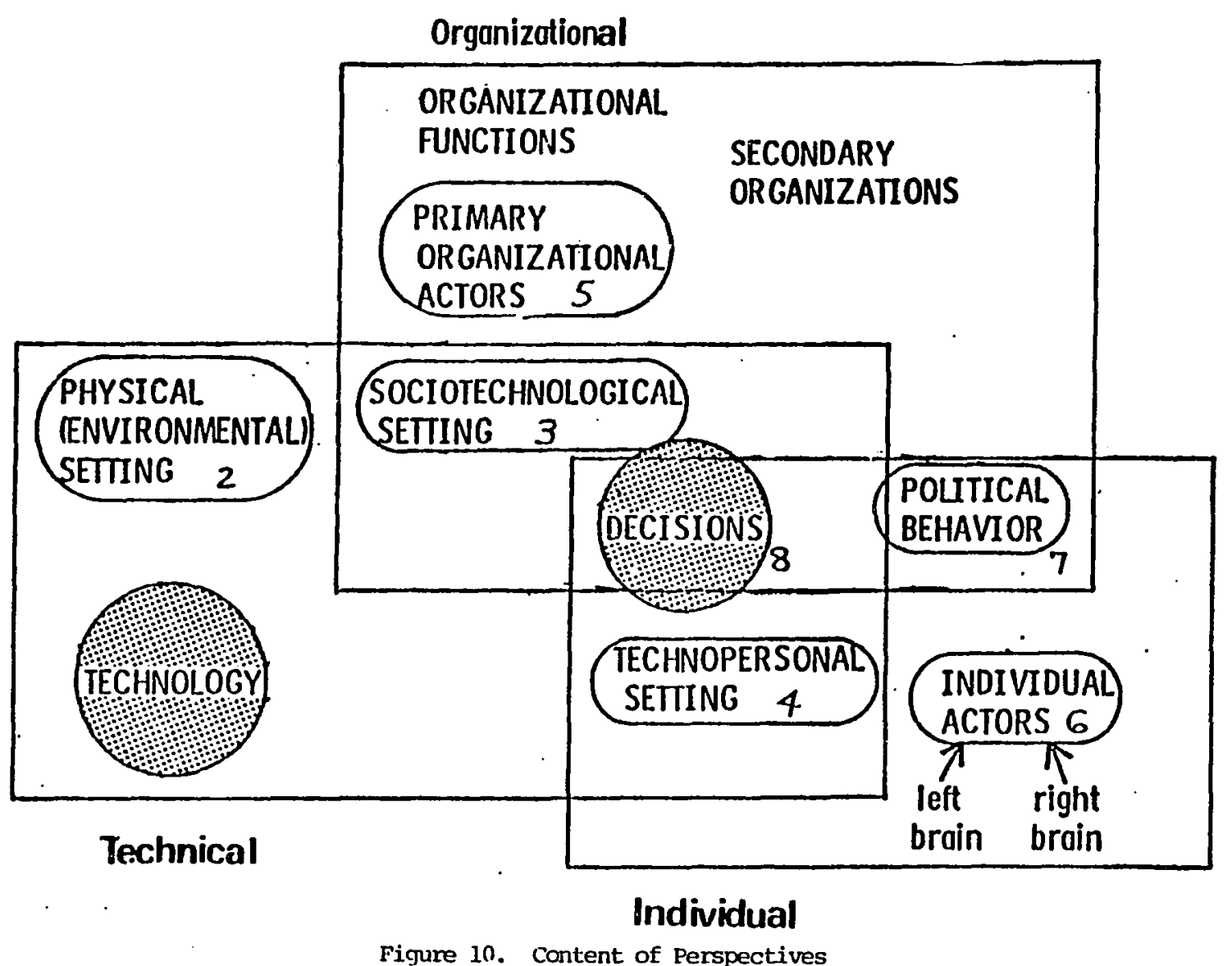

Source: H. Linstone, et. al., "The Use of Alternate Decision Models for Technology Assessment," NSF Project, Futures Research Institute. Portland, Oregon: Portland State University, 1980. 


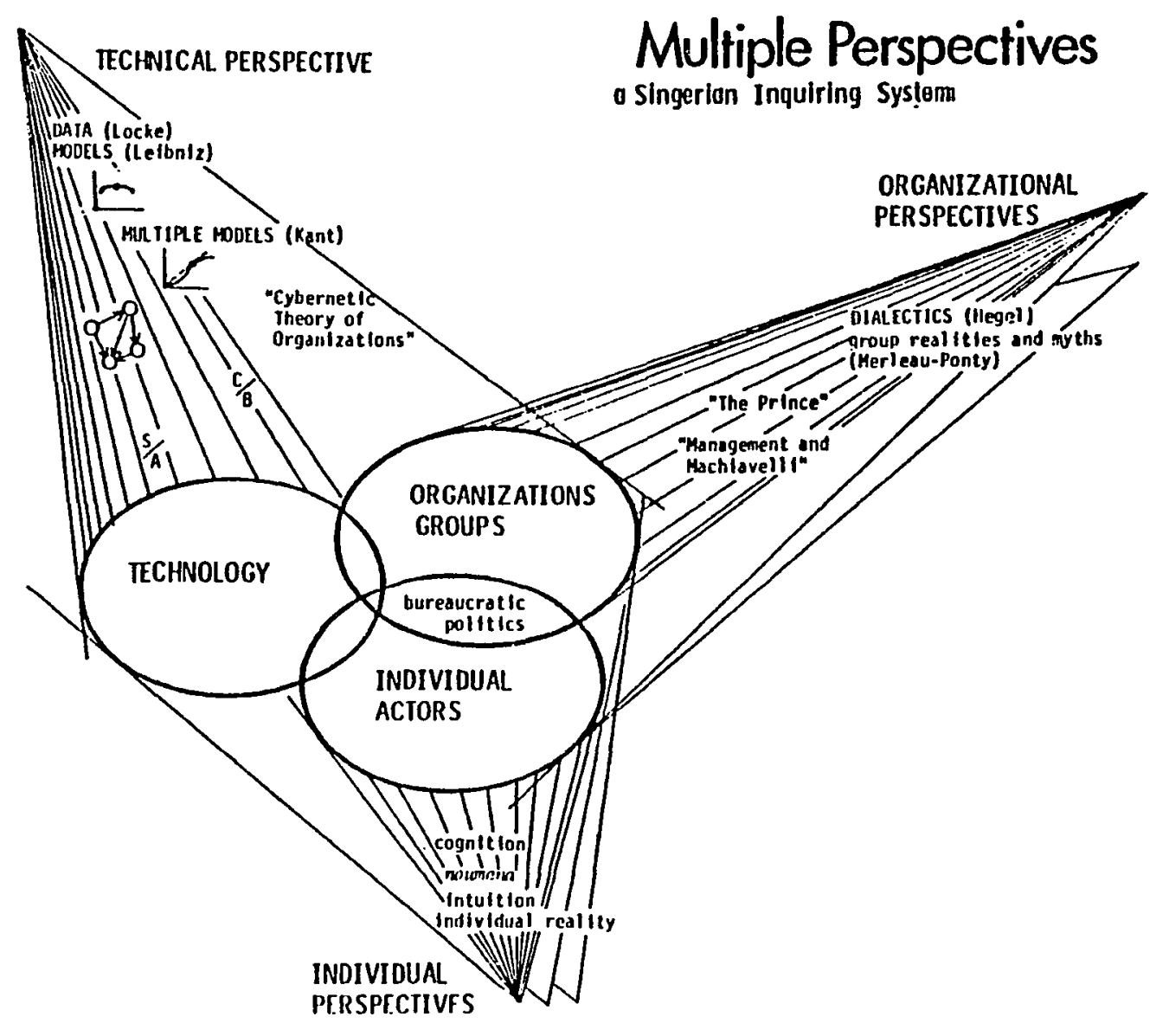

Figure 11. Multiple Perspectives: A Singerian Inquiring System

Source: II. Linstone, et. al. "The Use of Alternate Decision Models for Technology Assessment," NSF Project, Futures Research Institute. Portland, Oregon: Portland State University, 1980. 
usefulness of information for quite different purposes and, at time, different audiences. The developing use of multiple perspectives document their potential to provide a richness of understanding of an area of concern.

Delphi: The participatory nature of cooperative systems require more than an analytic approach sponsored by some subgroup. In fact, however powerful the perspectives, they may leave the impression of an attempt at external control when self-regulation and self-organization are the system-type requirement. It is clear that another approach is needed. A new kind of Delphi contributes the participatory method to the analytical methods of the perspectives. That the Delphi can be an appropriate participatory tool is suggested. by several Delphi studies in which medical professions have participated together successfully (97 through 101). Not only were informative results attained, time saved from meetings, and advantage gained by anonymity in sensitive areas, but a number of the studies noted the enthusiasm generated among participants.

Furthermore, the process is creative -- one akin to the very emergence of new system realities. The concept of "reality construction" as a product of Delphi is intriguingly advanced by Scheele (62), who has designed some of the most creative Delphis to date. He had laid a particular groundwork in Delphi, which because of its 
interactive nature, progresses towards an understanding of both problem(s) and solutions(s) simultaneously, in contrast to the limited analytical use of the perspectives.

The basic feature of the Delphi come into play here advantageously. It is believed that respondents are more likely to be candid and express more honestly their underlying feelings and concerns about sensitive aspects of the issues at hand than public forums permit (102). Delphis focusing on decisions will be especially helpful when there is much at stake and when respondents can reply anonymously (information, feelings, and ideas can be expressed without the politics of who said what intervening in desired goals). The iterative nature (102) of the Delphi allows for a developing process in which participants can:

- become familiar with the process

o trust it

- begin a web of participation which Kohn (42) refers to as the social equivalent of the redundancy principle -- the heart of system stability

- clarify the issues at the same time as growing to a conclusion about what should be done

- clarify their feelings about the issue

o identify for themselves what the real issues are to them

Thus, Delphi can be used to socially construct and intentionally negotiate realities (plural, based on 
the phenomenologists' formulation in the social sciences

(63, 64). This concept is inherent in the Merleau-Pontyean inquiry system, and its applicability to uses of the Delphi. Scheele (62) describes it as

applicable to situations either where a redefinition of contextual reality can facilitate the generation of new options, or where the acceptance of a new reality must be negotiated to create the impetus for technical or social change... this philosophical point of view leads to viewing the future as a situation where both the dominant reality and the technology (mode) are invented as well as inherited, and where culture is transformed as well as transmitted (p. 43).

Thus information shapes reality, identifies new options, introduces new considerations. Interestingly, he has also noted that group self-concept is formed in the Delphi process (p.57). The interplay of intention and circumstances is acknowledged.

The Decision Delphi was formulated by Rausch (84) as an interactive process involving the key people who have direct or indirect influence on the ultimate problem outcome. Participants do not advise a decision-maker but come to a conclusion about a course of action to be taken. The Decision Delphi is a kick-off point from which, if successful, the synergistic activity of the Delphi process propells into action. The mode is positive feedback -- or prospective. Moreover, it can incorporate a more thoroughly prospective use of the perspectives. In particular, perspectives $O$ and $P$ so not only do supplemented examine a relatively 
statis context, routine activity modes, and past development, but also permit the evolution of both strategies and relationships in design of a desired future situation. The Decision Delphi method is a process in which growing understanding of others' positions and devisiong of desirable strategies mutually reinforce each other.

\section{"Right Brain" Approaches: Guidelines}

Several authors have considered the general problems of using a dual analytic/synthetic approach. Most descriptions and comparisons come from the fields of therapy and art and are increasingly labeled left brain and right brain processing approaches. The policy/planning/design field itself offers several guidelines to the newer consideration of the so-called right brain approaches.

The most direct approach comes from Mitroff and Blankenship (103). Recognizing the distinction between radical social system change and smaller scale, structured problem solving, these writers conceptualize the requirements for what they call a holistic experiment. The use of the term experiment seems to have more in common with Dunn's (20) idea of social experiment than with classical concepts of experiments. They list as guidelines (emphasis theirs):

- AT LEAST TWO "radically distinct" disciplines of knowledge must be brought to bear on the 
conceptualization of any potential holistic experiment.

- AT LEAST TWO "radically distinct" kinds of conceptualizers (personality types) must be brought to bear on the conceptualization of any potential holistic experiment.

- AT LEAST TWO "radically distinct" philosophical inquiry models (conceptualizations) must be brought to bear on the conceptualization of any potential holistic experiment.

- The subjects (general populace) of any potential holistic experiment must be included within the class of experimenters; the professional experimenters must become part of the system on which they are experimenting -- in effect the experimenters must become the subjects of their own experiments

- The reactions of the subjects to the experiment and to the experimenters (and vice versa) are part of the experiment and as such must be swept into its design (i.e., conceptualization).

- The epistemic design rule for resolving the disparity between conflicting conceptualizations is CONFLICT -- NOT "agreement" or "consensus".

- The methodological (e.g., philosophical inquiry) 
system for handling conflict is that of a Dialectical Inquirer.

- An appropriate design tool for modeling any conceptualization is simulation but -- IF AND ONLY IF -- it includes LIVE HUMAN PLAYERS chosen in accordance with all the previous guidelines. (p. ) The guidelines involve principles of triangulation, participation, self-reflexiveness, and use of conflict.

Their approach can be greatly strengthened by reference to Maruyama's $(24,28,104)$, often proposed exhortation to recognize and include fundamentally different epistemologies -- which go deeper than philosophies or inquiry styles. He makes a number of recommendations for holistic planning.

- Avoid dimension-reduction: the conversion of a different frame of reference to one's own -which is consistent but misses the point

- Avoid a merely internal self-consistency: recognize the limits of explanation from any one given point of view however complete

- Use polyocular vision in which the third dimension emerges from the differential between two images

- Use dynamic balance of dissimilar elements, harmony of the diverse, as a design principle

- Use the principle of complementarity (two inseparable sides of the same thing) rather than dialectics (the combination of two separate things) 
- Seek relevance resonance (convergence of goals) and criticality resonance (appreciation of significance of an action in a particular situation) and experience resonance (shared experience)

- Use heterogenistic perception -- contextual versus categorical seeing

- Seek understanding in networks and contexts not just causal impacts and universals

- Use in-culture researchers in problem definition :

Techniques from other fields are adaptible for use in policy design. From the field of art, Edwards (50) has developed techniques for drawing on the right side of the brain which she, herself uses for fostering creativity in industrial managers. She demonstrates that one can feel the switch from left to right mode through use of some basic exercises. Her success is given objective verification in the resultant drawings Two examples from her book (50) are given in Figure 8 . The implications of her program go beyond the immediate (beyond the drawing board) experience. Learning the right brain mode of seeing involves:

- Removing blocks to creativity. The dominant left brain when presented with tasks it cannot do, is made to back off

- Directing attention to detail. When something is viewed from an unaccustomed perspective -- such as 
a picture upside down -- we see details that are ignored when the whole is a known entity, e.g. too familiar to warrant scrutiny

- Directing attention to relations -- especially corners, edges, angles

- Directing attention to the shape of the background, i.e., negative space

Psychotherapy has traditionally used certain right brain approaches including hypnosis, dreamwork, and gestalt techniques. The Language of Change (105) which focuses on techniques derived from right brain theory offers the following:

1. Block the left hemisphere

--paradox "is the Achilles' heel of our logical, analytical rational world view"

--symptom prescriptions -- use special power temporarily accorded by virtue of role --symptom displacements -- concentrate them in time and place and use for "useful" purpose --illusion of alternatives -- only one result is possible despite appearance of choice --reframing -- breaking the illusion of exclusive choice

2. Use the right hemisphere language patterns --condensation -- catch great detail and tone and structure and meaning and result in simple 
laughter as provoked by subtle nuances. Yields clues beyond "rationality"

--figurative language, like dreams which do not explain but evoke

--pars pro toto, one picture rather than a whole course of action, with power to represent and restructure the whole; may be an apparently insignificant point which induces change

--aphorisms

--ambiguities, puns, allusions

3. Use injunctive language

--speak the patient's language

--use the patient's resistance (as in martial arts)

--preempting -- such as "you'll find this silly but..."

--therapeutic rituals -- design an activity and setting whose form in and of itself, as well as its outcomes, has meaning and results

These suggestions are not as far removed from policy design as they may at first appear. Again, the admonition is to break with the left hemisphere and learn the particular modality of the right. The injunctive part is either

a) applied once group need is self-recognized and aid is requested of some "expert" for certain areas, or

b) assumed in the natural politics of the process by 
someone with ego strength and power in the group to do so -- a charismatic type is one example.

CONCLUSION

The literature search Fias led to conclusions in several areas: 1) clues for development as design considerations, 2) the need for a dual approach to the problem at hand, 3) the state of the art in both prongs of the dual approach, 4) the theoretical issues to be advanced.

1. Clues for development: design considerations.

- Planning is of a different mode and has a different meaning

o. Process must be endogenous in emergent, cooperative systems

- New boundaries are likely to be images (empowering potentials, participation, and constraints)

- Kick off points, or self-generating functions are essential to emergence

- The result is essentially open-ended and always unique to the system -- its desires, capabilities, options in real terms

2. Need for dual approach to the problem.

- Morphogenetic development is a non-routine process without pre-established guidelines 
- Social systems are inherently multistable and immune to mere tinkering except for that which produces a kick off point. Only involvement concerned with all aspects at stake and guided by a new image can produce such radical change positively

3. The state of the art in both approaches.

- "Right brain" approaches generally consist of guidelines for breaking through left brain dominance, learning to see contextually, dealing with paradox, and expressing nonliterally

- Multiple perspectives focus not only on additional types of context but on differing ways of organizing information -- different perceptions

- Delphi can be used as a type of action research

4. The theoretical issues to be advanced.

- How can points of emergence be recognized?

- What does form mean in policy design?

- What form of organization and organizing does each perspective take with regard to data collection, analysis, recommendations?

- What is the process by whichone not only accumulates pieces of information and enlarges 
its scope, but also forms perspectives into a reliable, coherent, moving image despite ideosyncratic aspects (i.e. inclusive of scientific agreement on what is seen and the artist's unique vision communicated so others can share in it)?

- Do the traditional dichotomies align with each other consistently when applied to policy design?

The practical applications of these four areas set the approach to the specific content areas to be studied here. The appropriateness of these applications follow from the nature of the problem (policy design/implementation), the requirements of the system (human/social system), and the interaction of human system - policy design at a point of emergence. The specific methods of data collection and methods of data analysis, and the communication of results are given in the following chapter. The practical results of application of these considerations will be commented on in Chapters IX and $\mathbf{x}$. 


\section{CHAPTER IV}

\section{METHODOLOGY FOR DATA COLLECTION, ANALYSIS, PROCESS FACILITATION, AND COMMUNICATION \\ OF RESULTS}

A two stage study is employed to reflect the bi-level research necessitated by the purposes of this study: the first, an analytic orientation uses Multiple Perspectives; the second, a participative action orientation, uses the Decision Delphi (Recall Figure 1). Both type of information and type of strategy derived frcm this information are compared in the Multiple Perspectives analysis. The comparison is descriptive rather than formal as in exrerimental designs. The goodness of the comparisons is approximate and determined by "fit" (within the problem and theoretical context) rather than by statistical measure. The methods for data collection in Stage 1 (See Table VII) are:

- participant observation

- content analysis

- interviewing

- sort techniques

- testing (and cross-checking)

All of the methods can be considered qualitative methods. The situational and the research requirements necessitated methods as unobtrusive as possible. 
TABLE VII

THE METHODS USED FOR ANALYSIS AND SYNTHESIS

PERSPECITVE I ANAIYSIS

Primary Method: Content Analysis

Supplementary: Interviewing

(Delphi, as analyzed)

PERSPECITVE II ANALYSIS

Primary Method: Interviewing

Supplementary: Participatory observation

Content Analysis

Testing

(Delphi, as analyzed)

PERSPECTIVE III ANAIYSIS

Primary Method: Participant Observation

Sorts (in the context of interviewing)

Supplementary: Interviewing

(Delphi, as interpreted)

Cantent Analysis

Testing

DECISION DELPHI--AS SYNIHESIS

Method:

Rounds 
Experimental manipulation by introduction of an intervention would contradict the purpose of analyzing existing organizational and political processes. Further, access to information is sensitive in some areas reflecting the coperative, yet-uncongealed nature of the regional program. Thus while complete access to an organization may have permitted such methods as formal network techniques for communication and/ or psychometric analysis in the perspectives, these were impractical and, more importantly, non-productive in view of the tone required by this perspective.

To emphasize, Perspective I reflects the rational approach in program design -- and is best "caught" and understood by a similarily oriented researcher, a cause-effect or input-output type. Its on-going use by the Regional Project is described rather than developed here. The development of a Perspective II approach which analyzes organizational processes may be performed best by a "management type" or a keen observer of processes. Organizational research, as noted perviously has many representatives from the trained observer fields of sociology, anthropology, and social psychology. Those most likely to pick up on the subtleties of the personal dimensions, the political interactions, and overtones of Perspective III are politically astute or communication experts in fields such as media and psychotherapy. Obviously, the ideal methods as well as the design will not be traditional research methods for Perspectives II and III. 
The most obtrusive measures used, interviewing and sorting, are adapted to the points of view used by those types described above.

Each perspective used a dominant mode of information gathering as well as supplementary ones. Most significantly these must fit the needs of the analytical methods appropriate to each perspective.

The primary method of information gathering used for Perspective I was content analysis. It sought to determine the "rational" methods actually used by the Regional project in its design. In contrast, the information gathering techniques used for the second and third perspectives seek to directly analyze regional development by the researcher. The primary method for Perspective II is interviewing. This technique most efficiently gathers both the factual information held by people and allows for probing of implications, attitudes, personal meanings, etc. Participant observation is the primary method used in Perspective III.

The second stage simultaneously produces additional information as it yields direct results, i.e. designs an outcome. The Decision Delphi is used as action research. The context and process dimensions of the Decision Delphi are well-suited to the Regional Perinatal Project in which time, independence, and political connections are key factors to be addressed. 


\section{PERSPECTIVE I: \\ TECHNOLOGICAL (OR RATIONAL) PERSPECTIVE}

Objective

The objective is to determine the goals, objectives, basis of choice, evidence of follow-through of the Project; secondly, to discover the nature of conclusions based on this Perspective in this situation and the future strategies it warrants.

Data Collection

The basic materials developed by staff and the contracting agency were used. These include the grant application, documents for the funding agency and its adjuncts (including baseline analyses of the existing situation), annual reports, teaching and public relations materials, vital statistics, demographic and health indicators for the target area, special analyses, and other pertinent materials. There was sufficient information to warrant exclusive use of existing material to illustrate the rational-planning process in use by staff.

\section{Data Analysis}

The primary means of data analysis was content analysis. Verification of analytic reliability was obtained from an individual outside the Project on the basis of two sample types of documents. Items were sorted under the heading of: goals and objectives, means considered, means chosen, basis 
of means chosen, costs and benefits articulated, indication of the role of actors in decision-making capacity. A check for consistency and time flow were also made. In addition, information gathering through participant ubservation and interviewing were included.

PERSPECTIVE II:

ORGANIZATIONAL PERSPECTIVE

\section{Objectives}

The first objective is to determine the operational patterns within and between institutions; second, to discover the nature of conclusions based on this Perspective in this situation and the future strategies it warrants.

\section{Data Collection}

The primary means of data collection was the non-structured interview. According to Gordon (106), the dichotomy between structured and non-structured interviews is based on the former collecting the exact same categories of information from all respondents so that the answers are capable of statistical summary. The latter does not collect the same information from each. It is more exploratory.

Discovering organizational structure and functions is an example Gordon uses to illustrate the non-structured interview. The approaches used in subsequent interviews depends on what was learned in preceeding ones.

Patton (78) distinguishes three kinds of qualitative 
interviewing: informal conversational, general interview guide approach, and standardized open-ended. The first type was considered most appropriate for the purposes of this research. It is similar to Dexter's (107) 'special, nonstandardized "elite interviewing" for certain purposes such as the interviewee's structuring of the topic. While some categories of information are predetermined to act as guides, not all categories are sought of all respondents since the purpose is not to compare their versions of organizational processes. The purpose is both to gather factual information on formal procedures and to discover perceptual information on the "real" operations and relations, especialIy since some powerful informally derived procedures are in effect. Loosely set topics allow exploration of individual frames of reference and meaning.

The reliability and validity questions raised are great. Would someone else have obtained the same results? Are they valid? These questions are also the concern of practitioners who depend on interviewing for various ends -- doctors, personnel, social workers, clinicians, reporters, lawyers. "The proof is in the pudding" -- even as it is here. Skill, and outcome, do vary. Reliability of the information is enhanced by cross-checking. It would be a waste to ask 50 people the same factual question when the first ten straight-forwardly agree on the response. Reliability is also enhanced by asking the question of the appropriate level: a nursing 
procedure is not likely to be known by an administrator.

Validity is more difficult. What information may be withheld because of the interviewer's position in the project or her race? Motivating the respondent is extremely important. Will the interpretation be accurate? For both concerns, a second interviewer is used. While the researcher is White, the second interviewer is Black, also female, from the community, with background in medicine, with experience in working with medical people including sensitive interactions with doctors, was an "outsider" to the Project, and was developing a career in law with emphasis on politics. She was already a keen observer of organizational processes in hospitals though not in this department, and identified immediately with the aims of the political analysis which was part of Perspective III.

One week was spend in orienting her to the specific task by familiarization with the three Perspectives, general interview strategies, technique and tactics, and the Perinatal Regionalization Project.

Both interviewers had a fair amount of skill and experience in interviewing. The first two weeks of interviewing were critically examined toegether on an ongoing basis to improve the skills necessary for this task. The first respondents were Project staff who were familiar with the purpose of the study. They were collegues and friends of the first interviewers, were not threatened by the study, 
could be asked for feedback on the interview process itself. Their familiarity with the various settings to be further examined also provided a spring-board for subsequent interviews.

Since the purpose was to gain additional information of use to the Project, the interview proceeded in a developmental manner. More detail was sought at the hospital and private office level along with verification or rejection of the descriptions provided by Regional staff. With the key objectives of the study in mind, respondents were asked questions as appropriate -- varying in kind, order, and wording according to the emerging context of the interview. Thus, in the rapport-establishing moments when a respondent explaimed on her frustrations of the day dealing with typical procedureal problems, the opening series of questions used this framework to get into half a dozen different content areas. The most natural ordering of sub-topics to be considered was used.

Besides on-going joint analysis of the pooled interview data, running lists of items to be verified or rejected and of items to track further, along with names of respondents from whom to seek the information were maintained. Each interview was strategically based on whatever knowledge of the respondent's position and personality was available; topic areas to be emphasized were decided, the items to be tracked and some possible approaches were 
discussed.

Respondents were informed of the two-fold objective of the study:

- To publish results in order to assist others who are interested in initiating regionalization efforts by relaying factors which made a difference in relative success so that others can decide whether or not to pursue regionalization and what tactics and strategies to select.

In particular the implementation aspects of how regionalization interacts with existing organizational structures and communication networks were to be relayed.

- Second, this study would be used by this Project to make improvements in regionalization efforts if regionalization were judged worthwhile

The respondents were informed that they were chosen because of their particular knowledge and experience and point of view.

They were assured that no names or identifying information would be used. Their permission was asked to tape the sessions, so that the interviewers could pay more attention to their answers and were informed that the tapes would be used only by the interviewers. If a tape recorder was an obvious liability, it was not used. 
The respondents were chosen fram four main sources (Table VIII): the Medical Center (a public County hospital and a postgraduate Medical School), two private hospitals (one non-profit and one for profit), and the Regionalization Project staff. For contrast, a few respondents external to this particular regionalization effort were included. They included potential participants, participants or leaders in other regions, and maternal/child health authorities. The respondents from the four sources were administrators, physicians (obstetrician/gynecologists, a family and general practitioner, and a pediatrician), nurses, and medical records and clerical staff. Since respondents' frames of reference were important, an attempt was made to include those from different disciplines and positions of knowledge and distinct types of conceptualizers (personalities). Some regional participants were already known to be important sources of information. Others were discovered through the recommendations and comments of other respondents. As with many field studies, very purposeful sampling of potential respondents was done. Checks and tests of information were used as described earlier.

\section{Data Analysis}

Information was organized on the basis of standard operating procedures of individual institutions and groups, (the components which affect the development of regionaliza- 
TABIE VIII

PEOPLE INTERVIEWED

\begin{tabular}{|c|c|c|c|c|c|c|c|c|c|c|c|}
\hline & MD's & $\begin{array}{l}\text { Nurse } \\
\text { Coordin. }\end{array}$ & $\begin{array}{l}\text { Ward } \\
\text { Supers }\end{array}$ & $\begin{array}{l}\text { Staff } \\
\text { Nurses }\end{array}$ & $\begin{array}{l}\text { Nurse } \\
\text { Educ. }\end{array}$ & Admin. & $\begin{array}{l}\text { Medical } \\
\text { Records }\end{array}$ & $\begin{array}{l}\text { Clerks \& } \\
\text { off. Mgrs }\end{array}$ & Residents & $\begin{array}{l}\text { Other } \\
\text { Professi. }\end{array}$ & Total \\
\hline $\begin{array}{l}\text { Level III } \\
\text { Publ ic Hosp. }\end{array}$ & $4(+)$ & 1 & 4 & 8 & 2 & 1 & 1 & 2 & 4 & & $27(+)$ \\
\hline $\begin{array}{l}\text { Level II - } \\
\text { Private Hosp. }\end{array}$ & $1(+)$ & 1 & 3 & 1 & & 1 & 1 & & & & $8(t)$ \\
\hline $\begin{array}{l}\text { Level I - } \\
\text { Private Hosp. }\end{array}$ & $2(+)$ & 1 & 3 & 1 & & 2 & 1 & 1 & $(+)$ & & $11(+)$ \\
\hline $\begin{array}{l}\text { Perinatal } \\
\text { Reg. Staff }\end{array}$ & $2(+)$ & & & & 5 & 1 & & 1 & & 4 & $13(+)$ \\
\hline $\begin{array}{l}\text { Other Reg. } \\
\text { Staff }\end{array}$ & $(+)$ & 1 & & & 1 & 3 & & & & 2 & $7(+)$ \\
\hline External Sources & 1 & & & & 2 & $1(+)$ & & & & 6 & b \\
\hline $\begin{array}{l}\text { Private Perinatal } \\
\text { Providers } \\
\text { (solo and group } \\
\text { practice, pre- } \\
\text { paid health plans; } \\
\text { G.P's \& Specialists }\end{array}$ & 13 & & & & & & & 2 & & & 5 \\
\hline Total & 23 & 4 & 10 & 10 & 10 & 9 & 3 & 6 & 4 & 8 & 87 \\
\hline
\end{tabular}

$(+)=$ Additional staff were counted in another category 
tion), the operational versus stated goals and policies of the institutions (to what extent they are ingrained), their time constraints, priorities, results, basis of initiation), the distinct organizational communication patterns (internal and external), the outside influences on organization policies and practices (e.g. HSA, hospital accreditation, Medi-Caid regulation, etc.).

The category system was initially based on Allison (87) as supplemented by extensive reading in the organizational field including newer analysis emphasizing the individual (108). The guiding question, how do organizations and organizational gropus see each other and how does this affect developing of new systems left the analyst frustrated and in search of new categories and arrangements of information which would be, as Guba (109) states internally and externally plausible (integrated), inclusive of data, reproducible by a competent judge and credible to those who supplied information.

The information was then formed into descriptions of unique institutional entities and operations of key subgroups c rossing them as viewed from both formal and informal levels of turfs, standard operating procedures, messages, external posture, and boundary spanning, both within and among the institutions. (See Table IX) This arrangement yielded powerful results when specific examples were summarized in this manner. Both internal and external means of 
TABLE IX

ORGANIZATIONAL PERSPECTIVE

\begin{tabular}{|c|c|c|c|c|}
\hline \multirow{2}{*}{ TOPIC } & \multirow[b]{2}{*}{ FOCUS } & \multirow[b]{2}{*}{ DEFINITION } & \multicolumn{2}{|c|}{ DESCRIPITION } \\
\hline & & & FORMAL & INFORMAL \\
\hline TURFS & Areas & $\begin{array}{l}\text { Layout of social system, power } \\
\text { system, reward and punishment }\end{array}$ & $\begin{cases}\text { Domains of } \\
\text { authority } \\
\text { Prescribed roles }\end{cases}$ & \begin{tabular}{|l} 
Spheres of \\
influence \\
o Enclutured roles \\
within various \\
groups
\end{tabular} \\
\hline $\begin{array}{l}\text { STANDARD } \\
\text { OPERATING } \\
\text { PROCEDURES } \\
\text { (SOPS) }\end{array}$ & Methods & Internal rules of the System & $\begin{array}{l}\text { Policies and } \\
\text { procedures (by the } \\
\text { book) }\end{array}$ & $\begin{array}{l}\text { As performed by } \\
\text { various sub-groups } \\
\text { within context of } \\
\text { system }\end{array}$ \\
\hline MESSAGES & Transactions & Communication patterns & $\begin{array}{l}\text { Content via } \\
\text { official channels } \\
\text { and media }\end{array}$ & $\begin{array}{l}\text { Interpretation system } \\
\text { by various groups: } \\
\text { never say just } 1 \\
\text { thing (the literal) }\end{array}$ \\
\hline $\begin{array}{l}\text { EXTERNAL } \\
\text { POSTURE }\end{array}$ & Stance & $\begin{array}{l}\text { Strategic position in relation to } \\
\text { others, to environment, i.e. } \\
\text { adaptation }\end{array}$ & $\begin{array}{l}\text { Share of the pie by } \\
\text { mission, goals, } \\
\text { functions }\end{array}$ & $\begin{array}{l}\text { Negotiated arrange- } \\
\text { ments by subgroups }\end{array}$ \\
\hline $\begin{array}{l}\text { BOUNDARY } \\
\text { SPANNING }\end{array}$ & Connections & $\begin{array}{l}\text { People who are links between } \\
\text { organizations creating cooperative } \\
\text { ventures }\end{array}$ & Representation & $\begin{array}{l}\text { Assumed dual roles } \\
\text { within and without }\end{array}$ \\
\hline
\end{tabular}


development and constraints and potentials were revealed. The resulting descriptions were checked by several types of observers: organizational process experts, people with insight into human dynamics, participants in the described..institutions, or others who work with them or have left them.

\section{PERSPECTIVE III:}

INDIVIDUAL (PERSONAL) PERSPECTIVE

\section{Objectives}

Objective one is to determine the unique context and critical insights operating im.the system: which players are in positions to foster or impede regionalization? What interests do they have? How do these interests link into regionalization? What game rules seem to be in operation? What organizing, ingrained contexts seem operable?

Objective two is to discover the nature of conclusions based on . this model in this situation and future strategies that may be warranted.

\section{Data Collection}

The primary means of data collection was participant observation. Bruyn describes participant observation as "sharing in the life activities and sentiments of people in face-to-face relationships." (110, p. 305). The role of this researcher as an active Project participant with prescribed responsibilities provided many natural situations for "being around" at functions and in on discussions to 
note activities, reactions, relations, inconsistencies, etc. While position in the Project provided a great many opportunities for access to many settings, the medical setting "naivete" of the researcher provided openness to various points of view and opportunities for "being taught" by the many people dealt with daily. Notes cover months of information and significant interactions in the manner advocated by such noted field workers as wax (111), Lofland (112), and Becker and Geer (II3).

\section{Data Analysis}

In contrast to systematic analysis and description of various settings, transactions, behaviors, concepts, values, classes, the methods used here was to search for cohesive images in the masses of information. What stood out in some clear way as representative of many levels of interaction, meaning, distribution of power, etc.? What was striking in the way a general impression congealed? The images are striking both because the investigator is "new" to some inside phenomenon and because the images are powerful integrators of vast amounts of information. This stage takes place long after the data has been gathered and worked with and incubated. Removal of bias takes place in these earlier phases in the confrontation of conflicting data and in the self-awareness of the researcher's role and position. 
DECISION DELPHI

\section{Objectives}

The aim of the Decision Delphi procedure was to design a set of Regional network organizations as devised (expanded, changed) which would meet the group's goals for regionalization and be compatible with their personal and organizational considerations.

This was to be accomplished by enlarging (even at is exposed constraints) the realm of possibilities to be considered for Regional structures and processed. This entailed "realistic" design (that is, implementable), new links between ideas, groups, etc., highlighted sources of differences in goals, needs, perceptions of the appropriate for access by all participants, and concurrent development of support for implementation.

Participants

Participants were chosen on factors of 1) personal criticalness to regionalization success as determined by Perspectives II and III analysis, and 2) the need for representativeness from the main organizational and professional components. The breakdown of participants is given in Table X. 
TABLE $\mathrm{X}$

DISTRIBUTION OF INVITED PARTICIPANTS

\begin{tabular}{|c|c|c|c|c|c|c|}
\hline$\frac{\text { Doctors }}{\text { Gen. Practitioners }}$ & $\begin{array}{l}\text { Private MD's } \\
\text { In Region } \\
\frac{2}{2}\end{array}$ & $\begin{array}{l}\text { Public } \\
\text { Hospital }\end{array}$ & $\begin{array}{l}\text { Private Hosp. } \\
\text { Non-profit } \\
\end{array}$ & $\begin{array}{l}\text { Private } \\
\text { Proprietary } \\
\text { Hospital } \\
\end{array}$ & $\begin{array}{l}\text { Project } \\
\text { Staff }\end{array}$ & $\frac{\text { Total }}{2}$ \\
\hline $\begin{array}{l}\text { Family Medicine } \\
\text { Specialists } \\
\text { Obstetricians } \\
\text { Pediatricians }\end{array}$ & $\begin{array}{r}1 \\
18 \\
2\end{array}$ & $9(1)$ & $\begin{array}{c}(12) \\
1\end{array}$ & (12) & $\begin{array}{l}(2) \\
(1)\end{array}$ & $\begin{array}{r}1 \\
27 \\
4\end{array}$ \\
\hline Administrators/Staff & & 3 & 2 & 3 & 2 & 10 \\
\hline Nurse Educators & & 1 & & 1 & 2 & 4 \\
\hline$O B$ and Ped Nurses & & 4 & 4 & 3 & & 11 \\
\hline TOTAL & 23 & 18 & 7 & 7 & 4 & 57 \\
\hline
\end{tabular}


No consumers were invited because their inclusion at this point would have jeopardized the credibility of the process to many. In fact, no new categories were included -- such as health educators, for the same reason: the participating group, especially the physician sector, sees itself as the power behind the effort. Giving equal weight to nurses' views already enlarges the decision-making arena.

\section{Procedure for Initiating the Delphi Process}

A letter from the Project Director introduced the Delphi topic and method of participants and invited their.involvement. Further information was compiled for those who requested it and discussion with them took place. A list of participants accompanied the first round. The design of the Delphi task entailed an estimate of the scope of the work, the time frame, and the task progression. Given the question "Where should perinatal regionalization go in the future? (after foundation funding is ended)" was a question of concern not only to the staff, but to many parcitipants who had asked it on various occasions. Nevertheless, the question is open-ended. It was conceivable that no concensus could be reached and the concept would die a natural death.

The starting point is critical to the developmental process of the Decision Delphi. Everyone must be in the same game so to speak, before creativity can unfold in the direction it will. To establish a viable kick off point, a common 
context was developed along with four alternative scenarios (See Appendix 3 ). The context was recognizable, yet set in the future to stimulate longer horizons. The four alternative scenarios covered the same basic context but from different unifying points of view.

These points of view were models of possible organizational options covering a range from "no regionalization organization" to "a very highly structured, centralized" model. The four models were created on the basis of the seven regional types discussed by Hallman (114). The criteria of manageability and time necessitated the elimination of two options (complete consolidation and consumer-based) because these were judged to be totally out of range of feasibility for this group since the impetus for these options would come from external sources. The range of models covered the parameters of locus of control, extent of decision-making power, and degree of formality of the desired organization. In addition, the conceptualization phase in the decision process (what could/should be in the future) derives from considered realities in the process of actualization in new modes. If futures are to be more than simple projections of current realities or fantasies free-floating at a distance from those realities, organizational and personal considerations must be legitimate components of the process and must be consciously brought into play.

Thus, participants were led to their decision through a 
series of steps. In general terms, these were:

1. Consideration of future scenarios to which they relate in terms of applicability, political-organizational appropriateness, and relation to desired characteristics, goals, forms of regional organizations.

2. Consideration of emerging goals, group differences, alternative interpretations, issues in relation to conceptualization of development of organizational structures, their goals, appeal, implementability, relation to existing structures, use of personal resources, etc.

3. Consideration of underlying issues and positiontaking regarding suggested proposals in terms of extend of their willingness to participate in and advocate for the proposals.

The format requirements for this particular group were extremely challenging. A round must not take more than 30 minutes in its entirety: introduction and directions, summary, tasks. It must not require an uninterrupted 30 minutes. It must reflect complex ideas simply and clearly. The tasks must be self-evident and yet relay a context for answering. The development of tasks must be obvious. It needs to spark interest.

To meet these requirements, an optimal section was always included with a more extensive summary and more 
detailed tasks for anyone who wished to go deeper. These tasks provided for more detail and clarity of thought processes rather than a weighting of the process by a few.

\section{Procedures for Facilitating the Delphi Process}

Few were familiar with the Delphi and certainly not with this type. Thus, it was imperative to constantly review the way the Delphi works, its objective, and the role of the participants and the study coordinator. In particular, the awareness of participant interaction in contrast to responding to an opinion survey or taking part in a traditional research project is a growth phenomenon, while it is simultaneously essential to one's trusting the process.

Given the particular medical field involved, (one does not schedule babies) and the level of fragmentation of energies inherent in it, both design of the procedure and attentive follow-up is essential. The system evolved to meet the needs of this group.

Follow-up created special demands on the study coordinator. In round 1, telephone calls to participants or their secretaries were used to remind them to mail back their responses. To speed up round 2 , calls were made to arrange for pick-up of their responses. In round 3, no due date was given. Instead, the study coordinator personnaly delivered each packet and arranged a time for pick-up. This also allowed questions and comments to be pursued and for 
those who were jumping in on the last phase to get better oriented. The oral summary and direction-giving seemed to save time.

While basic format considerations, topic, and direction had to be set at the start, the actual Delphi process created its own demands in terms of rhythm and pacing, style, depth, switch in direction. The extent to which there were issues, the level of them, the prior thinking people had done on the topic, all required flexibility on the part of the Delphi coordinator. In addition, they called for both objectivity and drawing out of potential.

To assist with the Delphi process, two external groups were used. A technical assistance group included editors, pre-testers, monitors of facilitator objectivity, communication, and design experts. An observer group was used in the final round to stimulate discussion, to expand imaging capabilities, and to provide angles which may break open other considerations. This group included a County Health Officer -- Maternal and Child Health expert from another county with experiences in many settings; a nurse-educator-author (a Mexican-American with special interest in health care availability for those with different socio-cultural orientation and needs); an organizational process consultant and communications facilitator (an expert observer of human process dynamics). Their comments on the content and dynamics to date were included in the optional section and did elicit 
further comments.

The importance of timing and momentum necessitated a compromise between completeness of returns, thoroughness in formating the subsequent round, and maintaining pace. While feverish effort could prepare the next round in short order, the round would necessarily suffer from lack of the perspective gained by being able to step back from a project -especially a more creative one like facilitating versus technical analysis. Yet, in the myriad diverse activities of practitioners and administrators, maintaining a sense of direction and progress depended on fast turnaround.

The exact type and sequence of tasks derive from analysis of what is happening in the process. Thus, after round 1 yielded a general direction and general indication of feasibility, it was evident that the feasibility question must be addressed in greater detail, with greater realism and with less direction if real issues were to emerge and a truer picture of how participants saw the efforts and consequences involved. It demanded thought -- which as some noted, took a lot longer than the agreed-to reading/writing time of 30 minutes. The results showed some contradictory expectations and also that some were choosing different models but coming from the same expectations. It seemed the models have served their purpose as starting points and that while participants had made variations on them as had been hoped, 
it was time to come at the process from another angle by looking at issues and tasks in greater isolation so they could then be regrouped to generate a more satisfying form. The task was to register the degree of support or opposition and willingness to actively participate.

Due to flow and timing, some proposed tasks were consequently scratched: assessment of appeal to various groups (an indirect estimation of how groups see each other); the impact of different contexts (which would have assisted in testing the flexibility of a structure); advocacy or argument pro and con given positions (which would have necessitated a fourth round which was scratched in terms of attention span and need to address the results in a more traditional group meeting); conditions of support (which would clarify issues and possibly expand support).

EXPECTED OUTCOMES AND COMMUNICATION OF RESULTS

The three perspectives and the Delphi were employed pruposefully because of expected differences in outcomes. Moreover, it is appropriate to communicate the results differengly as well -- both because each perspective is naturally more credible and clear to a certain type of listener and to demonstrate the usefulness of a legitimate range of presentation feasible within the array of the perspectives.

From Perspective I, factual information to contribute to the design of a system which is comprehensive, 
far-reaching in its effects, and efficient was anticipated. Analysis of the current development of regionalization contains information for planning its future directions which appeal to those who take a global, rational view of policy. Crispness of detail within a structure covering the important elements of consideration in relation to goals was expected. Thus, the method used to communicate these findings in Chapter $V$ is a straightforward report in which findings are mapped out under traditional headings.

From Perspective II close examination of constraints and practical considerations regarding how diverse organizations and groups can effectively link at critical interfaces while each maintains its organizational integrity was expected. More than formal organizational analysis, the informal networks and patterns which cross levels of analysis was not only to reveal how changes are actually incorporated and pursued, but to reveal the difficulties which can be expected in such a major venture as regionalization. This analysis was to contain information for those struggling with the circularities and deadends so common to the on-the-line implementaters trying to "get in" and accomplish any level of change. For programs not providing the "felt answer" to a "felt need" by an "appropriate group" in an "appropriate way," the expected outcome needs to point to the "needle in the haystack" mode of positive entrances to the various organizations, or to the "straw that broke the camel's back" 
mode of breaking down resistances. Demonstration of how the network operates comprised the expected vehicle of communicating this perspective. The particular organizing concepts emerged from a lengthy rumination process. Examples were selected to show how the organizations and various groups see each other in the context of some issue and see the issue in the way they view each other. A sense of the contours of the "lay of the land" and the ecological patterns of the various niches will be conveyed. The style of a columnist was used to describe this information.

From Perspective III, a greater familiarity was anticipated with some key personal forces operating in Regionalization. Motivations; styles of thinking, interacting, and communicating; and sources of power were touched on, hopefully with a feel for the situation from the inside -- the point of view of various people, the unique contexts emerging from walking into certain situations. The outcomes are in terms of images which ring true rather than from psychological analysis. The point is understanding. The method of communication is a personal tour of the psychological environment through various fictional forms -- portrait, chorus, existential story. The researcher deliberately used the personal filter to present a picture with impact as is the point of the perspective.

While all of the three perspectives yield information 
which is complementary (the contradictor not being excluded). the outcomes are all in terms of information for someone to use in planning. The objective of the Delphi was to dynamically set up the planning process. The information was directly exchanged among participants with a minimum of analytical filter. Information was thus simultaneously used for furthering the ends of the group as they gained in clarity and perhaps in cohesiveness.

This entire section may be summarized by considering the empirical and creative components of the methodology as given in Table XI . Even though the analytic orientation of Multiple Perspectives are basically to provide information for policy design, as used here they contain both empirical and creative aspects. By empirical is meant that the methods of data collection and analysis are reliable, validated by commonly accpeted criteria, replicable, and that the communication of results follow standard form. Creative, within the context of the analytical perspectives, means useful, insightful in contrast to reliable, validated by aesthetic principles, unique or selective point of view in contrast to replicable. Communication of results is "creative" to the extent that it presents a purposeful arrangement of information (others are possible) as in the examples in Perspective III. When the form is completely creative it is fictional, as in Perspective III. Creativity accrues to the work of the researcher as exogenous to the 
TABLE XI

EMPIRICAL AND CREATIVE, ANALYTICAL, AND SYNIHESIZING COMPONENIS USED TN THE STUDY

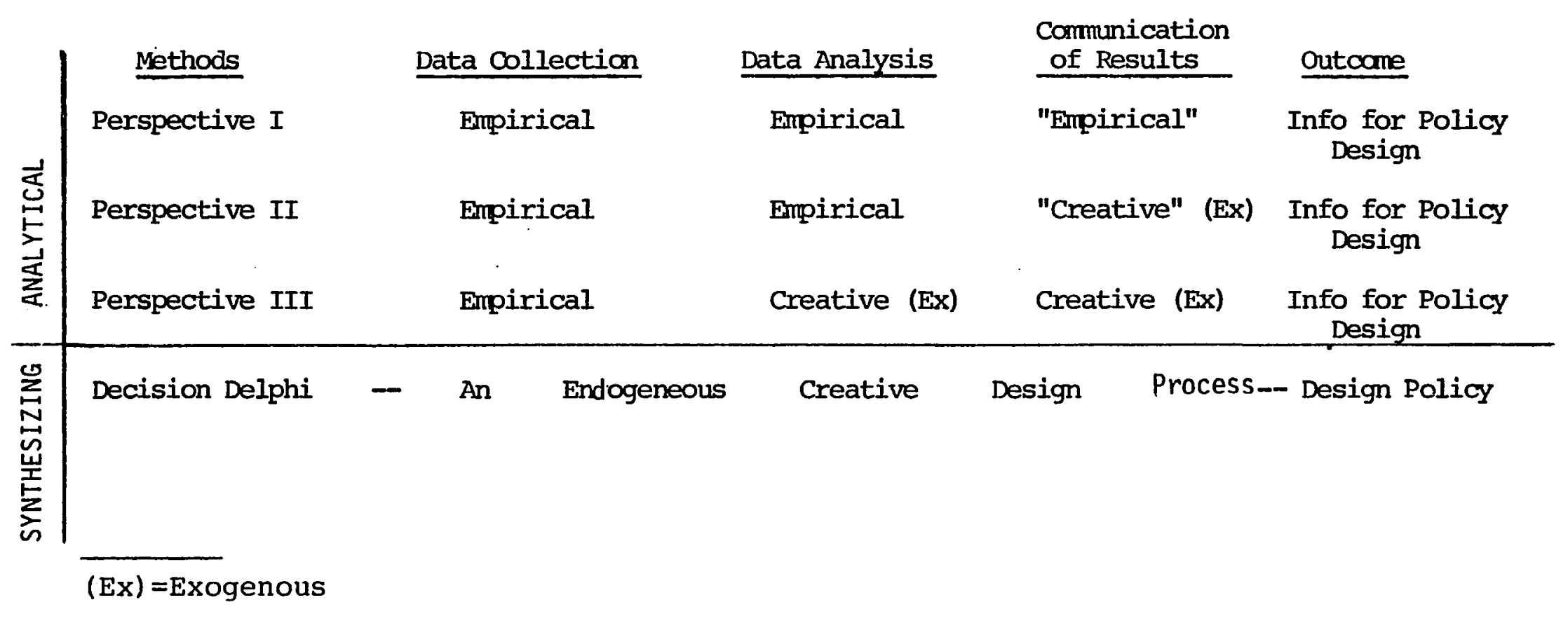


to the system.

The creative process of the Decision Delphi is of a different mode, one in and of itself designing policy through participative action. Data collection, analysis, communication, and design are simultaneous in the process. 


\section{CHAPTER V}

\section{ONE PERSPECTIVE ON REGIONALIZATION: RATIONAL}

PLANNING AND IMPLEMENTATION

This chapter maps the course the : Perinatal Regionalization Project took and the direction it is going. The primary source of information is the documentation contained in numerous reports, studies, news letters, and the like which were analyzed to demonstrate the planning, implementation, and evaluation methods used by the Project. While the documents themselves do not represent a "pure" rational planning or technological approach, it is their dominant emphasis and will be used here to contrast the organizational and individual perspectives of the next two chapters. The rationale, decisions, implementation strategies, costs/ benefits, impacts will be considered.

\section{THE RATIONALE}

The concerns and approaches found in national statements of perinatal regionalization are reflected in the local area under study. In fact they are found in the initial planning and organization statement used to solicit consensus among key potential participants even prior to obtaining the grant. The purpose of the regional network 
was :

to establish a cooperative network for provision of perinatal services in the... Region...to improve the outcomes of pregnancy by assuring all patients access to the facility or resource which provides the services most appropriate to patient needs, continuously improving the quality of institutional and professional services, increasing intraregional communication, and maximizing the efficient and appropriate utilization of all participants in the Regional network.

To assess and document the impact and effectiveness of such a network on pregnancy outcomes, on professional, paraprofessional, and institutional performance, patient and professional satisfaction and on efficiency of resource allocation. (Proposed statement of Philosophy and objective)

Efficient use of resources and effectiveness of methods to improve quality of care through a network of services meeting every level of patients risk was at the heart of the proposed effort.

In addition to providing support to these efforts, grant funding was sought to demonstrate that an urban minority high need area with a newly established medical school and level three hospital was capable of establishing a system specific to its needs.

The guiding goals of the Project were:

- To establish mechanisms for enlisting communitywide support

- To establish a uniform screening method for identification of high-risk mothers

- To provide access to intensified prenatal and intrapartum care for high-risk pregnancies 
- To extend the Center's resources to the Region as a whole

- To adapt a communication system for the network

- To augment Regional perinatal education activities

- To augment a Regional transport system for high-risk mothers and neonates

- To establish a method for systematic follow-up and continued surveillange of high-risk neonates These formed the basis of progress reports submitted annually to the funding agency over the five year period.

\section{THE KEY DECISIONS}

Initially, efforts to organize a regional network brought together doctors, nurses, and administrators from both the public and private sectors to increase quality of care in the Region through mutual cooperation. This group supported the decision to seek grant funding to provide staff for augmenting Regional resources both directly and indirectly. With many regional projects forming throughout the country, a variety of alternative approaches were available to draw on. Knowledge of regional providers along with the basic goals of improved health care delivery, shaped the particular philosophy and principles of the organization, formalized in November, 1974, as a Regional Perinatal Committee. This statement is given in Figure 12. 
* Such a network is established recognizing the basic right of patients to select their physician, and upholding the integrity of the positive relationship between the patient and physician

* The goals and philosophy of each institution, agency, and provider are respected, and achievement of these must be enhanced (or must not be deterred) by the functioning of the network

* The effectiveness of a regional network is related directly to the support, participation, and collaboration of all providers of perinatal services

* The active involvement of a communication between all members of the perinatal service "team", whether professional or paraprofessional, is essential to provision of quality services

* No patients or patient populations are alike, and therefore services must be planned and provided in a manner consistent with the ethnic, religious, social, educational, and health status of the varied patient communities within the region

* The regional network effort will provide to all participating agencies satisfactory procedures and criteria to meet requirements for obstetrical and newborn medical audits, continuing professional education, JACH accreditation, and, when required, PSROs. The Project provides an opportunity for technical and financial assistance to facilitate and augment these processes

* As much work as possible should be done by a Project staff to provide services to individual practitioners/agencies, with their prior approval

Figure 12. Principles of the Perinatal System

Source: Meetings of the Regional Perinatal Committee 
Decisions regarding the general objectives of the Regional network laid out the program components to be developed. See Figure 13.

\section{IMPLEMENTATION STRATEGIES}

Timeliness, staffing pattern, and budget allocations delineate the original plan to implement the objectives. Changes in them point to decisions to adjust and refine priorities and strategies. A detailed "Plan of Action" is a virtual map some $70+$ pages long of the original implementation strategies. An excerpt is given in Figures 14 and 15. The proposed and actual organization charts (Figure 16) show changes in the scale and specific components of the regional plan as staffed. Budget categories over time reflect a decrease in salary costs due to the decision to leave some items vacant, a decrease in contracted services for data system development, a decrease in the hospital fund : under capital equipment but an increase in the category reflecting the decision to lease/purchase on-site peripheral computer equipment.

The implementation path the Project took can be seen in the milestones of its achievements and examples of changes in its approach. These are sumarized in Figures 17 and 18 .

\section{COST/BENEFIT INDICATORS}

The basic question in consideration of continuity is 
* Regional Committee: to establish a regional steering committee to guide the development and operation of the regional perinatal service network by identifying regional resources and needs, establishing priorities, general policies, and standards/criteria acceptable active forum for communication among these participants

- Perinatal Care: to implement a broadbased system of prenatal screening, identification, and management of high risk mothers and infants through use of comnion high risk criteria, specialized diagnostic and evaluative resources, and defined referral and consultation procedures

* Referral Network: to establish a communication and referral system that will assure patients equal access to the appropriate medical, laboratory, hospital, socia servcie and educational support required for diagnosis, treatment, and management (including intensive and specialized consultation) as indicated by the patient's risk status, during the entire perinatal period

- Criteria Development: to define acceptable and appro priate criteria for use throughout the reyion for determination of maternal and infant risk status, and the
minimum screening procedures to make such determinations

- Personnel Training: to develop and implement continuing education and specialized training programs in all aspects of perinatal services for professional and paraprofessional personnel throughout the region through use of special sessions, on-site training and skills development, materials and inforination dissenination, and petariof personnel in order to provide training
* Transport System: Implement a regional perinantal transport system to minimize the negative impact of emergency transfer of mothers and neonates in cases where transfer is indicated, and expand current transport services (or utilization) to facilitate access to specialized diagnostic, treatment or management resources

- Community/Patient Education: to conduct a broadbased community and patient education and counseling program directed at improving preconceptional and interconceptional health directly affecting risk status of mothers and infants (e.g. (a) importance of early prenatal care; (b) improved nutrition; (c) teenage pregnancy risks; (d) infant care and parenting skills: (e) availability of resources: (f) advantages of regionalized care, etc.)

* Patient follow-Up: to expand regional capability for follow-up and referral of selected postpartum high risk mothers and infants to assure cor

* Record system: to develop a record and data system designed to facilitate assessment of risk status: intrafacility transfers and consultation; planning and manayement of interdisciplinary patient services throughout the entire perinatal period; and to muasure impact and effectiveness of the regiona 1 network on maternal and infant health outcomes, institutional experiences, etc.

* Program Development: initiate and support activities directed at expanding resources and programs throughout the region to meet special needs of high risk patients (i.e. teenagers, postabortion patients) and for professional and paraprofessional education. and other areas of identified need

Figure 13. Progriam Components

Source: Working papers, Regional Perinatal Connittee. 


\begin{tabular}{|c|c|c|}
\hline Activities/Objectives & $\begin{array}{l}\text { Time Line } \\
\text { Reference }\end{array}$ & $\begin{array}{c}\text { Budget } \\
\text { Reference }\end{array}$ \\
\hline $\begin{array}{l}\text { Agency and Profesgional Liaison } \\
\text { Liaison will be maintained with participating providers and related govern- } \\
\text { ing interests (e.g. municipal governments). The liaison effort, at its core, } \\
\text { will emphasize continuing informal communication, operational problem } \\
\text { resolution, and identification of agency needs. }\end{array}$ & \multirow{2}{*}{$\begin{array}{l}\text { Orientation/ } \\
\text { profiles }\end{array}$} & \multirow{2}{*}{$\begin{array}{l}\text { Project } \\
\text { administration }\end{array}$} \\
\hline $\begin{array}{l}\text { a. Provide program orientation and solicit provider input } \\
\text { b. Complete the performance of agency profiles to identify capabilities, } \\
\text { resources, and needs } \\
\text { c. Orient agencies' support staff prior to training sessions }\end{array}$ & & \\
\hline $\begin{array}{l}\text { 2. Assign a project liaison to the County Department of } \\
\text { Health Services, } \\
\text { nisms for coordinated planning and information sharing }\end{array}$ & County liais on & $\begin{array}{l}\text { Project } \\
\text { administration }\end{array}$ \\
\hline $\begin{array}{l}\text { a. Provide program orientation and solicit input } \\
\text { b. Utilize their newsletters to maintain communication with the pro- } \\
\text { feseional community at large }\end{array}$ & & \\
\hline $\begin{array}{l}\text { 4. Sponsor occasional workshops and retreats as a forum for consensus } \\
\text { reaching, problem solving, priority oetting, etc.; these activities will } \\
\text { address intensive and long-range program plans and efforts }\end{array}$ & Workehope & $\begin{array}{l}\text { Project admin - } \\
\text { istration, } \\
\text { other consult- } \\
\text { ants, meeting } \\
\text { costs }\end{array}$ \\
\hline
\end{tabular}

Figure 14, Plan of Action Objectives and Activities (Sample)

Source: Plan of Action, Perinatal Regionalization Project Proposal, 1974. 


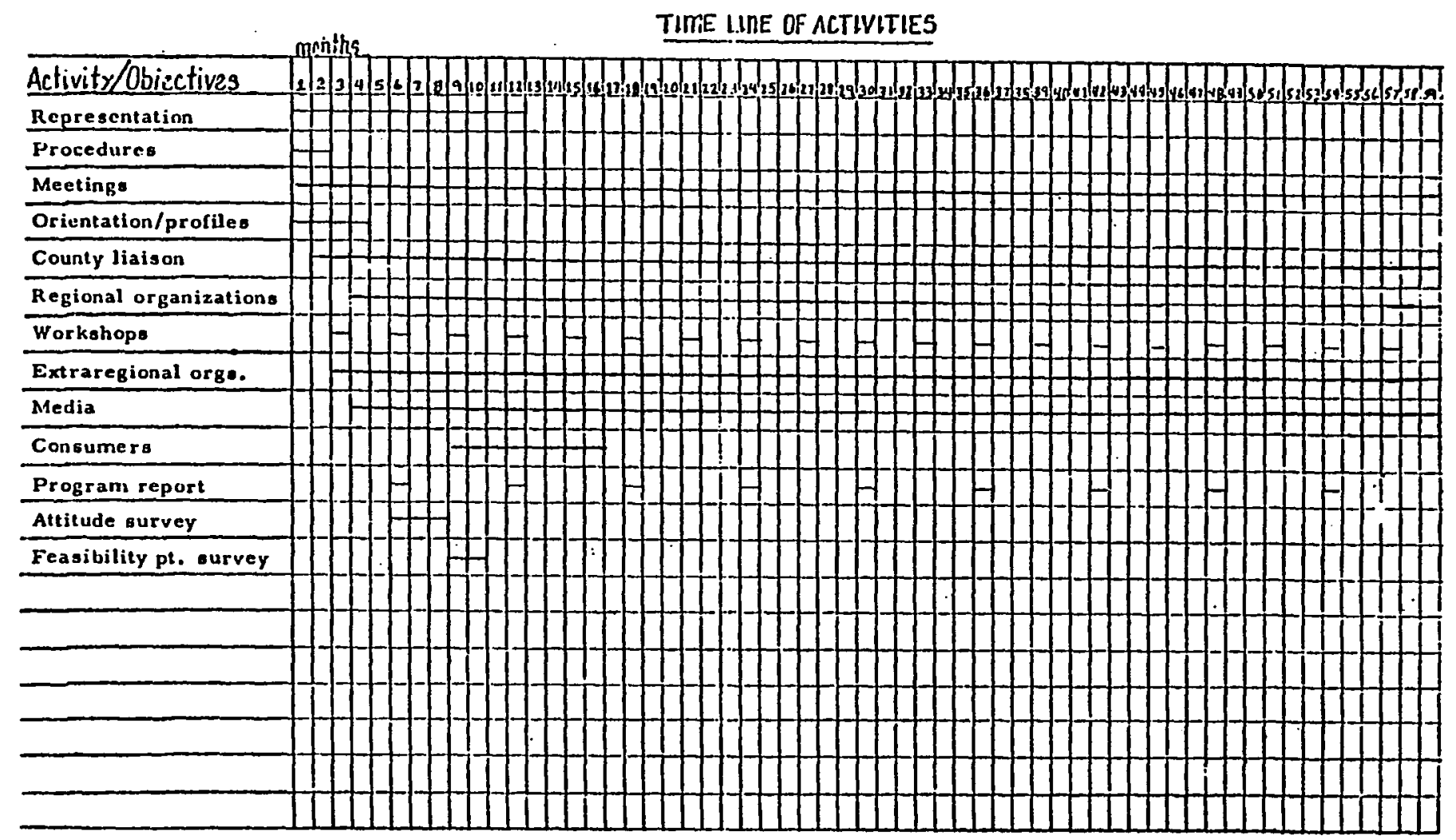

Fiqure 15, 'lime Line of Activities (Sample)

Source: Plan of Action, Perinatal Regionalization Project Proposal, 1974. 


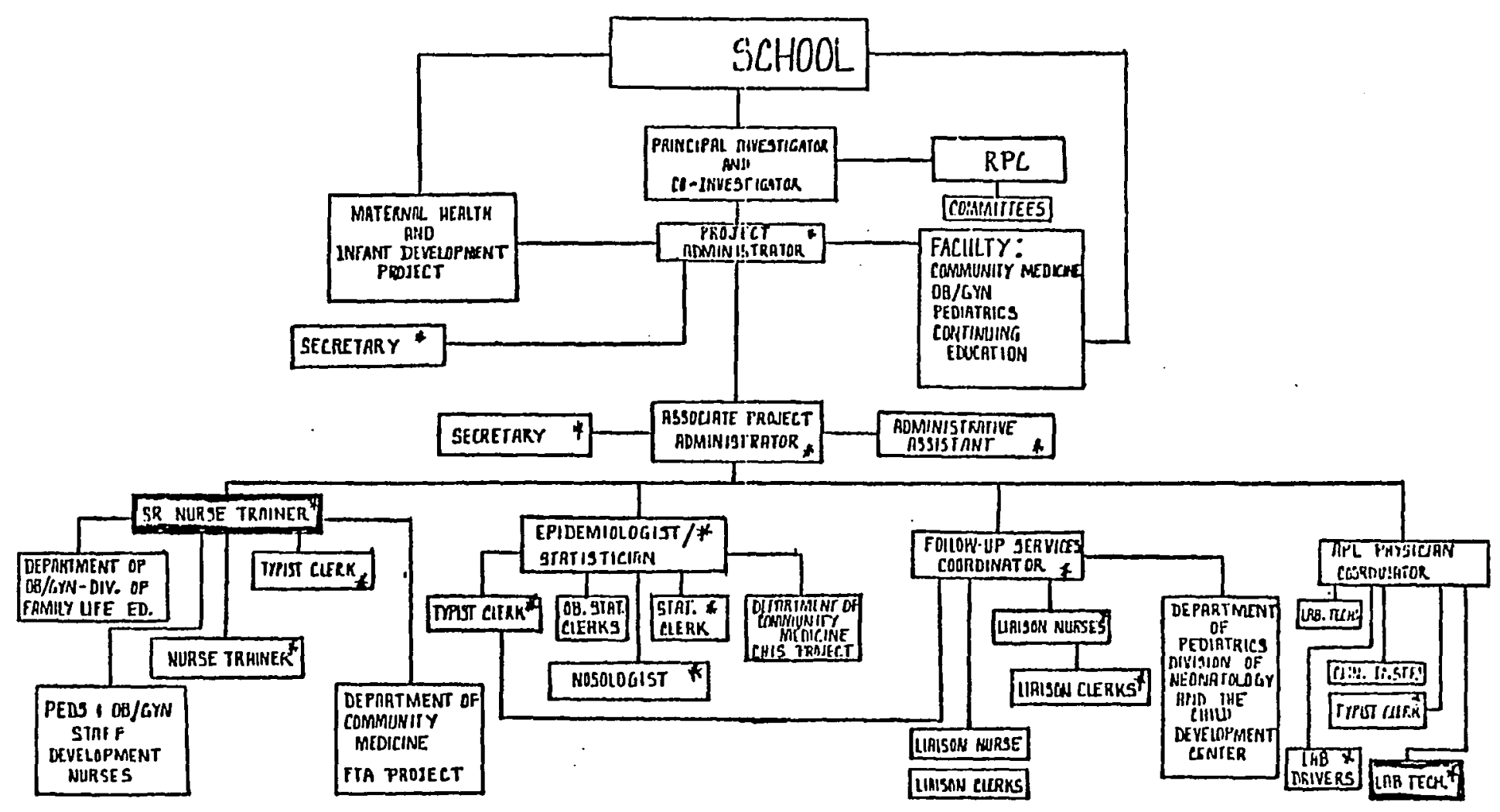

Eigauce 16. Proposed and Year 1 Organizational Charts Comparison

Sources: Plan of Action, Perinatal Regionalization Project Proposal, 1974 and Annual Report, Perinatal Regionalization Project, 1975. 


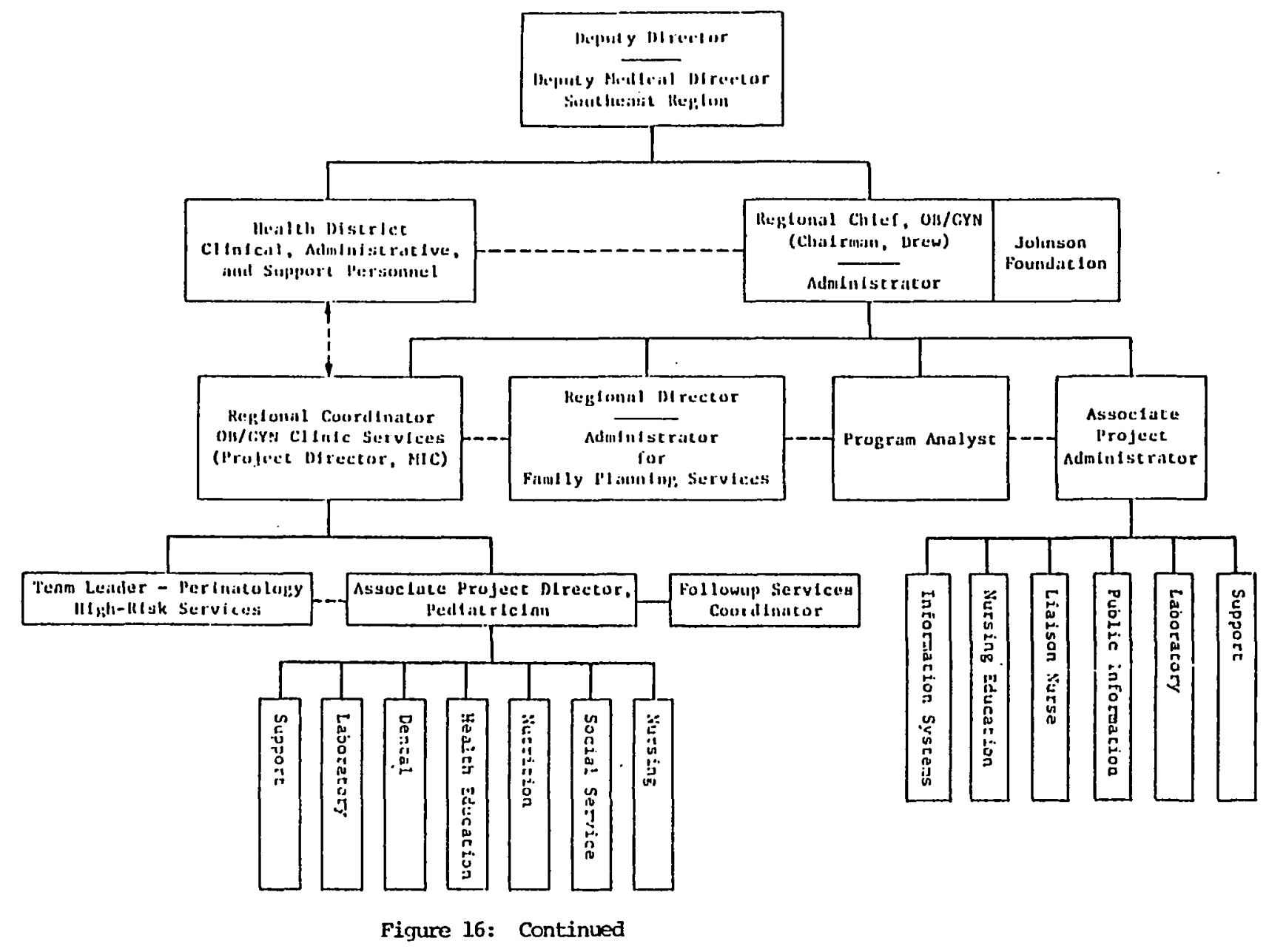


Liason with State, County, Regional Agencies established

Regional Perinatal Committee organized

$\mathrm{X}$ Special medical record implementes (policy) Regional Conference on Perinatal Health Care High risk diagnostic services available to region

Classes and meetings accredited

Data system operating

$\mathrm{X}$

HSA Agreemnt and Privacy and Confidentiality

Agreement

JCAH and Medicaid Approcal of forms

Agency Profiles completed

Pediatric Follow-up Assessment Forms deve-

loped and used

Neonatal Modules Completed

Infant Follow-up Conference

First Mortality and Morbidity Conference

Workshops for office Staff

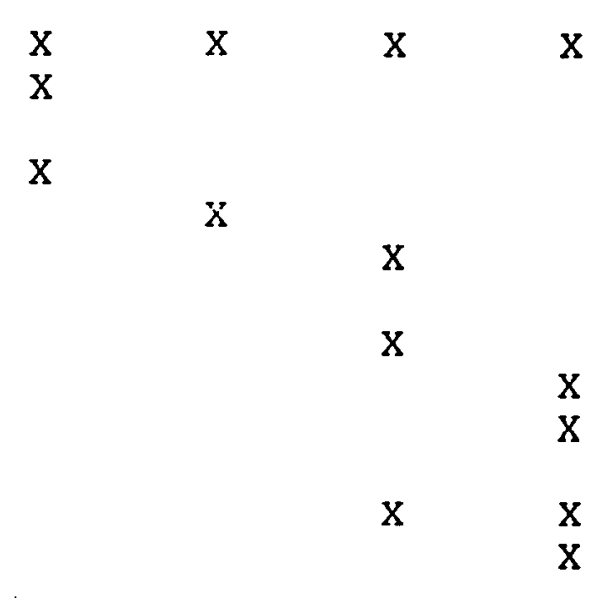

$\mathrm{X}$
$\mathrm{X}$
$\mathrm{X}$
$\mathrm{X}$
$\mathrm{X}$

Figure 17. Major project milestones.

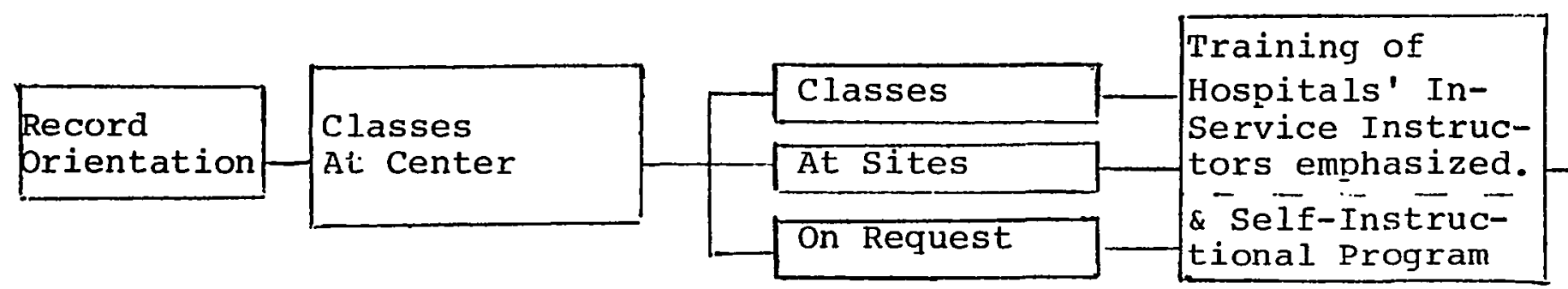

$75 / 76$

$76 / 78$

78

79

Consultation on Nursing Service Organization \& Hospitals' InService Program Development

Conferences fon office Staff

Figure 18. Major changes in project approach (sample). 
is what has been gained by $\$ 2.5$ million over five years? What on-going costs need to be picked up and are they worth it? The Project has generated many contributions to the Region. The outputs of these efforts can be measured on several levels -- first, number of specific activities and second, changes in patterns of resources, procedures, mechanisms in place, and results. Examples of first level outputs are seen in Table XII. As can be seen, the numeric outputs do not measure the total range of activities of the Project. Such items as number of hours spent in consultation have never been recorded. This particular function increased over time.

Changes in patterns of resources, procedures, and results have been well summarized by Gore (115) in a presentation to the American Public Health Association. The following series of Tables based on that talk review the changes which occurred between 1973 (pre regionalization efforts) and six years later. (Tables XIII and XIV)

Overall, dramatic changes in the pattern of care have resulted in large part through the impetus provided by the Project working with County and private agencies. Current area of need are staff space resources in the public sector (or load redistribution), physician inservice policy formulation, and patient education in the private sector and high risk infant follow up in both. There are no available measures of cost efficiency in 
TABLE XII

EXAMPLES OF FIRST IEVEL OUTPUTS

$$
\text { Yr.1 Yr.2 Yr.3 Yr.4 } \quad \text { Yr.5 } \quad \text { Yr.6 }
$$

Outputs

$\begin{array}{lllllll}\text { Contact Hours } & \text { N/A } & 970 & 5500 & 1750 & \text { N/A } & 1430\end{array}$

Number of Physicians

Involves

$\begin{array}{llllll}15 & 15 & 23 & 23 & 36 & 97\end{array}$

Number of Protocols

Approved

Number of Report Types

Available

0

3

5

3

$0 \quad 0$

0

1. Nursing inservice classes

TABLE XIII

CHANGES IN REGIONAL HEALTH RESOURCES

1973

0

7

20

12 wk.

3 $\underline{1979}$

1

3

36

$6 \mathrm{wk}$.

5
Private Level II Hospitals

Private Level I Hospitals

OB/GYN Specialists/765,000 population

Waiting time (public sector) between call for appointment and intake visit

High Risk prenatal clinics (doubles number of patients seen)

Source: James Gore, "Case Study: Perinatal Regionalization," Presentation to the Annual Meeting, American Public Health Association, November, 1979. 
TABLE XIV

KEY PROTECT INIERVENTIONS AND RESULTS

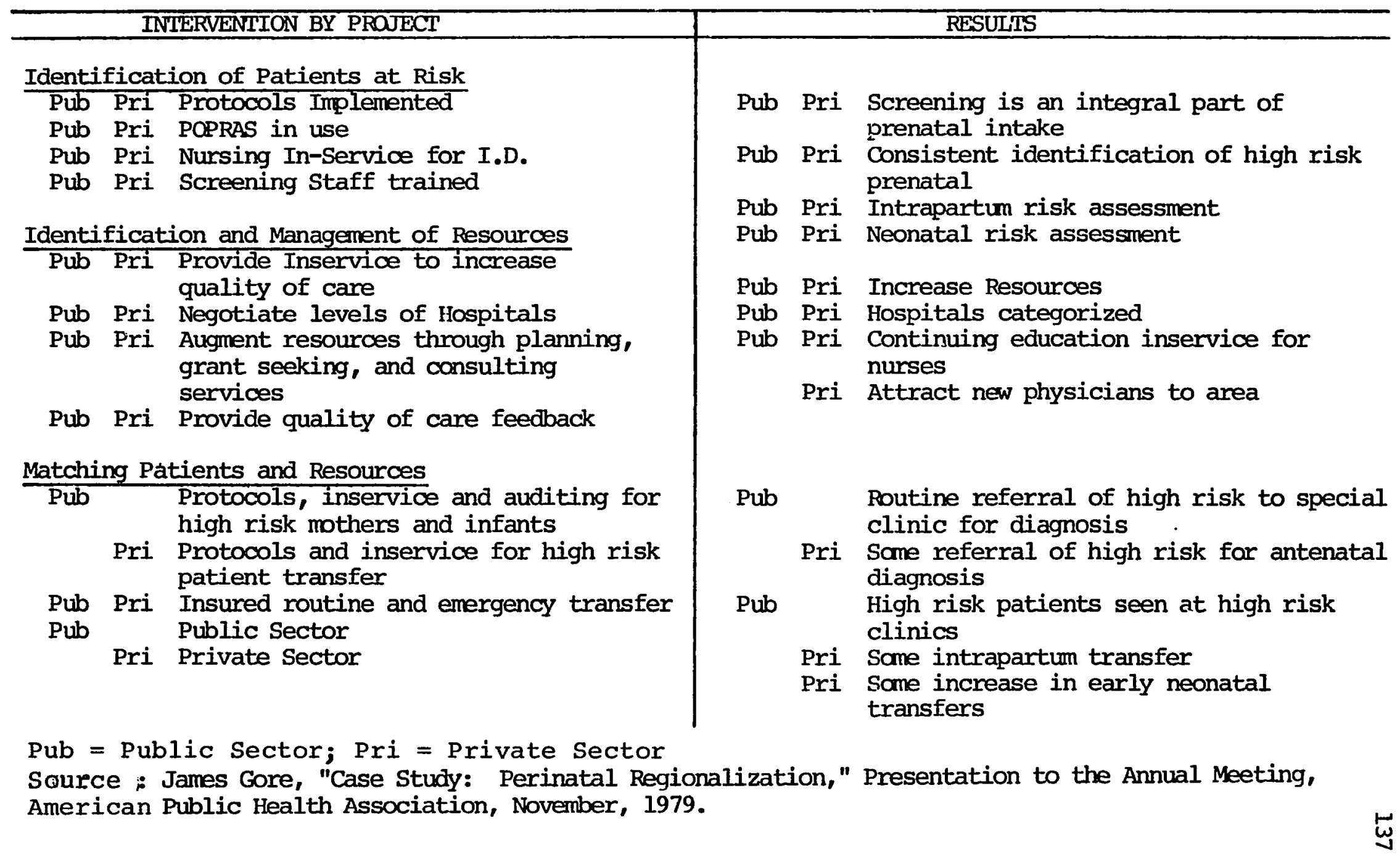


long-term costs for disabled children, changes in litigation costs for malpractice, system savings in perinatal costs versus costs to raise to standards. The closing of several hospitals does, however, represent cost effective concentration of efforts in large obstetric services more capable of producing positive results (generally said to be those with over 1,000 deliveries/year). Undoubtedly the remaining hospitals faced increased costs to upgrade staff and equipment. Some of these represent one-time costs; others improved management through staff reorganization -the long range cost of which is measured by decreased malpractice costs. On-going costs to maintain Project assistance include inservice education and data processing as means to maintain/develop quality of care and to monitor results and developing problems. Patient costs reflect the rising institutional costs with the closing of certain hospitals. There is no longer a choice of low cost delivery for self-payers. The alternative, the County hospital, is higher than private care.

\section{PERFORMANCE MEASURES AND IMPACTS}

What impact did this great amount of effort have on perinatal outcomes as measured by perinatal mortality and morbidity? A major research project by Johns Hopkins University compared results in Regional births in 1977 and 
1979 as part of a major Project including seven other Regions and control areas. Birthweight specific disability (see Figure 19) was measured on the basis of one year follow-up studies of all babies residing in the Region, irrespective of where they received care. The results showed no significant difference within this period. Another major study in 1977 based on Williams' (117) approach of comparing observed versus expected outcomes for birthweight and ethnicity-specific categories showed a poor ranking for the hospital when compared with hospitals statewide.

While the three regional hospitals were showing some improvement in their individual mortality statistics, the County hospital showed an increase in fetal mortality in 1980 .

A number of research issues are involved in these findings -- perhaps most significantly, the rapidly and radically changing conditions during the time of the intervention and measurement.

A number of specific results indicate program potential. Perinatal mortality among the highest risk group who has used the special $O B$ diagnostic laboratory was $8 / 1000$ in contrast to $14 / 1000$. Low birth weight, a prime predictor of mortality for this group, was 38 versus 88. Similarly women in a comprehensive program for high risk pregnancies had fewer perinatal deaths and other 
Morbidity in Infants to One Year of Age Analyzed from Four Perspectives

\section{By Birthweight}

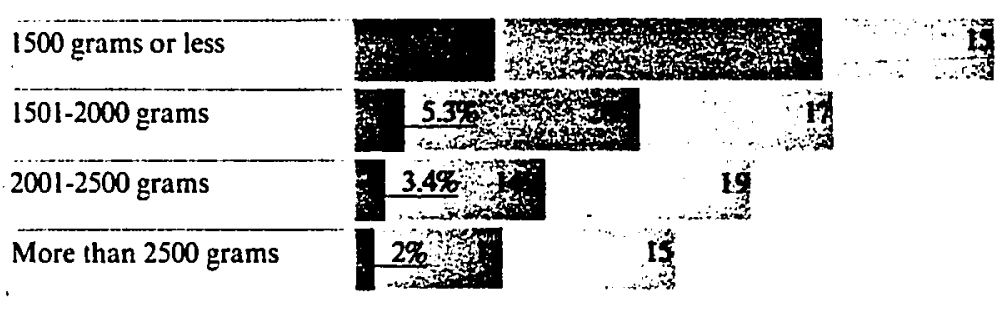

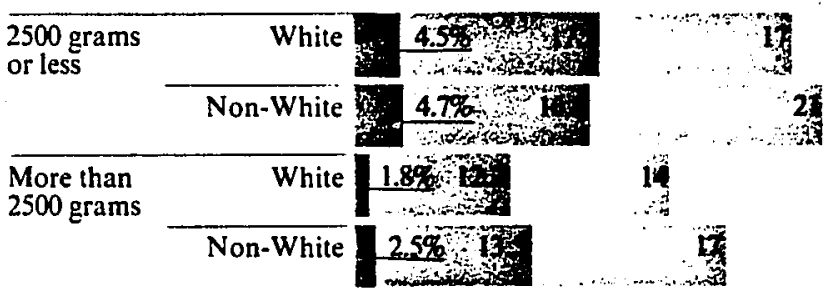

Figure 19. Birthweight-specific disability in

infants: I year follow-up study.

Source: Special Report. Funding Agency, No. 2, 1978 P. 16. 
indicators of morbidity. A concentrated education program for low risk women with fewer physician contacts also showed better results than did a comparable group. Special programs for pregnant adolescents yielded better outcomes for its participants as well.

\section{ANALYSIS OF CHANGING INPUT FACTORS}

A number of factors greatly affected the progress of regionalization mostly in a negative way: population changes, decreases in public sector funding, regulatory pressure, changes in professional workforce pool.

\section{Population Changes}

Both the number and distribution of patients in the Region changed over the course of the Project (See Table $\mathrm{XV}$ ). Most significantly the increase in the Spanish-surnamed population increased not only the birth rate but the redistribution of patient load into the public sector since many of these patients are "self-payers" and so unacceptable for private hospital admission. An estimate of impact can be gauged by the size of the shift from 23\% Spanish Surnamed births in 1970 to $48 \%$ in 1976 and from $41 \%$ Black to $36 \%$-- an 84 minority rate (116). In the public sector in 1980 minority women comprise 998 of deliveries -about $90 \%$ being Spanish-surnamed. The population shift brought with it medical and management concerns as well -- 
TABLE XV

REGIONAI DELIVERIES, BIRTH RATE AND COUNTY HOSPITAI PROPORTION, 1972 - 1978

\begin{tabular}{lcccc} 
Regional & $\begin{array}{c}\text { Birth } \\
\text { Deliveries }\end{array}$ & $\begin{array}{l}\text { County Hosp. } \\
\text { of Regional } \\
\text { Deliveries }\end{array}$ & $\begin{array}{c}\text { County } \\
\text { Deliveries }\end{array}$ \\
\hline 1972 & 14,542 & 19.7 & - & - \\
1973 & 15,994 & 21.2 & 11.3 & 1814 \\
1974 & 15,596 & 21.8 & 14.0 & 2175 \\
1975 & 15,843 & 22.2 & 17.3 & 2737 \\
1976 & 16,955 & 23.7 & 22.6 & 3831 \\
1977 & 16,816 & 23.2 & 25.1 & 4214 \\
1978 & 17,216 & N.A. & 28.3 & 4876
\end{tabular}

COMMENTS ON INCREASED PUBLIC SECTOR DELIVERIES

Increase from more regional patients delivering in Region vs. outside Region.

Increase from closing of 3 hospitals.

Increase from birth rate - likely to continue.

Increase from demographic shift and choice of hospital: more self-payers low income, Medi-caid ineligible, therefore County patients - likely to continue.

Source: Umbdenstock \& Komoto, Source Book, 1977. 
increased high risk pregnancies and deliveries, different types of problems such as hypertension, sickle cell, high multiparity (number of previous deliveries), age, patient behaviors including poor diet, increased lack of care seeking, etc., (see Table XVI), ?anguage and cultural sensitivity demands on the system.

\section{Decreased Public Sector Funding}

With the increase in public sector births (see Figure 20) and the additional risk involved, funding from State and County sources declined dramatically during this time. The differential between workload and budgeted staff at the County hospital can be measured by activity in the Labor and Delivery Unit (Figure 21 ) and in the NICU in comparison with hired stafi over time (Table XVII).

Hiring depends not only on availability but on budgeted positions and hiring freezes. In comparison, with other County facilities, this hospital has $23 \%$ of the public births, $15 \%$ of Labor and Delivery RNs and $0 \%$ of critical care nurses in Labor and Delivery. The number of budgeted registered nurses has remained 11 despite the doubling of births in five years. According to professional standards, 32 RNs are necessary for this caseload. According to a productivity study performed by the Arthur C. Young Co., a total of 79 staff (all levels combined) are necessary for the 
TABLE XVI

COMPARISON OF SPANISH/SURNAMED

MATERNAL AND INFANT COMPIICATIONS AND OUTCOMES,

FOR THOSE WITH \& WITHOUT PRENATAL CARE, DECEMBER, 1978

\begin{tabular}{|c|c|c|}
\hline & $\begin{array}{c}\stackrel{8}{8} \\
\text { PRENATAL } \\
\text { CARE }\end{array}$ & $\begin{array}{l}\text { \& NO } \\
\text { PRENATAI CARE }\end{array}$ \\
\hline TOTAL & 91.6 & 8.4 \\
\hline Low Birth Weight & 2.6 & 9.5 \\
\hline LOW APGAR & 2.2 & 4.8 \\
\hline Maternal Complications & 10.5 & 14.3 \\
\hline Infant Complications & 24.9 & 52.4 \\
\hline Born out of Asepces & 3.1 & 5.0 \\
\hline $\begin{array}{l}\text { Neonatal Intensive } \\
\text { Care Unit }\end{array}$ & 7.0 & 5.0 \\
\hline Difficult Delivery & 8.3 & 9.5 \\
\hline $\begin{array}{l}\text { Stillbirth/ } \\
\text { Neonatal Death }\end{array}$ & $\varnothing$ & 9.5 \\
\hline
\end{tabular}

Source: Spanish/Surnamed Study, 1979 


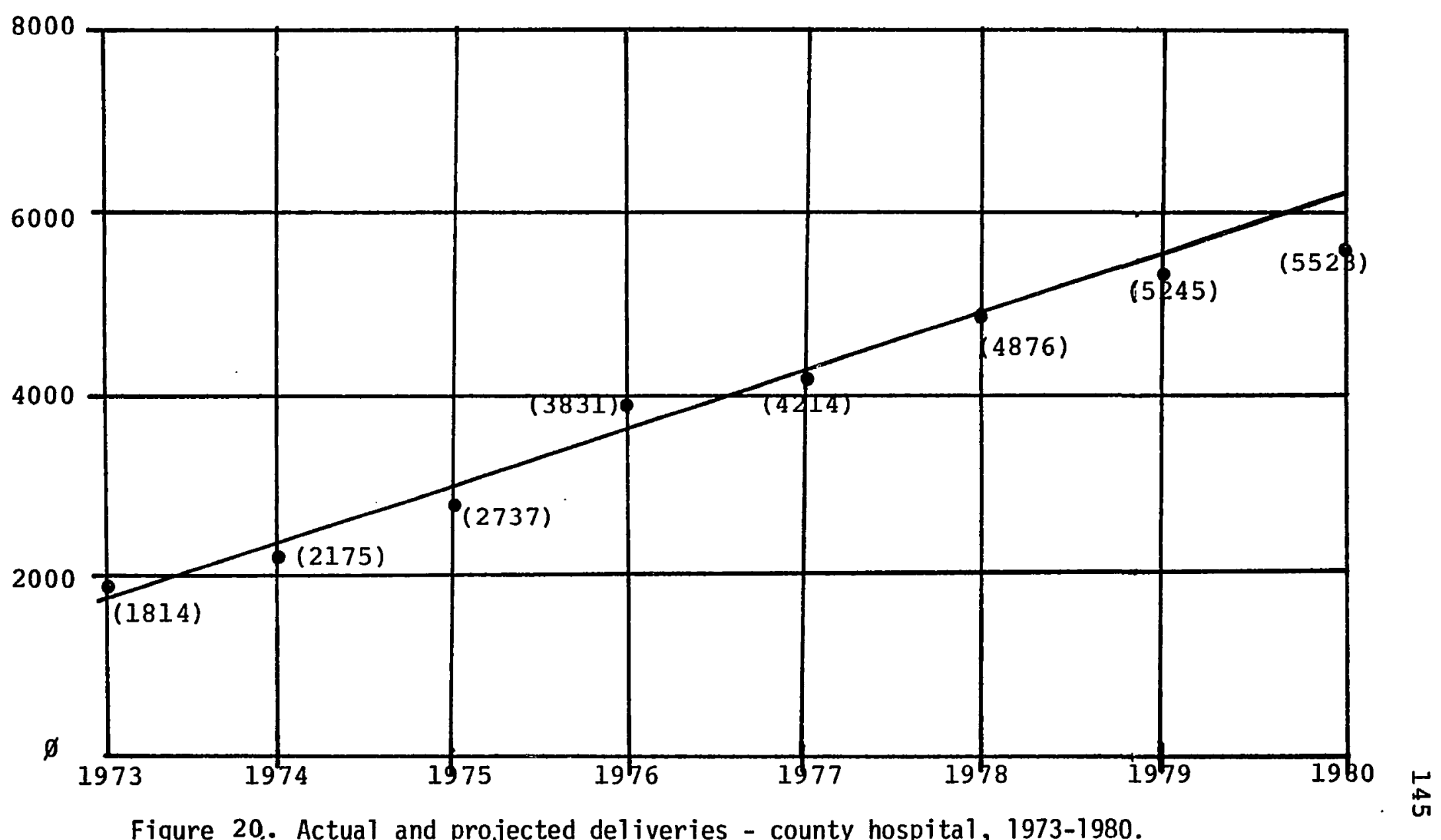




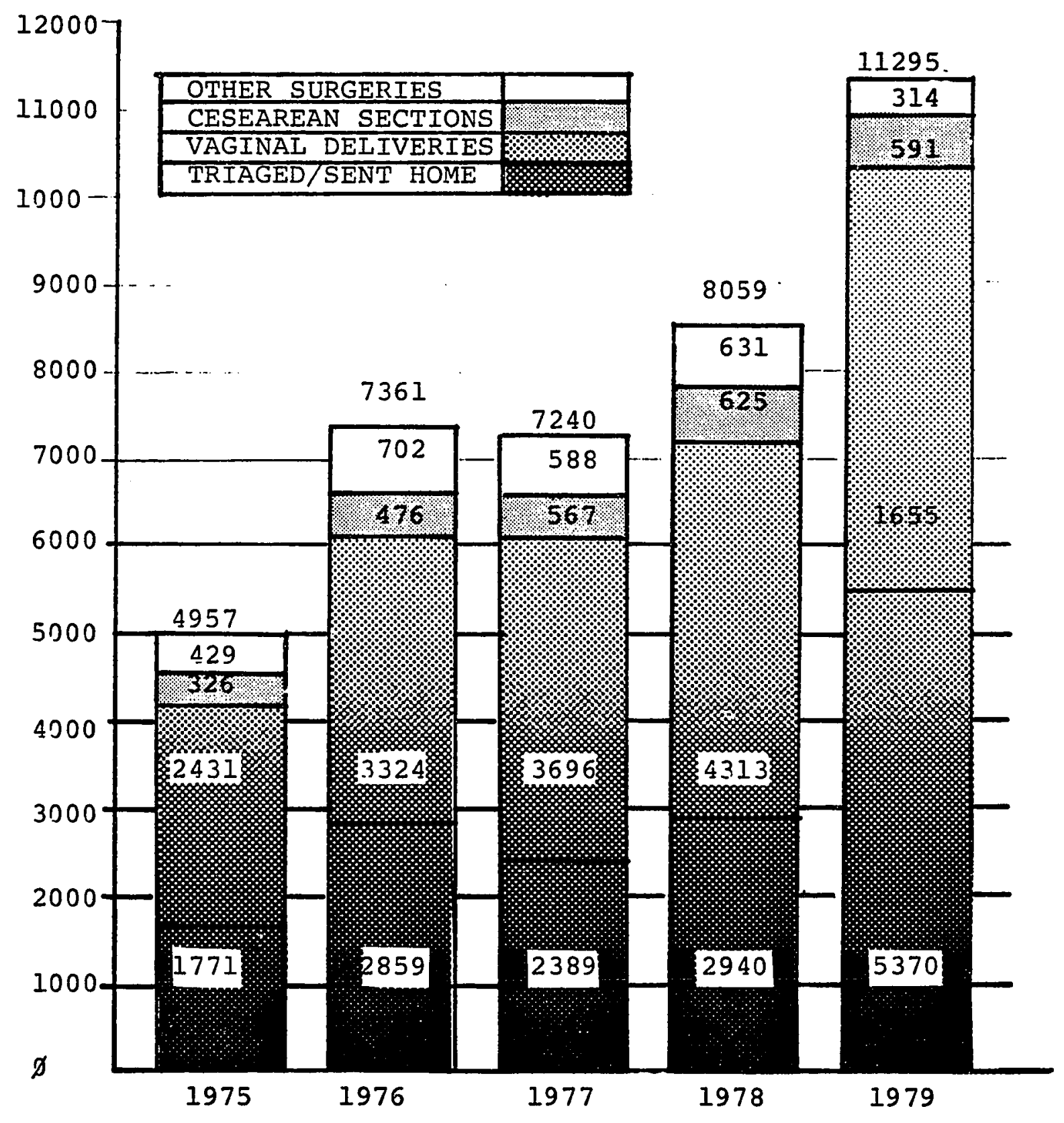

Figure 21. Workload in labor and delivery - county neneral hospital, 1975-1979 (Source: Labor and Delivery Overload Study, 1980). 
TABLE XVII

HIRED STAFF vS. WORKLOAD, COUNTY HOSPITAL, 1975 - 1980

\section{Year}

\section{Year}

1975

1976

1977

1978

1979

1980
Labor and Delivery: Total

\begin{tabular}{|c|c|c|}
\hline Deliveries & $\mathrm{RN}^{\prime} \mathrm{s}^{1}$ & LVN's \\
\hline 2747 & 14 & 16 \\
\hline 3800 & 12 & 16 \\
\hline
\end{tabular}

1 For all shifts, all days combined

2 Usually more than half are aides

$4263 \quad 11 \quad 16$

4883

11

13

16

15
Special Care Nursery: Averaqe

NICU: Average

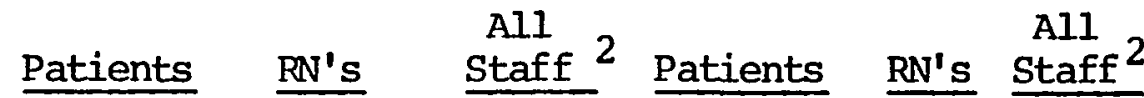

19

0.25

3.0

$\begin{array}{lll}9 & 2.0 & 9.0\end{array}$

23

0.50

5.0

$\begin{array}{lll}9.5 & 2.5 & 9.5\end{array}$

20

0.50

6.0

$\begin{array}{lll}11 & 3.0 & 11.0\end{array}$

15

0.0

3.4

20.5

$4.5 \quad 8.4$ 
current workload; the staff numbers 32 .

In addition, cuts in other support areas increased non-nursing functions such as cleaning, stocking, errands, meal distribution, etc.

Various political measures produced funding changes. In 1976, Proposition 13, an initiative passed by voters, drastically cut property taxes and consequently various services. The 1980 elections brought a wave of budgetslashing politicians to office including a majority on the County Board of Supervisors who had campaigned to cut medical services for "illegal aliens."

At the State level, a special program for high risk mothersand infants cut out pediatric services for high risk infants and decreased support of prenatal services in the Region.

\section{Workforce Changes}

The late 1970's saw the great nursing shortage. For many nurses, hospital work required the greatest work effort and the fewest rewards. In strictly monetary terms, one could work a registry for selected days (similar to substitute teaching) and make as much as in full time hospital work -- with more independence. Vacancies became extremely hard to fill (many were filled with foreigntrained staff) and turnover was high. The cycle of overload and staffing pattern is seen in the analysis performed by the 
Ob/Gyn Department in Figures 22 and 23. Their lineup of alternatives is seen in Table XVIII.

Not only nurses, but physicians and administrators changed. Of the 21 participants in the 1974-75 planning sessions, four represented institutions which are now closed and 14 are no longer in the Region. The remaining three were the Project Directors and Administrator.

\section{Regulatory Pressures}

The 1970's saw the dramatic rise in malpractice insurance, in fact an insurance crisis, and the increase in government-mandated attempts at cost containment -- Health Services Agency (HSA) Planning and Certificate of Need requirements for capital expenses. Both produced some impetus for cooperative self-regulation and planning. The Region produced an agreement with the local HSA acknowledging the Region's interest in and capability to plan in the areà.

\section{SUMMARY}

Despite the achievements and unfulfilled expectations of the Project, the true extent of its impact remains unknown because the outcomes had there been no program cannot be measured: there is no other "region" to be matched on critical dimensions; key conditions of patient inputs and regular levels of support did not remain constant but in fact, changed arastically; several areas of activity are 


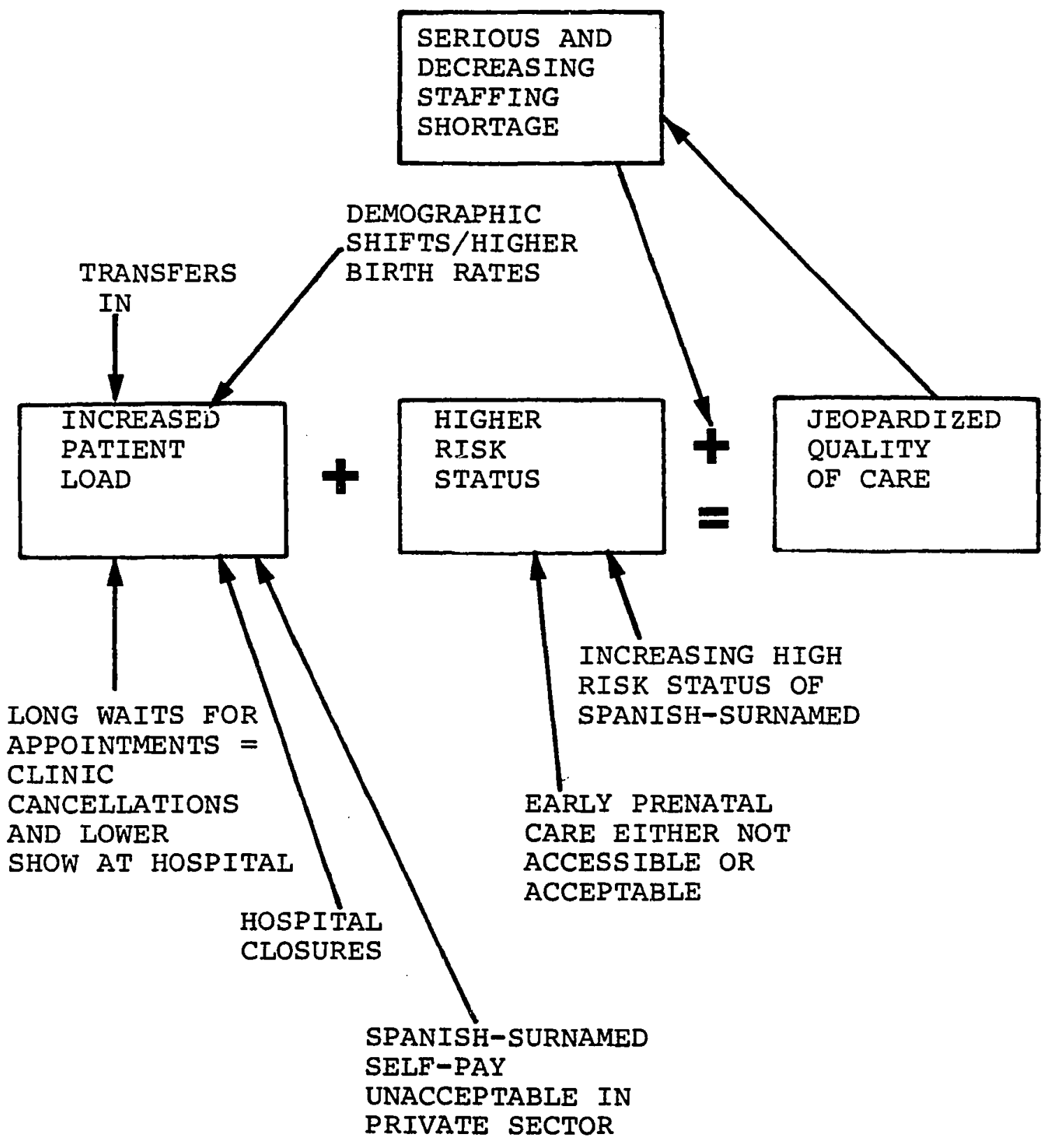

THE PROBLEM: There is a steadily increasing patient load, a higher risk status of patients overall, complicated by a serious staffing sho-tage. All of these variables work together to affect the quality of care.

Figure 22. Overview of the county obstetrics overload. 


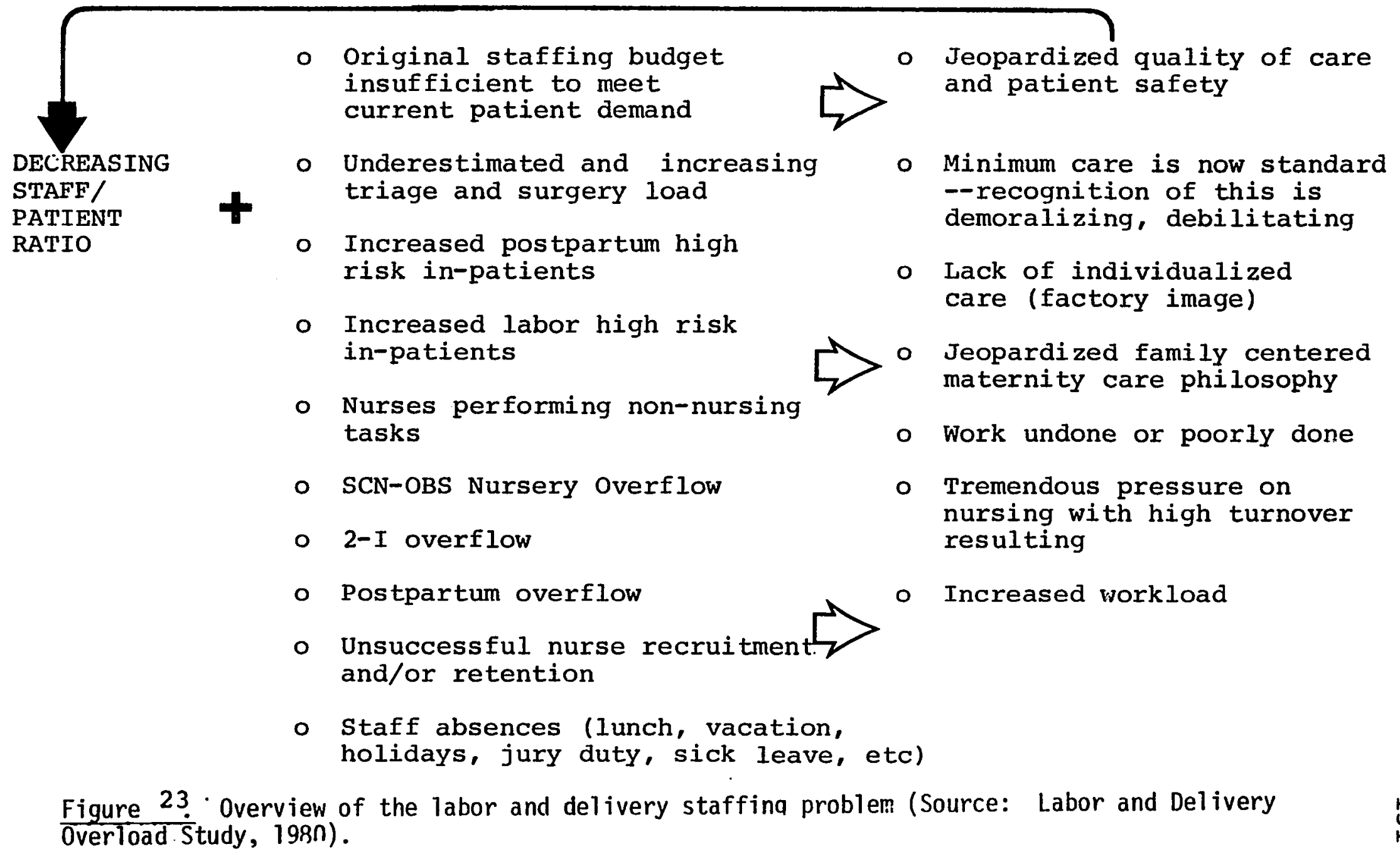


SHORT AND LONG TERM INTERVENTIONS FOR OBSTETRICAL OVERLOAD

\begin{tabular}{|c|c|c|c|c|}
\hline $\begin{array}{l}\text { CURRENT AND POSS } \\
\text { SHORT RE.IGE }\end{array}$ & $\left\{\begin{array}{c}\text { BLE INTESVENTIONS } \\
\text { LONG KINGE }\end{array}\right.$ & 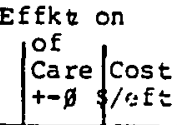 & $\begin{array}{l}\text { Over } \\
\text { impt } \\
\text { pai: } \\
1-10\end{array}$ & $\begin{array}{l}\text { a } 11 \\
\text { p.ros }\end{array}$ \\
\hline $\begin{array}{l}\text { PATIENT LOAD } \\
\text { - transters } \\
\text {-conczacts w/other hoso } \\
\text { - prenacal diversion to } \\
\text { orivite secror } \\
\text {-review risk criteria } \\
\text {-improve/revise sched. } \\
\text { - review patient flow } \\
\text {-separate CB \& Gyn } \\
\text { functicns, esp. surg. } \\
\text {-reduce lergrh of stay } \\
\text { with eariy discharges }\end{array}$ & $\begin{array}{l}\text { - family planning } \\
\text {-teen cutreach/adoles. } \\
\text { clinical services } \\
\text {-responsible human } \\
\text { sexualicy other } \\
\text { educatior. } \\
\text {-alternative birti } \\
\text { centers }\end{array}$ & & & \\
\hline 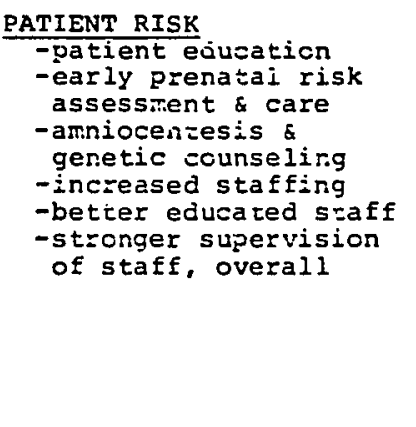 & $\begin{array}{l}\text { - WIC } \\
\text { - Dacient education } \\
\text { - scaff education } \\
\text { - increased access to } \\
\text { prenatal care }\end{array}$ & & & \\
\hline $\begin{array}{l}\text { NURSING/STAFF SHORTAGE } \\
\text {-recruitment } \\
\text { - train new ancillary } \\
\text { personnel } \\
\text {-adc new budget items } \\
\text { - negotiate tasks across } \\
\text { services } \\
\text {-improve orientation, } \\
\text { education of new staff } \\
\text {-establish separa ie } \\
\text { budget codes for } \\
\text { PAR, triage, 2-E }\end{array}$ & $\begin{array}{l}\text { - } \\
\text { - recruit } \\
\text {-create new speciali- } \\
\text { ties and new ancillar } \\
\text { stafe (e.g. OB Tech) } \\
\text {-renegotijte tasks } \\
\text { across depts, svs. } \\
\text {-modify facilities, } \\
\text {-add nei budget items }\end{array}$ & & & \\
\hline
\end{tabular}


still in the process of development hinging on changes extraneous to the system. Nevertheless current assessment of need and areas of success suggest directions for the future. These will be discussed in Chapter IX. 


\section{CHAPTER VI}

\section{ONE PERSPECTIVE ON REGIONALIZATION: ORGANIZATIONAL POTENTIALS AND CONSTRAINTS REGARDING}

CHANGING RELATIONS

This chapter serves as a guide through the web of organizational relations within, among, and across institutions. The sources are the intensive interviews covering all groups and participant observation. All information is cross verified though it tries to maintain the separate points of view of groups and organizations as they grapple with the various approaches attempted in regionalizing perinatal care. The narrative seeks to provide enough examples to create a description of key aspects of a coherent organizational perspective.

\section{THE ORGANIZATION AS AN ENTITY}

To lay out the regional topography is to describe the dominant institutions and organizations involved in the Region. These include three hospitals, their feeder clinics, and private physicians.

The largest provider of obstetric and pediatric services is the County Hospital which also serves as a resident training center, a post-graduate training site.

The role played by private practitioners in the private 
hospital is represented by faculty in the County Hospital, with an important difference. Because the County Hospital is a training facility, it must be prepared in terms of equipment, high level support staff, etc. to handle any perinatal problem. These special demands are set against a County funding crisis and an especially severe nursing shortage in the public sector. Management of this crisis is viewed differently by the training and service oriented faculty than by the cost-containment oriented administrators in the County Hospital.

The only multi-story, multi-acre structure in the area, the hospital is claimed as a powerful symbol of Black community effort. This status is rooted in the fact that the hospital bond measure was rejected at the polls by the larger, non-Black populace. It's construction represents major political maneuvering. And much is at stake in this successful operation, both on the part of the power that brought it into being and of those who voiced the demand on behalf of the community. The day-to-day operation of the hospital reflects these currents. The lack of support from the wider public is seen in the limited funding and in the tendency to stifle problems that might generate "bad press" for any political figures involved. The stake of the community leaders in proving the hospital feasible and themselves capable is seen in a mix of proprietary and self-aknegating tendencies. The Region's often unseasoned public 
administrators will attempt the impossible rather than demand assistance from "downtown". They espouse a philosophy of preferential hiring from a high unemployment community and pursue the resulting mix of social, ethnical, and competency issues raised, thus giving strength to critics within and outside the hospital.

In front and in back of the new structure, old cars circle endlessly, looking for parking. Inside, around the corner from the lobby where a television set entertains the multitudes waiting for care, a total of ten elevators move visitors, staff, gurneys, linen wagons, surgical equipment, and lunches between floors. A guard at his post chats with passers-by as he keeps an eye on the elevators and hallways filled with the animated conversations of friends and acquaintances as well as the vacant anxious faces of the lost -- the community transplanted into the hospital.

As in any institutinn: there is a disparity between the one that exists on paper and the one that is a functioning reality. As a County institution, this discrepancy is evident in many ways and points up the nature of county institutions. For example, the County persists in basing its planning and projections on 90 postpartum beds, whereas there are fewer than 60 due to the allocation of over onethird to gynecology and antepartum patients. The department is desparately short of faculty and nursing staff, but the 
books show "capacity staffing." This discrepancy is due, in part, to reserving one slot for a special teen program while waiting for promised grant money to fund the position, to using hospital staff to cover critical'Regional clinics (rather than hospital functions), to overhiring in certain positions which are budgeted so unbudgeted functions can be covered by these staff. For example, workload in labor and delivery is measured by the number of deliveries. As a result, staffing levels were established to reflect the number of deliveries. What management did not account for, however, was the disproportionate number of patients who were admitted into the Labor and Delivery Unit, observed, treated, and then sent home without delivering. One recent analysis showed that half of the work effort was spent with these types of cases ... cases which did not appear in the delivery count (the "reported" workload) and thus, were not considered when staffing budgets were determined.

There is a disparity also in the "nursing profession" and nursing in reality in an overcrowded, understaffed hospital. While nurses are trained in bedside procedures and are socialized professionally in that nurturing role, the sheer numbers of patients and their relative criticality overrides the nurturing functions in favor of medicaltechnical life-saving, efficient, expedient procedures. People come and go, but the unique institution remains recognizably the same. For all the internal hassels, 
interviewed staff from the top down would switch into a proud mode when addressing the role of this hospital vis-avis other medical institutions in becoming a model and possible training site for others.

Also in the Region is a similar-sized private, nonprofit hospital, religiously affiliated, and long-established in this community. A woman in the parking lot booth greets visitors. They pass the large statue in front and enter the lobby where several women sit behind an elaborate wooden information desk. A volunteer attends to the needs of families who have come to learn the outcome of surgeries. Nearby, two operator-run elevators take patients and visitors between floors. A large, glossy tabloid monthly tells of special programs, successful fund-raising in the community, service awards, and promotions. Relatively speaking, in this time period, the nursing turnover has not been great, usually a sign of relative satisfaction. Yet, unionizing efforts have started and inter-unit friction is high. The various units maintain a high degree of independence and the doctors relate directly to the unit nurses: The hospital claims a full-time on-site neonatologist and an intensive care nursery which takes in many babies transferred from smaller hospitals nearby. An Assitant Nursing Director is responsible for all the perinatal units -- both obstetrics and nursery .

The third hospital is a small community hospital 
operated by a national hospital corporation. It is the newest of the three and is located at the farther reaches of the Black community. The large, usually quiet lobby -- beautifully appointed -- is perhaps the least used of several access points extending down carpeted hallways which look out on planted courtyards. A large complex of medical offices shares the property.

While most private obstetricians in the Region work at both private hospitals, a few work only here and several are investors or have direct ties to the Board of Directors of the hospital. While many staff have been with the hospital since its opening, there has been significant turnover in some key positions. The Assistant Administrator became the Administrator, the Nursing Directorship changed three times in two years, and several reorganizations of administrative responsibilities (including unit supervision and in-service education) occurred especially in the last year. As the testing ground for administrators moving up the corporate ladder, the hospital seems to revolve in a cycle of changes and crises.

Several other hospitals had been variously involved. Two distant, smaller, predominantly white hospitals related (if to anyone) to a large, private white hospital in an adjoining area. One hospital in the Region closed for predominately financial reasons. Another, was closed for reasons of quality. 
Additionally, providers of prenatal care and follow-up services are important to note. Each private prenatal provider's office is a separate organization. In fact, each provider, whether at his office or at the hospital, is, by virtue of his profession, as completely independent as are the hospitals.

Traditionally, the County clinics are part of a system of preventive medicine available to the public. There are nine of these scattered throughout the Region, providing prenatal, postpartum, and pediatric care to low-income families.

\section{ORGANIZATIONAL DYNAMICS}

The various organizations characterized in the preceding section produce a climate within the Region through the dynamics of each organization internally, the confluence of forces between then, and in relation to their environment. Within each organization, the dynamics center on professional roles, power distribution, and socialization of front-line workers. Understanding these is a key to understanding the dynamics affecting the acceptance of regionalization and its implementation.

To give a few examples: doctors give orders and are to be assisted. When the nurses are busy and one pulls rank or makes an unreasonable request such as having nursing order his supper, they may keep him waiting. They will be "too 
busy" with other doctors or patients who require attention. In this way, they can also let a new intern who is practicing the status of "doctor" sink for lack of information as opposed to another case where nurses might subtly advise, "Doctor, we usually give this medication..to a patient in this situation. Do you wish to prescribe the same?"

Points may be scored by doctors in other ways, such as case conferences. The primary purpose of case reviews is to provide education and, as a result, to improve the quality of care. This is one place where the variety of medical cases becomes an actractive recruitment tool. An intern who is presenting a case in front of his/her peers and in front of a collection of faculty, nurses, and technicians is on the spot. Not only is $s /$ he publically reviewed for the way in which $s /$ he handled the patients, but $s /$ he is also on the firing line as part of the initiation required to join the fraternity. S/he may escape censure if $s /$ he can blame an identified problem on a nurse. This meeting is a battleground where nurses have no position and thus, nurses have ceased to participate. Another subtle result of these conferences traditionally is team identification. Party lines between obstetrics, pediatrics, or anesthesiology and the behavioral protocols are hammered out.

Yet another dimension of the system is the relationship between nurses -- more specifically, the relationship of RNs to LVNs. RNs supervise and are accountable by virtue of 
their training and responsibilities. Since RNs have more career opportunities and are generally overextended due to severe nursing shortages, they have a much higher turnover rate. LVNs generally have the greatest longevity and have used it to develop a system of their own. A kind of reverse supervision may take place in terms of workload and privileges. Certain practices are retained: who takes more extended time off the ward, who does most of the clean-up, and who can relax rather than perform busy-work in between the surge of patients. There are initiation rites in which the mythologies of the place, the proper attitudes and roles, the priorities and channels are learned so one can know his/ her place in the system. When a new nurse comes in $s / h e$ is tried in various ways to determine his/her willingness to perform group (as opposed to supervisor) assigned tasks without questioning or causing trouble for others by off-balancing or making waves within the system. Someone sensitive to these internal dynamics and cueing methods can be easily integrated while one who does not understand the game will not . 3t long. Doing a job at a pace conflicting with the established standard (rate-breaking) or questioning the stock rationale for opposing suggested changes marks one as "unacceptable". Acceptance is essential for individual survival in the system as well as for survival of the system, itself. Between the hospitals, a number of dynamics are evident. The traditional dominant relationship has always been one of 
competition between the private hospitals -- competition for doctors. This is set against a lack of interaction between the public and private sectors. There is some flow of patients between private and public facilities as patients come for free pregnancy tests to the clinics and apply for Medi-Caid cards which they then take to a private physician for prenatal care. A few patients without private physicians present at the emergency room of a private hospital for delivery when in active labor. These patients are sent to the public hospital as soon as feasible. The competitive stance between private hospitals is primarily an administrative one, for about $90 \%$ of the doctors in the vicinity practice at both private hospitals and their patients may be admitted to either one.

Regionalization seeks a complimentary relationship and thus, as noted previously, distinguishes between three levels of hospitals, based on the level of risk they are capable of handling. There is a natural basis for this three level distinction: size of hospital, number of deliveries, staff expertise, numbers and types of equipment. For instance, the hospital that delivers 500 babies a month has greater experience and practice in handling high risk patients, whereas the smaller hospital has a more intimate atmosphere to recommend it. Nevertheless competition persists. Another dynamic militating against Regional cooperation rests in the attitudes of front line staff and how they 
perceive the other hospitals in the Region. These attitudes may be shaped by rumors traveling through the grapevine or may be based on personal experiences as staff from the hospitals interface with one another. For instance, transferring sick babies to another, perhaps "more capable" facility provides also an excuse to compare procedures, attitudes, and protocols.

Two main forces affect the relations between the environement and the internal operations of the medical providers. The rapidly changing socio-demographic situation brings with it change in the ratios of self-paying patients to those covered by insurance or Medi-Caid. A concommitant change occurs in the ethnic distribution of patients and is attended by a shift in the tyoes of risks to be.considered. Cultural sensitivity may be required -- including coping with language barriers and a different level of consumer sophistication.

\section{ORGANIZATIONS AS INTERLINKING NETWORKS}

Hospitals lend themselves to analysis that probes beyond their formal and informal aspects of organization. They are complex institutions and as such may be seen as minicultures or societies. Implicit in their structure may be found games, bureaucracies, or even wars. $(107,116,117)$

Certain aspects of organization can best be seen through their relationships occuring at various levels and the ways in which they interconnect. We choose to examine 
here:

- turfs -- the arenas of action and decision as defined by formal or informal prerogative

- standard operating procedures (SOPs) -- the way in which action is taken

- messages -- the images developed and the context for interpretation in this system

- external operating positions -- the stance of the organization in relation to others and within its environment

- boundary spanning -- connecting activities especially between organizations

Over time, these terms define an institution and become its inherited repertoire.

In this context, change and development come, not simply from a plan of action, but by hooking into the patterns of constraints and potentials, or as the Chinese would say 'dangers and opportunities' (the same character stands for both).. Implicit in the latter term is recognition of the insight available to a person who truly understands the situation in all its subtleties. s/he not so much walks the fine line between them or simply turns problems into opportunities as grasps the simultaneous "yin and yang" effects and by doing so is empowered to move forward.

The examples below show how different levels of the systems under study operate and interconnect -- and further 
analyzes the aspects of danger/opportunity in the process of development.

Turfs

Turfs are areas of established prerogatives -- domains of authority or spheres of influence developed over time as belonging to some group. The former are official, the latter are learned from the organizational enculturation process:

The first set of examples deals with doctors and nurses. Organizationally, nurses report through a nursing hierarchy to the administrators. Doctors are a parallel source of authority when it comes to patient care (See Figure 24) but are responsible for prescribing all medical procedures carried out by nursing. In the hospital with residents, nurses have developed their own means of influence. When the new fourth-year residents (final year, in charge of patients) are too heady to seek faculty assistance, nursing staff may quietly call for a faculty doctor to "drop in" on a certain ward.

In another hospital, the established domains of doctors and nurses came to light in the course of regionalization efforts. A new head nurse received support from the doctors when she approached administration, and requested sufficient nursing staff to provide a given quality of care. The doctors stood with her despite administration, and despite the recommendation of the corporation's efficiency expert's report 
SAMPLE MEDICAL HIERARCHY

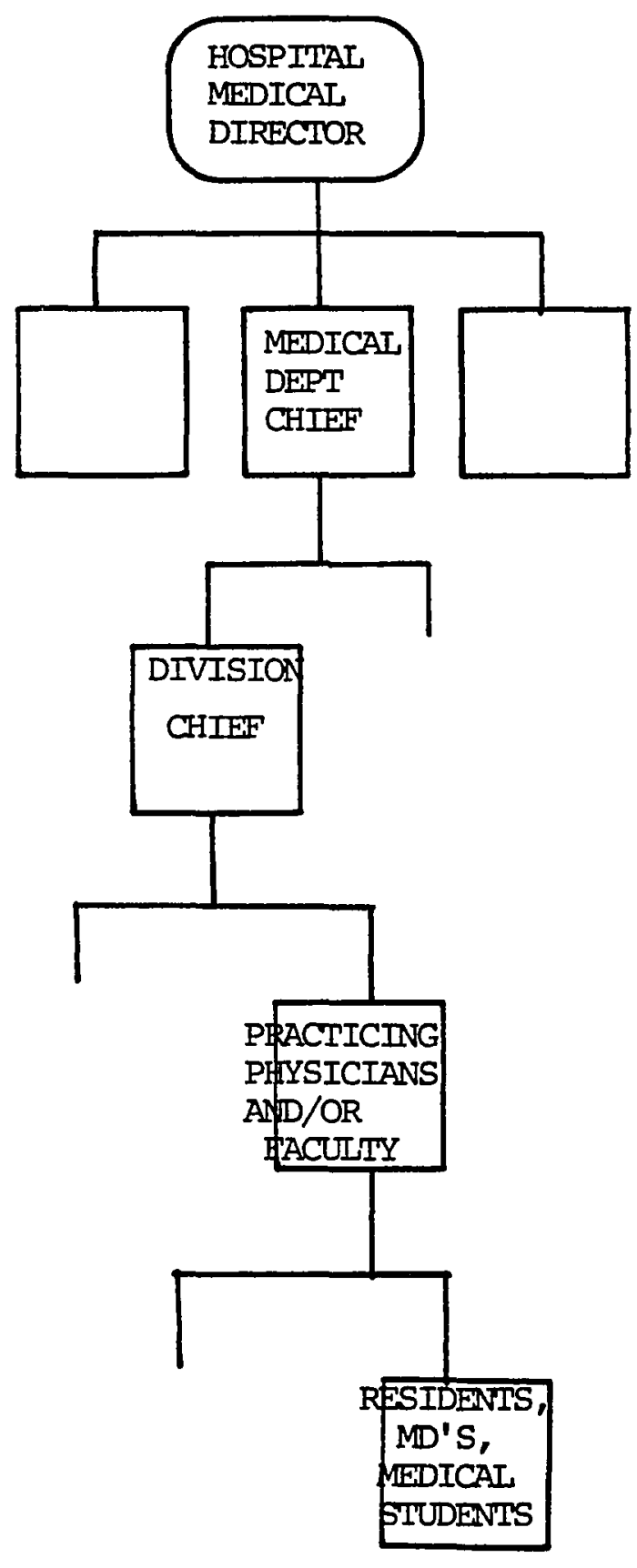

SAMPIE NURSING HIERARCHY

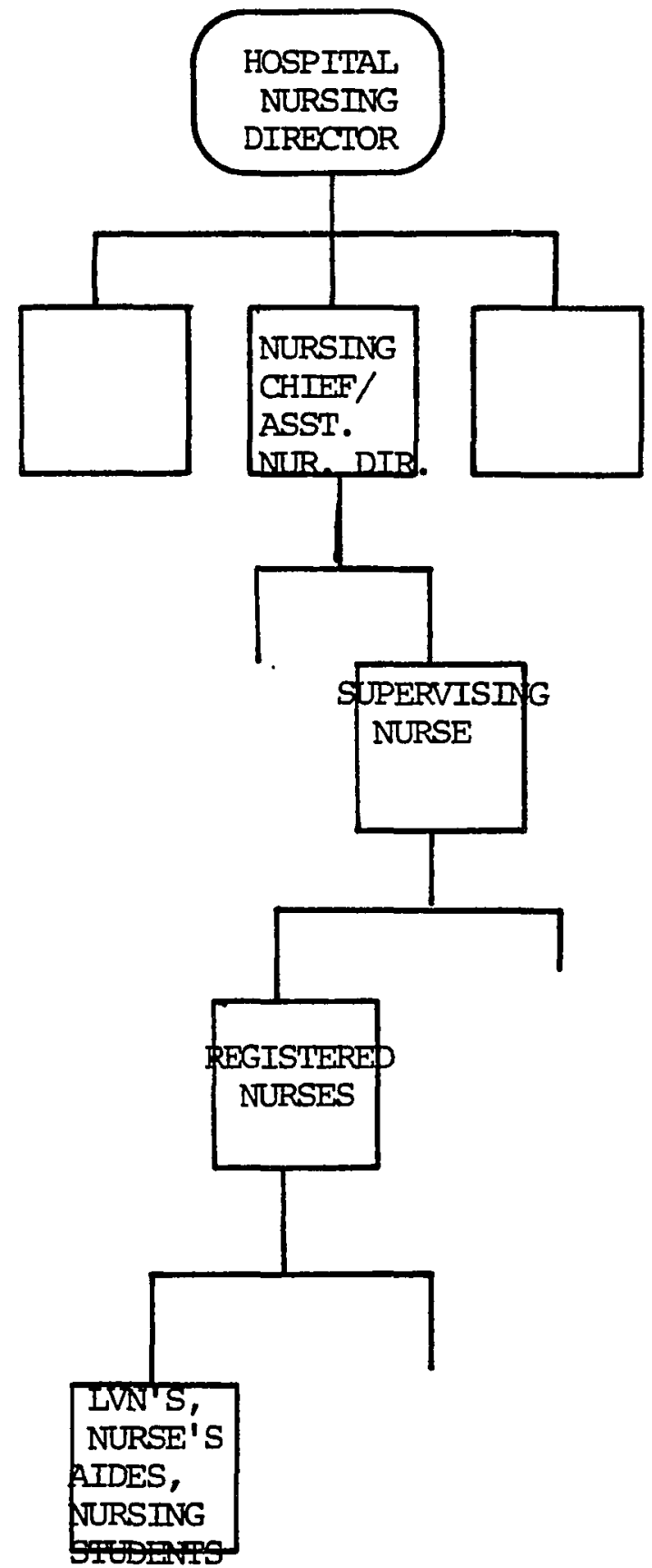

Figure 24. Sample medical and nursing hierarchies 
that nursing staff be slashed. Yet, when she again, in line with the concept of regionalization, suggested to doctors that her staff was not yet sufficiently trained to handle high risk babies which the other hospital could handle, the physicians dropped their support. She had overstepped her bounds. The issue was eventually resolved by her leaving. The physician domain remained intact: choice of where a patient delivers her baby is the doctor's and the hospital's capability is but one factor. It is his prerogative to also consider where the bulk of his admitted patients are for that week, the privileges offered by administration in pursuit of non-Medi-Caid patients, whether $s /$ he has been temporarily suspended for incomplete records (several doctors alternate hospitals by this process of catch up), or whether the woman wants a tubal ligation at the time of delivery (one hospital does not perform them).

In one unit, the attractive competent head nurse provides a complete support system (traditional nursing role) for the convenience of doctors at the same time as she ensures that hospital standards are adhered to.

Turfs were also mani.fested in examples of Regional education and training sessions for physicians. One of these involved orientation to the Problem-Oriented Perinatal Risk Assessment Medical Record -- POPRAS. It was appropriate for these to be taught by nurses, who were the most qualified teachers in these areas. Interns and residents, however, 
failed to attend these orientation sessions because the sessions were taught by nurses. When their presence was mandated by the Chief and roll call was taken, they would show up late and be disruptive.

Fetal monitoring is another area of expertise required by both doctors and nurses, with Regional nurse educators having the necessary skill for teaching. However, a program of instruction for residents is non-existent due to the above prevalent attitudes.

A third turf issue arose directly between the Regionalization Project and the private doctors -- again concerning the question of delivering a very high risk mother in a facility with special equipment and staff. Here, the doctors felt the traditional doctor/patient relationship was being hampered even though it was made clear that the patient's own doctor would be allowed to attend her in the special facility. It is common practice for doctors to deliver one another's patients -- and it often happens that in the all important moment (both medically and psychologically) one's own doctor may not be present. What was lost in the Regional plan was not the doctor/patient relationship, but the financial reimbursement for the private doctor. The high risk hospital's doctor would be listed as "attending physician" and the patient's doctor, present under special privileges, could not recoup costs even for prenatal care from Medi-Caid, and only by charging additional fees for other types of 
insurance, which imposes a hardship on the patient.

A fourth example of conflicting turfs involved the Medical Records Department front-line workers at the Regional Center. Several years ago, new management was brought into the department to "straighten the place up." During this period, Regionalization staff took the opportunity to raise their problems with Medical Records. The new administration seemed to grasp quickly the value of the POPRAS record in use and enthusiastically promised assistance so the Project could retrieve their copy of the record for research and management purposes. It was agreed that the Project's copy of the record would be separated from the patient's chart just after discharge when the entire record was transferred from the ward to Medical Records. Staff in Medical Records, supervised by the new management, would be responsible for pulling and sending the Project's copy to the Project data processing area. This agreement, however, was never fully implemented due to staff shortages, problems with weekends and holidays, lack of clear procedures, poor communication, and most importantly, to internal resistance to new management. Not only were records late in returning to the Project, but they also got lost or were difficult to retrieve. Everyone persisted in maintaining their own way of doing things which resulted in the lost records. Decisionmaking and management of the system continued in an ad hoc fashion, determined by front line workers whose primary 
concern was "getting the job done," or in other words, simplifying their own jobs. After a period of time, this experiment was discontinued and records were pulled by a Project staff member on the ward, prior to transfer to Medical Records. Thus, the turf was successfully defended against the threat of new supervisors and from outside interference.

A fifth example of conflicting turfs concerns doctors and administrators, both of whom claim ultimate responsibility for quality of care. Their positions are clear but overlap. Doctors claim ultimate authority by virtue of their professionalism and maintain that personal professional integrity and Peer Review are the only critical methods necessary to maintain quality standards. Administrators, on the other hand, stand legally liable and exercise their control through quality assurance programs, standards for medical practice, and admitting privileges. But, in reality most of these are adminstered by the doctors, themselves. Attempting to use peer consensus in an effort to raise standards, one of the first efforts to involve physicians in regionalization was the development of medical protocols. Generally, these were designed by faculty at the medical school and were discussed in meetings by the Regional physicians. When, after several years, they were asked about their own methods of risk assesment and procedures, many doctors commented that they had their own, based on their medical training and experience. 
The only physician mentioning Regional protocols commented that in any possible litigation, they could prove too restrictive when a doctor may have had a good reason for deviating in that particular case. It is also interesting that the protocol for teenage pregnancies, a problem in the Region on which the head of the Project is a national expert, never was approved by the Committee, despite much debate.

A sixth example relates to nursing inservice education responsibilities. For several years, Project staff offered accredited continuing education classes designed to relate nursing concepts and practices to regionalization in such areas as fetal monitoring and intra-partum risk assessment. During this period, another specialized grant provided for developing self-instructional modules in neonatal care. Class announcements were posted at the various hospitals. Working relations with some of the unit heads fostered an organized "sending" of staff to the classes. One unit, however, never had any representatives in attendence. Three people were asked at this hospital who was responsible for educational development of the unit. Each one -- the Director of Educaticn, the Director of Perinatal Nursing, and the Unit Head claimed ultimate responsibility. When questioned further about whether there was any need for additional education in the unit, two said "yes, they planned to get in there and develop something." The third said she was "handling it informally" herself and if only there were time, more could be done. But, 
anyone else trying to set up something should beware of "stepping foot into an area they really didn't understand" i.e. the routines by which the unit operated. One of the two eventually quit, the other linked education with another issue and mandated, through contract with another hospital outside the Region, for an in-service program relating to hospital needs.

The other hospitals also had turf battles over provision of education for perinatal nursing staff. In one, an obstetrics nurse was elevated to the hospital in-service department. She received advanced nursing obstetrics training from Project nurse educators in order to function as a nurse educator for the obstetric department's special needs. still, since this nurse was reporting to the Director of Hospital In-service, she was constantly called upon to do hospital-wide orientation for new staff, to write training manuals, and to perform myriad other duties rather than concentrate on the area of obstetrics for which she had been trained. Less than a year later she moved out of town and it was more than a year later before someone was found to replace her. This period was marked by conflict between the In-service Department and the Assistant Director of Nursing in Charge of Obstetrics because of the cricial need for obstetrical training. Nursing turnover had produced a situation in which there were virtually no nurses with specialized training in obstetrics just at a time when there was a heavy influx of patients and a larger 
proportion of high-risk patients who required highly skilled obstetrics nurses. At that point two educators were chosen because of the critical problem. This constituted a loss of two nurses critically needed in the unit. The Unit Supervisor gave them up only after gaining assurances that they would serve the obstetrical area and be accountable to her. Despite the long and difficult negotiations, when these people were given up for the training positions, they were once again taken away from the obstetrics unit and wound up teaching cardio-pulmonary resusitation to general hospital staff and other far-removed tasks.

Meanwhile, another conflict arose in this hospital between the Division Chief of the Nursery and the Director of Nursing over nursing in-service in the Neonatal Intensive Care Unit (NICU). The Division Chief (physician) is responsible for the level of care in the unit and was eager to use the self-instructional packages or modules he had developed. The modules taught specialized techniques such as use of radiant warmers, intubation, and disease monitoring through written and audio-visual materials, practice sessions, and performance evaluation. Recognized for their versatility in being adjustable to hospital needs for various levels of staff and for the competency-based approach, the instructional modules had won a national award for an education program for adult learners. They had been tested in use and in a number of hospitals and were in demand across the country for use in 
this critical area of training. However, in the general. context of the county hospital, the nursing division is responsible for inservice training. County approval was needed for inservice training programs for intensive care. Hence, the nursing division argued it must fit the county criteria and format. The inservice department of the Nursing Division had begun its own assessment of need and setting of objectives for training in neonatal intensive care. The Director of Inservice Training in line with a philosophy of staff participation, felt that it was necessary for the nurses to be involved in determining what is needed and how it is taught. In line with the increasing professionalization of nursing, her supervisor, the Director of Nursing agreed that this was important. Recognition of the independent role of nursing is at the heart of its educational and professional responsibility accruing to its own standards and methods. Whatever time pressures, priorities, memory slips, disagreements, and power plays intervened, the Chief of the NICU found that a plan was submitted to the County without his even having seen it.

The third hospital hired a special perinatal nursing instructor. She, too, was given individual assistance by Project staff in developing an education program. About the same time, other administrative personnel were changed and several reorganizations of their function caught the Project staff re-explaining the role they were attempting to play in 
relation to hospital need. While conclusions had been reached and agreements entered into by previous supervisors, the new group.. felt intruded upon by Project staff assistance. This special hired instructor was reassigned to outside tasks and eventually left.

\section{Standard Operating Procedures (SOP)}

Standard operating procedures are formally established policies and procedures. Informally, they constitute the actual methods by which a place operates and which are maintained by peer pressure.

Several examples of SOPs indicate the strength of their role when Regionalization efforts encounter them. One area in which it is easy to see how SOPs function is medical records flow and control.

When the new POPRAS forms were introduced by the Project, voted on by the doctors, and sent to the Board of one of the Regional hospitals, a Medical Records Director made known that her fuction was being by-passed: in her hospital all forms start with her review for compatibility with accreditation, legal, insurance, and other requirements before being recommended by her to the next committee in the forms review sequence. She encourages the doctors to bring their forms, but does not see it as her responsibility to and hence her work is made more difficult by the Project's lack of follow-through. 
At another hospital, the officially adopted procedure is for mothers to carry their prenatal forms to the hospital -a method that has proven successful in many public facilities. Important medical information is thus available to a "new" set of providers at this point. With proper coaching, most women brought their forms. In the course of one year, however, the percentage of women with forms dropped from $85 \%$ to 25: -- apparently because of lack of enforcement at various junctures. Even the outpatient clinics on the same floor as the delivery area did not insure that records reached the staff in Labor and Delivery. Besides missing information, it meant that all basic labwork (such as blood type) had to be redone. This meant duplicate work, time, and money. Except for extreme emergencies, this amount of extra work in the lab meant that results were not available until discharge, sometimes holding up discharge by a day, and took more nursing time to track down and record. In tracking this problem of record management, it was discovered that since the protocol was written several years earlier, many of the directives were outdated. In itself, that was no practical problem: oral tradition and ad hoc change prevail with written protocol serving to document policy in case of controversy between groups. The failure was one of informal procedures by which tasks were dropped.

Another forms problem relates to their storage and delivery. Due to bulk they are warehoused six miles away and 
are delivered by a person with multiple responsibilities. Since problems had arisen when forms were needed but could not be delivered immediately, two clerks in different units informally arranged to maintain duplicate supplies for each other. However, problems arose when each counted on the other to have a supply whereas neither did on the eve of a major holiday weekend. This informal procedure, unknown to Project staff, also confused its estimate of use based on requests for forms.

The multiple functions of the form make it the occasional target of intense criticism and threats to return to the old, simple ones. The old form consisted of a few items plus spaces to write copious, illegible notes. The new POPRAS form, basically a check-off list, serves as a vehicle of communication between different staff serving the same patient a method of risk assessment and folllow-up, the official medical record, the discharge summary of normal deliveries for Medi-Caid billing, the data processing instrument for reporting and research. On the one hand, the more purposes it serves, the more forms it can replace. On the other hand, the more complex it becomes, the more standard operating procedures are affected.

Another SOP record problem is that while obstetric and pediatric services in hospitals, doctors' offices, and clinics throughout the Region can effectively communicate on individual patients and regional trends, problems, and successes, 
individual organizations no longer have a standard record for all departments within their facilities. In another way, i.t raised issues by consolidating nursing and physician forms. While protocols at each hospital may differ regarding who is ultimately responsible for a given section, there is sufficient leeway to use it as a battlesite between physician, nursing, and clerical areas. Not only professional/legal issues, but time and status come into play. Despite all this, the general response from all corners several years after the introduction of the forms is that "they were hard getting used to, but not I see how they help so I don't mind them." SOP's form the rules played by until some power moves can change the rules of the game. A conflict among several SOP's occured in the Regional Center's Pediatric ICU regarding staffing patterns. The Unit's Medical Director used national professional standards to determine the desired staffing pattern for the NICU. These standards specify the number of RN and LVN hours per intensive and intermediate care patient. The Director of Nursing, however, insisted that the Unit be staffed according to County standards, which did not differentiate between the hours per patient spent by RNs and LVNs or by aides. In addition, the County standards stipulated a lower number of nursing hours per patient overall and diluted the actual RN hours per ICU baby since these nurses actually covered both IC and intermediate care infants. Both practices, however, were in accordance with state standards 
because the state did not specify the type of staff required. SOP's as game rules are evident in another example concerning the Project's proposal to buy a computer for its data processing needs. While money was allocated in the Project budget for the item:and the School's administration had authorized a consulting agreement for specialists to assist in the difficult selection process, another set of SOP's came into play to thwart the process. After months of negotiations with the computer company selected in the bid process, after top company officials had flown in to oversee the final details, after a special lawyer had been consulted on the final package, and after.all were satisfied, the School's new purchasing manager -- on the day the contract was to be signed -- delayed the signing for 24 hours and then cancelled the arrangement on the grounds that his newly initiated procedures required his personal consideration of the specifications and bids. The entire matter was dropped when some months later the School began to consider a School purchase of a computer. Earlier suggestions from various departments had generated no interest in the matter. As Project time was running out and the need for a transition to a fee-for-service operation was eminent, the Project requested purchase, from its budget, of the necessary peripheral equipment to hook into any computer likely to be purchased and in the interim capable of linking to the existing mainframe off-campus. Again, the day the request for 
bids was to be released, the specifications, which were determined by specialists in the field, were challenged by another purchasing supervisor. He handed the request for bid over to the School's fairly new data system director. This person had already been consulted and had approved the bids, but now, on having an opportunity to reconsider, held the bids while he planned for his large scale system. Eventually, he chose a system incompabible with any other company's peripherals. He promised to order appropriate equipment -- but there were numerous other priorities to be dealt with. These events had taken place over three years.

Six months before the Project was to end its grant support, the new Vice President of the School, overseeing the development of the School's data system, asked what all the pressure to obtain equipment for this Project was about. Six years of system development had occurred but operational continuity was in jeopardy due to the typical way in which SOP's slow necessary actions in the face of the priorities of other units.

\section{Messages}

Messages are the real transactions of the system. They operate not only on the literal level but as is now well recognized through tone and body language, in complex sequences. In the organizational structures with which we 
are dealing, communications between individuals are overlaid with organizational or systemic implications which impose their own weight upon the transaction. This can cause a form of confusion not specific to individuals so much as to the learned context and system of influences within which they carry on their daily activities. On the other hand, provacative images can emerge which trigger all sorts of additional chain reactions. Two areas of messages seem particularly significant in terms of regionalization. These are the messages regarding the role of nursing and the role of the Regional Center.

In the area of nursing, a certain anxiety arises because of differences in levels of training among nurses and mixed directives as to their role in the delivery of care, some of which stem from efforts nationally to professionalize nursing. To illustrate, the County hospital is geared to move patients through as quickly as possible. This is a necessity because the hospital is overloaded with demand and short of staff. Many of their nurses are graduates of a basic two year program in local junior colleges or in foreign training programs. The training programs, themselves, while covering general nursing practices, are geared to following the doctor's instructions; nonetheless, student nurses are introduced to the concept of becoming part of a medical team. Their independent professional status implies certain standards concerned with patient-oriented bedside 
care; nevertheless, there is precious little time for this type of care.

Nurse educators hired as Project staff to upgrade the level of Perinatal nursing throughout the Region specifically in the three hospitals, the clinics, and the doctors' offices, encountered considerable ambivalence on the part of nurses who were at once awed by the importance of their role as professionals yet frustrated and uncertain about how to effectively perform at a higher level within the existing system. Hence, Project nurse educators could never be certain to what extent their training was carried into practice within the various hospitals. It became apparent that in the classes taught by the educators, what was communicated was as much an attitude toward the role of nursing as it was specific techniques. Nurses whose basic training was to follow the doctor's orders often felt anxious when they were presented with the idea of confronting a doctor over procedures within the nursing profession that act as a check on doctors practicing in a hospital. An example of this is a case in which a doctor prescribes by telephone some medication or treatment to be administered by a nurse. There is a procedure for recording the time and details of this instructions and notifying a supervisor of this. When a doctor is notified by a nurse of critical symptoms shown by a patient under her care, it is a point of procedure to record 
that the information was properly conveyed to the doctor, the time, and his response. While doctors are not expected to always come at a moment's notice or to come in the middle of the night to tend a patient, neither do they have the option of denying the next day that they prescribed or refused to prescribe the necessary treatment. Also, when a doctor's order is clearly wrong and detrimental to the patient's welfare, the nurse has the obligation to inform her supervisor prior to taking any action. Implicit in the nurses' training in fetal monitoring techniques, levels of analgesics, sterile procedures when moving between patients, recognizing stages of labor and patterns of dysfunction is the message of responsibility as a professional.

A large area of confused messages lies in the fact that the Regional Center for perinatal care is the County Hospital/private Medical School complex. It is a tertiary level facility capable of handling patients of any risk status and is responsible for educating and coordinating the inter-institutional programs, regionally. Confusion here exists both within the Center itself and between the Center and the other hospitals in the Region. Within the Center, confusion revolves around the split between teaching and practical delivery of services. The doctors in the Project who are responsible for carrying through regionalization efforts are paid out of two different budgets, the County budget for doctors and the Medical Center budget for faculty. 
Their position is clear. This is not true of other Project staff. The Project is a consultant to the County hospital at the same time it is part of the Regional Center. The Director of Nursing at the County hospital is, by title, Regional Director of Nursing -- yet, Project nurse educators, are organizationally completely independent of her, assigned to fill an aspect of nursing. At the same time, while the Project is part of the School, it is not clear how Project staff fulfill the goals of the school.

An essential function of a Regional Center is to provide highly specialized services to highest risk patients. However, due to an extreme shortage of staff, it cannot act as a referral point for transfer patients. And, due to the fact that it is a County hospital, it is considered inappropriate for private patients who expect more personalized service and care. In addition, there is overlapping authority in the Regional public clinics between the Chief of the Department of Community Medicine and the Division Chief of Ambulatory Obstetrics and Gynecology. Both are in departments of the Medical School. Ob/Gyn is associated with Project staff and is responsible to oversee the services in the public prenatal clinics of the Region. These clinics deal with thousands of patients each year and make up the bulk: of patients in County clinics. Yet, when a conference was held on clinical services in the Region, the Director of Community Medicine in charge made no mention of the Ob/Gyn 
area.

One example which: illustrates the multiple levels of messages and their self-generating effects was the approach taken to private doctors' offices. Usually the initial risk assessment of prenatal patients is performed by nurses. In doctors' offices, there is rapid turnover of staff and whoever is available, even a clerical officer manager, may be in charge of a task handled as "routine filling out of forms." Basically, an approach to introduce the proper use of forms and the purpose of risk assessment, a workshop for office staff had many other effects. It provided these tools and skills with which to do a job they had felt frustrated by and inadequately prepared for and also supported busy doctors with more satisfied and better trained staff. It brought this neglected group of workers together and communicated the message that they were important. Several commented that they had never before received any kind of recognition. It generated further support in offices -encouraging doctors to send staff and demonstrating its personal usefulness to their practices.

\section{External Posture}

Any organization standing among others adopts a certain stance or strategic position vis-a-vis others in its field. In the case of the hospitals under discussion here, it is possible to look at them as entities relating to one another 
and to their environment. Their interrelations involve competition, cooperation, and adaptation. Each organization seeks its own piece of the medical pie by virtue of its particular mission, goals, and functions. The pie, itself, is seen somewhat differently by each organization and each perspective on the" "pie" in large part, determines what entitles one to a piece of it.

Project staff see the health care system as serving patients. In that respect, staff serve an auxiliary role in terms of facilitating operation of a regional system. For them, regionalization is mission, goals, and functions. The hospitals, on the other hand, see the "pie" as a service industry or sector in which they claim a unique place. In so doing, they must maintain themselves as members of the industry and make money in the process. The hospitals under discussion in this Region, in order to assure their unique position, must define and distinguish themselves in type or approach.

One hospital provides an industrial accident facility designated under State Workman's Compensation which brings a significant amount of money. Additionally, it is attempting to upgrade its emergency room as a trauma center. While the highest number of patients in the hospital are obstetric cases, this category of care is not profit-generating. The majority of cases do not require long-term care nor many auxiliary services such as pharmacy, surgery, anesthesiology, or lab 
work. Thus, primary energies within the hospital are directed to those other specialities which are profit-generating. The second hospital prides itself in building a community image. It promotes family-centered medicine and does fundraising in the community on this basis. The hospital has an established obstetric service and, in addition, a neonatal ICU. As with the first hospital, the obstetric unit is not a money maker, while the NICU unit is markedly profit-producing. The money-making areas are the places where administrators are willing to invest time and dollars in expectation of an economic return.

Even in the public hospital, economic return has a bearing as shown by the two main reasons why managers are unresponsive to the need for resource investment. They cite greater need in other areas, for example medical ICUs, which are sometimes closed for lack of personnel, and the drain on financial resources in the obstetrical department brought about by the social and economic circumstances of catchment area. To an extent larger than any other department in the hospital, its patients are not Medi-Caid eligible and for this reason the obstetric unit loses money. Each of these hospitals has many concerns and the generally low level of interest in obstetrical care produced an even lower level of interest in regionalization of such care in terms of overall hospital priorities. 
Environmental factors also affect the stance of the hospital in that they exist within the matrix of County funding. County public health decision-makers see obstetrical care, particularly for a large "alien" population, as not primarily their responsibility. They feel it is a federal policy issue and federal dollars, not those of local property taxes, should pay. Also, the state has mandated control of infectious disease and public sanitation as the responsibility of County public health. Within the health department, then, priority is given to those. State MediCaid payments do not cover non-citizens, whether legal or undocumented residents, thus there is a concommitant unwillingness on the part of the county to pay the costs -- particularly since Proposition 13 and the general cut-back of funds affecting other such well-supported services as fire and police.

Providers, the doctors themselves, exist as independent organizations and as such they are of course, more directly concerned with developing a profitable business. Due to the relative shortages of obstetric and pediatric practitioners in the area, they are heavily in demand. obstetrics is not a particularly lucrative field, and relative to other specializations, obstetrics demands more time and is less adaptable to scheduling. For this reason, many ob/Gyn specialists emphasize the Gyn side of their practice which is amenable to scheduling and income-producing in terms of 
surgical procedures. In view of these factors, the ideals of regionalization are seen as having more academic than practical interest. They see themselves as board-certified and not in need of Regional guidance. Like hospitals, they see Regionalization as more interference than assistance to them in their practice.

Understanding the role of the doctors in hospitals adds another dimension to competition. The primary consumer of hospital services is not the patient but the doctor who is a principle source of revenue to the hospitals. Doctors admit patients into hospitals. It is generally the doctor's decision as to which hospitals his patients use. Thus, hospitals -- profit and non-profit -- actively compete for doctors and for the business they bring with them. The inducements offered to doctors may range from profit-sharing plans, low rent office space, posh setting, to modern equipment and quality staffing. Non-profit hospitals tend more to offer high level staff and equipment as opposed to the share of profits offered by proprietary hospitals.

One hospital which is a private hospital with profitsharing, decided to upgrade their facility in terms of staff and equipment to be attractive to physicians and so that they could handle patients with more serious problems. These problems, often requiring . cesearean section deliveries and resulting in ICU babies, bring greater income and hold the potential for making obstetrics not only self-supporting, but 
profit-generating.

A second hospital, religiously affiliated and nonprofit, already has an NICU and a well-trained staff desirable to doctors. It finds, however, that they are receiving more of the doctors' Medi-Caid rather than the insured patients. Expecting their non-profit religious status to be charity oriented is frustrating to managers.

Both of these hospitals operate in the private sector, hence there is competition between them for the patient dollar. The second hospital currently handles $50 \%$ more patients. The first hospital is under-utilized and therefore, not as cost efficient. Although it is a new hospital and thus, desirable from the patient's standpoint, its managers fear the second hospital is trying to take over.

A clear example of the stance of the public sector vis-a-vis others in the health field is seen in the ordering of forms. For five years the Project had delivered, ordered, and provided free a standard set of forms for use by all perinatal providers. These forms had been designated the official county forms. As the grant-funded Project was phasing down, the County agreed to take over the ordering and distribution of forms for the public sector. The Project assisted with this process and coordinated the ordering of forms for the private sector to be paid for separately at the same time. A hold was placed on the entire order and an investigation launched regarding the propriety of "County 
forms" being used by anyone else. In fact charges were made that some kind of fraud had taken place since bulk ordering from the same printer benefitted the private sector as well as the county. The attitude was well expressed by line workers in the County now responsible for their own storage and distribution of forms: "Some civilian got his hands into County business and really screwed things up. Now we have all this mess on our hands."

Competition between hospitals is a key factor in hampering efforts to build regional cooperation, yet certain adaptations have evolved to bring the institutions together. One of these was brought about by the doctors, another by the Project.

A requirement of hospital accreditation is that their doctors attend a percentage of departmental meetings. Since a majority of the doctors working in the private sector belong to the staff of both hospitals, they were expected to attend a monthly ob/gyn department meeting at each hospital, plus a regional meeting. Under the pressure of three meetings per month, the doctors decided to adapt them to their own convenience by making each meeting serve the dual purpose of covering departmental matters and regional ones. They cut the number of meetings to one per month and rotated them between the three hospitals. While some managers feel that each hospital's specific departmental needs are: not given adequate attention in the hour and a half meeting, still the 
plan has potential as a mechanism by which regional purposes can be served. The pragmatic and the far-reaching have met at the juncture.

Another problem that was resolved on a regional basis was that encountered by individual hospitals in billing MediCaid for services. Since normal deliveries are not scheduled procedures, the emergency form which includes a discharge summary, had to be completed. This usually required a dictation and transcription time, although it was a routine matter. Efforts by the Project on their behalf made it possible to substitute one page of the POPRAS form for this entire task -- thus simplifying and standardizing a process, eliminating paperwork, and demonstrating the usefulness of Regional cooperation.

In another area, as well, Regional cohesiveness offered advantages. The National Health Planning and Resourse Devel-

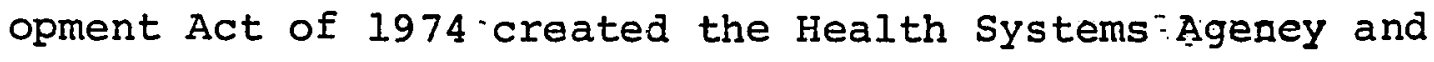
gave it regional jurisdiction for planning and monitoring ("region" in this case refers to SMSA's -- standard metropolitan statistical areas). A Memorandum of Agreement between the HSA and the Perinatal Regionalization Project (the entire group of participants) gave recognition to the interests of regionalization and established their prerogative in providing technical assistance, advice, review, and comment in the area of plan development, implementation, and standards. This was significant since a major area of 
planning and development for health care is concerned with obstetric and pediatric programs. This memorandum recognized the legitimate interest of the Perinatal Regionalization Project. In this way, the self-regulating efforts of the entire Regional group were given precedence over an agency whose function was perceived by some as federal interference. Thus, while the traditional stance of institutions within the Region is one of competition or avoidance, there exists potential for specific areas of cooperation.

\section{Boundary Spanners}

Boundary spanners is the name used to describe those who can link their organization (or section of $i t$ ) to others in some way. The vision and desire to do so is usually implied in the statement.

A look at several people who grasped the value of regionalization and interfaced well with Project staff both to make changes in their own area and to contribute to the development of regionalization point up the excitement and hope generated by the Project as well as the difficulty of actually affecting change.

Recall the example where the new perinatal nurse director had gained support from the physicians for upgrading nursing. Assigned to upgrade the services, she had worked with Project staff assistance to integrate the two separate areas of obstetrics and nursery into one perinatal 
service. The object of integration was to develop standards, train staff, and delineate improved policies and procedures. The effect would further professionalize the nursing role emphasizing patient care and upgrade the level of risk which could be handled by the unit.

The doctors supported her during a seige of efficiency experts brought in by the administration who insisted that the essential tasks of patient care didn't require all the nurses' time and therefore set them to rolling bandages and making cotton balls for another department. Management too wanted to upgrade the hospital, bringing it from a level one to a level two hospital in the Region, but wanted to use fewer nurses when additional nurses were required. Doctors wanted nurses better trained, but weren't willing to support the training period required. Rebuffed by administration and physicians, no longer effective in managing her area, she left.

Sometime later, a nurse educator was hired at the hospital. She worked enthusiastically with Project staff to provide in-service instruction to raise the level of care in the unit. She developed objectives, adapted teaching materials and strategies for the hospital, and gained practice by team-teaching with those more experienced. Meanwhile, a rapid series of higher level reorganizations changed her reporting relationship and the scope of her functions, her priorities, and her supervisors' commitment to perinatal 
education. All had been oriented to the Regionalization Project and its approach. Various suggestions had been discussed with various levels of understanding and acceptance within the priority structure evident in the group. Blocked by lack of sufficient support, her role diluted from the gratifying innovative one she expected, she eventually left for a more challenging position.

At another hopsital, the head of one unit had consistently provided for her and her staff to attend the continuing education sessions offered by the Project. She found them very helpful in her work. Low on the totem pole, her isolation in her own department prevented the benefits from spreading or even from being coordinated with other units.

The Nursing Director of Obstetrical Services at another hospital is in a much more powerful position. She negotiated her in-service needs with the Hospital Director of Nursing and the In-service Director. Then she arranged directly with the Project staff for in-service assistance.

What is evident from the preceding examples in this section is that the weak organizational position of people with enough interest to make them links between their organization and the Regional Project counteracted the effect of their enthusiasm in this potential boundary spanning role. Perhaps in contrast, another unit head recognized as more of a power and who had shown only peripheral use for. the Project, eventually called upon the staff to present the 
program to her new administrators. It is not yet clear whether this entrenches her existing power to the new group by providing them with resources they seek, or whether it represents a slip from power.

The Project staff, itself, represents the most persistent boundary spanning group in the Region. They carry a consistent message from place to place and provide a forum, often through classes, whereby those from different hospitals recognize that the problems they have are not so unique and shameful and some common approaches may be helpful. The Project staff, itself, however, comes from the "Center" -and unclear mix of County private-medical school organization as discussed above. Even within the department, their place on the organization chart does not fall under the usual divisions and consequently, though working with a variety of staff, there remains a certain isolation and a unique relationship with the private sector. Certainly neither the School nor the County hospital understand their own roles regionally or vis-a-vis this group which simultaneously represents them and is outsider to them.

One of the most successful and long lasting in roads was made by a staff person who, upon leaving the Project at completion of her role, became a private consultant for one of the Regional hospitals and instituted organizational and systematic educational change. 
A powerful source for boundary spanning is the group of doctors who practice at both private hospitals. They, by virtue of their power on hospital committees, especially the obstetric committees, could effect a coordination of the complementary aspect of the two hospitals. For example, the Project advocates use the hospital with the neonatal ICU as the hospital of choice for mothers in premature labor. These infants generally require immediate intensive care. The use of the two hospitals, however, is more convenient in their current, uncoordinated status. The natural competition of the two enhance physicians' own position on any issue since what one hospital may advocate or resist, the other is likely to give in on.

An individual physician, however, has used his dual role as hospital neonatologist and education director to challege some of the practices of the obstetricians. Countering their dominant role in botr. hospitals' perinatal area and in the Region, he contracted with a nearby, but outside the Region, competitive program to review morbidity and mortality data and related hospital practices and to provide some continuing education lectures and discussions on pertinent topics.

.The role of interest, dedication, openness to new methods, and personal power and position are intertwined in many of the above examples. Alignment. with "troublemakers" or weak people in an organization, however attuned and 
interested, does not particularly "help the cause," On the other hand, one powerful enough to resist particular apprøaches but still supportive of basid goals can be an ally.

\section{SUMMARY: KEYS TO UNDERSTANDING}

Some of the problems arising from organizations' attempts to accomodate to changes are self-evident and inevitable -- problems of policy enforcement, clarity of procedures when they cross units of responsibility, interorganizational competition, timing priorities, on-going reorganization shuffles, management/employee relations. Some more subtle aspects of organization, however, are key to the necessary transitions. It is true that:

*"Turfs" are maintained against threat of take over, invasions, trespass, infringement -- by ignoring new demands, cutting back on activities to show the new is too time consuming, finding ways to circumvent new demands, accomodation based on the lowest common denominator

*Interorganizational coordination requires timing -each institution attends to its own concerns based on mechanisms of internal priorities, demands of the crises of the moment, the primacy of habit, the tried and tested SOPs

*Messages are conveyed through policy directives and interpreted through the grapevine 
*That the stance of an organization toward others is part of its well-protected identity and independence

* Some people have the interest to span the usual boundaries separating those of like interests in another organization

It is also true that successes and frustrations are found in the cracks of these truisms. Accomplishment is found not so much in the merits of the plan, its overt acceptance or even organizational feasibility (objective capacity to incorporate it) but in

*the creation of activities which trigger other advantages having little direct connection with the main concern

*crossing levels of system interrelationship -economic, status, satisfaction, ease as well as work output

*breaking through traditional polarities so that a new option is conceived as desirable

*producing strong alignments of interests on given issues

*the coalescance of pride, expectation, and realistic goals within the gaming framework

Just as there are formal and informal aspects to the organizational network of purposes and functioning, so too the 
change, especially in emergent systems, has internal and external dimensions -- both of which affect results. Besides teaching, consulting, planning, data processing, staff as change agents persisted, modelled roles, made connections between activities and results and between stages of the patient care process, personally supported ideas and groups, fostered the Regional concept. Internally, longlasting transitions are made when the group itself begins to grasp the personal benefit of the ideas, when their own insights and capabilities and goals are stimulated, when some proposed activity is instrumental " in accomplishing another type of ambition, when the whole can be "owned" because it aligns with recognized and felt capabilities and directions. Table XIX summarizes the interpretation of these findings. 
TABLE XIX

ORGANIZATIONAL PERSPFCTIVE: KEYS TO UNDERSTANDING

\begin{tabular}{|c|c|c|c|c|c|c|}
\hline & 1 & & $\begin{array}{c}\text { MEANS OF DI } \\
\text { EXTERNAL }\end{array}$ & $\begin{array}{l}\text { PELOPMENT } \\
\text { INTI:RNAL }\end{array}$ & CONSTRAINT/DANGER & POTENTIAL/OPPOKTUNIIYY \\
\hline TRUFS & hreas & $\begin{array}{l}\text { Layout of social } \\
\text { systein, power } \\
\text { system, reward and } \\
\text { punishment }\end{array}$ & $\begin{array}{l}\text { Postures in } \\
\text { territories }\end{array}$ & $\begin{array}{l}\text { hccess via connec- } \\
\text { tions or dual } \\
\text { turfs or recogni- } \\
\text { tion or multiple } \\
\text { levels }\end{array}$ & $\begin{array}{l}\text { Subversion of creativity } \\
\text { by survival mechanisms } \\
\text { LCD-- lowest common } \\
\text { denominator }\end{array}$ & $\begin{array}{l}\text { Creation of non-zero } \\
\text { sum games, connection } \\
\text { of pride and group } \\
\text { expectancy, and } \\
\text { realistic goals }\end{array}$ \\
\hline $\begin{array}{l}\text { S'TANDARD } \\
\text { OPERATING } \\
\text { PROCEDURES } \\
\text { (SOP's) }\end{array}$ & Hethods & $\begin{array}{l}\text { Internal rules of } \\
\text { the system }\end{array}$ & $\begin{array}{l}\text { Authority and } \\
\text { reinforcement }\end{array}$ & $\begin{array}{l}\text { practical, personal } \\
\text { penefit to } \\
\text { pufficient extent }\end{array}$ & $\begin{array}{l}\text { Subversion of positive } \\
\text { change by crisis SOPs, } \\
\text { habit as mainframe, } \\
\text { limited expectation by } \\
\text { the tried and true, } \\
\text { legitimated exercises }\end{array}$ & $\begin{array}{l}\text { Can humanize the means } \\
\text { by which tasks are } \\
\text { done as well as } \\
\text { accomplish them; forms } \\
\text { of organization as } \\
\text { mutually beneficial: } \\
\text { make life easier }\end{array}$ \\
\hline MESSAGES & Transactions & $\begin{array}{l}\text { Communication } \\
\text { patterns }\end{array}$ & $\begin{array}{l}\text { Marketing image; } \\
\text { self-evident } \\
\text { context }\end{array}$ & $\begin{array}{l}\text { Medium is the } \\
\text { message } \\
\text { pelf-cenerating } \\
\text { Jink } \\
\text { Internal context }\end{array}$ & $\begin{array}{l}\text { Can never say just } 1 \\
\text { thing so can result in } \\
\text { double bind of } 2 \text { levels } \\
\text { which leaves one helpless } \\
\text { and immobile }\end{array}$ & $\begin{array}{l}\text { Can create an image } \\
\text { which is provocative } \\
\text { and charismatic: } \\
\text { creates its own need } \\
\text { and motivation wnicn } \\
\text { once triggered is self } \\
\text { generating and expand- } \\
\text { ing; small change has } \\
\text { great potential }\end{array}$ \\
\hline $\begin{array}{l}\text { INTERNAL } \\
\text { POSTURE }\end{array}$ & istance & $\begin{array}{l}\text { Strategic position } \\
\text { in relation to } \\
\text { others, to } \\
\text { environment, i.e. } \\
\text { cooperation, } \\
\text { competition, } \\
\text { adaptation }\end{array}$ & Persistence & $\begin{array}{l}\text { Wwitch system leved } \\
\text { ht juncture }\end{array}$ & $\begin{array}{l}\text { Status quo stalemate- } \\
\text { see other organizations } \\
\text { stereotypically }\end{array}$ & $\begin{array}{l}\text { Beyond opposites; } \\
\text { conflict or } \\
\text { cooperation, free } \\
\text { enterprise or } \\
\text { socialized medicine }\end{array}$ \\
\hline $\begin{array}{l}\text { BOUNDARY } \\
\text { SPANNING }\end{array}$ & Connections & $\begin{array}{l}\text { People who are } \\
\text { links between } \\
\text { organizations } \\
\text { creating } \\
\text { cooperative } \\
\text { ventures }\end{array}$ & $\begin{array}{l}\text { Position of } \\
\text { spanner }\end{array}$ & $\begin{array}{l}\text { Enterest of } \\
\text { ppanner }\end{array}$ & $\begin{array}{l}\text { Alignment with wrong one- } \\
\text { a trouble-maker--car. lead } \\
\text { to deteriorating } \\
\text { relations; with too } \\
\text { powerful seen as threat } \\
\text { of expansionism; with too } \\
\text { weak seen as sign of lack } \\
\text { of understanding of the } \\
\text { system } \\
\text { Or was designed to kill } \\
\text { the connection }\end{array}$ & $\begin{array}{l}\text { Can produce changed } \\
\text { alignments between } \\
\text { organizations: } \\
\text { conditions, network } \\
\text { of growing interests } \\
\text { for the organization }\end{array}$ \\
\hline
\end{tabular}




\section{CHAPTER VII}

\section{ONE PERSPECTIVE ON REGIONALIZATION: THE MILIEU OF PERSONAL IMAGES AND INSIGHTS \\ IN THREE STORIES}

The age-old story-telling tradition hands down a way of communicating human insights -- whether through tall tales, myths, drama, short stories, whatever. The fictional form is simply a medium for a point of view at once highly personal and deeply common -- evolving recognition of the human dimension shaping facts and experiences. The writer is aware of many of the influences and certainly of the data contributing to these images. Some of these will be considered briefly in the commentary. For now, it is important to read each of the following three "stories" in its own terms. The first is a little scene, a portrait piece. The second is a choral piece, an aural drama. The third is a dram-like venture in the existentialist style. Each seeks to present some of the nuances to the question, how do you see regionalization fitting into your ways.

\section{STORY 1, A PORTRAIT: THE DOCTOR IS IN}

i

It was almost 12:30 when I arrived at the doctor's 
office and introduced myself to the receptionist. I had called earlier to ask the best time to come on business, explaining that I was one of several people working in a regionalization project. We were interested in learning how theproject's objectives were being perceived -- how might doctors such as this one, who is established and influential, "hook into it." How might we be of service to him? -- make our project more effective in coordinating available resources.

From her window, the recpetionist waved me toward a small waiting room across the hall. I sat down near the door. The waiting room was plain, rose and beige plastic covered the furnutire. There were a few well thumbed magazines on a small table to one side. Sitting in the room were several women with children. I wondered about my timing. It didn't seem right for me to be here with all these patients waiting. Across the hall I could hear the doctor's voice. "Who? From where? "No. I don't want to be bothered. Get rid of her." There it was, I thought, the answer to my question; still I waited, curious to know how I would be handled.

While I continued to wait, the receptjonist came to the door to call one patient after another. Not once did she look my way. After nearly an hour, I got up and approached her window. "When will the doctor be able to see me?" I asked. "Maybe I could return after office hours." 
She flushed. "The doctor is very busy."

"Yes, I can see that he is."

"Today isn't a good day. Especially right in the middle of everything."

"I see. I'm sorry. I was told that this would be a good time to come. But, things go that way sometimes. May I make an appointment for a better time?"

"All right," she said, hesitantly. "But you can't see him tomorrow. Wednesday's his day off you know. Could you come on Thursday?" I nodded assent. "Office hours begin at 11:00 so come before then."

"I'Il be here by 10:00," I assured her, and asked her name. I thanked her for her help, and left the office, aware that I was learning the hard way what medical salespeople learn fast in getting in to see a doctor on business. Come an hour ahead of time.

\section{ii}

On Thursday I arrived at 10:00. The doors were locked, but inside the office was bustling. I rang the bell. The receptionist recognized me and let me in. I sat in the same chair near the door of the dim waiting room. After about thirty minutes a woman arrived with a small child in tow. They settled on the other side of the room. The little girl gingerly sat at a child's chair and table. The receptionist followed them in and turned on another bank of lights. The day of patients had officially begun. Soon a 
second woman arrived, and then another. They spoke as if they had run into one another before. The first woman picked up one of the two magazines and leafed through it watching her child abstractedly, her mind on the door. Soon a patient was called. Then a second. I began to worry but reasoned they would be waiting in the examination room for some time, and so I continued to wait. More patients arrived, in one's and two's. The waiting room was filling quickly with women. Some with patient faces, others harrassed or anxious. Some with children. One child was flushed and sleepy. Another began immediately to crawl under the table, like an earth moving machine. His mother smiled apologetically at the women across from her who stared past the child. Suddenly I was aware of the doctor coming down the hall from his office. He was strolling casually toward the outer door with a man in a three piece suit. My attentive ears picked out bits of their conversation. Gold. One of them is taking a trip. They joked easily with one another. The man exited. The receptionist called the doctor into her office. Again I could hear some muffled conversation. "No! I told you earlier. I'm too busy. I don't have time for that stuff." I continued to wait. Another patient was called. A tired looking woman followed the nurse to the examination room. The first patient was out now, ready to leave. I waited behind her at the receptionist's window. "Oh, you're still here," said the receptionist. 
"Will the doctor see me today?" I ask.

She didn't look at me. "I'm sorry. The lawyer took up all his time today. He had some important business to discuss."

I persevered, "Could I reschedule for tomorrow?"

She glanced back over her shoulder to an older woman in the office who shrugged and nodded. I smiled at her, feeling I was catching on to the game. "Are you Mrs. Brown? I spoke with you on the telephone, didn't I?" She rose and came to the window. We exchanged pleasantries and exclaimed over busy days. I left with another appointment for the following day.

\section{iii}

Once more I arrived at 10:00 and took up my post near the door of the waiting room. It was 50 minutes later, almost time for office hours to begin, when I was finally ushered to the doctor's inner office. As I entered I saw him seated behind an ornate desk, flanked by large windows. Opposite him against the interior wall a bank of aquariums bubbled. and gave off a soft light. In one corner the statue of a nymph spilled water from a perpetual urn into a small stone basin. The doctor was on the telephone. I could not escape hearing some of his conversation. He was evidently talking to his broker. "Shall I sell now, or next week?" he asked. "What effect is that going to have on my taxes?" 
Finally he hung up and looked my way. Rising, he leaned forward to shake hands. I introduced myself and explained that I had come to hear his views on regionalization of health care, since his views in this area were very important.

He prefaced his answer by explaining that he was a long-time friend and associate of the physician who headed the project. They had traveled together to many conferences. He told me the head of the regionalization project was a man for whom he had great respect, who had shown his strength of leadership on many issues, and was recognized throughout the country.

"How do you see regionalization yourself?" I asked.

"Well, it increases the quality of care while decreasing the overall costs and eliminating duplication of services. Who can be against it? Why in this area..." he stopped mid-sentence and buzzed the outer office.

The nurse entered. "I can't see through these," he said, handing her his glasses.

She pulled a tissue from the box on his desk and wiped the lenses while he continued, "I hope you understand why I couldn't see you the other day. There was the business with my lawyer -- and besides the girls didn't tell me you were waiting. I'm very busy, you know." The nurse handed back his glasses. He took them, held them at a distance for a moment, then put them on and waved her away. Rising he 
leaned over the desk and looked directly into my eyes over the rim of his glasses.

"You know," he said, "regionalization will work, when we doctors want it to. We've got the power to make it go. Maybe the time is coming."

\section{STORY 2, A CHORUS: VOICES OF THE PEOPLE}

\section{Introduction}

Apart from the formal interviews with hospital staff -the ways in which people present themselves and their situation for the record, there is an undercurrent of attitudes and feelings that comes out only informally -- in the commonplace of everyday talk. As one moves, works, becomes familiar with the Region, the community, the people, a sense of place emerges that cannot be expressed in any better way than through the voices of people.

These are presented in a dramatic form that seemed appropriate to the situation. Imagine a stage -- theater in the round. There is a chorus representing the most commonly expressed views of the Community Speakers - Nurses, Doctors, Staff, Patients -- all these voices in their own words. The speakers are Black unless otherwise indicated.

\section{The Chorus}

CHORUS: Blacks are aifferent. We have special medical needs. Take sickle cell for example, or hypertension. 
We have our own way of doing things. White folk don't understand.

What we need is sensitive health care. What we need is people who understand.

SPEKAER: A while back there was a private university, (White and generally conservative) tried coming in here to set up a program. Black doctors here didn't trust them. They protested and tried to keep them out.

SPEAKER: At the dedication of a health center here, every politician in town showed up to give a speech. We'd never seen any of them here before, but they all wanted credit.

GROUP: Now the politicians say, let them do it themselves. GROUP: The politicians can wash their hands of it.

SPEAKER: We got our hospital.

CHORUS: Out of the ashes of the Riots, this place was built. It's a symbol of committment to the Black community.

SPEAKER: When the bond failed one politician supported us. He got the initial funding. Now they call it his "plantation." His reputation's at stake so he keeps a tight rein 
on the place.

CHORUS: Politics, Politics, Politics

MANSPEAKER: Now its fiscal politics.

WOMAN SPEAKER: Infantile politics

GROUP: Now dollars come first, not health needs. Even

Black administrators play the game. They try to prove to the Man downtown that Blacks can manage. Prove that we can take care of ourselves.

GROUP: The politicians can wash their hands of it.

CHORUS: Out of the ashes of the Riots this place was built. It's a symbol of hope, of committment to the Black community.

SPEAKER: This center is built on race not competence. SPEAKER: It's designed to fail. THREE GROUPS IN UNISON: The doctors' offices here are not better than the County.

WOMAN: They're crowded day in and day out. MAN: You wait for hours. GROUP: And Medi-Caid pays for it just the same. SPEAKER: This is the only hospital in the County where patients have to pay for the building in just 10 years. SHORUS: The politicians say let them do it themselves -- the politicians can wash their hands. 
SPEAKER: But Blacks don't trust each other. SPEAKER: Blacks don't want to go to Black doctors. They don't think they're as good.

GROUP: It's the old brainwashing. Unless you're number one, you're no good at all and when something bad happens, people say "I knew it all the time."

SPEAKER: A lot of older Blacks won't go to Black doctors. SPEAKER: That's changing now. SPEAKER: Well, for some people, the young ones, maybe.

CHORUS: Martin Luther King was the only one that ever pulled Blacks together.

BLACK DOCTOR: There aren't any partnerships among Black doctors here. They're too basically suspiscious. BLACK DOCTOR: Black professionals discriminate against those Blacks who come from prestigious White schools. Most of the doctors here graduated from two Black medical schools.

SPEAKER: People raised in this community have to go somewhere else for an education. In order to become a doctor, you have to give up your Blackness. SPEAKER: When a Black leaves for training, he never comes back to the community he left. He goes away to gain skills. 
but his attitudes and values change too. More than he could have imagined. He doesn't fit in anymore.

SPEAKER: He's not the same old guy.

SPEAKER: But you can't fight ignorance with ignorance. For those with the motivation, there's no choice. You have to get out.

SPEAKER: And you end up different.

SPEAKER: You can't cover it up later with beads and dashikis. SPEAKER: If you're going to be a professional, you better look like one.

FACULTY: I'm proud to say many of our residents are now serving right here in the community.

WHITE SPEAKER: Some years ago there was a racial problem, but due to the changing character of the area, it's not a problem any longer -- it's not White flight. Whites just don't like to be treated by Black doctors.

SPEAKER: Blacks have a hard time relating to Blacks in an authority position. You're always underestimated. You always have to be over qualified. So there's a lack of respect for superiors and more insubordination.

BLACK DOCTOR: There used to be more problems with the administration because the administration is White -- it's a 
difference in orientation. Not a conscious desire to obstruct.

CHORUS: Maybe we are a little paranoid, but we've learned you have to be.

SPEAKER: There's a terrific race consciousness here. Some people don't understand that.

CHORUS: Our community fought hard to build this hospital. Out of the ashes of the riots. It's a symbol of hope to us. A commitment to the Black community. GROUP: But the hospital isn't serving the population for which it was built.

VOICE: And for which Medi-Caid would pay costs.

NURSE: Most of the Spanish-speaking are self-payers. That is, they have no insurance. Not even Medi-Caid... that means $\ldots$

CHORUS: They don't pay. They're crowding us out.

SCENE: Latino couple in the billing office. Man: But $\$ 837$ for 3 visits? The nurse at the clinic said to come to this hospital if there was bad pain and discharge when the clinic was closed.

Billing Officer: Yes. A vaginal infection it says here. Well there are the emergency room charges and 
they apparently sent you upstairs to the obstetrics ward and then there were all these tests ... blood type, ultrasound...

Woman: But I had all those tests at the clinic already .

Officer: But of course the hospital didn't know that. Now, if you'll just sign here, at least $\$ 10$ a month...

SPEAKER: You've got to understand. There's hostility toward Mexicans because in the Civil Rights days they didn't stick their necks out and join with us.

CHORUS: They should learn English. They're crowding us out.

NURSF: There's hostility to the Spanish on all levels -- to preserve one's own job.

SCENE: A recovery room. A group of nurses joke together loudly around a table. Someone enters. "May I speak with you? Then, noticing a patient at the end of the room, "Excuse me."

"Oh, don't worry about her. She can't understand English anyway."

SCENE: In a ward corridor. Many people, patients, and professionals coming and going. 
Doctor to Pregnant Woman: Go home. Vallase. You're not ready yet.

Woman in Hospital Robe: ¿Habla espanol? ¿Donde esta mi baby?

Pregnant Woman with Bottle of Medicine: ¿Habla espanol? ¿Que decis de medicina me tomo?

Man: ¿ Habla espanol? ¿Como esta mi esposa?

Doctor to First Pregnant Woman: It's too late. Es muy tarde. If you had been here I could have helped you.

Small Group, Mimicing: ¿Habla espanol? Why don't they learn to speak English?

CHORUS: This place was built for us.

WHITE DOCTOR: All this race stuff! It doesn't make any difference. Competence is what counts. Take that nurse for example she gets along fine...

She's worked here a long time. She really

knows her stuff.

WHITE SPEAKER: Besides, most of the nurses aren't Black. They're Asian now.

BLACK RN: She knows her stuff alright, but she's well, pushy. You know what I mean. She doesn't understand that 
you don't come walking in here as if there's nothing worthwhile going on and just take over. She's nice enough, but they talk about her.

BLACK RN: The Project is, practically speaking, just about all white, you know.

SPEAKER: The Center is just a stepping stone. Professionals come in here and do their research or get their practice, then go on to more prestigious places. SPEAKER: You've almost finished your paper, haven't you? When will you be leaving?

GROUP: You see everything here. It's a great place to get experience.

FACULTY: I'm proud to say that many of our interns are serving right here in the community. GROUP: Our docs can't go elsewhere. They resent the community. They resent being told they don't know something. Being told they need to update their knowledge.

YOUNG WOMAN IN CROWDED ELEVATOR: I know some people call this hospital a killer. But you can't tell me that... Do you know who I am? I'm the very first patient this hospital ever had -- and they saved my life. I was thirteen. Everyone thought I was a goner. I had been stabbed in the 
in the leg, and I hid it from my mother. I hid it for three days. When she found out, the infection had set in and it was almost too late. They brought me here to the hospital. I don't even remember coming in, I was so far gone I was out of it. But I'm here today, and I tell you truly it's because they saved my life.

CHORUS: Out of the ashes of the Riots. This place was built. Its a symbol of hope. A committment to the Black Community.

STORY 3, A STORY, AFTER KAFKA

i

I enter an unfamiliar room. It is crowded. A meeting is in progress. All the chairs face forward, toward the wall. I can't see anyone's face. The wall is dark. As I look, I see it is not a wall, but a partition obscuring my view of the space beyond. Only a dim light falls on the participants. I scan the corners of the room to see where the light comes from and notice equipment everywhere. A gurney stands in one corner. Next to it a rack covered by a sheet. The room is undergoing renovation. The walls have been painted with a grey under-coating. Arms, tubes, cords, a broken I-V apparatus hang from the ceiling or lean precariously from the walls.

In the center of the room the participants sit in 
straight rows. Some of the doctors and nurses present wear white uniforms. Others are dressed in green surgical garb with crinkled paper caps and boots. Seated among them are men in grey business suits. Everyone seems to be talking at once. They are animated, urgent sounding. I listen, trying to make out the sense of the discussion. They sound busy and purposeful, yet I sense confusion.

"The need...overwhelming...the babies... We've tried... I lean closer straining to hear. The walls absorb and deaded the sound. "It's serious...The problems are massive... We can only hope... But... But... There is massive need..." The voices rise, agitated, but muted to an incoherent drone. I strain. "The babies... How many deaths... Whose blood... They're dying... The babies are dying. We have to do the best we can... We can only hope... Do your best and trust... The problem... Support is only the bare bones... They have to understand... We have to trust. Somehow."

ii

I am walking down narrow halls. At the end I come to a door. The name on the door is Richard Bond, M.D. I enter. The office is dim. The only light comes from a lamp over the desk. It's metal shade reminds me of the light over a pool table. The room is small, like a dormitory with no windows. Around the desk, just beyond the pale of light, are stacks of papers, documents, and reports. They are shoulder high and 
poised for balance. The doctor is on the telephone with his back to me, feet on a smaller stack of documents. As I enter he swivels around and gestures for me to be seated. In front of the desk is a small round table with two metal and plastic chairs. These too are covered with documents. I clear off a chair and wait, observing the man behind the desk.

He is wearing a plaid shirt. He has the burly look of a frontiersman. The chesk exposed slightly above the buttons reveals curly, dark hair as do his arms below the sleeves he wears rolled to the elbow. He puts down the phone and looks at me. I know I look worried. I am troubled by what was said in the meeting. I want to help. This man should be able to take some action. Make something happen. So we can solve the problems. He furrows his brow in response to my look. "What about the meeting?" I ask. As I watch he assumes a larger than life pose. "Is there something I can do?" I continue. "Do you need some figures worked up?" With all the assurance of the Marlboro man, he shoots me a smile and pats the stack of reports closest to his desk. "I have it all right here."

"But what about getting the figures out? Presenting the the committees or..."

He rises and strides around the desk. I notice he is wearing cowboy boots. He is not as tall as I'd expected. "All the figures in the world won't do any good. Those people can't do anything, but... he turns suddenly, facing me 
with the stance of a gunfighter, "I have a plan." His thumbs hook in his pockets. He's waiting to draw. "I'm working on something."

\section{COMMENTARY}

What do these stories mean? A good story puts something before us to work with, respond to, engage in. To the extent these stories are "good," their meaning resides in that process in which the story meets the reader. Even in highly crafted stories, the fullness of what is caught and to be shared is not always conscious. It's what makes each storyteller at once unique and in touch with something identifiably real.

This storyteller, an amateur, would like to share some of the shaping of the stories, some reflections on them and some responses to them -- for the sake of this paper. As always, stories should speak for themselves -- or they don't converse at all.

Story-Shaping: Contextual Research

The portrait of the doctor in his office is a vivid image in my mind. If I were a painter, I could frame the pose and expression. The reason the picture is powerful is because I felt what I had heard about from others -- the presence of one in charge of an orderly world at his command. I felt it, in part, because as a woman I identified (I see now) with the other women in the waiting room, in the office, 
the nurse. I felt it because I was new to the scene and did not yet take for granted the way this little world operates (I didn't yet fit). The presence is not, however, uncaring, simply "other". The doctor is not "typical," but I recognized something of "doctor-ness" which is hard to put one's finger on in that situation. His office portrays his world. His world frames regionalization.

In the Chorus, the form here has several sources. The Greek chorus represents very classical, myth-laden drama. Black voices, for example, from the civil rights demonstrations, represent extremely powerful resonnances. They hold special meaning for me from a certain time in my life. The dramatic line develops and comes back on itself in reinterpretation of the theme in a way congruent to how I was taught about this particular community. Its members, my friends, co-workers, challengers -- to the extent they trusted me and I fit in fostered my understanding. It was a developmental process, one recognized as obviously incomplete to anyone on the inside. In fact I am leary of exposing myself and my understanding because I do not have a sense of the endpoint and how far I am from it. I sense being in and out to varying degrees. At the same time, these samelearnings exposed for me the different voices and the contradictions in the situation -- a tumultuous context laden with intense feelings shaping the path of regionalization. The third story portrays my sense of the situation at 
given time. In many ways it was a crisis year and the whole foundation of good care seemed to be slipping. There was an atmosphere so thick you could slice it. It seemed unrelenting. There was also a "crusader," sure that a least part of it could be made right if the message was conveyed, and singleiandedly set about it. Originally the title of this section was "After Waiting for Godot". There was also a third section in which the "plan" resulted in a grant which developed into a fortuitous pot of gold when the benefactor died and left a sizable will to assist with the problem. There was a feeling of waiting for some magical answer. But that did not convey the deeper sense of it which struck me as "Hope." I recognized the rightness of the suggestion that culturally "faith" was the better descriptor. Not blind faith, but that expectation based on long experience which is both full of effort and full of release. This tone dominated regionalization efforts. for a significant time at a critical juncture. Some of the underlying relationships and structures hold in lessor ways at other times.

\section{Some Responses}

Portrait: A doctor I don't know who read another's copy, "yeah, that's the way it is. She caught it."

A woman friend, "That's the problem I feel with my gynecologist. There's a certain attitude."

Another friend, intriguied with people and settings,

"Who is this person? Does he make a difference?" 
Chorus: A Black graduate student friend of a friend: "It fits what I know of the area and the place. I've heard some other stuff. That's why I'm here instead of there."

A friend, minority, formerly worked in the area, "You don't have the sense of the language right. What people say to each other and what is understood when repeated to 'outsiders' is quite different. You've got to be careful of context here. Your audience for this paper will not understand it the way your co-workers do. For example,' 'Blacks are different," your opener, can be taken as a condescension." Story: Friend, a counselor, student of Jung's works, who had had a long hospital stay, "Part $i$ feels very depressing. I know this place (figuratively). It's scarey, just like a County Hospital. It's anonymous, impersonal, not even efficient. Hospital mumble jumble. I'm alone. What meeting? We didn't even meet. It's an event but it didn't occur. It's incongruous -- Iike people tossed in. Patients, doctors, nurses, businessmen don't meet together. Staff is so overwhelmed by work. Still trying and working. There's a sense of futility, exhaustion, going to go on but a sense of desperation, inadequacy. Grinding it out. Random energy. No direction. Even staff is isolated. Shrouded in greyness. Building image around. Left handing. Still caring, some hope. Part ii, the Marlboro Man is just P.R., he doesn't exist, a great fantasy. He's too bogged down with paper so 'he's unable to take action.-- all those figures, yet he's 
ignoring them. He's too individualistic, the frontiers approach, he has a plan, has it all, but nothing's happening. Sounds disorganized. Can't accept help. He's not making use of any technology."

Friend of a friend, businessman, "In part ii the "I" is a dreamer whose dream is revealing that $s /$ he should trust her instincts and not trust the one coming on too sure of himself -- it's a front, he's not a doer."

Friend, "There's contrast in the two sections -abstract and concrete, group and individual, the stuck and the planner." 
CHAPTER VIII

THE DELPHI PROCESS

The dynamics of the Delphi process resulted in the recommendations presented in Chapter IX. Since the purpose of using this methods was to allow the regional participants themselves to actively shape the future of regionalization, the dynamics of process will be described by using the results of each round. A copy of the instrument is contained in Appendix 1.

The process took four months and involved 45 key participants crossing professions and institutions as shown in Table $\mathrm{xx}$. Since the system is built on a cooperative arrangement the focus was on private public sector relationships. The aim of the process was to design a plan for the future of regionalization which would suit the participants. The guiding questions were "Where do we want Perinatal Regionalizaton, in this area, to go from here?" and "How do we get there?"

\section{ROUND 1: DIRECTION OF REGIONALIZATION}

The initiai Round submitted a range of inter-organizational arrangements as scenarios to be viewed in the context of a 1985 setting. These were the Regional Consortium Model, 


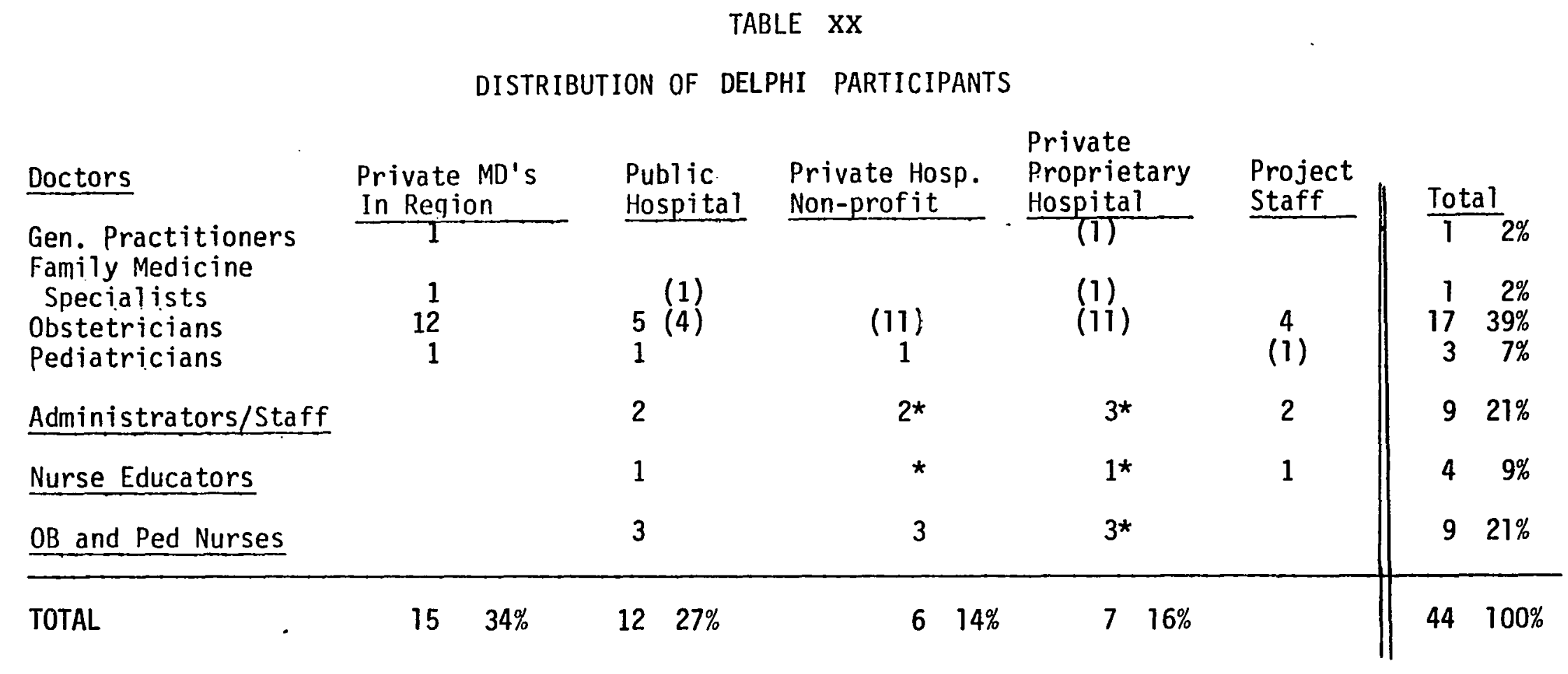

*Several positions were added, became vacated, or remained vacated in the course of the Delphi rounds. ( ) indicate where people could be counted in an additional category.

**Administration includes hopsital and nursing administration and relevart support services. Nurses inciude unit supervisors, perinatal coordinators, and Certified Nurse Midwives. 
Board of Directors Model, Pyramid Model, Free Enterprise at Work Model. Participants were to choose one and check the particular activities which they felt contributed to good regional organization and would work well for them.

The majority of participants chose scenario B: Board of Directors Model. The reasons cited were, it

- is workable

- has coordination without too much control; balance between public and private sectors

- encourages teams and participation from various disciplines and hospitals

- reflects the best interest for patient care in all settings

- good rational participation organization with authority

- a system for functioning

- regional council must have the right people -- not just M.D.'s and head nurses; administrators, both nursing and hospital, must be included

- team education should be based on patient problems --not just M.D. problem or N.N. problem. Need to encourage colleague relationship

- membership and election to council would have to be worked out

- various disciplines sit in the decision-making council 
- standardization of administrative forms, protocols, afford a commonality for consultation/communication

- leadership vested in a multidisciplinary body

- concerted effort implied to address regional problems by all facets of health care agencies

- analysis of problems possible from all levels, i.e. agencies, hospitals, and professions

The next most often chosen was scenario C: Pyramid Model. It was modified by a participant to emphasize more responsibility on the part of components and more input from them. The reasons for favoring $c$ include, it

- is comprehensive while diverse in patient care approaches

- maintains standards

- minimizes waste

- uses resources well

- diversity in approach along with uniform standards is important in the model

- appears to offer solution to perinatal problems without the effect of bureaucracy

- doesn't duplicate services and equipment-economical

- uses resources of tertiary center - educational and service

Some, however, gave reasons for their rejection of the model. Another offered a modification.

o too big brotherish. Will only work with at benevolent 
big brother

- incredibly authoritarian - no hospital/physician participation

- representation of each regional component is

$\circ$

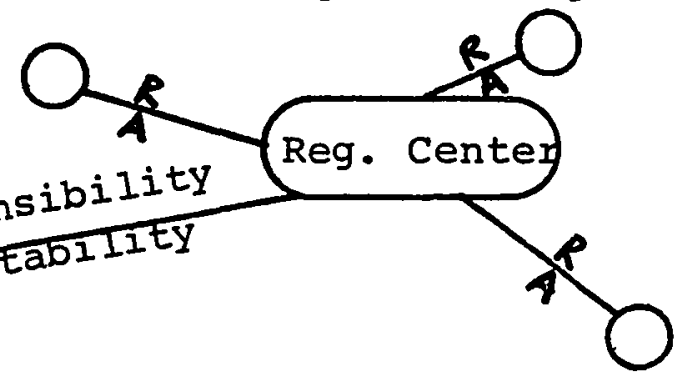

The Center must reflect the Region and the Region must reflect the Center -- then Regionalization has taken place

Several participants chose scenario A: Regional Consortium Model. It

- creates unity and mutual bonding by encouraging participation in decision making

- provides for exchange of ideas, thereby consistency in the Region

o is more applicable

- provides an avenue of effective triage Reasons for its rejections were stated as

o is worse than what we have not because team members in this model don't even mean well

- defies all concepts of regionalization and communication -- a step backwards

No one chose Scenario D: Free Enterprise at Work Model -- though some commented on it 
- voluntary aspect seems to prevent participation

- is chaotic--like now

o too dependent on politics and personalities and profits (thought well-meaning)

Most mechanisms in $A, B$, and $C$ appear to "contribute greatly" to regionalization to those who chose that model. Generally there was not a wide difference in responses to "mechanisms which would work very well for me." However, respondents who chose scenario D; pyramid model, most favored the activity, "The Center assesses needs and coordinates educational resources." There were no noticeable differences in the choice of models or rating of mechanisms either by institutions or professions.

Some measure of enthusiasm can be assessed by the number of people who did the optional task of commenting on their reasons for chosing a given model. Others went on to make modifications and additions.

\section{ROUND 2: IMPLICATIONS AND TASKS}

Two worksheets formed the basis of round 2 . In the first, participants were asked to reaffirm their choice of model or register a change of opinion based on the reasons given by others. An Alternate Pyramid Model was added, the model no one chose was deleted, and a black Other category replaced i.t. Based on this choice participants were to list (free form) positive and negative factors associated with 
the model itself. Implications affecting costs, benefits, distribution of power, quality of care, requisite changes, in procedures and practice, ethical, legal, economic, individual considerations were suggested as possible topics to specify. In addition they were to list the necessary tasks to make the type of organization functional and to consider who should be responsible for direction for implementation, what resources were necessary and which were available. The second worksheet repeated the exercise, focusing on olse activity chosen on the basis of projected impact.

Again, the vast majority (72\%) chose the Board of Directors Model. The loose Regional Consrotium Model was chosen by $8 \%$ and the Pyramid Model by $20 \%$-- a few more than in round one. All who chose it, chose it in its alternative version. There was no clear difference based on institution or profession. The responses of the County hospital were most diverse -- perhaps size itself being a major factor. The specific programmatic activities most often chosen were "the sharing and exchanging of institutional resrouces," and "Council activites are goal oriented and measurable." Education and referral programs, and the continued participation of doctors were rated next highest. Many of the noted implications indicated basic differences of opinion and variations in emphasis. Since a significant minority (28\%) were holding strongly to other models, the list of implications was used to form a list of issues to test the extent of agreement on 
underlying factors. These factors would perhaps reveal more agreement or disagreement than the choice of model. To further test the extent of resistence to the tasks implied by the models, participants were asked to register the extent of support or opposition or whether they could "go along with it" if it's what the majority favored.

\section{ROUND 3: SUPPORT AND DECISION}

The above topics formed the basis for round three. In addition, participants were asked to take a personal stand on what they would be willing to do if a given model were chosen. A modified semantic differential asked for overall reactions to the process. An optional section provided observations by different types of process observers to stimulate further reflection on the group process itself. The results of this round form the conclusions reached by the Delphi and are listed in Chapter IX. The process can be commented on as thefollowing observations:

- $100 \%$ of responsents were willing to participate in some way in some future organization

- $70 \%$ rated the whole process as "Important" versus $.03 \%$ checking "Mickey Mouse". (The remaining $29.07 \%$ did not answer or rated it in the middle category.)

- There seemed to be a basic acceptance of other types of participants as working partners in the process. Some commented that broad representation aids 
acceptance. This has implications for the types of representatives, number of the, and the issue of "real interest." Some believe that vote but not action weakens what can be accomplished through the demonstrated results of those who plunge ahead - There was some indication that work effort was displaced. Doctors supported the assigned responsibilities of institutions more strongly than did their administrators. Most felt the Regional Center should be responsible for keeping the whole system running smoothly and maximizing participation. However, coordination by the Center, as an indicator of some level of authority, yielded the greatest diversity of responses from every sector. Some comments on resources assumed that the Center would continue to have and to provide certain resources even though that issue of continuity was part of the initial question -- what happens after the grant.

\section{AFTER THE DELPHI}

Some degree of momentum was achieved during the process itself. A number of factors, however, put the results in limbo including the energy absorbed by some of the major crises referred to in other chapters, the lost timing by a couple of late returns which were critical, and the decision to wait with proposing subsequent specific activities until 
the Project's Principal Investigator returned from a year away. A concentration of energy on the public sector, the lack of $O B$ physician involvement in the Project, continuous change of top staff in the private sector, data processing problems hindering the report function, the closing of the tertiary center to transfers -- all greatly decreased the activity between the Project and private sectors. What is more significant perhaps, is that some degree of relationship continues and some initiative is coming from certain segments of the private sector. Some limited but specific activity here has the potential for re-sparking interest in some structured relationship. 
CHAPTER IX

\section{RECOMMENDATIONS RELATED TO THE PERINATAL REGIONALIZATION EFFORT}

The preceeding Chapters V, VII, and VIII, described the rational planning activities, organizational networks, and images shaping regionalization. This section summarizes key problems and remaining issues in developing a regional system and provides examples of the type of strategies (prospective approaches) suggested by the analysis. The specific approaches of the various perspectives as well as the directions mandated by the Delphi process may cover similar ground but take a different or even contradictory shape depending on the perspective. Each viewed the problem differently and by virtue of the perspective's organization, recommends different strategic responses as appropriate. While Perspective $I$ is most specific and straight forward, Perspective III is in many respects most significant.

This section culminates with the most central finding of the entire regionalization process herein discussed and the implications for its on-going development when considering all aspects of the study. 
FROM PERSPECTIVE I

The Issues in Developing a Perinatal Regional System

- How can the system be made more effective in the outcome of care?

Should the focus of education efforts be the usual interesting topics or the most frequently seen basic problems? Should inservice staff concentrate on teaching classes, teaching teachers, or consultation? Should arrangements be made within the system for transfer and referral of mothers as well as babies, or should individual facilities be upgraded and neighboring regions be used based on patient preference, space, and County arrangements for payment and liability? Should the system operate as a kind of quality assurance group in monitoring case outcomes?

- How can the system be made more efficient and cut needless duplication?

How can hospital-wide forms be eliminated when they duplicate the POPRAS record? How can hospitals desiring growth and upgraded services do so without duplicating existing services in the same way? How can quality control 
committees be assisted with existing data?

- How can the Project staff deal with resistance to change evidenced by declining meeting attendence, lack of protocol use, lack of Tertiary Center use?

- How can the system be made more accessible to patients?

Strategies for Continued Development: Aspects of Rational Planning Currently Underemphasized

- Develop an on-going master plan with carefully selected emphasis and commitment of resources Gradually this plan and resources may be the province of a "Board" discussed in the Delphi section. In the interim it is essential for system management to provide direct and systematic coordination of service components and direct contact with agencies in the network on all levels

- Provide a formal surveillance system for a finer analysis of problem areas and plans to address them. This includes analysis of sources of mortality and morbidity by providers, type of patient, type of problem, extent of prenatal care, level of resources, changing environmental conditions, etc. Follow-up routine communication, propo: als for improvement, and on-going monitoring of needs and progress. 
- Based on activities which show impact, expand Regionalized prenatal services in the public sector using mid-level practitioners (non-Doctor), systematic patient education, and expanded liaison staff

- Evaluate each stage of change by comparison with a matched, non-interaction group in the Region after sufficient start up time

- Explore expansion and use of the high risk diagnostic center

- To upgrade the level of practice in the hospital, and with the RN's, focus on development of a second level, specialized LVN through an OB Technician program

- To attract RN's and provide more intensive care in the tertjary center, develop the OB ICU

- Given the staff turnover problem, initiate the use of self-instructional packages and maintain training of trainers in each hospital

- Given the increasing public sector deliveries, negotiate a patient diversion plan for low risk patients through other hospitals and/or alternative birth centers, and

- Explore the use of a private tertiary hospital by private level I and II hospitals 
- Given problems of research design of extraregional researchers, collaborate on some extensions of the designs

- Given scarcity of funds develop a fee-forservice plan for data processing and nursing in-service, combining the two as a complete consulting program

- Given new County policies affecting patient access to care, project increases in workload and mortality and monitor results

- Develop performance criteria to evaluate achievement from classes as well as attendance and knowledge gain

- Emphasize the mealical record as a risk assessment referral tool

- Develop a high risk infant follow up plan

- Intensify the residency training program to improve care for term pregnancies based on risk assessment

FROM PERSPECTIVE II

The Issues in Developing a Regional System

- How to develop an operable regional network despite massive systemupheavels, incredible need, shrinking resources? 
- How to assure the economic viability of subsystems (hospitals, doctors, etc.) as an inducement to regionalization?

- How to foster an increase in quality of care without "meddling" and violating independence?

- How to foster relations between private and public sector when political and thus program stability affect type of care, attitude toward patients, and capacity in the public sector which is also the tertiary center?

- How to foster positive relations among professionals toward a common goal?

- How to foster continuity of care between prenatal and intrapartum providers in the public sector given the conflict between overlapping authorities?

- How to focus on the level of patient care when the basic orientation is one of fragmentation ("my patient.s") and the non-insured patient is discriminated against?

- How to foster a regional consciousness despite in built conservatism?

- Are the most significant measures of achievement the ones set at the start of the program -- or the measures of involvement, attitude change, desire for continuity, etc.? 
Strategies for Continued Development: Finding Links and Switchpoints to Enhance Organizational Position

These recommendations emphasize search strategies and relational aspects.

- Recognize the opportunities inherent in overlapping interests, e.g.

- professional and economic --job satisfaction (including control, manageability, respect and performance) --independence and team needs

- Find an external focus to join forces "against" in addressing internal common needs (JCAH, state MediCaid, new HSA, malpractice insurance companies, etc.)

- Involve non-OB doctors in programs for office staff, in mortality and morbidity conferences

- Model team work among obstetricians, pediatricians, nurses, data staff, administrators, etc.

- Develop an orientation program for all new participants at every level via attractive media

- Market special services appealingly

- Maintain relationships with hospital chiefs and administrators

- Develop Mortality and Morbidity conferences at the 
tertiary center and involve staff from other hospitals as simultaneously consultants and learners in a team setting

- Develop a non-profit registry of highly trained nurses and contract to local hospitals for staffing and training -- a resource which would cut across many types and levels of system needs

- Have time reserved for flexibility in responding to requests and ooportunities as they arise

- Be on the look out for interests of certain groups which could be developed in some low energy way and would take off on their own momemtum. Respond quickly to requests.

- Assist the public hospital in compensating for its decreased resources and negative regional image through its improved competency, involvement, image development. Assist them in development of arguments for increased resources. Do not use they as a tertiary facility until more settled

- Assist physicians and motivate front line workers through special conferences for prenatal office staff. Add follow-up with physicians at $O B$ meeting.

- Improve attending physician coverage back-up for relief and on-site availability since the presence of this group contributes to a sense of security and order as well as performance 
FROM PERSPECTIVE III

Issues in Developing Regionalization

- who are the key movers and how do they relate to regionalization -- including partial and contradictory types of support, other personal priorities, and personal styles of operating?

- How can the image of regionalization be developed by various interests and help to congeal them?

- How can enculturated patterns and attitudes shape regionalization?

- What is the role of the consumer in perinatal regionalization?

- What is the consensus of the Spanish-surnamed community on various issues related to regionalization?

- In what way is regionalization unique to this time and place?

Strategies for Continued Development: Developing People and Images

- Develop an image of regionalization

--as a unique resultant of personally useful and professionally advanced cooperation specific to these participants. Both necessity and attractiveness must be developed

--as simultaneously noble and pragmatic 
--As a desirable way to avert outside interference and socialized medicine

--As sensitive to Black professionals and their unique and controversial role in the community

--As supportive and expanding of humanistic health care with practical and immediate results alleviating growing pressures on providers and staff

--Show that what each participant wants can be achieved well by regionalization and their desires can define the shape of it

- For orientation and review use an updatable medium (slides) with pictures of participants in specific activities, especially those unique to this Region

- In policy discussions support a positive and unique image

- Develop the initiative of participants through encouragement, support, linkages, assisting their fit into group context

--assist "A" with coordination of clinic and hospital service

--Give recognition to " $\mathrm{X}$ " for work with new doctors --Involve "M" in Center Mortality and Morbidity Conferences --Provide "S" and "C" with information for their approach to upgrading clinic services --Support "K"'s efforts to increase awareness of 
Regional potential among her co-workers by providing a requested forum

--Invite "F" and include on list of participants in courtesy recognition of her function even if not involved

--Enhance the position of "J" and "G" who have a more developed consciousness and enthusiasm regarding regionalization while maintaining balance of power in their groups

--Circumvent "B"'s racially insensitive behavior --Provide examples and stories to help sensitize workers. De-mythologize the "other" group

- Develop consciousness of expanded nursing roles

- Develop community awareness of Regionalization and their shaping of it -- example, UNA, media, health fairs

--Develop a range of options to meeting perinatal health needs and awareness of them --Coordinate with community groups on issues such as acceptability, costs, medical/cultural approaches, patient responsibilities

- Increase morale by support at critical junctures, back-up and accomplishments 
FROM THE DECISION DELPHI

The Issues in Developing a Regional System

- What should the role of the Regional Center be? (responsibility versus authority, support versus leadership)

- How to maintain a balance of power and still be effective

- Who has expertise in what, by what standard, and how can it be used?

- What is the role of the consumer?

- How do regional standards affect malpractice cases and doctor-patient relationships?

- What can be accomplished with limited time?

- Who gets the tasks accomplished and pays for them?

\section{Strategies for Continued Development}

- Develop an effective regional structure with

--defined roles and responsibilities

--unity of direction

--control (guidance of support staff)

--a "head," a guiding force

--elected representatives from institutions and professions

- Develop an effective regional structure by giving it authority to 
--define policies

--set goals and objectives

--evaluate progress

--develop standards

--identify needs, plans, and implement programs

--collect data on problem areas

- Develop effective orientation to the regional program

- Provide avenues for exchange of ideas and effective communication including medical consultation

- Develop an agreed-upon means of reporting to all providers

- Develop flexible mechanisms for contributing to Regional discussions and decisions

- Develop a master list of each institution's resources

- Acknowledge and use expertise from throughout the Region

- Tertiary Center should assist in the smooth functioning of the above but should not run it

$$
\text { REGIONALIZATION POTENTIAL }
$$

While each Perspective and the Delphi casts a unique and cohesive view on regionalization, an in-depth image of an integrated whole emerges. What is seen is an idea or ideal type developed uniquely against the 
backdrop of the local setting and because of some particular people and circumstances. The ideal sets up a comprehensive set of mechanisms to provide appropriate health care access for pregnant women. Arrangements to assess risk, to refer for specialized tests or delivery at a more suitable hospital, to evaluate results and to provide in-service on relevant topics has all, to some extent, occurred and appears at face level to be straight forward except for the usual initial resistance. The system, however, is in the process of total redefinition with a glimmer of awareness of the focus "all patients in this area" versus "my patients"; with an orientation emphasizing cooperation versus competition; with ircreasing relationships between private and public sector (previously two separate systems of care); with expanded nurse roles and consequently changed nurse-doctor relations; with hospital-clinic linkages established for patients despite differing governing structures for professionals; with increased monitoring and accountability replacing complete independence of judgement. These too are in process -- and in a way different from other Regions. There is advocacy of private tertiary center outside the Region for patient referral while maintaining educational, consulting, and data relationship between the public tertiary center and private hospitals. The designation of hospital levels I and II are not specifically according to standard statements on hospital levels as originally laid out 
by the Committee on Perinatal Health. These were both selfdetermined and negotiated rather than assessed and assigned. The clinics are also being seen as leveled, a concept not found in the literature. The private practice of the Regional Center's faculty acts as a private high level consulting group and a way to divert patients into the private hospitals. The role of a former staff person as a consultant hired by hospitals was more instrumental in setting up improvements than years of working with the hospital. The staff itself serves as a vital communication link throughout the Region. The role of the nurse educators has been far more comprehensive than that of most nurse educators in other regions. Not only do they offer classes and presentations on a take-it-orleave-it basis, but they attempt to affect organization, standard operating procedures, and behaviors through consultation. They also assess whether in-service education had any demonstrable effect on practice which affects the level of care as well as the level of knowledge. All this is taking place in a setting characterized by massive cutbacks in resources, increasing need, organizational instability, staffing upheavals, and terrifically conservative providers. Moreover, there is a current loss of motivational, state and county professional momentus towards Regionalization. Even so, potential for local development is seen in the increasing stirrings in some previously quiet areas as reflected in requests for assistance and offering of some ideas and plans 
for using and further developing Regional mechanisms and awareness. In the regionalization system under consideration, the image projected at this point is one in which the landscape has been laid out, the soil well-prepared, and the seeds planted but the watering has been a bit erratic for a not entirely draught resistent crop, and the climate has been inordinately severe. The struggling results are beginning to make a showing, but the growth can hardly be described as lush. What is needed is the green thumb approach (intuitive nurturing as proposed by Perspective III) in crucial areas (as proposed in Perspective II) and systematic attention (the activities of Perspective I). 
for using and further developing Regional mechanisms and awareness. In the regionalization system under consideration, the image projected at this point is one in which the landscape has been laid out, the soil well-prepared, and the seeds planted but the watering has been a bit erratic for a not entirely draught resistent crop, and the climate has been inordinately severe. The struggling results are beginning to make a showing, but the growth can hardly be described as lush. What is needed is the green thumb approach (intuitive nurturing as proposed by Perspective III) in crucial areas (as proposed in Perspective II) and systematic attention (the activities of Perspective I). 
CHAPTER X

\section{ANALYSIS OF CASE STUDY CONCLUSIONS: CONTRIBUTIONS TO METAMETHODS AND TO THE ISSUES SURROUNDING POLICY DESIGN IN ESSENTIALLY DEVELOPING SYSTEMS}

The study completed and prospective suggestions put forth, a reflection on the process contributes in two areas: the state of the art in metamethodology and its application to policy areas which are essentially developmental (emergent) and cooperative.

CONCLUSIONS ADVANCING THE STATE OF THE ART IN METAMETHODOLOGY

Multiple Perspectives

How the Perinatal Regionalization situation is viewed by the three perspectives is summarized in Table XXI. Based on the examples and conclusions in Chapters V, VI, VII, and IX, it gives some of the characteristic differences resulting from what each perspective focuses on, in what way, and what it is likely to miss. THE PERSPECTIVES YIELD QUITE DISTINCT PICTURES OF AN EMERGING SOCIAL TECHNOLOGY.

The $T$ Perspective on perinatal regionalization emphasizes its well-ordered approach to the problem of initiating the concept. It systematically sets out to present its case, implement a plan of action, and evaluate the results in 
TABLE XXI

HOH THE 3 PERSPECTIVES SEE ASPECTS OF REGIONAL DEVELOPHENT

\begin{tabular}{|c|c|c|c|}
\hline & PERSPECLIVE 1 - RALIONN & PERSPECCIYE 11 _- ORGANIZAUIONAL & PERSPECTIYE III - PERSOHAL/POLITICAL \\
\hline Goals & $\begin{array}{l}\text { To develop mechanisms for action } \\
\text { necessary to effect change }\end{array}$ & To be in an advantageous position & \\
\hline Focus & $\begin{array}{l}\text { Decrease mortality and morbidity } \\
\text { based on level of risk and level of } \\
\text { care-Cost eff icient }\end{array}$ & $\begin{array}{l}\text { Cooperative functional interorganiza- } \\
\text { tiondl health care delivery system }\end{array}$ & $\begin{array}{l}\text { Roots } \\
\text { unique shaping of system }\end{array}$ \\
\hline Expectation of Change & $\begin{array}{l}\text { Relatively smooth and systematic } \\
\text { Planned outcome per ef fort }\end{array}$ & $\begin{array}{l}\text { Long time, takes patience } \\
\text { Also the opportunity -- now or never in } \\
\text { its own time frame }\end{array}$ & $\begin{array}{l}\text { Unpredictable, self-generating yet timing } \\
\text { is of the essence } \\
\text { Understanding develops slowly }\end{array}$ \\
\hline Implementation Approach & $\begin{array}{l}\text { Serial effort. via action ties } \\
\text { organized by budget and staff } \\
\text { patterns } \\
\text { Based on goals-- normative } \\
\text { Interactive and self-correcting from } \\
\text { evaluation, impact }\end{array}$ & $\begin{array}{l}\text { Constant effort repetition, reinforce- } \\
\text { ment or "fit" within existing system: } \\
\text { Extrapolative, force of tradition, habit }\end{array}$ & $\begin{array}{l}\text { Spark--not too pushy, demanding, ins istent } \\
\text { unless power to back it } \\
\text { Leadership and persuas ion. peer pressure } \\
\text { is leavening to raising of standards } \\
\text { People who are "in's" to system ensure } \\
\text { balance, however because of interplay of } \\
\text { situation and personal dynamics change is } \\
\text { "breakthrough" }\end{array}$ \\
\hline Involvement Role of Staff & $\begin{array}{l}\text { To support good (rational) ideas in } \\
\text { action } \\
\text { As an expert }\end{array}$ & $\begin{array}{l}\text { To gain access in order to change pro- } \\
\text { cesses through authority channeis or in- } \\
\text { formal effective networks } \\
\text { As } 7 \text { interinstitutional partner }\end{array}$ & $\begin{array}{l}\text { To shape, inspire, nodel through personal } \\
\text { contact } \\
\text { Expertise \& respect-based relations }\end{array}$ \\
\hline Success depends on & A good plan managed well & Threshold effect in organization & $\begin{array}{l}\text { Personal interest and motivation of } \\
\text { each and of key leader }\end{array}$ \\
\hline Strength \& Stability & $\begin{array}{l}\text { Powerful because logical } \\
\text { Rightness of cause }\end{array}$ & $\begin{array}{l}\text { Powerful because works within own sys- } \\
\text { tem, self-reinforcement of multi-stable } \\
\text { system aspects; organization as terri- } \\
\text { tory }\end{array}$ & $\begin{array}{l}\text { Powerful because personally satisfying/in- } \\
\text { spiring --prestige direct or indirect } \\
\text {--self-fulfilling gratifying } \\
\text { volatile "forces" }\end{array}$ \\
\hline $\begin{array}{l}\text { Non Match points at } \\
\text { System Interfaces }\end{array}$ & $\begin{array}{l}\text { Details to be manipulated (outcomes } \\
\text { are unknow) to fit the whole plan by } \\
\text { establishing an umbrella organization } \\
\text { seen as possible in a relatively } \\
\text { short (i.e. conceivable) time frame }\end{array}$ & $\begin{array}{l}\text { Different strokes for different folks } \\
\text {--qo different routes--pathway is the } \\
\text { essence } \\
\text {--break habits } \\
\text { Complex time relationships/habits are } \\
\text { essential for routine details so that } \\
\text { energy can be devoted to crisis demands }\end{array}$ & $\begin{array}{l}\text { Main concerns to be negotiated } \\
\text { (outcone uncertain) } \\
\text { Persuasion (based on respect, image) }\end{array}$ \\
\hline
\end{tabular}


TABLE XXI Continued

\begin{tabular}{|c|c|c|c|}
\hline & PERSPECTIIE I -- RATIONAL & PEKSPELIIVE 11 -- OHLIANILATIONAL & PERSPECTIVE III -- PERSOHAL/POL ITICAL \\
\hline Withholding Enthusiasm & $\begin{array}{l}\text { Resistance to Change/Fear of Change } \\
\text { Seeking better options }\end{array}$ & $\begin{array}{l}\text { Inefficiencies in hureaucratic org. } \\
\text { Holding onto what works }\end{array}$ & $\begin{array}{l}\text { Power plays, self interests } \\
\text { Bargaining for the best, working } \\
\text { through }\end{array}$ \\
\hline $\begin{array}{l}\text { Image of Regionalization } \\
\text { efforts to those not-yet part } \\
\text { of it }\end{array}$ & $\begin{array}{l}\text { Goals are great: you have the } \\
\text { money and you want } x \text { so you give } \\
\text { staff...etc. and do it. }\end{array}$ & Try it, life goes on/Hait and see & $\begin{array}{l}\text { Doing it for self-aggrandizement: } \\
\text { prestige, papers }\end{array}$ \\
\hline Types of Issues Raised & $\begin{array}{l}\text { Efficiency } \\
\text { Effectiveness } \\
\text { Access } \\
\text { Resistance to Change }\end{array}$ & $\begin{array}{l}\text { Relationships in organizational up- } \\
\text { heaval, economics, cross points }\end{array}$ & $\begin{array}{l}\text { Context, image, patterns, uniqueness. } \\
\text { key movers }\end{array}$ \\
\hline Type of Recomendation & $\begin{array}{l}\text { Activities of project based on } \\
\text { demonstrated effectiveness or need } \\
\text { assessment }\end{array}$ & $\begin{array}{l}\text { Role of project: model, involve, } \\
\text { orient, assist, recoynize multi- } \\
\text { levels, look for switch points }\end{array}$ & $\begin{array}{l}\text { Role of project in relation to others: } \\
\text { oDevelop image to others } \\
\text { onevelop initiative of others }\end{array}$ \\
\hline
\end{tabular}


terms of system efficiency/effectiveness. Project staff contribute by establishing system linkages and procedures. In an of itself, however, the perspective misses many role aspects of staff (i.e. modelling behavior) and critical elements of gaining entry to organizations and inducing change (as found in the multi-layger network of organizational functioning). Nor is it attuned to such aspects as "climate," "image," and taken-for-granted fundamentals of interpretation found in professional and cultural insights. Thus it is likely to see efforts to regionalize as non-productive in the near-term and dismiss them too early.

The $O$ Perspective on perinatal regionalization, meanwhile, emphasizes the intricacies of breaking through the traditional roles, established procedures, and drives devoted to other priorities at every level of staff, across professions and institutions, and involving the inter-relation of personal, economic, and positional factors. Project staff are sensitive to their roles in "others' territory." They look for entrances in relation to all these factors and seek to use existing lines of momentum but find it easy to get caught in their entangling web.

The $P$ Perspective provides the most immediate grasp of essential and unique world of participants, but is the most elusive to deal with. In this situation, the role of staff as conveyers and developers of an image and as developers of others in this context is quite different 
than their role seen in the other two perspectives. The subtleties are such that without the measures of progress of the $T$ Perspective or the organizational in-roads of the 0 Perspective, a project is unlikely to get off the ground.

At another level, the perspectives call for distinct differences in data collection, analysis, type of researcher. The brief history of multiple perspectives has shown the most disagreement around the third type. Linstone's group, labeling it the $P$ or personal perspective, found nearly as many interpretations of it as there were members in the group. Some of the problem seems to revolve around the individual as a content focus seen in the unique effect a specific individual has on a process under consideration or seen in the politics of how individuals (or types of individuals) view themselves and each other in the process. THIS STUDY HAS DEMONSTRATED THAT YET ANOTHER INTERPRETATION OF THE P PERSPECTIVE IS THE ORGANIZATION OF A UNIQUE CONTEXTUAL POINT OF VIEW ON THE TOPIC FORMULATED EXPERIENTIALLY AND COMMUNICATED GRAPHICALLY BY THE RESEARCHER HER/HIMSELF. As each artist presents a unique vision, so too the researcher admittedly enters into an emersion process and through struggling with enormous amounts of contradictory information and impressions and mixed emotions $s /$ he emerges with an integrated view of thes situation or slices of the key tones and shades of the reality at play. These are offered for consideration or tested by recognition or expanded 
understand, and yield a resonnance within the group. If one accepts this possibility the role of the "researcher" is then opened to a radically different kind of person -the mime, the storyteller, the comedian, the poet, the artist -- who sees and interprets in a different way is perhaps the most valuable. Each is used to letting go of pre-established frames of interpretation, to catch the moment and try alternate frames, to crystallize an image, convey a tone, involve an audience emotionally. Playing a more "straight" role, the columnist, ethnologist, and applied anthropologist may also be appropriate types of investigators. All can deal with insights into conditions of fundamental uncertainty by presenting a coherent and involving view of all the information at hand. Chapter VII tried to convey a tone, an insight which could not be obtained by citing objective fact. Yet the heart of understaning this particular Region is contained in this chapter. The linked socio-economic-political issues described in Chapter VI arise out of the personal and individual-professional/cultural context elucidated in Chapter VII and inerplays in very specific ways with policy goals, implementation strategies, and planning facts given in Chapter V. While it should be noted that the data gathered in the perspective is objective (available to anyone entering the situation without prejudgement to the extent any researcher does), a filtering process of course takes place and is very consciously employed in the analysis phase -- 
seeking alternate filters of interpretation but ultimately presenting a highly personal one.

The organizational perspective too presents a dilemna for the reseachers. The types, characteristics, and interplay of organizations are examined by numerous organizational theories -- some themselves are perspectives on organization rooted in rational systems approach or arising out of organizational development research. Chapter VI tried to demonstrate that the organizational perspective is precisely the way events, decisions, processes are viewed by organizations and organizational units by virtue of the fact they are unique, to some extent monolithic entities with distinct points of view. Thus an attempt to change the practices of a hospital unit may be challenged by the unit not just because its head is paranoid, incompetent, or resistent to change, but for one example, because that prerogative of change belongs to someone who, if bypassed, results in destabilizing the multi-layer network of authority, status, working relationships, job satisfaction, retention of employees, at times even definition of situations such that one can consider the work situation sane. On the other hand, these very linkages make possible radical change which while ostensibly contributing to one function greatly enhances linked ones across various groups. The data collection methods of the perspective then, provide information but the framework of interpretation falls together at the point one reaches a 
stage of closure (for either inherent or merely practical reasons). Again, it can be seen that the organizational perspective depends on more than the traditional research mode involving a preset framework of interpretation. The best investigators for the perspective here advocated would probably be a combination of those sensitive to organizational functioning such as managers and union representatives, applied anthropologists, group process psychologists, human ecologist, alternative organization advocates. THUS HOW EACH PERSPECTIVE COLLECTS AND ANALYZES DATA (THE TYPE AND ORGANIZATION OF INFORMATION) AND THE TYPE AND ROLE OF THE RESERRCHER CAN AND SHOULD VARY GREATLY DEPENDING ON THE PERSPECTIVES USED. (See Appendix A for further considerations.) Given such radical differences in approach and given that they are feasible tasks, do the Perspectives work at cross purposes? Do they serve any useful purpose in the face of action to be taken? How are they put together? While the conclusions from each perspective taken separately may yield even conflicting strategies and whole emphasis is undetermined amongst the three, a coherent whole is possible. The process is not merely one of assembling a composite picture from jig saw puzzle pieces, nor ironing out the contradictions by some rules of thumb, nor arranging the information hierarchically from the objective abstractions of the need, dask, and plan analysis in the first perspective to the implementation constraints of the real world in the second 
and the motivating components at the individual level in the third. It seems that the dimensional quality yielded by multiple perspectives operates similarly to the integration of left and right hemispheric functioning. While the information is uniquely organized, the hemispheric processes provide contexts for each other -- they "cross cue" each other. (See Table XXII)

Thus use of the $P$ Perspective as a context -- as the key dimensions -- demonstrates that a plan is not merely applied with certain adaptations (trivial details) but is shaped both in its end results and its process by a unique image, forming pervasive power forces. In this context the $T$ Perspective serves as a kickoff, a statement of need and/or formation of possible configuration; the 0 Perspective serves as the current order, the real-life lay of the land containing the potential of transformation. Use of the 0 Perspective as a context, demonstrates a strategic consciousness: orientation, position, dynamics. The T Perspective provides a policy/plan to consider and adapt vis-a-vis its role and functions across levels and across the institutional array. It lobbies against whatever is not profitable or enhancing (economically, power-status position, etc.) and creates markets and products/services for whatever is. The $P$ Perspective serves as its understanding of "market conditions" both by the organizational entity and by its subcomponents eyeing their own strategic positions. 
TABLE XXII

PERSPECTIVES AS MUTUAL CONTEXTS

\section{PERSPECTIVE I}

Need, task, plan

(effectiveness, efficiency)

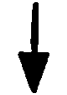

Organization (II)

(Implementation, Feasibility)

$$
1
$$

Individual Positions (III)

(motivation, acceptability)

\section{PERSPECTIVE II}

Organization Position

(orientation, dynamics strategy)

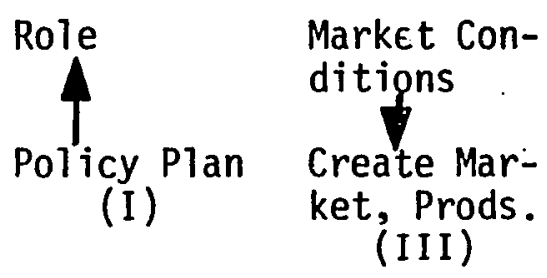

\section{PERSPECTIVE III}

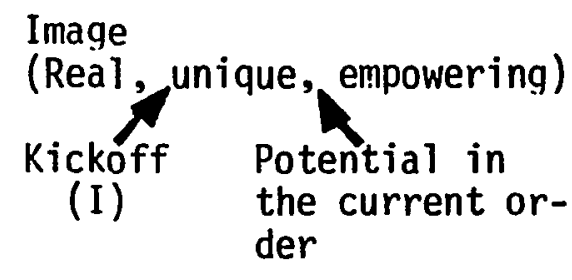

(II) 
Use of the $T$ Perspective as context demonstrates the hierarchical (level of detail), one diménsional, additive view initially described above. Even to those in policy planning who are open to more kinds of information, the $T$ Perspective is a most "natural" context for integrating the whole. Nevertheless, THE DEPTH AND RICHNESS DERIVE FROM INTEGRATION OF THE PERSPECTIVES.

THEY ARE INTEGRATED BY FORMING WHAT HOFSTODTER (120) CALLS "STRANGE LOOPS" WHERE THERE IS NOT FIGURE-GROUND, BUT ONLY FIGURE-FIGURE OR MUTUAL CONTEXTS as in Escher's drawings, Bach's fugues, Godel's principle of uncertainty, the mutually encompassing frames in the play Marat/Sade. While one can intellectually analyze the lines of the fugue, for example (a stimulating and rewarding exercise), the musical ear registers satisfaction with the whole, pleasingly dynamic and balanced (artistic criteria), a process quite natural and effortless.

The Delphi

While much effort has been expended in legitimizing the Delphi as a research tool (reliability and validity measures), its use as an open-ended, action-oriented effort is just beginning. The Delphi discussed in Chapter VII yielded conclusions and directions and expressed willingness and committment to action. It has not, to date, yielded much direct action. Whether the process is inherently weak or 
other factors are involved deserve consideration.

The Delphi generated interest among Project staff seeking to orient themselves along the lines desired by other participants. One participant external to the Project expressed particular interest in results and initiated a course of action which potentially affects Project continuity. On the whole, however, not much energy (as distinct from interest) seemed to be generated.

TIMING IS OF THE ESSENCE IN PROCESS ACTIVITIES NOT ONLY TO GENERATE ACTION BUT BECAUSE THE PROCESS IS THE ACTION, I.E., THE IMAGE IN THE HAPPENING. Several aspects of timing contributed to the resulting malaise. The Delphi was initiated after a year of declining or non-involvement in group Regional activities resulting in a cessation of these activities $(O B$ subcommittee meetings, mortality and morbidity conferences). The fact that physicians in particular participated in the Delphi at all was a positive indicator of some on-going interest. Timing wise, however, it would probably have been more productive to initiate the process before the cessation of other activities or after they had been picked up to even a small extent or at the very start. Compounding this, there was insufficient follow-up of the results in a timely fashion.

Another fault seems to lie in lack of leadership -either spontaneous, assumed, or designated. The organization was designated by the Delphi in its broad parameters but its 
initial implementation was caught within an existing system at that point leaderless and overextended. Moreover, a kingpin in the system was both looked to by some and criticized by others -- he was probably threatened by the democratization of the system he had spearheaded years before. A TRANSITION FROM ONE FORM OF ORGANIZATION (WITH THE POWER OF PURSE-STRINGS DESPITE WIDE-SPREAD VOTE) TO ANOTHER THROUGH A PARTICIPATORY, IMAGING PROCESS REQUIRES THE DESIGNATING OF THE INITIAL PERSON(S) TO TMPLEMENT STEP ONE. Perfectly logical, but hindsight is easy.

The Delphi results themselves emphasized that Regionalization is a type of effort that will not proceed in hierarchical terms. PARTICIPATORY DECISION-MAKING IS INDEED ESSENTIAI IN COOPERATIVE SYSTEMS EVEN IF SYSTEM RESOURCES (IEVELS OF CARE) ARE HIERARCHICAL.

A more skillful designer of the Delphi process would be able to enhance its imaging capabilities. While the flexibility of the process has been demonstrated in this exercise, ENLARGING THE IMAGING POWER OF DELPHI IS AN AREA FOR FURTHER DEVELOPMENT.

In Chapters II and III the need for a different approach to policy design for systems which are radically new was discussed. What has been learned about identifying the development of these systems and about their unique form of policy 
design is the focus here.

The difference between the concepts of policy implementation and policy design is not one of pre and post-decisionmaking: design before and implementation after. In fact, implementation is a phased planning and enactment of policy over time through specific steps considering finer levels of detail and ever more programmatic and operational tasks. DESIGN, ON THE OTHER HAND, IS THE SIMULTANEOUS CONSIDERATION, THE DISCOVERY, OF THE FORM OF THE NEW SYSTEM. This distinction is shown in figure 25. The concept of form is central to that of design. As discussed in Chapter III, it is perceptual, philosophical, and, in a manner of speaking, "right brain" functioning. Thus form is active perception (shaping what is seen) and the ordering of relationships, structure, and meaning (the philosophical gestalt of the whole). What does the new system look like? How do you know when it has "arrived"? What defines it or holds it together? FORM AS SELF-IMAGE, SYSTEM BOUNDARY, AND SYSTEM CONTROL DISTINGUISHES THE NEW SYSTEM FROM THE OLD. For example, in the particular Perinatal Regionalization Project under study, requests for collaboration hint at an identification with a region network. Many of the issues raised reflect the setting of boundaries regarding what constitutes the region, not just geographically, or in terms of participants, but in scope, relationships, province of concern. The endogenous control methods include types of 
IMPLEMENTATION: TIME/HIERARCHICAL RELATIONSHIP

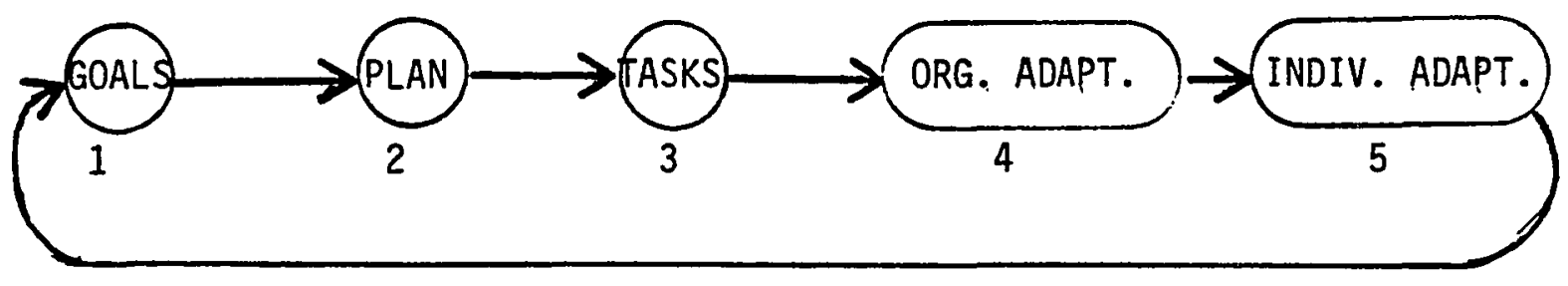

DESIGN: IMAGE/FORM RELATIONSHIP

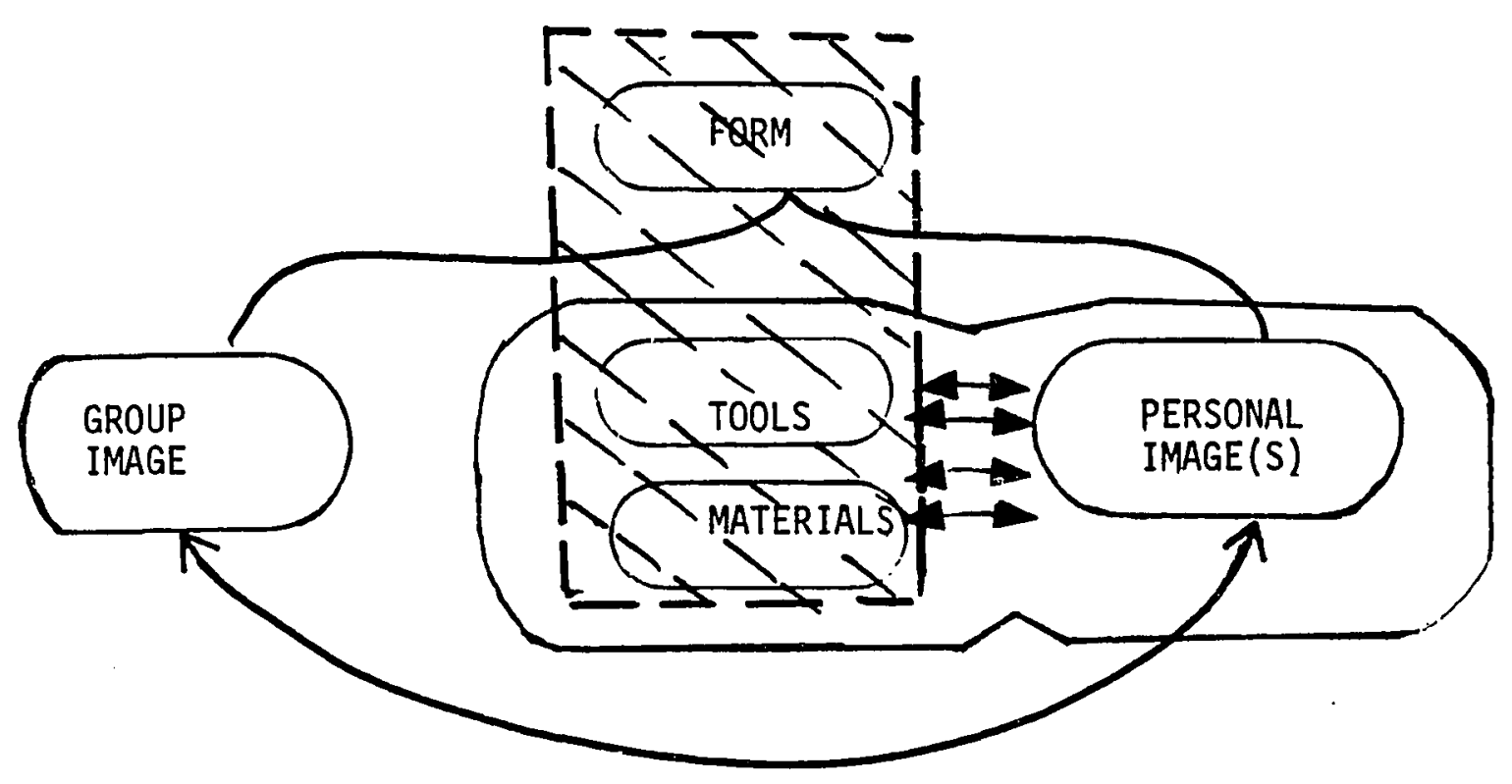

Figure 25. Comparison of implementation and design. 
peer pressure and expectations, endogenous norm setting, consciousness-raising, use of information. The working out of issues, the ways people see to collaborate in view of their regional identity, establish regionalization more than the accomplishment of specific tasks and development of specific mechanisms and procedures. The measure for this type of system is image-in-actuality, not death rates.

The question arises, nonetheless, whether expenditures are sufficiently justified to continue specific efforts on this area or whether everyone should revert certain energies elsewhere. How do you know regionalization is happening to the extent that it will continue as the system of perinatal health care delivery? Are there any short cuts to getting "fully" there or are we back to "muddling through?" These questions center on predictability in design and recognition of emergence. Several characteristics of emergence both contribute to its recognition and design.

If the catastrophe theory model holds, then the discontinuity or leap from the old system to the new may be recognized by identification of a third dimension along which this leap occurs. In other words, our perception is tracked by our routine way of interpreting. But THE ESSENCE OF THE SHIFT IS A NEW RELATIONSHIP EXISTING AMONG PARTICIPANTS AND A REINTERPRETATION OF THE MEANING OF EVENTS AND RELATIONSHIPS. Bateson refers to the figurative punctuating of the same sentence for a different meaning as the use of context markers. 
(26, p.287) Catastrophe theory holds that the new interpretation is not only a threshold change - passing over to the new - but one such that the step over is much shorter than the step back to the way things were. ( 39 ) (Figure 26 shows the 3 dimensional change mapped onto 2 dimensions).

This is exemplified in the regionalization project in two examples. The first example is within the public sector. In 1981 when the County Department of Health Services deregionalized, i.e. completely split the formal administrative links between the County hospital (the Regional Center) and the ambulatory centers (clinics), perinatal regionalization in terms of patient care did not lose ground. In fact coordination is gaining momentum and there is a good probability that within the year even deeper involvement between the two will exist with the expansion and consolidation of the high risk program. Routine interpretation would see the power play between the clinics and hospitals and note in the reversion to the former relationship, an indication that the ambulatory powers had won. But the reformulated view of the relationship and a more regionalized view of patients sees also demonstrated ways to improve patient care through working together.

The private sector example, while weaker, nevertheless shows that they are beginning to divert patients appropriately and continue to request assistance in staff development. This 


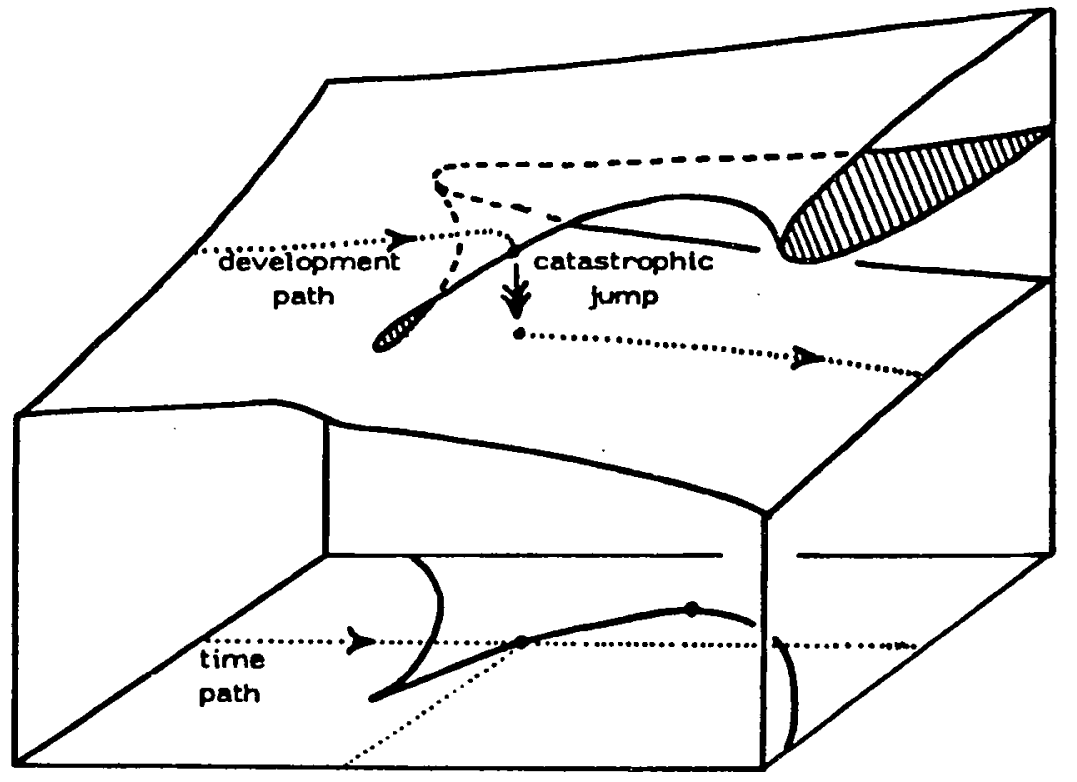

Figure 26. Catastrophe theory model of development

Source: E. C. Zeeman, Catastrophe Theory. New York: Addison-Wesley, 1977. 
could be interpreted as a result of competition in which the hospitals attract physicians through competent staff. Again, in the reformulated view, the advantages of regional resources (in-service educators and consultants) and the regional concept of patient care are seen and emphasize the cooperative aspects. A higher standard of care has begun to take hold. This last example also brings out ANOTHER CHARACTERISTIC OF DESIGN - STYLE, OR THE PERSONALIZATION OF THE REGIONAL CONCEPT. Besides transfers from the Level I to the Level II hospital, the Level III hospital which is gaining usage for transfers is not the public sector hospital but a nearby, out-of- Region private one. However, the admitting privileges gained in the public Level III, make the process easier to conceive of in relation to the private Level III. Moreover, the latter is a rather prestigious white hospital in which mutual benefit could be derived from the participation of local Black Doctors who are now somewhat less defensive about their role is a Level III setting. In addition there are also economic advantages to them.

Another characteristic is the relationship of ultrastability and metastability. WHILE THE OLD REDUNDANCIES ACROSS MANY TYPES OF SYSTEM FUNCTIONS REINFORCE AND MAINTAIN EACH OTHER, A SWITCH INTO A NEW REGION OF STABILITY INCREASES OTHER CONNECTIONS AND REINFORCES THEM. MOre than the adoptive control or internal negative feedback nf metastabilitv, ultrastability involves RELATIONAL CONTROL IN THE CONTEXT OF A 
COMMON, DEVELOPING AND STIMULATING IMAGE - POSITIVE FEEDFORWARD. A plan for the fullest development of Licensed Vocational Nurses as licensed staff, and of Registered Nurses in a critical care and supervisory capacity through increased competency affects not only the work performed but position amongst themselves and vis-a-vis doctors, self-image as professionals, and economic reward. These are new multistabilities. They are often determined by system aesthetic considerations of balance and harmony, repetition and uniqueness the distinction between "working through" and "muddling through" is the concept of a guiding image which is changing and personally relevant. The more it is grasped, the more it is formed, and the more it guides what is done. Working through, then, is not the bargaining of muddling through with its emphasis on power plays and the fun of the game. These tensions may well be present but the type of negotiations are also in the context of shaping a more important and more long range endogenous control. In this example, an entire service may be upgraded through a special L.V.N. program but it involves reconsideration of R.N. roles as well.

A paradoxical characteristic is seen here. The merits of the planning/implementation approach have often been touted in terms of their long-range horizons. Yet, IN THE DESIGN APPROACH DISCUSSED IN RELATION TO EMERGENT SVSTEMIS, GOALS APPEAR AS SHORT TERM FIANNNING IN THE SERVICE OF AN IILAGE, POTENTIAL AND REAL, LONG RANGE AND IMMEDIATE. While a goal is 
iteratively re-examined, the image is constantly re-focused and re-interpreted by each. What maintains interest in it is what is important. The old adage that people do more of what they do well hints at the personal and organizational considerations of the ease and satisfaction with which the work of the system is accomplished as well as its intrinsic merits. Alignment within a shared frame of action with sufficient tensions to make it interesting are supporting considerations which can be seen in many of the preceding examples.

Because it is an emergent system, there is a high degree of risk and uncertainty involved, an essential open-endedness. THE ROLE OF PROSPECTIVE STUDY CAN SERVE A DIFFERENT FUNCTION, ONE RELATED TO THE CREATIVITY OF THE DESIGN CONCEPT. The specific methods gather information for prospective use as seen in Table XXIII. The results appear to be along traditional normative/extrapolative lines. However, the forms of communication already modifies the way potentials are viewed and pathways to them. They further enhance discussion in the ongoing creation of the new system by their reflectiveness. Thus a scenario drawn from the history and plans of the $T$ Perspective is really a view of the present in the guise of a new technology. The examples of the $O$ Perspective are really the present seen as capable of a new future because of the overlay of relationships which acknowledge their positive roots as a basis for switch into different expression of them. The stories of the third is really the future in process by 
PROSPECTIVE VALUE OF THE METHODS

\section{Methods of Analysis}

Planning/Evaluation Documents

Interviews

Participate Observation

Delphi Rounds

Methods of Communication

History and Plans

Examples

Stories

Delphi
Future Impact

Project intent, goals (normative)

Project consequences (extrapolative)

Continue plan (extrapolative)

Anticipate future in terms of expectations \& desires for self and others from standpoint of current situation

Observes directions and motivations

Forms, over the course of it, an active image (reat, changing, operative)

Indicates areas of demonstrated success

Exposes network of opportunity for strategy

Reveals "roots" and "imaging" power

Shapes image and form of future structure (develops and shares relationship between perception of desireable and investment of energy) 
exposure of the symbol systems guiding meaningful transition. The Delphi most directly examines and shapes the image and form of system commented on by the others. The prospective approach is essential to creativity. THE MEANING IS "CREATIVE" IN SYSTEM DESIGN AS OPPOSED TO THE "INNOVATIVE" IN THAT THE LATTER IS AIMED AT BETTER ARRANGEMENTS OR TECHNOLOGICAL SUBSTITUTION WHILE THE FORMER IS A UNIQUE EXPRESSION, AESTHETICALLY JUSTIFIED, A REINTERPRETATION AND TRANSFORMATION. The time required to "stew" the aspects together is often long and the process imperceptible. At other times, the process is tumultuous with some aspects of traditional control diminshed and the result simultaneously feeding self-serving and fringe elements as well as the creative process. 
REFERENCES CITED

1. Gor, Gio and Brian Richter. "Macroeconomics of Disease Prevention in the United States." Science, 200 (June 9, 1978) 1124-1130

2. Selim, Robert. "Health in the Future: In the Pink or In the Red?" The Futurist, (Oct. 1979), 329-342

3. Demographic Yearbook, New York: United Nations, 1974 $330-341$.

4. Committee on Perinatal Health. Toward Improving the Outcome of Pregnancy: Recommendations for the Regional Development of Maternal \& Perinatal Health Services. White Plains, N.Y.: The National Foundation - March of Dimes, 1977.

5. Curet, L.B. "Perinatal Centers and Regionalization of Perinatal Care," Journal of Reproductive Medicine, 18:6 (June, 1977), 343-346.

6. Heins, Henry C, Jr. "A KAP (Knowledge-Attitude-Practice) Approach to the Regionalization of Perinatal Health," Journal of the Arkansas Medical Society, 73:6, 229-233.

7. Gluck, Louis, ed. "Symposium on Organization for Perinatal Care," (entire issue) Clinics in Perinatology, 3:2 (September, 1976).

8. Russe11, Keith P., Sprague H. Gardiner, and Ervin E. Nichois. "A Conceptual Model for Regiunalization and Consolidation of Obstetric-Gynecologic Services," American Journal of Obstetrics and Gynecology, (March 15, 1975), 756-764.

9. Shott, Roger J. "Regionalization: A Time for New Solutions," Pediatric Clinics of North America, 24:3 (August, 1977), $657-657$.

10. Tyne, Michael D. "Assessing Trends in Perinatology" Hospital Progress, (Apri1, 1978), 67-69,74.

11. Regionalization of Perinatal Care: Report of the Sixty-Sixth Ross Conference on Pediatric Research. Columbus, Ohio: Ross Laboratories, 1974. 
12. Berger, G.S., D.B. Gillings and E. Siegel. "The Evaluation of Regionalized Perinatal Health Care Programs," American Journal of Obstetrics and Gynecology, 125:7 ( August 1976), 924-932.

13. Hein, H.A. "The Iowa Statewide Perinatal Care Program," Journal of the Iowa Medical Society, 68:6 (June, 1978), $201-4$.

14. Mazzi, Edwards and Ronald Butberlet. "The Maryland State Intensive Care Neonatal Program: Description and One-Year Evaluation," Maryland State Medical Journal, (November, 1977), 61-65.

15. Perelman, R. and P.M. Farre11. "The Impact of Perinatal Intensive Care and Regionalization in Wisconsin," Wiscons in Medical Journal, 77:3 (March, 1978), S35-S36.

16. Ginzberg, Eli, ed. Regionalization and Health Policy. U.S., Department of Health, Education, and Welfare, Publication Number HRA77-623, Bethesda, Maryland: DHEW, 1977.

17. Morris, Clifton T., Jr. "Voluntary Regionalization of Neonatal Care: Will It Work? Could It Be Done in Louisiana?," Journal of Louisiana State Medical Society, 129:6 (June, 1977) 155-160.

18. Goldstein, Arthur, I., Deryck R. Kent, and Martin J. Feldman. "Regionalization of Perinatal Care in Orange County, Ca.," Western Journal of Medicine, 126 (March, 1977), 245-249.

19. Dinerman, Beatrice, "Regionalization of Obstetric Services: Problems and Opportunities," American Journal of Obstetrics and Gynecology, (October 1, 1974), 309-318.

20. Dunn, Edgar S., Jr. Economic and Social Development: A Process of Social Learning. Baltimore: The John Hopkins Press, 1971.

21. Wilden, Anthony. System and Structure: Essays in Communication and Exchange, London: Tavistoch Publications, 1972.

22. Holling, C.S., "The Curious Behaviors of Complex Systems: Lessons from Ecology," in Linstone, H., and Simmonds, W.H.C. eds. Futures Research: New Directions. Reading, Mass.: AddisonWesley Pub. Co., 1977.

23. Maruyama, Magoroh. "The Second Cybernetics: Deviation - Amplifying Mutual Causal Processes," American Scientist 51, (1963), 164-179. 
24. Maruyama, Magoroh. "Paradigmatology and its Application to Cross Disciplinary, Cross-Professional and Cross-Cultural Commlunication," Dialectica 28 (1974), 135-196.

25. Maruyama, Magoroh. "Paradigms and Communication," Technological Forecasting and Social Change, 6 (1974), 3-32.

26. Bateson, Gregory. Steps to an Ecology of Mind, New York: Chandler Publishing Co., 1972.

27. Maruyama, Magoroh. "Meta.Organization of Information: Information in Classificational Universe, Relational Universe and Relevantial Universe", Cybernetica (1965), 224-236.

28. Maruyama, Magoroh. "Human Futuristics and Urban Planning, "AIP Journal, (September, 1973), 346-357.

29. Maruyama, Magoroh. "Trans-epistemological Understanding: or Wisdom Beyond Theories," 1977. (Mimeographed.)

30. Jantsch, Erich. Design for Evolution: Self-Organization and Planning in the Life of Human Systems. New York: BraziTler, Inc., 1975.

31. Vickers, Geoffrey. Freedom in a Rocking Boat: Changing Values in an Unstable Society. Harmondworth, England: Penguin Books, 1972

32. Dror, Yehezke1. Design for Policy Sciences, New York: American Elsevier Publishing Co., Inc., 1977.

33. Maruyama, Magoroh. "Hierarchists, Individualists, and Mutualists: Three Paradigms Among Planners," Futures (April, 1974), 103112.

34. Lindblom, C. The Intelligence of Democracy: Decision Making Through Mutual Adjustment. New York: The Freedom Press, 1965.

35. Friedman, J. Retracking America. New York: Anchor Press/Doubleday, $197 \overline{3}$.

36. Michaels, Donald N. On Learning to Plan - and Planning to Learn: The Social Psychology of Changing Toward Future - Responsive Societa 7 Learning. San Francisco: Jossey-Bass Pub., 1973. 
37. Kohn, Leopold. "Towards a General Theory of Planning: A Systems Perspective," (Mimeographed)

38. Thompson, D'Arcy. On Growth and Form. London: Cambridge University Press, 1961.

39. Thom, René. Structural Stability and Morphogenesis: An Outl ine of a General Theory of Models. Translated by D.H. Fowler, Reading, Mass: The Benjamin/Cummings Pub. Co., Inc., 1975.

40. The Random House Dictionary of the English Language, the unabridged edition, 1967.

41. Sahal, Devendra. "Homeorhetic Regulation and Structural Stability," Cybernetica, 19 (1976), 305-375.

42. Kohn, Leopold. "Policy: Conditions of Failure and Success" (Mimeograpned.)

43. Buckley, Walter, ed. Modern Systems Research for the Behavioral Scientist: A Sourcebook. Chicago: ATdine Pub. Co., 1968.

44. Boulding, Kenneth. The Image. Ann Arbor: University of Michigan Press, 1956.

45. Polak, Fred. The Image of the Future. Trans. by El ise Boulding. San Francisco: Jossey-Bass, Inc. Pub., 1973.

46. Emery, F.E. and E.L. Trist. "The Causal Texture of Organizational Relations," Human Relations 18 (1965) 21-37.

47. Terreberry, Shirley. "The Evolution of Organizational Environments," Administrative Science Quarterly, 12:4 (1968), 590-613.

48. Kuhn, Thomas S. The Structure of Scientific Revolutions, 2nd ed. Chicago: University fo Chicago Press, 1970.

49. Bruner, Jerome. On Knowing: Essays for the Left Hand. New York: Atheneum, 1965. 
50. Edwards, Betty. Drawing in the Right Side of the Brain, New York: J.P. Tarcher, Inc., 1979.

51. Sperry, Roger W. "Lateral Specialization of Cerebral Function in the Surgically Separated Hemispheres," in F.J. McGuigan and R.A. Schoonover, eds., The Pschophysiology of Thinking, New York: Academic Press, 1973, 723-733.

52. Levy, Jerre. "Differential Perceptual Capacities in Major and Minor Hemispheres," Proceedings of the National Academy of Science. 61 (1968), T151.

53. Gibson as paraphrased in Murch, Gerald M. Visual and Auditory Perception, New York Bobbs-Merri11 Co., Inc., 1973.

54. Means, Russe11. "Fighting Words on the Future of the Earth," speech given JuTy, 1980, Pine Ridge Reservation. Reprinted in Mother Jones, (December, 1980), 22-38.

55. Capra, Fritjuf, The Taos of Physics: An Exploration of the Para17 els Between Modern Physics \& Eastern Mysticism. New York: Bantam Books, Inc., 1976.

56. Musashi, Miyamoto. A Book of Five Rings, Translated by Victor Harris. 1645; rpt. Woddstock, N.Y.: The Overlook Press, 1974.

57. Persig, Robert. Zen and the Art of Motorcycle Maintenance, New York: Bantam Books, 1974.

58. Bohn, David \& B. Hiley. On the Intuitive Understanding of Nonlocality as Implied by Quantam Theory. Foundations of Physics, Vo1. 5, 1975, 93-109.

59. Bohr, Neils. Atomic Physics and the Description of Nature. Cambridge, England: Cambridge University Press, 1934.

60. Withelm, John. "The Magical Musicality of Roger Penrose," Science 80, (December, 1990), 42-43.

61. Churchman, C.W., The Design of Inquiring Systems, New York: Basic Books, Inc., 1971 .

62. Scheele, D. Sam. "Reality Construction as a Product of Delphi Interaction" in Linstone, H. \& M. Turoff, eds. The Delphi Method: Techniques \& Applications. Reading, Mass.: Addison-Wesley PubTishing Co., Inc., 1975, 37-71. 
63. Schutz, Alfred. Collected Papers, Vol. I \& II. The Hague: Nijhoff, 1962.

64. Berger, Peter and Thomas Luckman. The Social Construction of Reality. Garden City, New York: Doubleday and Co., Inc., 1966.

65. Gazzaniga, Michael. The Bisected Brain. New York Appleton-Century Crofts, 1970.

66. Gazzaniga, Michael and Joseph LeDoux. The Integrated Mind. New York Plenum Press, 1978.

67. Kinsbourne, M. \& R.E. Hicks. "Mapping Cerebral Functional Space: Competition and Collaboration in Human Performances", $n$ M. Kinsbourne, ed. Assymetrical Function of the Brain. Cambridge, England: "Cambridge Universtey Press, 1978.

68. Nebes, Robert. "Direct Examination of Cognitive Function in the Right and Left Hemispheres," in M. Kinsbourne; ed. . Assymetrical Function of the Brain. Cambridge, England: Cambridge University Press, 1978.

69. Harcum, E. Rae. "Lateral Dominance as a Determinant of Temporal Order Responding". in M. Kinsbourne, ed., Assymetrical Function of the Brain. Cambridge, Enaland: Cambridge University Press, 1978.

70. Sibutani, Atuhiro. "The Japanese Brain," Science 80, (December, 1980), 22-26.

71. Geschwind, N. "Specialization of the Human Brain: Learning Capabilitios and the Two Cerebral Hemispheres," Scientific American, 241 (September, 1979) 180-182.

72. Sagan, Carl. Dragons of Eden: Speculations on the Evolution of Human Intel1igence. New York: Raandom House, 1977.

73. Fadely, Jack and Virginia Hasler. Understanding the Alpha Child at Home and in School: Left and Right Hemispheric Function in Relation to Personality and Learning. Springfield, I11.: Charles C. Thomas, 1979.

74. Foster, George. Applied Anthropology. Boston: Little, Brown, and Company, 1969.

75. Parmedes, J. and M. Hepburn. "The Split-Brain and the CultureCognition Paradox", Current Anthropology, 17 (March, 1976). 
76. Twain, Mark. Life on the Mississippi. 1883; rpt. New York: Signet Classics, 1962.

77. Parlett, Michael and David Hamilton. "Evaluation as Illumination: A New Approach to the Study of Innovatory Programs," in G.V. Glass, ed., Evaluation Studies Review Annual, Vol. I. Beverly Hills: Sage Publications, 1976.

78. Patton, Michael Quinn. Qualitative Evaluation Methods. Beverly Hills: Sage Publications, 1980.

79. Presented on the NBC production "Donahue and the Kids," featuring the work of Dr. Gerry Jampolsky, March 16, 1981.

80. Wildavsky, Aaron. "Receiving Policy Analysis from PPBS," Public Administration Review, 29 (March/Apri1, 1969), 189-202.

81. Tribe, Laurence. "Policy Science: Analysis or Idealogy?" Philosophy and Public Affairs 2 (1973).

82. Hoos, Ida. Systems Analys is in Public Pol icy: A Critique. Berkeley: University of California Press, 1972.

83. Baum, Howe11 S. "Toward a Post-Industrial Planning Theory," Policy Sciences 8 (1977), 407-421.

84. Wiseman, C. "Selection of Major Planning Issues", Policy Sciences 9 (1978), 71-86.

85. Pressman, Jeffrey L. and Aaron Wildavsky. Implementation: Los Angeles: University of California Press, 1973.

86. Rausch, Wolf. "The Decision Delphi," Technological Forecasting and Social Change, 15:3 (November, 1979), 159-169.

87. Altison, Graham. Essence of Decision. Boston: Little, Brown and Company, 1971.

88. Mitroff, I. \& Murray Turoff. "Technological Forecasting and Assessment: Science and/or Mythology?" Technological Forecasting and Social Change, 5 (1973), $113-1 \overline{34}$.

89. Marmor, Theodore. The Politics of Medicare. Chicago: Aldine Publishing Co., 1970.

90. Mead, Lawrence M. Institutional Anaysis: An Approach to Implementation Problems in Medicaid. Washington, D.C.: The Urban Institute, 1977. 
9i. Elmore, Richard. "Organizational Models of Social Program Implementation, Public Policy, 26 (Spring, 1978), 185-228.

92. Steinbrunner j.D., The Cybernetic Theory of Decision Princeton: University Press, 1974.

93. Andersen, D.F., "Mathematical Models and Decision Making in Bureaucracies: A Case Story Told from Three Points of View, "Ph.D. Dissertation, M.I.T., Aug. 1977.

94. Linstone, H., et. al, "The Use of Alternate Decision Models for Technology Assessment", NSF Project, Futures Research Institute. Portland, Oregon: Portland State University, 1980.

95. Katz, D. and R. Kahn, The Social Psychology of Organizations, revised edition. N.Y.: John WiTey and Sons, 1978.

95. Denzin, Norman. The Research Act. New York: McGraw-Hil1, 1978.

97. Grimes, R.M. and S.K. Moseley. "An Approach to an Index of Hospital Performance," Health Services Research, 11:3 (Fa11, 1976), 288-301.

98. Katz, P.V. and B.J. Frey. "Oral Health Services: A Delphi Technique Estimation of Their Role in Adult Inpatient Rehabilitation Programs," Archives of Physical Medical Rehabilitation, 57:4 (Apri1, 1976), 183-188.

99. Kumaran, K.M., M. Lemieux, and G. Satchell. "Problem Solving With the Delphi Technique," Dimens ions in Health Services, 53:8 (August, 1976), . 34-5.

100. Smith, K.A. and R.L. Johnson. "Medical Opinion on Abortion in Jamaica: A National Delphi Survey of Physicians, Nurses, and Midwives," Studies in Family Planning" 7:12 (December, 1976), 334-339.

101. Policy Research, Inc. and Center for Technology Assessment. "A Comprehensive Study of the Ethical, Lega T, and Social Implications of Advances in Biomedical and Behavioral Research and Technology". 1979 Unpublished materials.

102. Linstone, H.A. and M. Turoff, eds. "Introduction" The Delphi Method: Techniques and Applications, Reading, Mass.: Addison-Wesley Publishing Company, Inc. , 1975, 3-12. 
103. Mitroff, Ian I. and L. Vaugh Blankenship. "On the Methodology of the Hol istic Experiment." Technological Forecasting and Social Change, 4 (1973), 339-353.

104. Maruyama, Magoroh. "Epistemology of Social Science Research" Dialectica, 23 (1969), 229-280.

105. Watzlawick, P. Language of Change. New York: Basic Books, 1978 .

106. Gordon, R.L. Interviewing: Strategy, Techniques, and Tactics. Homewood, Illinois: Dorsey Press, 1975.

107. Dexter, Lewis. Elite and Specialized Interviewing. Evanston, I1: Northwestern University Press, 1970.

108. Culbert, Samuel and John McDonough. The Invisible War: Pursuing Self-Interests at Work. New York: John Wiley and Sons, 1980.

109. Guba, Egan. Toward a Methodology of Natural istic Inquiry in Educational Evaluation. CSE Monograph Series in Education No. 8 Los Angeles: Center for the Study of Evaluation, U.C.L.A., 1978.

110. Bruyn, Severyn. "The Methodology of Participant Observation", Human Orqanization, 21 (1963) 224-235.

111. Wax, Rosalie. Doing Fieldwork. Chicago: University of Chicago Press, 1971.

112. Lofland, John. Analyzing Social Settings. Belmont, Ca: Wadsworth, 1971.

113. Becker, Howard S. and Blanche Geer. "Participant Observation and Interviewing: A Comparison," In William Filstead, ed., Qualj.tative Methoderagy. Chicago: markham Pub. Co., 1970.

114. Hallman, Howard W. Small and Large Together: Governing The Metropolis. Beverly Hills, Ca: Sage Publications, 1977.

115. Umbdenstock, Linda M. and Shirley A. Komoto. Perinatal and Selected Health Indicators with Projections: A Source Book, Private Publication, 1978.

116. Gore, James. "Case Study: Perinatal Regionalization;" Presentation to the Annual Meeting, American Public Health Association, November, 1979. 
117. Williams, Ronald L. "Measuring the Effectiveness of Perinatal Medical Care," Medical Care, 17:2 (February, 1979), 95-110.

118. Harragan, Betty Lehan. Games Mother Never Taught You to Play: Corporate Gamesmanship for Women. New York: Warner Books, 1977.

119. March, J.G. and H. Simon. Organization. New York: John Wiley and Sons, 1958.

120. Hofstodter, R. Godel, Escher, and Bach: The Eternal Golden Braid. New York: Vintage Books, 1980 . 
APPENDICES 


\begin{abstract}
APPENDIX A
SUGGESTIONS FOR APPLYING MULTIPIE PERSPECTIVES BASED ON LEARNINGS FROM THIS STUDY
\end{abstract}

GETTING TO THE BOTTOM OF IT: INVESTIGATIVE INTERVIEWING STRATEGIES

If highly specific and sensitive information is necessary, if a "feel for" the situation as well as facts are desired, if the structuring of the area is not clear cut (one is open to contradictions, unpredetermined alternate points of view, context sensitivity), than the more or less structured interviewing of traditional social science must give way to the investigative techniques of the reporter hot on the trail of a new discovery.

Selection of Interviewers

Not everyone can be trained to do this kind of interviewing. Highly structured, clear cut people in particular should not be selected. The depth of insight achieved through such a study depends on two characteristics of the interviewers -- style and perceptual ability. Style contains elements of skills but also acknowledges the dynamics naturalIy occurring between certain types of people. There is, for example, a "Columbo type" of underplay, a "Mike Wallace style" in which blunt accusation and leading questions have a place, 
an Oriana Fallaci technique of entrapment, etc. At least two interviewers are generally necessary. Factors of race, sex, status, insider-outsider position, personality, orientation to the study including hypothesis-in-formation should be considered. Some interviews should be done together. They should certainly be analyzed together to check on interpretation, weighting of information, follow-up of information, and subsequent strategizing.

Selection of Respondents and Gaining Access

Find the roles necessary to provide for a cross-cut of points of view necessary to the study. For the organizational perspective, it is necessary $t 0$ talk with "front line" people as well as middle and top management. The comparison allows for tracing of lags, relationship networks, socialization into the "real" organization, standard operating procedures. Look for an "in" to the system you alwo feel comfortable with -- preferably someone who can map out the territory and peoples. Maintain an active list of people and roles that might be pussible to interview. This will, of course, undergo revision, but it's a start. Doorkeepers are very important both as access to others and for their knowledge of the system. Often those easiest to talk to are not power-holders and do not have access, however. Carefully build your sense of the situation. Only by demonstrating that you know the protocol of the place will you be trusted with "real" information -- and that after being assured you will do something 
"good" with it be of interest to them. Use questions like "who else" should I interview to get a range of perspectives on this topic?" "On whom do you rely to get $x$ done? ... to get word through?"

\section{Conducting the Interview}

Identify a role (and style) that the interviewee will be comfortable in and the type of information you can gain from it. This establishes quicker rapport. (Also identify "types.") EXAMPLES:

Teacher role - to learn the ropes, organizational socialization process

Organization man - how things get done, connections to the top

Rumor monger - used by others to circulate bits of information into the system, though never trusted with heavy stuff

Official - only a formal perspective as in a prepared press release (best caught off-guard for more than that)

Politician - all is innuendo and only if you're catching on subtly

Informant or Confidante - must have reasons for relating to you or maybe for catharsis

"Deacon" - in leadership position but dependent on sources of information and guidance and backing -not the charismatic type 
"Weathervanes" - their stories will change each time you see them. Information, not their interpretation is useful. (Relays day-to-day climiate of opinion.) Leaders - in position of leadership give indication of where change may occur - by power or consensus depending on who they are

"Outsiders" - who know they are outsiders and can describe the influence clique

"Boundary-spanners". - links between groups and organization, with insights into both and how they relate

Decide of their interview is handled best by full control (direct or indirect), by give and take, or by allowing the interviewee to take thelead once the copic introduction has been made.

Have handy sinall cards with names of people relevant to the study. Numerous questions can be asked in terms of ordering the cards and observing relationships.

Probe, probe, probe. There are lots of good references on this. Look for phrases like "off the record," "what you don't understand is..." as cues to both the way you're coming across and how $s /$ he sees the situation and labels its subtleties and sensitive points. Sense the appropriate timing and don't end too formally. Walking out the door is sometimes the best time for people to let down. Don't schedule too closely in trying to save time. You need thinking and happenstance time as well as travel time. 
Checks

One must always be conscious of one's credibility to respondents and of the study's validity to the professional community. Investigative interviewing requires gauging the depth of information one is receiving and the extent of progress being made in covering key ground. How one handles contradictory information is critical. Does it represent different impressions, points of view, incomplete information, factual error?

Sometimes you must interview someone from who you anticiapte little additional information because an atmosphere of trust will quickly determiorate if certain people feel left out. If some one recommends a number of sources $s / h e^{\prime} s$ sure will be of use, at least one should be contacted to show you take the whole interview seriously. If in general, a group perceives certain people as key or simply "important," credibility of your approach is at stake.

Be careful to recognize "middle level information" which is neither vague generalities nor trivia and petty office intrigues with no predictive value. How it fits together in patterns is most meaningful.

Present clashes of information to interviewers for interpretation and refinement. "Someone mentioned.... do you agree?"

Circulate bits of information into the system that are interesting but will not betray confidences in order to trace 
communication patterns.

Look for half truths, asides, tones, and nuances, double meaning, internal inconsistencies, image versus operational, stock phrases which mean something different to each.

Be observant to "test" situations. Keeness to information which dare not be traced (as in informal versus formal policies) is tried before further information is given. You can get better information only to the extent you've gotten some good information. Catching on to inside humor is a good test also -- shows what one knows.

Use "non-information," (one administrator told me more in eight minutes of explaining why she couldn't talk to me than she did in a subsequent 45-minute interview.)

Observation, especially of interactions, is as important as interviewing. Use waiting rooms, common lunch areas, meeting, social functions, etc. Any unobtrusive measures possible are nelpful. Be around as much as possible.

While seeking a depth of information on the "real system" and people involved, guard against a clandestine operation attitude. Some situations lend themselves to it but the whole study could become suspect.

Test your observations also on others you know to be insightful in one or other of the perspectives. They will also give you clues to look for in continuing the study. 


\section{DOING RESEARCH FROM THREE PERSPECTIVES}

The three perspectives require not only different skills, (for instance statistical or interview skills) but different approaches to research itself in the gathering of different types of information.

The $T$ perspective emphasizes expertise and competence in specific research areas. It requires a plan of research acceptable to the scientific community. The plan is rigorous and lays out carefully developed hypotheses and specific methods of analysis. The exact strategy and time frame is specified out ahead of time and constitutes the design by which the researcher is held accountable.

The $O$ perspective is applied to the research process itself and examines the role of the investigators: are they "insiders" or "outsiders" to the organization being studied; if insiders, what are their assigned versus assumed (by virtue of the study) roles? The dynamics of the "real world" on the conduct of research is an important consideration. Many important decisions are made as the study progresses when constraints make themselves felt and opportunities present themselves: someone being interviewed offers an introduction to a key source, a key agency refuses access.

In team efforts, group dynamics and practical arrangements are also a consideration for the study. The timeframe is more responsive to the timing of opportunities, money 
available and deadlines than to preset research requirements to accomplish certain tasks in specified order.

The $P$ perspective is unique if it is to be considered more than the analysis of types of individuals and their influence on the topic. It is essentially a self-reflective research model in which the researcher is not only aware of how $s /$ he affects the matter being studied but is also aware of the process by which his/her open-ended research process comes to insights (versus conclusions). The type of check employed during the process is a measure of both integrity and insight. "What am I seeing here?" constantly checks the extent to which the image-in-formation is the result of who one is personally, culturally, etc. of being new to this category of information of situation, etc. The check system seeks contradictory information, alternative explanations, challenge to personal formulations from a wide variety of sources. It recognizes that interpretation happens at various levels and seeks both the integration of them and their relative usefulness to a given purpose. It recognizes that interpretation changes constantly not only with more information but with more reflection on its significance in changing the whole picture -- the way pieces are put together and emphasized, the tone of the whole.

It finds ways to communicate the insights gained -usually formal written reports are the least effective. Ongoing use of information in the context of a wide variety of 
discussions is often possible. Feeding the information appropriately back into the entire system (if this is the contractor of the study), assuming advocacy roles, interpreting rationales and frameworks from one group to another, using stories to demonstrate meanings difficult to convey are all possible -- and generally inappropriate in traditional research.

It seeks frameworks of understanding -- those unique ways of seeing which arise out of an individual's whole of biology and life experiences.

Even as it gets a handle on some part of the situation being studied, it asks "what else is happening?" and successively focuses and opens up, looks for contradictions and paradoxes.

The research is as good as the experience and facilitating ability of the researcher. It ends when artificially brought to a close or at a stage of temporary closure.

If the research is meaningful, it is drawing on something in the researcher and building her/him too even as it contributes insight into a situation under study.

\section{COMMUNICATING MULTIPLE PERSPECTIVES}

of key importance to understanding and using the Multiple Perspectives approach is the fact that not only do the perspectives present a self-evident different picture of the 
matter under consideration, but people who need that information themselves fall into different types -- sometimes to the extent that the other perspectives are virtually useless to them -- the lack of credibility.

While Anderson points out that a "common language" can be developed from the perspectives with which to raise issues of concerns and make plans, the communication process appears not so simple. Typologies of communication styles are available. It is useful in this context to relate communication styles as they react to the various perspectives. A rational manager type in the extreme, for example, tends to see the other perspectives not merely as inadequate but as inappropriate, wrong, petty, or self-serving. In turn that manager in a meeting of other managers taking an organizaiional perspective may appear eminently unrealistic and hence incapable of accomplishing the very goals they may agree on. A manager attuned to the dynamics of individual strategies, interests and power, may consider the others as insensitive. If the group is predominantly of the attuned type, the discussion will not only center on appraisingly involved parties, relaying political inside stories, and advocating political maneuvering, it will tend itself to be a game of position establishing within the circle. Further, this discussion takes place on a metalevel, i.e. communication happens at a subtle "I know that you know that I know..." level with respect to the gaming elements so that a non-type III person is left out 
and isn't even aware of the process. The others are "spinning their wheels and going around in circles," or are just being petty. (See Figure 27)

The importance of the perspectives then is that they can reach more than one group of people because they provide pertinent information (content focus) for each type from their accustomed point of view (style of seeing, hearing). An area which needs consideration is how to present the various types of information in accessible formats. This is not too difficult to conceive. Number -- whether counts of interrelationships in organization or scores yielding predictive profiles of key actors appeal to a type I person. On the other hand, numbers can be transformed into experiences (the number of standard nursing hours required to fulfill " $\mathrm{X}$ " number of functions as a specified rate for a certain number of women in labor and delivery means that three times the number of nurses should be on duty and instead of a nurse dashing from one fetal monitoring device to another, she could comfort an anxious first time mother by telling her what to expect and helping her with breathing exercises to alleviate pain.) Numbers can also be dramatized by an example (as columnist Jimmy Breslin does in his picture of the low income pregnant mother sitting on the stoop and speaking of kids, poverty, and abortion).

The more important issue, however, is the enlarging the capacity of people to see any situation from alternate 


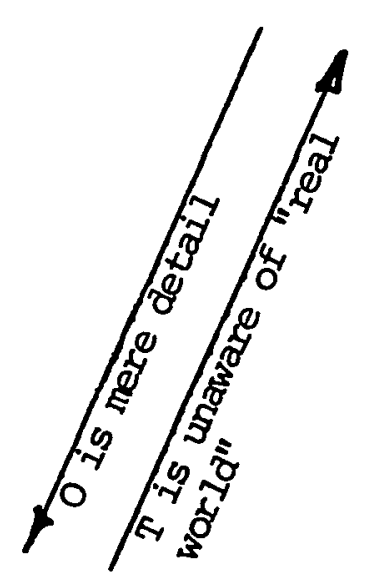

\begin{tabular}{l} 
Tants a Plan \\
Goals \\
Methodology \\
\hline
\end{tabular}
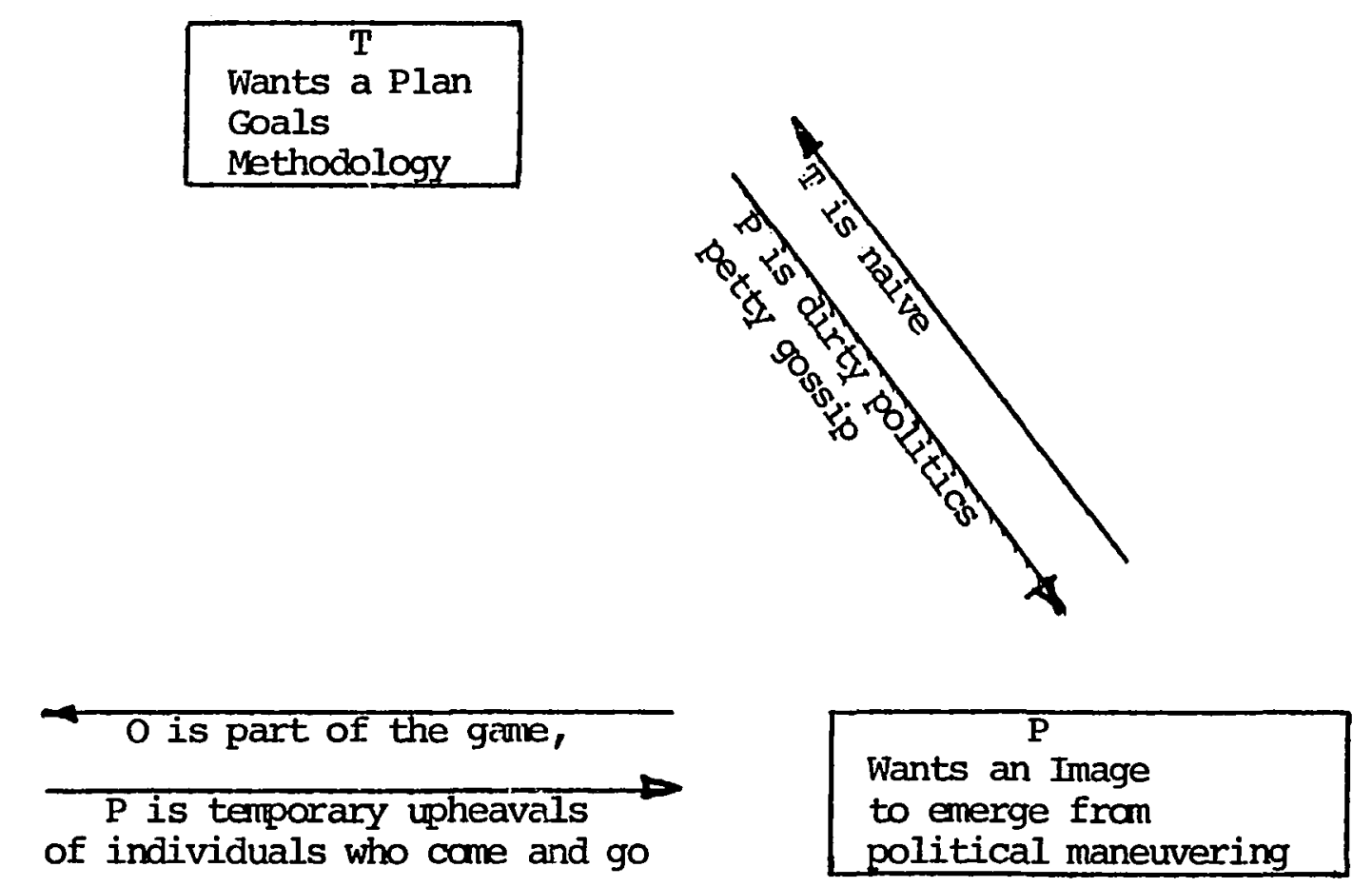

0

Wants a smooth operation

based on SOP

Fiqure 27. Perspective-bound basis for miscommunications. 
points of view. This has not been accomplished unless the perspectives have been performed by the appropriate types who aiso truly understand another type and are capable of clicking in on an area that can be used as a transition to understanding. Whereas Perspective III in this study is conveyed as a distillation of meaning in fictional form to suggest nuances and pervasive "forces," another means of communicating could have given episodes of interactions from each of the participants point of view when each participant agrees on some important aspect but area of disagreements is very rational.

An important caution in all of this, learned the hard way (again) by this writer, is that amount of information gathered is not communicated even though one necessarily accumulates a vast amount given the very use of multiple perspectives. Reams of notes were not used directly. The temptation to generalization versus adequate integration of generalization and detail is obvious. Perspective I calls for choice of critical parameters to consider, Perspective II portral of key interconnections, Perspective III for a basic feel for the whole. What do people need to know to do what they need to do? The perspectives contribute some interesting considerations to the imposition of limits. 


\title{
APPENDIX B \\ THE DELPHI INSTRUMENTS
}

\author{
THE FUTURE OF PERINATAL REGIONALIZATION: \\ A DELPHI
}

CONTENTS

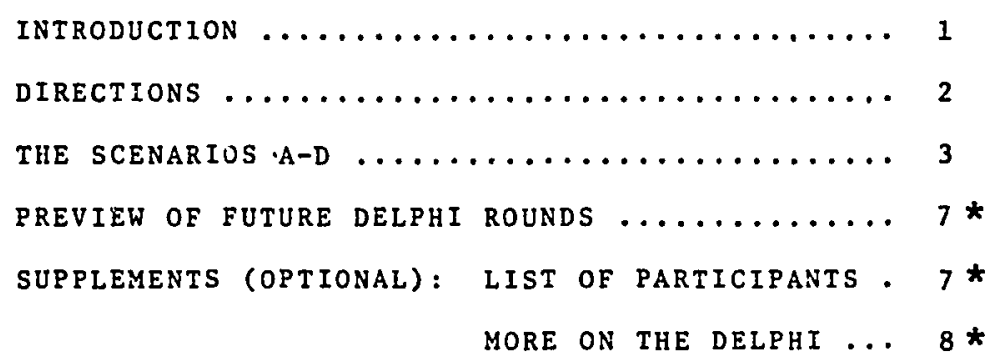

* Goldenrod colored in the original 


\section{INTRODUCTION}

You have been selected to participate in this event because of vour leadership position, influence, and knowledne. With your insinhts and experiences, we hope to use the Delohi Technique to answer the auestions:

- Where do we want Perinatal Regionalization, in this area, to go from here?

- How do we get there?

The aim of this Delphi is to desian a plan for the future of regionalization which will suite you, as a participant.

\section{PROCEDURE}

The Delohi works like this: Each month, for 4 months, vou will receive a packet with 2 parts. Each nacket is called a round and includes:

- A summary of what was said by people in the PRF.CE\&DING round, and

- Your tasks for THIS round.

Your part of the Delphi is designed to take 30 minutes. There are, however, sunplementary materials which may interest your. They describe in more detail the results of the preceeding round and provide optional avenues for expressing your ideas in areas you feel strongly about.

\section{SCHEDULE}

In order to keep on schedule (one round per month), it is important that you return this month's responses by OCTOBER 12, 1979.

To ensure that your interests and your profession are fairly and adequateiy represented, it is crucial that we receive YnuR replv.

\section{DEFIHITIOASS}

Please note the way we will use 2 terms throughout this exercise:

Scenario: a picture of a possible situation

Mechanism: a way of organizing to accomplish a goal.

PLEASE CALL LINDA UMBDENSTOCK AT 603-3146 IF YOU HAVE AIIY OUESTIONS. 
1. READ ALL 4 SCENARIOS. Each scenario starts with the same setting, but is based on a slightly different organizational theme. The focus of Round 1 is to determine the direction for more detalled discussion later. The scenarios in each round will change, depending upon your comments.

2. CHOOSE.1 SCENARIO: Select the one scenarlo which best describes the Region In 1985 , in which you would like to work. Each scenario describes a form of organization for attaining regional perinatal goals. You need not agree with every detall, but only with the overall plan of the one you choose.

3. ANSWER THE QUESTIONS which accompany the scenario you have chosen. They are on the back of that page. The questions ask about specific ways to form a good system and how well they suit you.

4. RETURN RESPONSES BY FRIDAY, OCTOBER 12, 1979. To ma11, please tear out the page with the questions you answered and return it in the envelope enclosed. The envelope has been coded so we can check you off the list when it is recelved. Your individual responses will be known only to the Researcher.

If you would prefer to dictate your responses, please do so by calling my Secretary, Betty Cheatham, at 603-3146, weekdays, 9-5.

\section{THE SETTIAG FOR EACH OF THE 4 SCENARIOS IS AS FOLLOWS:}

Today 1s halloween, 1985. It is $c 001$ and crisp and the children are awaiting their yearly adventures. Strange, how traditions remain with us over the years -yet everything around us is changing.

Things have changed since I've been here -- there are even more Spanish-speaking patients now, than five years ago. The birthrate continues to climb, although increases in specialists and family doctors have slightly reduced the doctor/patient ratlo. Patients usually have Medi-Cal or no insurance. They are more priceconsclous and aware of alternative types of health care. The public clinics continue to be over-capacity. None of the national health insurance bills has been implemented yet, so we're still fairly self-regulated.

USE THIS TO SET THE STAGE FOR THE FOLLOWING FOUR SCENARIOS. 
SCENARIO A:

REGIONAL CONSORTIUM MODEL

Some years back, complex problems in this area led to a number of voluntary arrangements. For instance, In-service and contfnuing education programs are now frequently open to staff from other hospitals in our network at no cost.

We have foint hospltal $O B$ meetings and each $O B$ Chief determines who is invited. Perlodically, the Comittee reviews the informal analysis performed on information from the common medical record. (Not everyone uses the same record, although there is encouragement to do so.) Changes in patient population, risk assessment, and quality of care, along with trends in medical practice are discussed.

A few years ago, the joing hospital comittee drew up a list for consultation and referrals. This has encouraged an exchange of services which helps to increase effectiveness and hold down costs.

Infant and maternal transfers on the basis of patient risk and hospital capability are encouraged. Nevertheless, hospital and patient preferences and the doctor's standing in the hospitals greatly affect individual arrangement.

Problems of occupancy rates, patfent education, staff shortages, diagnostic testing, and risking costs of medical care face each of the institutions in the network. Occasionaliy, two institutions will contract with each other on specific problems and solutions which are mut'dally beneficial. We're more than willing to work cooperatively in a group -- but we maintain ultimate control over our own part of the system! 
This scenarto describes a form of organization for attaining regional perfllatal goals. Below are the specific mechanisms which appeared in the scenario in support of that organizational form. For each mechanism on the left: If you agree with statement $I$, check that box, if not, leave it blank; 1f you ayree with statement II, check that box, If not, leave it blank.

Th1s mechan ism 1s

important to wor1d

trade.

$\mathbf{x}$

World Affalrs Council meets regularly

Mechan Isms
This mechantsm contri-

bureg greatly to a

regional organtzation.

This mechan18m

would work very

well for me.

$\mathbf{x}$

II

\section{Th1s mechantsm}

would work very

well for me.

Informal voluntary arrangements develop.

Voluntary arrangements for sharing of classes occur.

Jolnt $O B$ meetings are arranged by $O B$ Chiefs.

Use of the same medical forms is encouraged, but optional.

Informal analysis of problems and issues occurs.

Discussion of medical trends takes place.

A referral and consultation list is developed.

Encouragement of patient transfer $1 \mathrm{~s}$ based on risk/capability.

other mechanisms you want to include (name them)

\begin{tabular}{|c|c|c|}
\hline & $\mid$ \\
\hline
\end{tabular}


SCENARIO B :

BOARD OF DIRECTORS MODEL

A few years ago, in an effort to accomplish some jolntly held goals for the patients in this area, we started a Regional Council composed of doctors, nurses, administrators, educators, and others. This Council plans and implements regional programs with the tertiary center. The Council made a decision that the tertiary staff will meet separately with each institution's team to discuss areas of need and progress. Th1s is done by reports based on the common medical record. The record is used with some local variations and reports also vary in format and in use by each institution.

Continuing education is sponsored for teams. Family doctors, nurse gidwives, HMO staff, and health educators are encouraged to particlpate. Regional professional meetings for supervisory $O B$ and neonatal nurses in clihics and in hospitals are rotated among hospitals. The Counctl sponsors an orfentation to regionalization once a year for new staff.

Another feature that we designed is a system to ease transfers through conmunication and simplifted paperwork. A subcomittee assesses transfers and outcomes on the basis of patient risk and facility capability. Medical protocols are written for comon problems in the Region by delegated teams. Also, formally established is the consultation/referral system using multiple resources in the Region.

The Council exerts concerted leverage on other related agencies regarding the Region, Including JCAH, HSA, and Med1-Cal. In the Council, we are able to address Region-wide problems through jointlyshared resrouces and mechanisms of borrowing and repayment. This has helped to balance out bed use rates, staff shortages, and educational needs. The bottom line is -- we're in this together and we have a powerful vehicle to use to affect the changes we want! 
This scenarto describes a form of organization for attaluing regional pertnatal goals. Below are the spectfic mechanisms which appeared in the scenario in support of that organizational form. For each mechanism on the left: If you agree with statement $I$, check that box, If not, leave it blank; if you agree with statement II check that box, if not, leave it blank.

EXAMPLE Newspapers provide information Th1s mechanism 19 important to world trade. Th1s mechanism would work very well for me. World Affalrs Council meets regularly

$\mathbf{x}$

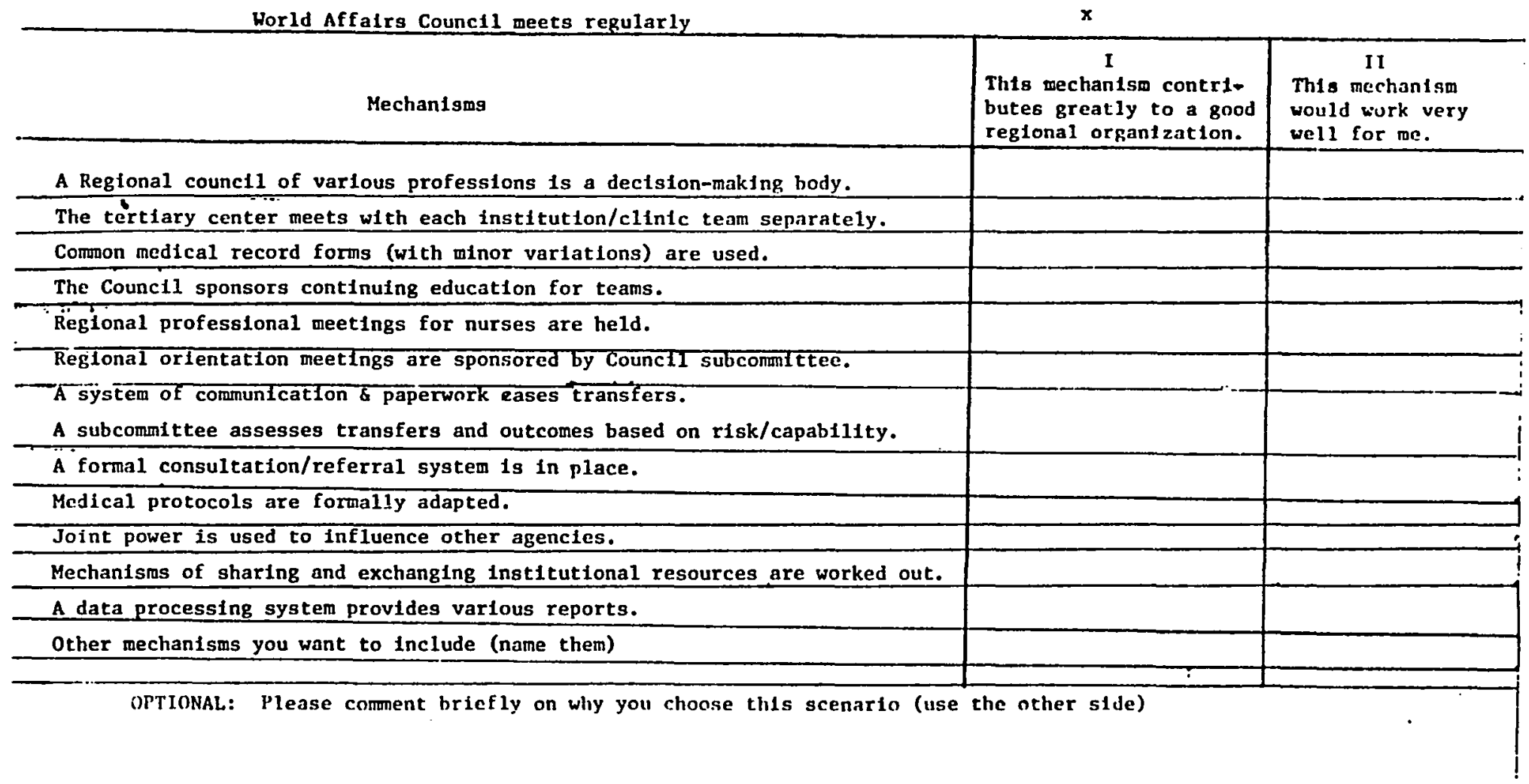


SCENARIO C: PYRAMID MODEL

Several years ago, we faced the problem of much higher-than-average mortality and morbidity rates in our institutions in this area. So we spearheaded a move to form a regional network for perinatal care. We gave the tertiary center authority to upgrade standards and practice in the Region by providing information, education, and follow-up. Individually, we knew we couldn't provide the level of education that was required to keep up with medical advances and with govermment red tape.

The Center sets regional standards for various levels of care. Assessments of each hospltal's needs and the conrdination of education resources are important parts of this task. Classes and conferences from the Center are almed at ensuring minimal standards.

A comon medical form is used for education, hospital assessment, and patient risk management by all doctors and hospitais. The forms are computer analyzed and each hospital is provided with useful information as to how the risk trends in the Region are reflected in each institution. Significant changes are monitored by the Center and result in regional protocols.

Consultant and referral guidelines for optimal ; atfent flow through the system are 1ssued by the Center. Infant and maternal transfers, based on the patient's risk and the hospital's capability, are monftored by the tertlary center. An analysis of transfer results and centrallzed high risk Infant follow-up are also provided by the Center. Practical approaches to acknowledged region-wide problems and imbalances are reviewed by the Center, such as $O B /$ surgery bed utilization and diagnostic and laboratory fac1lities.

Although there are uniform standards by hospital level, there is diversity among hospitals, clinics, and private offices in their approach to patient care. We are now thinking of a way to coordinate planning to address other problems which can Improve staff morale and recruitment, cost reductions, and profit margins. What can be dune with strong leadership and the backing of our comitment is amazing: 
Th1s scenar1o describes a form of organization for attalning reglonal perinatal goals. Below are the spectfic mechanisus which appeared in the scenario in support of that organizational form. For each mechanism on the left: If you agree with statement I, check that box, if not, leave it blank; if you agree with statement II check that box, if not, leave it blank.

EXAMPLE -

Newspapers provide information World Affalrs Counc1l weecs regularly

\begin{abstract}
This mechantsm is
important to wor 18
\end{abstract}

trade.

$\mathbf{x}$
This mechan $1 \mathrm{sm}$ would work ver well for we.

$x$

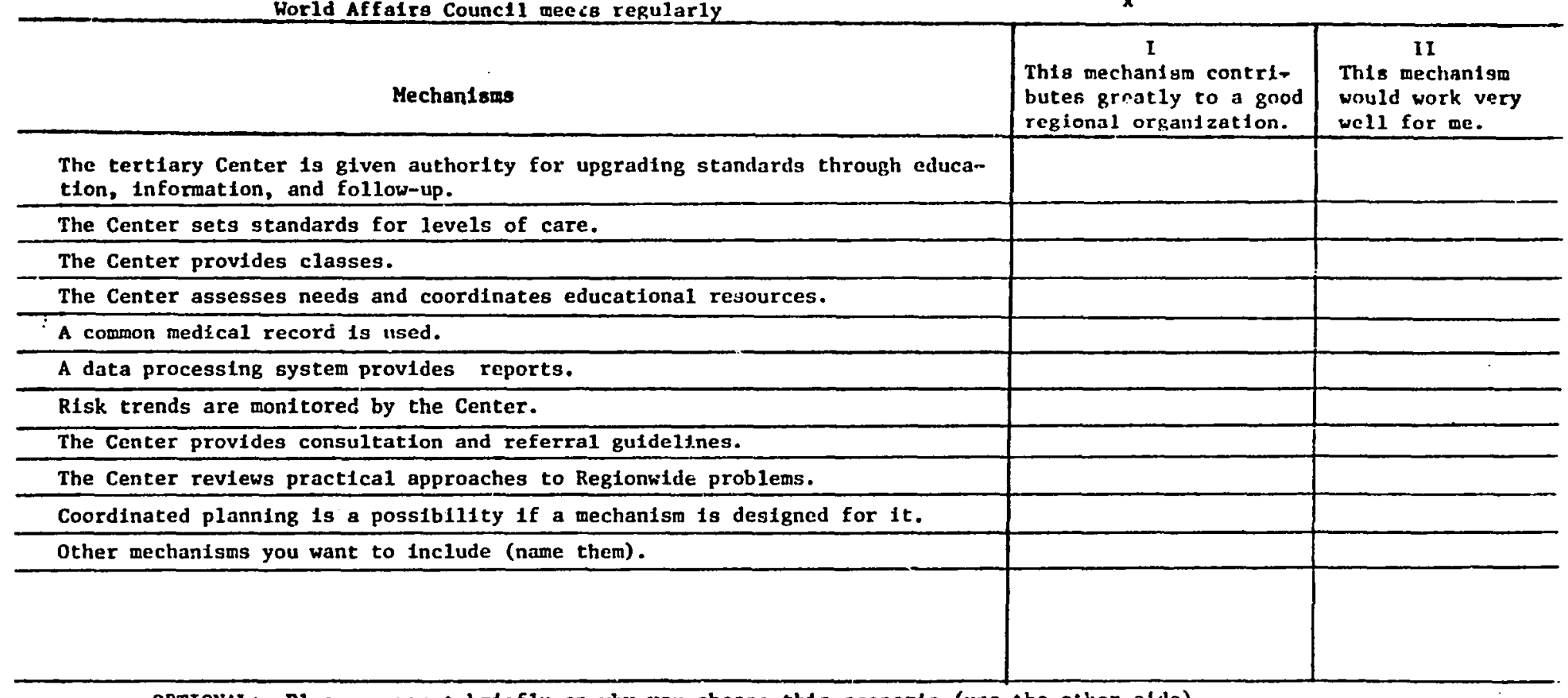

OPTIONAL: Please coment briefly on why you choose this scenario (use the other side) 
SCENARIO D:

FREE ENTERPRISE AT WORK MODEL

If variety is the splce of I1fe, this is not a bland diet. Each hospital, clinic, doctor's office is its own domain. The dectsion on where to deliver is left entirely to the patient and her physician. Quality of care varles some, but we all know, you get what you pay for. Most women prefer to deliver at the hospital closest to home and there are other practical considerations too, like payment source and physician standing. It's a very rare case where the physician feels that medical problems or possible risks to mother or baby warrant a different hospital "on doctor's orders". Transfer of sick infants are unusual-most physicians find that there are very feu cases where the "technologic supremacy" of the larger hospital outweighs the benefits of the smaller

one.

Decisions to counsult are based solely on the physician's perception of the problem and most doctors have only a very few cases beyond their expertise. There never were enough problem cases to make establishment of a formal network worth all the bother. Each hospital, based on its priorities and resources, decides whether to provide continuing education programs or to expect staff to pursue thefr own methods of keeping up. Each place has its own medical record form. Staffing and equipment needs are always debatable. But at least we have control over our own system. No one can tell us what to do, when to do $1 t$, or how 1 t should be done! 
This scenario describes a form of organization for attaining regional perinatal goals. Below are the specific wechanisus which appeared in the scenario in support of that organizational form. For each mechanism on the left: If you agree with statement $I$, check that box, If not, leave it blank; if you agree with statement II, check that box, If not, leave it blank.

This mechanism is Irportant to world trade.

\section{EXAMPLE -}

Newspapers provide information World Affairs Counc1l meets regularly

\section{Mechantsms}

This mechanism would work very vel1 for me.

$\mathbf{x}$

Thts mechanism contri-

butes greatly to a good

regional organization.

There is no regional organization.

Each hospital has inservice education to the extent 1 wishes and is able to provide.

Consultations occur only as individually desired.

Transfers occur only as individually destred.

Each hospital and prenatal office selects 1 ts own forms.

Each hospital or doctor sets its own protocols.

other mechanisms you want to include (name them)
This mechanis

would work very well for me. 


\section{COMING ROUNDS}

ROUND 2 A. A sumary of the scenarlos favored in Round 1

- Reasons for their selection

- Which professions (1f there are differences) favored each one

B. The scenarios are revised based on responses in Round 1 . Round 2 questions will deal with:

- Implications

- Appeal of the mechanism to various groups

- Means of achlevement (what should be done and by whom)

ROURID 3 A. A sumary of Round 2

B. The scenarios will be revised, based on responses in Round 2 . Round 3 questions will deal with:

- Effects of alternative settings (external events which we have Ifttle or no control over, such as the Century Freeway, federal imigration laws, energy crises)

- What mechanisms participants are willing to actively support

- Under what conditions w111 participants support a certain mechanism

- Arguments to consider in Round 4

ROUND 4 A. A summary of Round 3

B. Vote on final mechanism

\section{LIST OF PARTICIPANTS}

This 11 st will be enclosed next time as replles are still coming in. To date, participants include over 23 doctors and 20 nurses, amdinistrators, medical records people representing the various hospitals in the Region. 
DELPHI IN GENERAL

a)Description of DeIphi from The Delphi Method: Techniques and Applications. by H.A. Linstone and M. Turoff, 1975. (emphasis added)

Delphi may be characterized as a method for structuring a group communication process so that the process is effective in allowing a group of individuals, as a whole, to deal with a complex problem.

To accomplish this "structured communication" there is provided: some feedback of individual contributions of information and knowledge; some assessment of the group judgment or view; some opportunity for individuals to revise views; and some degree of anonymity for the individual responses.

When viewed as communication processes, there are few areas of human endeavor which are not candidates for application of Delphi. While many people label Delphi a forecasting procedure because of its significant use in that area, there is a surprising variety of other application areas. Among those already developed we find:

-Evaluating possible budget allocations - Exploring urban and regional planning options - Planning university campus and curriculum development

Delineating the pros and cons associated with potential policy options -Exposing priorities of personal values, social goals

See examples from the fields of medicine and health organizations on attached references]

Usually, one or more of the following properties of the application leads to the need for employing Delphi:

- The problem does not lend itself to precise analytical techniques but can benefit from subjective judgments on a collective basis

- The individuals needed to contribute to the examination of a broad or complex problem have no history of adequate communication and may represent diverse backgrounds with respect to experience or expertise

- More individuals are needed than can effectively interact in a face-to-face exchange

- Time and cost make frequent group meeting infeasible

- The efficiency of face-to-face meetings can be increased by a supplemental group communication process

- Disagreements among individuals are so severe or politically unpalatable that the commuication'process must be refereed and/or anonymity assured

- The heterogeneity of the participants must be preserved to assure validity of the results, i.e., avoidance of domination by quantity or by strength of personality ("bandwagon effect") 
DELPHI IN GENERAL

The most common [Form of DelphD is the paper-and-pencil version which is commonly referred to as a "Delphi Exercise." In this situation a small monitor team designs a questionnaire which is sent to a larger respondent group. After the questionnaire is returned the monitor team sumnarizes the results and, based upon the results, develops a new questionnaire for the respondent group. The respondent group is usually given at least one opportunity to reevaluate its original answers based upon examination of the group response. To a degree, this form of Delphi is a combination of a polling procedure and a conference procedure which attempts to shift a significant portion of the effort needed for individuals to communicate from the larger respondent group to the smaller monitor team.

Usually Delphi, undergoes four distinct phases. The first phase is characterized by exploration of the subject under discussion, wherein each individual contributes additional information he feels is pertinent to the issue. The second phase involves the process of reaching an understanding of how the group views the issue (i.e., where the members agree or disagree and what they mean by relative terms such as importance, desirability, or feasibility). If there is significant disagreement, then that disagreement is explored in the third phase to bring out the underlying reasons for the differences and possibly to evaluate them. The last phase, a final evaluation, occurs when all previously gathered information has been initially analyzed and the evaluations have been fed back for consideration.

b) Examples of some Delphis Used in the Health Field

Moscovice, I. et.al., "Health Services Research for Decision-makers: the Use of the Delphi Technique to Determine Health Practice," Journal of Health Politics Policy and Law, $2(3): 388-410,1977$.

Hillman, B.J. et.al., "Improving Diagnostic Accuracy: A Comparison of Interactive and Delphi Consultations", Investigations in Radiology, 12 (2):112-5 Mar-Apr 77.

Grimes, R.M. and S.K. Mosely, "An Approach to An Index of Hospital Performance" Health Services Research 11(3):288-301, Fal1 1976.

Wooley, P.O. and B.A. Wooley, "IMP:A New Method for Health Problem Assessment," Journal of Community Health 2(2):107-12, Winter, 1976.

Smith, K.A. and R.L. Johnson, "Medical Opinion on Abortion in Jamaica: A National Delphi Survey of Physicians, Nurses and Midwives Studies in Family Planning, 7(12):334-9, Dec., 1976.

Goodale, F. and G.W. Gander, "The Future of Pathology: A Delphi Study by Pathology Department Chairman", Journal of Medical Education S1(11):897-903, Nov., 1976. 
DELPHI IN GENERAL

Schoenbaum, S.C. et.al., "The Swine-Influenza Decision," New England Journal of Medicine, 295(14):759-65, 30 Sept, 1976.

Rosser, R.M. and B. Chir, "The Reliability and Application of Clinical Judgment in Evaluating the Use of Hopital Beds, "Medical Case 14(1):39-47, Jan., 1976.

"A Delphi Study of the Ethical, Legal, Socal Implications of Advances

in Biomedical Research and Technology" Gov. Contract No. NO1-HU-6-2105 (As yet, unpublished).

Bender, A.D., et.al. "Delphi Forecast of the Future of Medicine," Futures, 1:289-303, 1969. 
THE FUTURE OF PERINATAL REGIONALIZATION:

A DELPHI

ROUND II

CONTENTS

ORIENTATION TO ROUND $2 \ldots \ldots \ldots \ldots \ldots \ldots \ldots \ldots \ldots \ldots \ldots \ldots \ldots \ldots$

PART 1 - SUMARY OF RESPONSES FROM ROUND $1 \ldots \ldots \ldots \ldots \ldots \ldots \ldots 2$

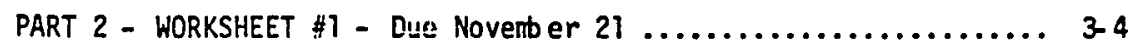

WORKSHEET \#2 - Due Novertber $21 \ldots \ldots \ldots \ldots \ldots \ldots \ldots \ldots \ldots, 5-6$

OPTIONAL (goidenrod-colored section)*

Add itional worksheets $\ldots \ldots \ldots \ldots \ldots \ldots \ldots \ldots \ldots \ldots \ldots . . \ldots \ldots$

Detailed description of responses ................. 9-11

Original scenarios of models A-C .................. 12-13

List of participants .......................... 14

* In the original 
ORIENTATION FOR ROUND 2

This Delphi study is undertaken to look at the future of perinatal regionalization in this area: where do you want it to go? How do we get there? The Delphi method allows participation and interaction without meetings.

In round 1, just completed, scenarios were chosen to shape the direction of regionalization efforts in the future and to provide a structure for more detailed work in rounds 2 and 3 . As would be expected, there is some iifference of opinion as to which scenario is most desirable. Scenario D, Free Enterprise Model-no regionalization organization, was eliminated by the participants. Scenario $C$ was modified. (See summary, page 2.) The Delphi method allows for participants to change their minds based on the reasoning offered by other participants.

In round 2 , then, the task is to reaffirm or change your mind about the basic dirccticn you desire for perinatal regionalization. You are then asked to consider the implications of that direction and the practicalities of making it work-both for its basic organizing mechanism (worksheet 1) and for one supporting activity you choose (worksheet \#2).

In round 3 , these issues and suggestions will be sumnarized and means of support will be looked into.

RETURN YOUR COAPLETED PAGES IN THE ENVELOPE PROVIDED BY [NONĒEMBEER $2 \overline{1}$ OR, AGAIN, YOU MAY DICTATE YOUR RESPONSES BY PHONING MS. BETTY CHEATHAM AT 603-3146. TO AVOID THE HOLIDAYS IN SENDING OUT THE NEXT ROUNDS, IT IS IMPERATIVE THAT WE HAVE YOUR RESPONSES BY NOUVEMBER $\ddot{2} i I$. THIS ROUND INILL BE ANALYZED THE IVEEK OF NOVENBER 26 AND THE NEXT ROUND SENT THE HEEK OF DECEMBER 3 . THANK YOU ON BEHALF OF ALL THOSE INTERESTED IN THE FUTURE OF REGIONALIZATION FOR YOUR PARTICIPATION

Remember, the process is designed to take you only a half hour (in lien of all participants trying to meet for this important discussion). However, those who wish to comment on more than one mechanism on worksheet 2 may use the OPTIONAL goldenrod worksheets. These comments will be included with the others. 
ORIENTATION FOR ROUND 2

This Delphi study is undertaken to look at the future of perinatal regionalization in this area: where do you want it to go? How do we get there? The Delphi method allows participation and interaction without meetings.

In round 1 , just completed, scenarios were chosen to shape the direction of regionalization efforts in the future and to provide a structure for more detailed work in rounds 2 and 3 . As would be expected, there is some difference of opinion as to which scenario is most desirable. Scenario D, Free Enterprise Model-no regionalization organization, was eliminated by the participants. Scenario $C$ was modified. (See sumnary, page 2.) The Delphi method allows for participants to change their minds based on the reasoning offered by other participants.

In round 2 , then, the task is to reaffirm or change your mind about the basic direction you desire for perinatal regionalization. You are then asked to consider the implications of that direction and the practicalities of making it work-both for its basic organizing mechanism (worksheet 1) and for one supporting activity you choose (worksheet \#2).

In rounc 3 , these issues and suggestions will be sumnarized and means of support will be looked into.

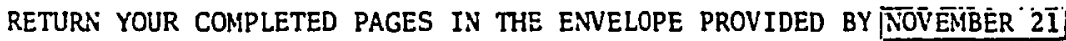
OR, AGAIN, YOU MAY DICTATE YOUR RESPONSES BY PHONING MS. BETTY CHEATHAM AT 603-3146. TO AVOID THE HOLIDAYS IN SENDING OUT THE NEXT ROUNDS, IT IS IMPERATIVE THAT WE HAVE YOUR RESPONSES BY (NOVVEMBEER 211 . THIS ROUND VILL BE ANALYZED THE IVEEK OF NOVEMBER 26 AND THE NEXT ROUND SENT THE WEEK OF DECEMBER 3. THANK YOU ON BEHALF OF ALL THOSE INTERESTED IN THE FUTURE OF REGIONALIZATION FOR YOUR PARTICIPATION.

Remember, the process is designed to take you only a half hour (in lieu of all participants trying to meet for this important discussion). However, those who wish to comment on more than one mechanism on worksheet 2 may use the OPTIONAL goldenrod worksheets. These comments will be included with the others. 
SURMARY OF RESPONSES FROM ROUND-I

- The majority of participants chose scenario B: Board of Directors Model. The reasons of ten cited were, it

- is workable

- has coordination without too much control; balance between public and private sectors

- encourages teams and partictpation from various disciplines and hospitals

- reflects the best interest for patient care in all settings

- The next most often chosen was scenario C: Pyramid model. It was modified by a particlpant to emphasize more responsibility on the part of components and more input from them. The reasons for $C$ include, it

- Is comprehensive while diverse in patfent care approaches

- maintains standards

- minimizes waste

- uses resources well

- Several partfcipants chose scenario A: Regional Consortium model. It

- creates unity and mutual bonding by encouraging participation in decision making

- provides for exchange of ideas, thereby consistency in the region

- is more applicable

- provides an avenue of effective triage

- No one chose Scenario D: Free Enterprise at Work model-though some comented on its mechanisms

- Most mechanisms in A,B, and C appear to "contribute greatly" to regionalization to those who chose that model.

- Generally there was not a wide difference in responses to "mechanisms which would work very well for me." However, respondents who chose scenario $C$; pyramid model, most favored the mechanism, "The Center assesses needs and coordinates educational resources."

- There were no noticeable differences in the cholce of models or rating of mechanisms either by institutions or professions.

FOR THE COUNTS OF RESPONSES AND MORE DETAILS ON RATIONALE FOR CHOICES, SEE OPTIONAL SECTION PAGES 9-11. 


\section{WORKSHEET \#1 - CHOICE OF TORIC}

- CHECK below, the one basic organizing mechanism for regionalization you prefer. (This will be the same as last round unless you have changed your mind. If you did not return your reply last time, and need more information, see pages 12-13).

A. Regional Consortium model: Informal voluntary arrangements develop.

B. Board of Directors model: A Regional council of various professions is a decision-making body.

c. Pyramid mode1: The tertiary Center is given authority for upgrading standards through education, information, and follow-up.

C. ALTERNATE: Like $c$, but with emphasis on mutual Responsibility/ Accountability: The tertiary Center makes decisions with input and cooperation from the components.

D. OTHER: Please descrive

- Using the organizing mechanism you have chosen above, COMPIETE Worksheet "1-continued on the next page.

In the first section, Iist "Positive and Negative Factors" you see associated with the mechanism you have chosen. You may wish to consider aspects of costs, benefits, distribution of power, quality of care, change in procedures and practice required, ethical, legal, economic, individual implications, etc. Please be specific.

Under "Implementation" Iist the practical arrangements necessary if the mechanism is to work. 
WORKSHEET * 1 CONTINUFP DISCUSSION

Using the mechanism checked on the nreceding page. digcuss the followlof

POSITIVE \& NEGATIVE FAC,TORS

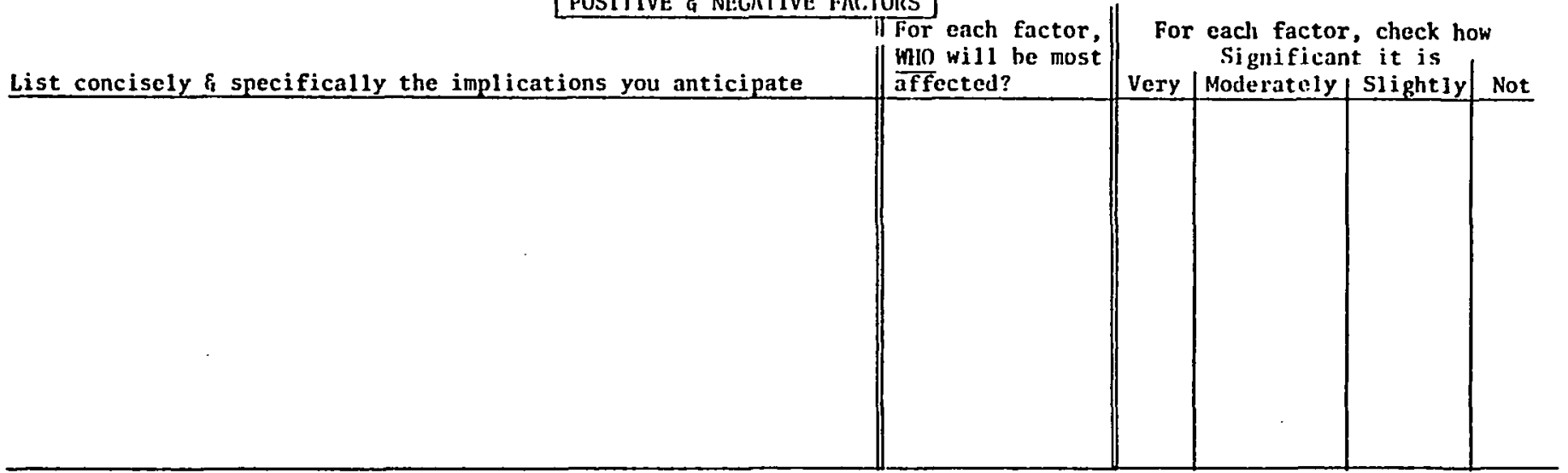

IMPLEMENTATION

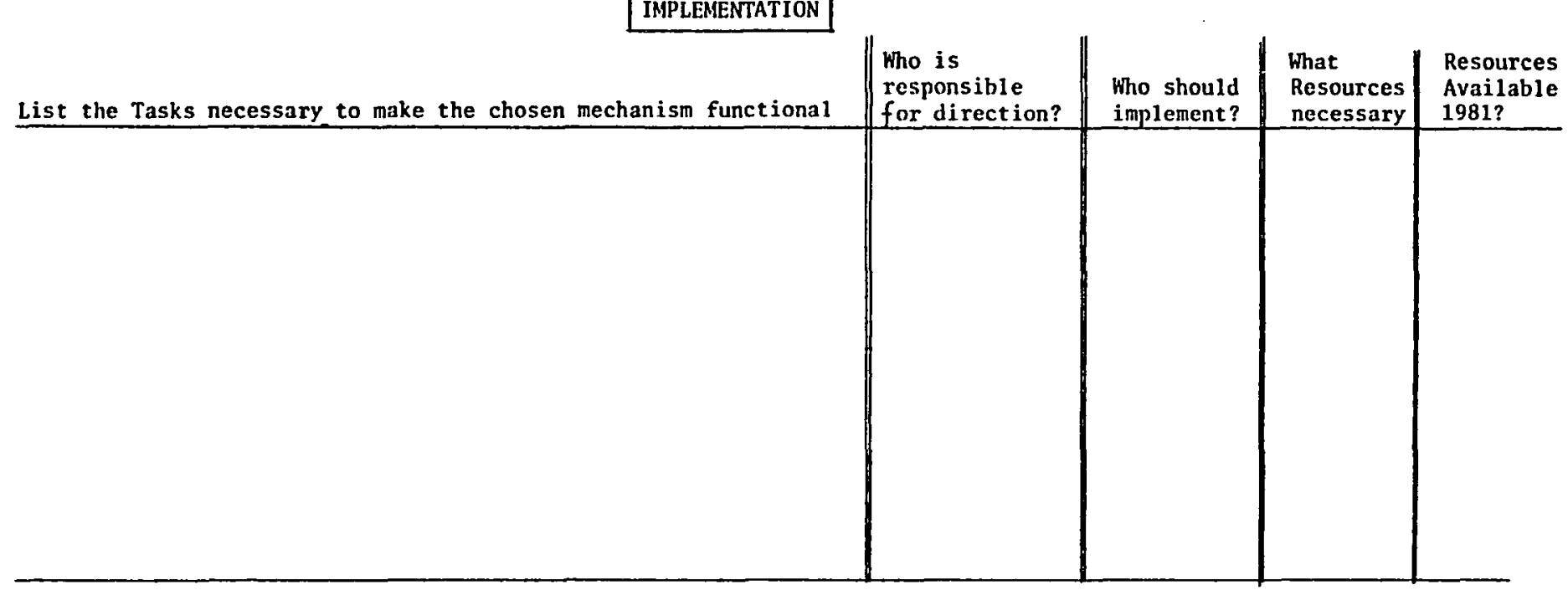




\section{WORKSHEET \#2: CHOICE OF TOPIC}

For the model you have already chosen on worksheet 1 , (e1ther A,B, or C) look over the set of supporting mechanisms with the same label. CHOOSE ONf; mechanism which you think has the most 1mpact on the success of regionalization and CIRCLE IT. You need only conslder that one set and may disregard the rest. (If, however, you feel that a mechanisw frow another set best sufts your cholce, that is acceptable.) Some items below were added by participants. Dfscuss you choice

on Worksheet $\| 2$ - continued on the next page.

$$
\text { A. MECHANISHS: MECLOHNL CONSORTILM MODEL }
$$

A-1 Voluneary arrangements for shering of classes occur.

A-2 Joint $O B$ Meetings are arranged by $O B$ Chiefs.

A-3 Use of the same medical forns is encouraged, but optional.

A-4 Informal analysis of problems and issues occurs.

A-5 Discussion of medieal trends takes place.

A-6 A referral and consultation list is developed.

A-7 Encouragement of patient transfer is based on risk/capability.

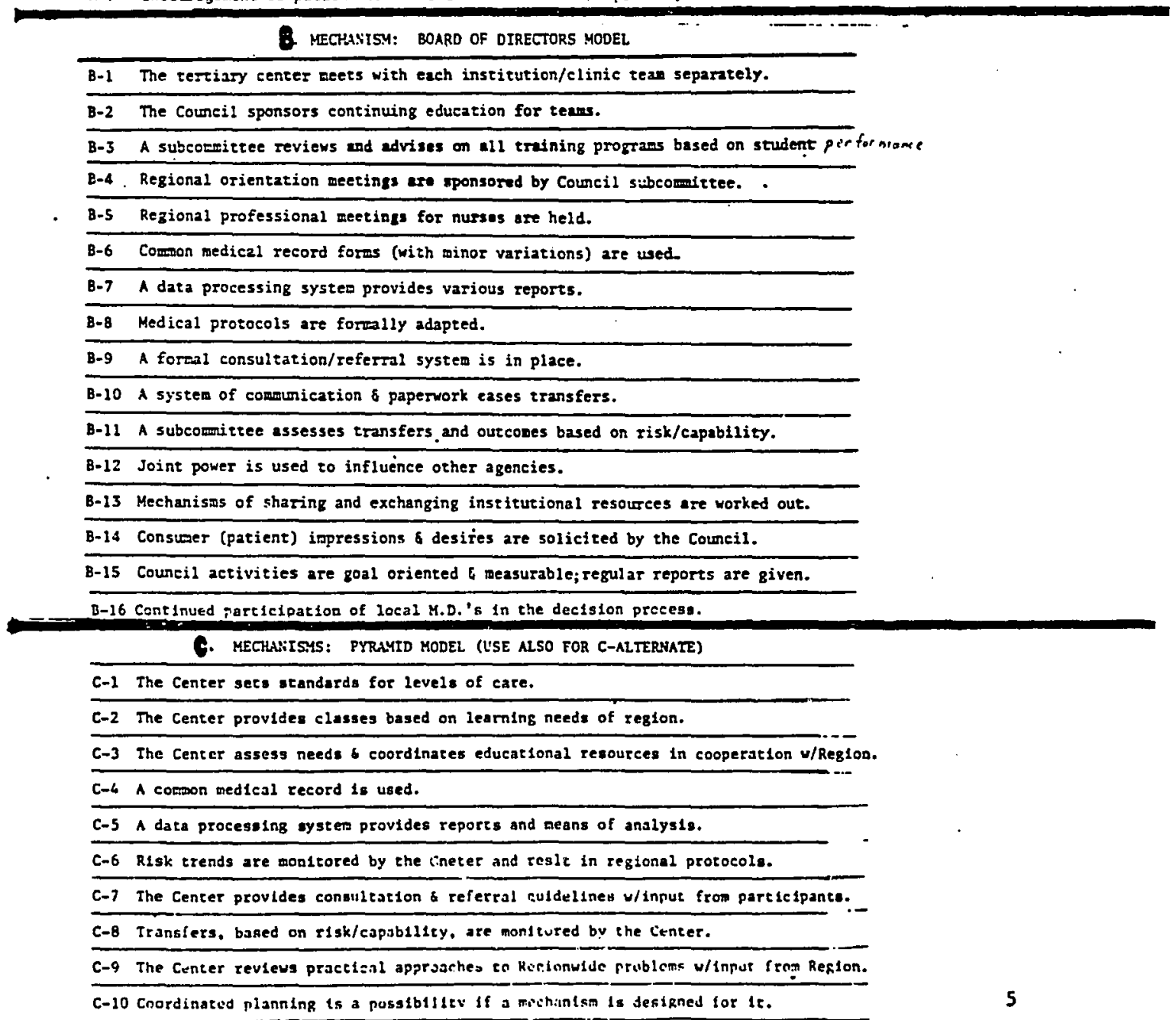


WORKSHEET 2 CONTINUED DISCISSION

Using the mechanism checked on the nreceding poge. Clscuss the following

POSITIVE \& NEGATIVE FACTORS

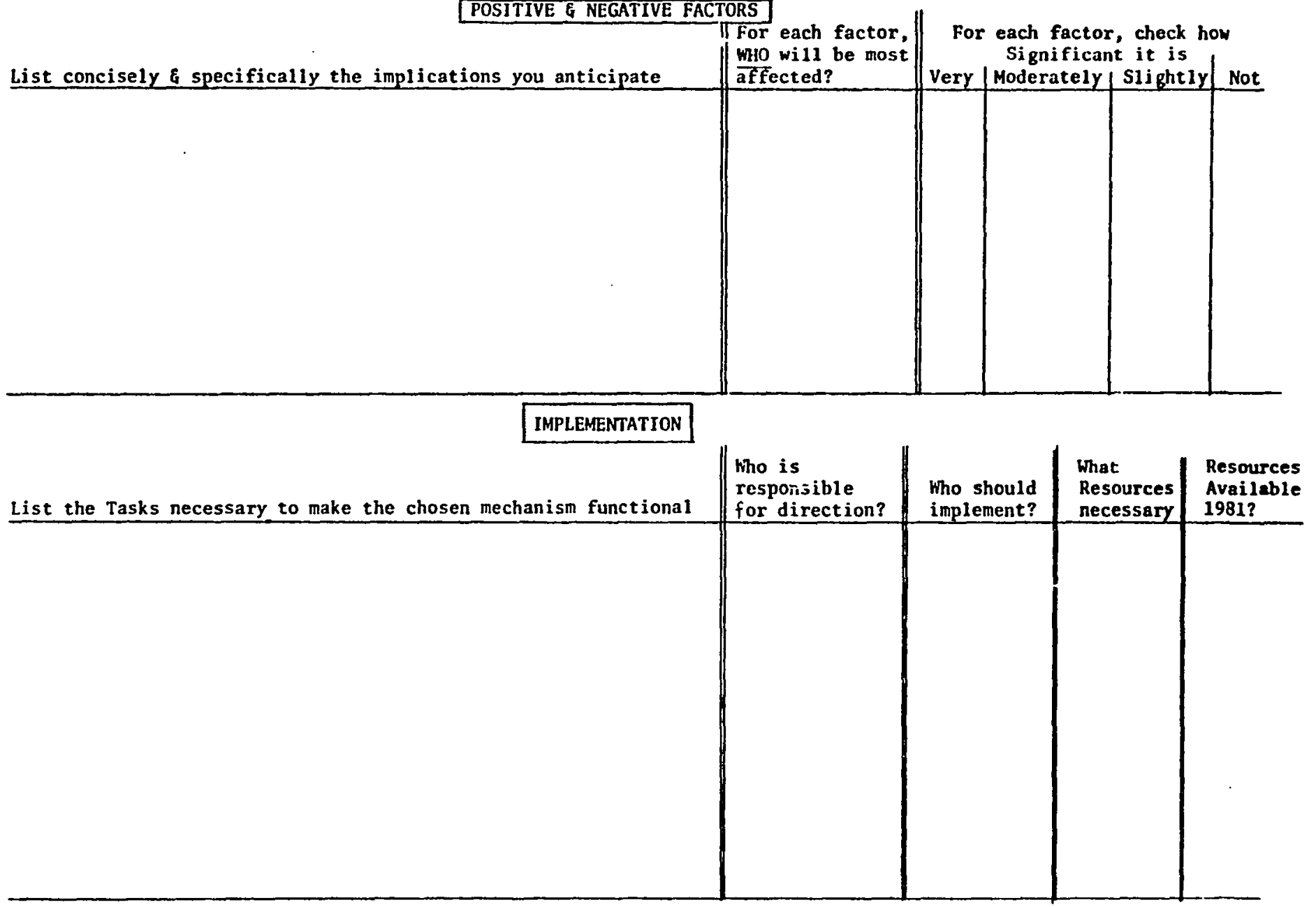


WORKSHEET : OPTIONAL

Give the letter and number of the mechanism you chose from page 5:

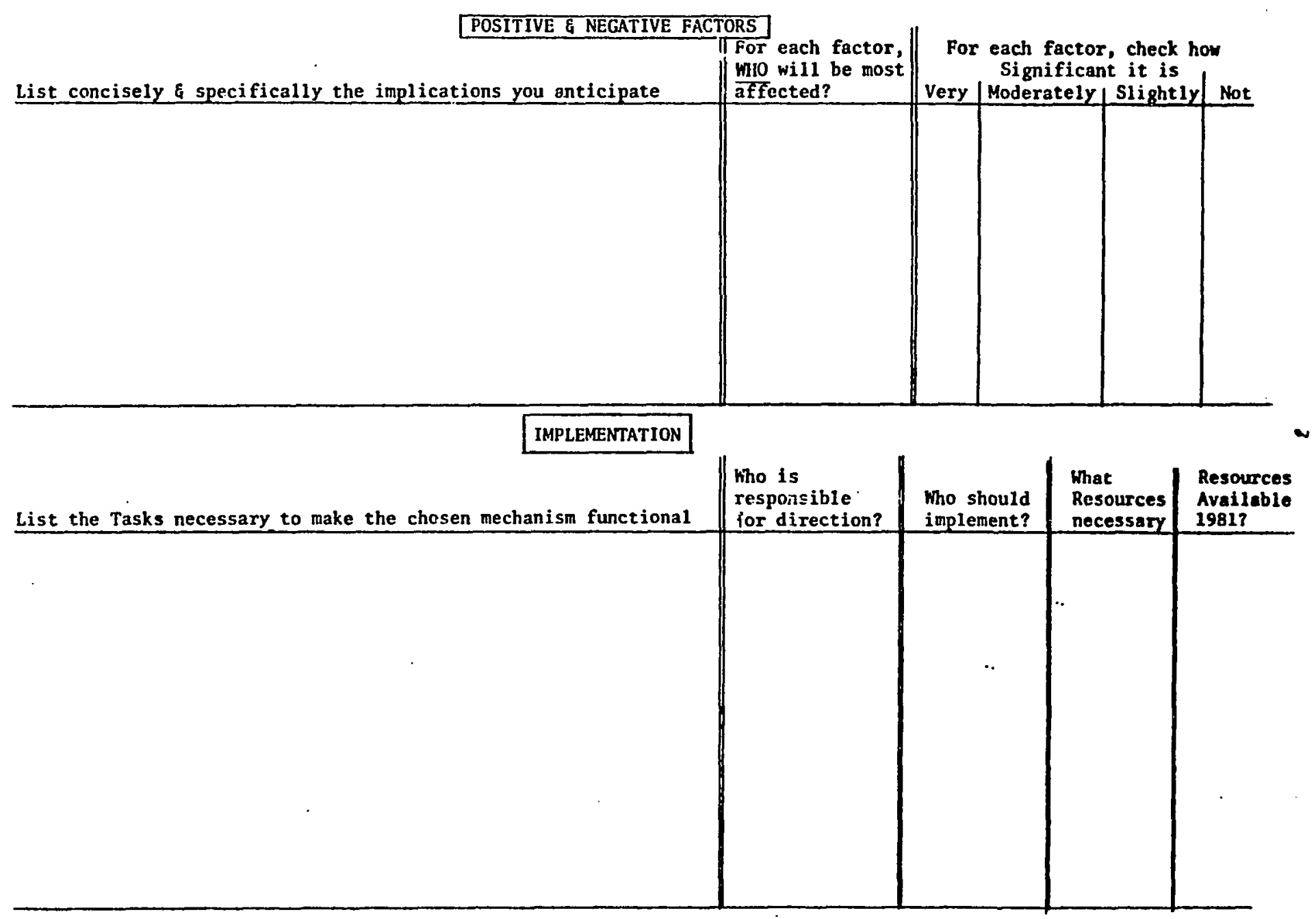




\begin{tabular}{|c|c|c|}
\hline $\begin{array}{l}\text { SCENARIO A: REGIONAL CONSORTIUM MODEL } \\
\text { Mechanisms }\end{array}$ & $\begin{array}{l}\text { I } \\
\text { Th1s mechan1sm contri- } \\
\text { butes greatly to a good } \\
\text { reglonal organtzation. } \\
\end{array}$ & $\begin{array}{l}\quad \text { II } \\
\text { This mechanism } \\
\text { would work very } \\
\text { well for me. }\end{array}$ \\
\hline Informal voluntary arrangements develop. & 3 & 1 \\
\hline Voluntary arrangements for sharing of classes occur. & 3 & 2 \\
\hline Joint $O B$ meetings are arranged by $O B$ Chiefs. & 5 & 4 \\
\hline $\begin{array}{l}\text { Use of the same medical forms ts encouraged, but optional. } \\
\text { Informal analysis of problems and issues occurs. }\end{array}$ & 2 & $\frac{3}{2}$ \\
\hline Discussion of medical trends takes place. & 4 & 4 \\
\hline A referral and consultation 11 se is developed. & 4 & $\frac{3}{2} \ldots \ldots$ \\
\hline Fincouragement of patient transfer $1 \mathrm{~s}$ based on $\mathrm{r} j \mathrm{sk} /$ capabllity. & 3 & \\
\hline $\begin{array}{l}\text { SCENARIO 8: BOARD OF DIRECTORS MOILLL } \\
\text { Mechantsma }\end{array}$ & $\begin{array}{l}\text { I } \\
\text { Th1s mechanisa contri- } \\
\text { butes greatly to a good } \\
\text { reglonal organtzation. }\end{array}$ & $\begin{array}{l}\text { ll } \\
\text { Th1 a merhanism } \\
\text { would wurk very } \\
\text { well for me. }\end{array}$ \\
\hline A Regional council of vartous professions is a dectsion-making body. & 15 & 12 \\
\hline The tertlary center meets with each institution/clintc team separately. & 10 & 10 \\
\hline Common medical record forms (with minor variations) are used. & 14 & 11 \\
\hline The Council sponsors continuing education for teams. & 14 & 10 \\
\hline Regional professional meetings for nurses are held. & 13 & 8 \\
\hline Regional orientation meetings are sponsored by Councll subcomittec. & 11 & 10 \\
\hline $\begin{array}{l}\text { A system of communtcatton \& paperwork eases transfers. } \\
\text { A subcommittee assesses transfers and outcomes based on risk/capability. }\end{array}$ & $\begin{array}{l}13 \\
13 \\
\end{array}$ & $\begin{array}{r}10 \\
9\end{array}$ \\
\hline A formal consultation/referral system is in place. & 14 & 11 \\
\hline Medical protocols are forma1ly adapted. & 15 & 10 \\
\hline Ioint power is used to influence other agencles. & 14 & 12 \\
\hline Mechanisms of sharing and exchanging institutional resources are worked out. & 14 & 11 \\
\hline A data processing system provldes varfous reports. & 13 & 10 \\
\hline
\end{tabular}




\begin{tabular}{|c|c|c|}
\hline SCENARIO C: PYRAMID MODEL & $\begin{array}{l}\text { I } \\
\text { Th1s mechanism contri- } \\
\text { butes grnatly to a gnod } \\
\text { regional organl zation. }\end{array}$ & $\begin{array}{l}\quad 11 \\
\text { This mechantsm } \\
\text { would work very } \\
\text { we } 11 \text { for me. }\end{array}$ \\
\hline $\begin{array}{l}\text { The tertiary Center is given authority for upgrading standards through educa- } \\
\text { tion, Information, and follow-up. }\end{array}$ & 3 & 3 \\
\hline The Center sets standards for levels of care. & 3 & 1 \\
\hline The Center provides classes. & 5 & 4 \\
\hline The Center assesses needs and coordinates educational resources. & 6 & 6 \\
\hline A common medical record is used. & 5 & 3 \\
\hline A data processing system provides reports. & 5 & 3 \\
\hline Risk trends are monitored by the Center. & 5 & 3 \\
\hline The Center provides consultation and referral guidelines. & 5 & 3 \\
\hline The Center reviews practical approaches to Reglonwide problems. & $\dot{6}$ & 4 \\
\hline Coordinated planning is a posslbility if a mechanism is designed for it. & 4 & 4 \\
\hline $\begin{array}{c}\text { SCENARIO D: TREE ENTERPRISE AT WORK MODEL } \\
\text { Mechanisms }\end{array}$ & $\begin{array}{l}\text { This mechanisw contri- } \\
\text { butes greatly to a good } \\
\text { regional organization. }\end{array}$ & $\begin{array}{l}\text { This mechantsm } \\
\text { would work very } \\
\text { well for me. }\end{array}$ \\
\hline There is no reglonal organization. & 0 & 0 \\
\hline $\begin{array}{l}\text { Each hospital has inservice education to the extent it wishes and is able } \\
\text { to provide. }\end{array}$ & 1 & 1 \\
\hline Consultations occur only as individually desired. & 0 & 1 \\
\hline Transfers occur only as individually desired. & 1 & 1 \\
\hline Each hospital and prenatal office selects its own forms. & 0 & 1 \\
\hline Each hospital or doctor sets its own protocols. & 1 & 2 \\
\hline
\end{tabular}

These mechanisms were checked by those who also chose other models. 
Some participants did the optional task of giving reasons for why they chose their scenario. Some also gave reasons for rejecting others and commented on further requirements for the one they chose.

SCENARIO A

- Voluntary aspect seems to prevent participation.

- Is chaotic--iike now.

- Too dependent on politics and personalities and profits (tho well-meaning).

SCENARIO 8

- Good rational participation organization with authority

- A system for functioning

- Regional council must have the right people--not just M.D.'s and head nurses; administrators, both nursing and hospital, must be included.

- Team education should be based on patient problems --not just M.D. problem or R.N. problem. Need to encourage colleague relationship.

- Membership and election to council would have to be worked out.

- Various disciplines sit in the decision-making counctl.

- Standardization of administrative forms, protocols, afford a commonality for consultation/communication.

- Leadership vested in a multidisciplinary body.

- Concerted effort implied to address regional problems by all facets of healthcare agencles.

- Analysis of problems possible from all levels, i.e. agencies, hospitals, and professions.

SCENARIO C

- Too big brotherish. Will on1y work with a benevolent big brother.

- Incredibly authoritarian-no hospital/physician participation.

- Representation of each regional component is essential.
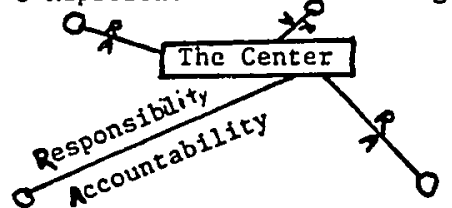

The Center must reflect the Region \& the region must reflect the Centerthen Regionalization has taken place.

- Diversity in approach along with unfform standards is important in the model.

- Appears to offer solution to Perinatal problems without the effect of Bureaucracy.

- Doesn't duplicate services and equipment-economical.

- Uses resources of tertlary center - educational and service.

\section{SCENARIO D}

- Is worse than what we have now because team members in this model don't even mean well.

- Defles all concepts of reglonalization and communication-a step backwards, 
SCENARIO A: REGIONAL CONSORTIUM MODEL

Some yeare back, complex problems in this area led to a number of voluntary arrangements. Por instance, in-service and continuing education programs are now frequently open to staff from other hospltals in our network at no cost.

We have foint hospital $O B$ meetings and each $O B$ Chief determines who is invited. Periodically, the Committee reviews the infornal analysis performed on information from the common medical record. (Not everyore uses the same record, although there is encouragement to do so.) Changes in patient population, rlsk assessment, and quality of care, along with trends in medical practice are discussed.

A few years ago, the joing hospltal comittee drew up a list for consultation and referrals. This has encouraged an exchange of services which helps to increase effectiveness and hold down costs.

Infant and maternal transfers on the bas10 of patient risk and hospltal capabllity are encouraged. Nevertheless, hospital and patient preferences and the doctor's standing in the hospitals greatly affect Individual arrangement.

Problems of occupancy rates, patient education, staff shortages, diagnogtic testing, and risking costs of medical care face each of the Institutions in the network. Dccasionally, two institutions will contract with each other on specific problems and solutions which are wutually beneflclal. We're more than willing to work cooperatively in a group -- but we maintaln ultimate control over our own part of the system!

SCENARIO B: BOARD OF DIRECTORS MODEL

A few years ago, in an effort to accomplieh some folntly heid goals for the patients in this area, we atarted a Regional Council composed of doctors, nurses, administrators, educators, and others. Th1s Counc1l plans and implements reglonal programs with the tertiary center. The Council made a deciston that the tertiary staff will meet separately with each Institution's team to discuss areas of need and progress. This is done by reports based on the comon medical record. The record 1s used with some local varlations and reporte also vary in format and in use by each Institution.

Continuing education 18 sponsored for teams. Family doctors, nurse midirives, two staff, and health educators are encouraged to participate. Regional profesBtonal meetings for supervisory $O B$ and neonstal nurses in clihics and in hospitals are rotated among hospitals. The Council sponsors an orfentation to regionalization once a year for new staff.

Another feature that we deslgned is a syotex to ease transfers through - comunication and simplified paperwork. A subcomittee assesses transfers and outcomes on the besis of patient riak and facility capability. Medical protocols are written for common problems in the Region by delegated teams. Also, formally established is the consultation/referral system using multiple resources in the Reg1on.

The Councll exerts concerted leverage on other related agencies regarding the RegIon, Including JCAH, HSA, and Medi-Cal. In the Counc1l, we are able to address Reglon-wide problems'through jolntigshared resrouces and mechanisms of borrowing and repayment. Th1s hap helped to balance out bed use rates, staff shortages, and educational needs. The bottom line 1s -- we're in this together and we have a powerful vehicle to use to affect the changes we want! 
SCENARIO C: PYRAMID MODEL

Several years ago, we faced the problem of much higher-than-average mortality and morbidity rates in our institutions in this area. So we spearheaded a move to form a regional network for perinatal care. We gave the tertiary center authority to upgrade standards and practice in the Region by providing information, education, and follow-up. Individually, we knew we couldn't provide the level of education that was required to keep up with medical advances and with govermment red tape.

The Center sets regional standards for various levels of care. Assessments of each hospital's needs and the coordination of education resources are important parts of th1s task. Classes and conferences from the Center are almed at ensuring minimal standards.

A common medical form is used for education, hospital assessment, and patient risk management by all doctors and hospitals. The forms are computer analyzed and each hospital is provided with useful information as to how the risk trends in the Region are reflected in each institution. Significant changes are monitored by the Center and result in regional protocols.

Consultant and referral guidelines for optimal patient flow through the system are issued by the Center. Infant and maternal transfers, based on the patient's risk and the hospital's capability, are monftored by the tertiary center. An analysis of transfer results and centralized high risk infant follow-up are also provided by the Center. Practical approaches to acknowledged region-wide problems and imbalances are reviewed

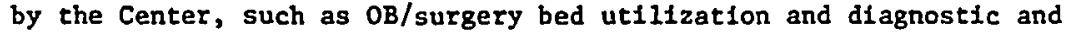
laboratory facilities.

Although there are uniform standards by hospital level, there is diversity among hospitals, clinics, and private offices in their approach to patient care. We are now thinking of a way to coordinate planning to address other problems which can inprove staff morale and recruitment, cost reductions, and profit margins. What can be done with strong leadership and the backing of our commitment is amazing! 
THE FUTURE OF PERINATAL REGIONALIZATION

A DELPHI

\section{EINAL ROUND}

A CHECKLIST (WHITE PAGES) COMPRISES THE TASKS FOR THIS ROUND.

Goldenrod-colored kection is optional.

* In the original 


\section{OVERVIEU OF THIS DELPHI}

ROUND I We looked at a direction for perinatal regionalization in the future. Most chose a representative Board of Directors model; some preferred a completely informal network or a strang Center role.

ROLE II We looked at implications and necessary tasks to accomplish the above options.

ROUND III We will look at the degree of support which exists for the first tasks and decide, if possible, on the form of regionalization to pursue.

REPORT A report to participants will provide the results and conclusions of this entire process: whether there is a strong enough consensus to begin work in a given direction; where unresolved issues are.

\section{The objectives of these rounds are:}

- to provide a vehicle of communication among participants

- To allow for development, refinement, and change of mind

- to arrive at an acceptable \& stable decision re: where participants in regionalization want it to go.

\section{SUMMARY OF ROUND-II RESULTS}

Choice of Model

The Board of Directors model was chosen most often $(72 \%)$ and by every group. The informa Regional Consortium model was chosen by 8 , the Pyramid model by $20 \%--a$ few more than last time and representing several different groups. All who chose the latter, chose the alternative version emphasizing input and cooperation. The group with the most diverse responses was Martin Luther King Jr. General Hospital.

\section{Significant Programs}

The programs chosen most often were "the sharing and exchanging of institutional resources", and "Council activities are qoal oriented and measurable." Education and referral programs and the continued participation of doctors were rated next highest.

Resources People (time) were most often listed as necessary and available resources. The data system and RWJ-funded staff were also listed - implying a consideration of availability.

Implications and Tasks

Among the many thoughtful responses given for implications and tasks are those used in Round III. A complete list of these will be in the final report.

\section{DIRECTIONS FOR ROUND III}

COMPLETE THE WHITE PAGES This task can be completed easily despite interruptions. (It doesn't take as long as it looks). Any comments you wish to make on specific items or additions are always welcome. 
CONTEXT: The most likely to be controversial issues were drawn from the responses and are listed below, CIRCLE THE EXTENT TO WHICH YNII SIIPPORT (AFRFE) OR OPPOSE (DISAGREE WITH) EACH IDEA.

There needs to be some "pressure" authority (enforcement power) to get things done...... It is the obligation of the Tertiary Center to keep the system runnina sinosthly and io maximize participation.

More malpractice cases would result from the Board of Director Model.

A loss of doctor-patient relationship would result from Board of Director Model.

An increased confidence in physicians by patients would result from the $B$ of $D$ Model... Consumers (Conmunity) should have input to the Board of Directors.

Providers should have access to level 283 centers, 1.e. cormon transferrable privilenes. The costs of regionalization should be shared by institutions at all levels........... Local \& Federal funding is necessary.

There should be an equal distribution of power

A) though dictatorial in some respects, a Pyramid model will produce needed changes in huickly than a Board of Directors

Expertise is available widely in the Region and should be used.

Smaller hospitals have little expertise to offer.

Topics of inmediate and practical importance should be discussed rather than "exotic" ones All professions should meet as peers.

Decisions are more likely to be relevant $\&$ acceptable with broad representation......... MLK is not ready for some aspects of the tertiary role at this time; another Level III

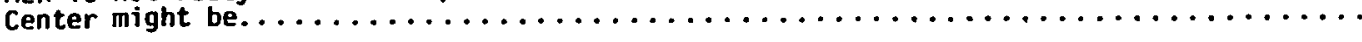
The common medical record should be useful as an audit tool for quality of care...... A common drug formulary or philosphy is needed.

\begin{tabular}{|c|c|c|c|c|}
\hline $\begin{array}{l}\text { I'S } \\
\text { GREATL }\end{array}$ & $\begin{array}{l}\text { POORT } \\
\text { SOME }\end{array}$ & $\begin{array}{l}\text { DON'T } \\
\text { CARE }\end{array}$ & SOME & $\begin{array}{l}\text { OPPOSE } \\
\text { GREATLY }\end{array}$ \\
\hline 5 & 4 & 3 & 2 & 1 \\
\hline 5 & 4 & 3 & 2 & 1 \\
\hline 5 & 4 & 3 & 2 & 1 \\
\hline 5 & 4 & 3 & 2 & 1 \\
\hline 5 & 4 & 3 & 2 & 1 \\
\hline 5 & 4 & 3 & 2 & 1 \\
\hline 5 & 4 & 3 & 2 & 1 \\
\hline 5 & 4 & 3 & 2 & 1 \\
\hline 5 & 4 & 3 & 2 & 1 \\
\hline 5 & 4 & 3 & 2 & $1=$ \\
\hline 5 & 4 & 3 & 2 & 1 \\
\hline 5 & 4 & 3 & 2 & 1 \\
\hline 5 & 4 & 3 & 2 & 1 \\
\hline 5 & 4 & 3 & 2 & 1 \\
\hline 5 & 4 & 3 & 2 & 1 \\
\hline 5 & 4 & 3 & 2 & 1 \\
\hline 5 & 4 & 3 & 2 & 1 \\
\hline 5 & 4 & 3 & 2 & 1 \\
\hline 5 & 4 & 3 & 2 & 1 \\
\hline
\end{tabular}


CONTEXT: To implement their chosen structure, respondents qave many options in round 2 . For EACH activity in EACH model, CIRCLE THE EXTENT TO WHICH YOU SUPPORT, OPPOSE, OR feel an activity represents an acceptable alternative to you, i.e. something you could GO ALONG WITH if most other participants favor it.

Tasks for A - Regional Consortium model (informal voluntary arrangements develop)

Responsibility rotates for monthly meetings

- Institutions allow and encourage open debates in decision making

Institutions provide avenues for exchange of ideas and effective

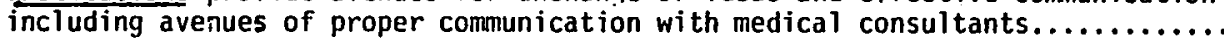

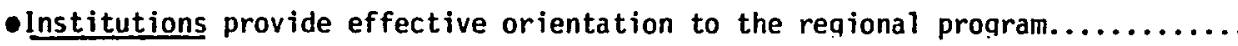
- Institutions reinforce the importance of every member of health care team's participation in the program.

- Institutions have educational resources available.

Tasks for C - Pyramid model (the Center makes decisions w/input \& cooperation from the components)

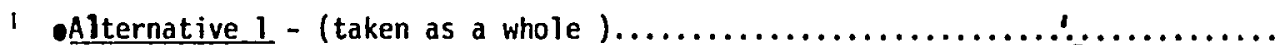
Tertiary Center develops a committee with representatives from each hospital in the region (represent $\mathrm{OB}-\mathrm{Ped}-\mathrm{Nsg}$ and Hosp. Admin)

The Center provides the committee with objectives for reqionalization

The Center obtains feedback from comittee members re: their goals for region. The Center develops an overall plan w/comnittee re: how mechanism for regional zation will be carried out.

The Center establ ishes subcomittees--chaired by various persons from region.

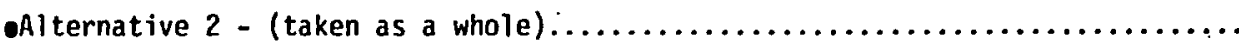
Tertiary Center invites participation from other centers for agreement on general model.

Initial group selects small working Task Force.

The Task Force redefines definition and objectives of reqionalization.

The group sets up meetings at various centers to outline the strategy for rea.

Participation on every facet of center-reqion interaction is obtained from satellites and tertiary center includina delineation of philosophy, noals, objectives, government (organization) and protocols (medical, nursing, educa-

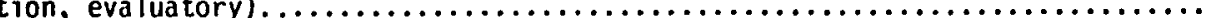

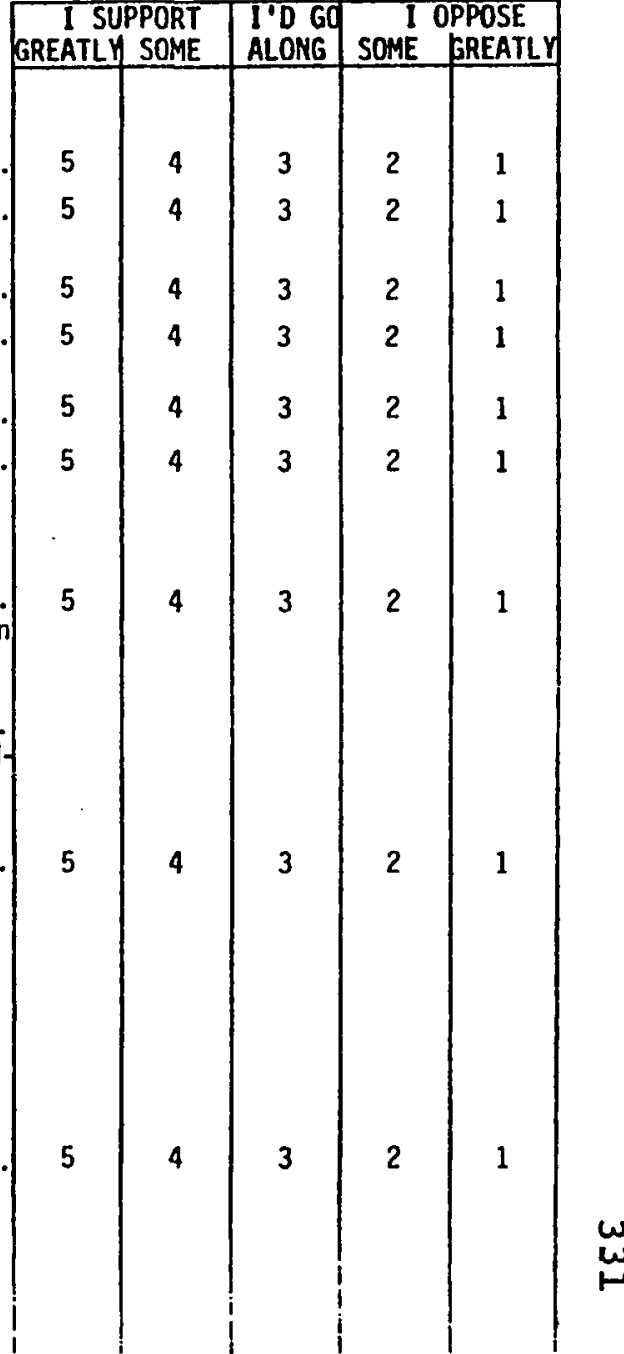


Tasks for B - Board of Directors Model (a regional council of various professions is a decision-making : body.

Reach concensus on purpose and authority

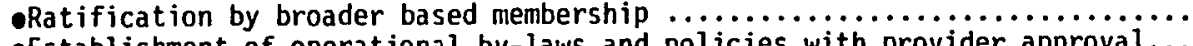

Establishment of operational by-laws and policies with provider approval...
-Defined roles and responsibilities $\ldots \ldots \ldots \ldots \ldots \ldots \ldots \ldots \ldots \ldots \ldots \ldots \ldots \ldots \ldots \ldots \ldots \ldots \ldots \ldots \ldots \ldots \ldots \ldots$

Unity of direction .............

Enforcement power

- Control of support staff functions

Reach agreements on structure of Council/Board

- Voluntary structure.

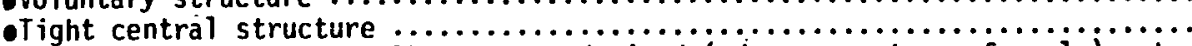

- Composition to reflect all programs desired (educ., reports, referrals), etc

- Steering Committee and subcommittees

- Subcomittees are multidiscipl inary and program-based

-Communication process established between subconmittees $\ldots \ldots \ldots \ldots \ldots \ldots \ldots$

Means of reporting to all providers

Design a process for identifying Board Members

\section{Members elected}

Members recruited

Members appointed

-Ident ify those strongiy interested

Include consumer representative

Include representatives of interested health workers

Determine functions

To define policies

-To set goals, objectives, evaluate progress

To identify needs, plan, iliplement programs in subcommittees

- To guide support staff functions by priority setting

To develop standards.

Other tasks

Highly organize meetings with substantive agendas $\ldots \ldots \ldots \ldots \ldots \ldots \ldots \ldots \ldots$ Develop a master list of each institution's resources

-Develop master schedules for scheduling

- Collect daca on probleni areas

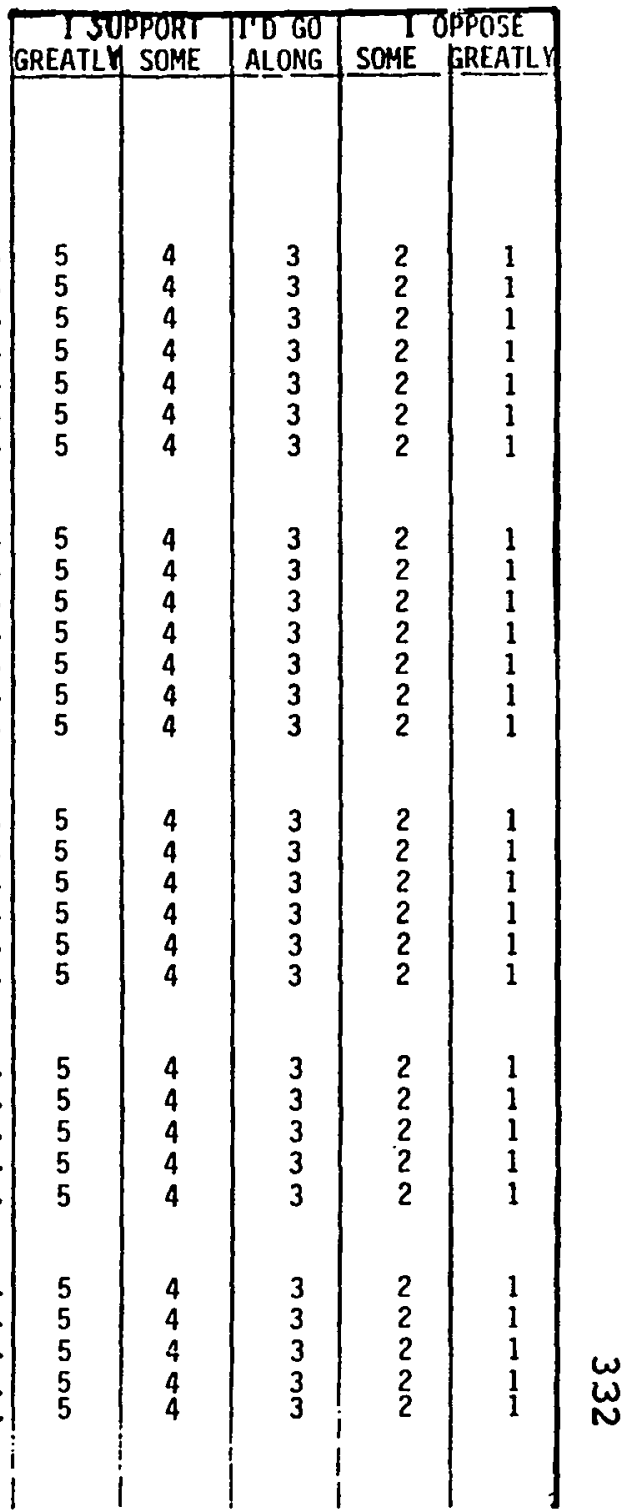


WHERE DO YOU STAND ON PERSONAL PARTICIPATION

If A (Regional Consortium model - informal voluntary arrangements develop) were chosen by the majority:

- Would you be willing and able to actively participate in regular Regional

Meetings which informally analyze problems and make reconmendations?

- What other activity would you actively participate in/assist with?

If B (Board of Directors model - a Regional Council of various professions is a decision-making body) were chosen by the majority:

- And if you were selected/elected to the Council/Board or a subcomittee, would you be able and willing to serve and take an active role?

- And if the Council determined that certain protocols should be implemented, would you be willing to incorporate them?

- What other activity would you actively participate in/assist with?

If $C$ (Pyramid model - the Tertiary Center makes decisions with input and cooperation from the components) were chosen by the majority:

- And if you were invited to work on a Task Force with the Regional Center, would you be willing and able to actively participate?

- And if the Tertiary Center, using input from the Region, determined that certain practices needed to be changed, would you actively support the changes, incorporate them, and attend (require staff to attend) inservice sessions on them?

- What other activity would you actively participate in/assist with? 
WHAT WERE YOUR OVERALL REACTIONS TO ALL 3. DELPHI?

CIRCLE the numbers which represent your feel ings.

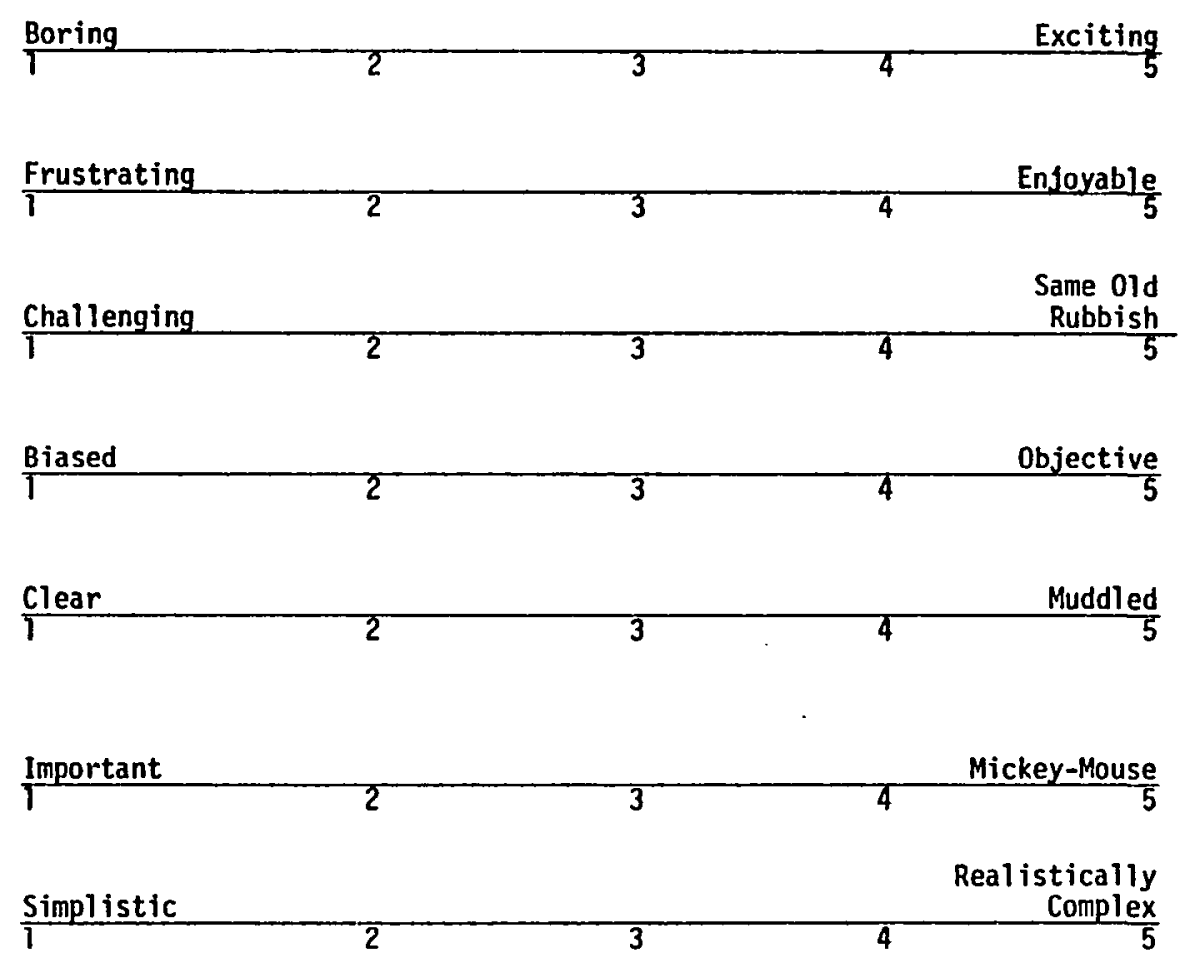

Any reasons or other reactions you care to express are welcome. 
The comments below were offered by several observers from outside the Region. Their observations were solicited because of their background and ability to perceive many angles. The purpose is to stimulate further discussion. These comments are not part of the internal working of the Delphi and will not be calculated in the final analysis. However, any response you make to any of the ideas will be included.

\section{Observers: Ann Mary Bender - Organizational Process Consultant and Communications Facilitator} Rex Ehling, M.D., M.P.H. - County Health Officer, Maternal and Child Health Expert Marta Borbon Ehling, R.N., M.S. - Nurse, ediscator, author

- In democratic type institutions (as is the suggested Board), the expected roles and styles of people need to match. Some people are good in relating - are good people builders or are good at connecting ideas, but neither type tends to "get things done." Others are strong at directing or selling ideas.

- Ecards can be advisory or policy-making. Its functions can grow (phase in).

- If detailed "sparkiling" agendas go to all regional participants, those not elected can input on items of special concern to them and keep up with what's happening.

- Goard and coimittecs can be set up to self-destruct through (s)election of people who are powerless, uninterested, Gr. super-political.

- Physicians are generally unfamiliar with the need to define objectives in a measurable way. These are imfortant to the planning of systems such as regionalization.

- Many practitioners are concerned about change, and fearful of it, because they do not have experience in $i t$. A disadvanlage with loose nordels is that they reed so iuch morientum to achieve change. But when "pushed", it's easier for people to deal with change than to complain abcut it.

- Nurses need to be viewed as leaders in the process.

- If there is acceptance of the reoional system, then good communication between referrers and the tertiary cente could facilitate a positive attitude on ti:e part of the frovider - which would facilitate the attitude of the patient also.

- To what exient are patient prefereners concidered? (Choicc of liospital, manner of delivery, how she feels ahout medical technology's role in the birth process).

- Is the consumer aspect of reginnalization represented in the system?

COMMENTS (use other side if necessary) 